\title{
The Thermochemistry of Proton-Coupled Electron Transfer Reagents and its Implications
}

\author{
Jeffrey J. Warren, Tristan A. Tronic, and James M. Mayer ${ }^{*}$ \\ Department of Chemistry, University of Washington, Box 351700, Seattle, WA 98195-1700
}

\section{Introduction}

Many, if not most, redox reactions are coupled to proton transfers. This includes most common sources of chemical potential energy, from the bioenergetic processes that power cells to the fossil fuel combustion that powers cars. These proton-coupled electron transfer or PCET processes may involve multiple electrons and multiple protons, as in the $4 e^{-}, 4 \mathrm{H}^{+}$ reduction of dioxygen $\left(\mathrm{O}_{2}\right)$ to water (eq 1), or can involve one electron and one proton such as the formation of tyrosyl radicals from tyrosine residues $(\mathrm{TyrOH})$ in enzymatic catalytic cycles (eq 2). In addition, many multi-electron, multi-proton processes proceed in oneelectron and one-proton steps. Organic reactions that proceed in one-electron steps involve radical intermediates, which play critical roles in a wide range of chemical, biological, and industrial processes. This broad and diverse class of PCET reactions are central to a great many chemical and biochemical processes, from biological catalysis and energy transduction, to bulk industrial chemical processes, to new approaches to solar energy conversion. PCET is therefore of broad and increasing interest, as illustrated by this issue and a number of other recent reviews. $12^{-} 3$

$$
\begin{aligned}
& \mathrm{O}_{2}+4 e^{-}+4 \mathrm{H}^{+} \rightarrow 2 \mathrm{H}_{2} \mathrm{O} \\
& \mathrm{TyrOH} \rightarrow \mathrm{TyrO}^{\bullet}+e^{-}+\mathrm{H}^{+}
\end{aligned}
$$

Proton-coupled redox reactions are by no means a new concept. The Nernst equation of 18894 describes how aqueous redox potentials vary with $\mathrm{pH}$ when protons are involved. Physical and organic chemists have been studying hydrogen atom transfer reactions of organic compounds for over a century, and a hydrogen atom is simply a proton and an electron. It has more recently been realized that these areas are connected; organic Htransfer reactions are part of a broader class of reactions in which $1 \mathrm{H}^{+}$and $1 e^{-}$are transferred. As a result, the ubiquity of $\mathrm{H}^{+} / e^{-}$transfers has come to the forefront of chemistry and biology.

The first issue that needs to be addressed in any PCET process is the thermochemistry of the electron, proton, and PCET processes. While many aspects of PCET are of great interest, from hydrogen tunneling and isotope effects to photoinduced processes, they all rely on knowledge of the thermochemistry. The thermochemical description is essentially a map of the system, showing each of the possible reactant, intermediate and product states where the system can reside (for at least a few vibrational periods), and the energies of each of these states. Having such a map is fundamental to understanding any PCET system. 
In particular, the free energies of the various species will, in large part, answer one of the central questions in any PCET process: whether the electron and proton transfer 'together,' in a single kinetic step, or whether the process occurs by a sequence of electron transfer (ET) and proton transfer (PT) steps. In many cases, as described below, there is a large thermochemical bias that favors moving the two particles together, in a concerted process, since this can circumvent high energy intermediates formed in elementary ET or PT steps. While ET and PT are two of the most fundamental chemical reactions, the understanding of how $\mathrm{H}^{+}$and $e^{-}$transfer together is still emerging. In fact, even the concept of 'transferring together' can have a number of meanings, as discussed below and in a number of the other reviews in this issue.

This review provides, to the best of our abilities, the current "best" values for the solution thermochemistry of several classes of proton-coupled redox cofactors. Many of these PCET species are either involved in, or have been used to understand, key chemical and biochemical reactions. These thermochemical data can be used, as illustrated below, to analyze the mechanisms of specific $\mathrm{H}^{+} / e^{-}$transfer reactions using common 'square schemes.' Analogous thermochemical data are available for some biochemical small molecules, allowing us to illustrate that the same approach can be used to analyze biochemical transformations. We begin with a discussion of definitions and thermochemical background.

\section{Scope and Definitions}

This review tabulates and analyzes the thermochemical properties of reagents that transfer electrons and protons. Our focus is on processes involving $1 e^{-}$and $1 \mathrm{H}^{+}$, and connecting this proton/electron perspective with hydrogen atom transfers and $\mathrm{X}-\mathrm{H}$ homolytic bond strengths. We do not deal extensively here with processes involving multiple electron and/or proton transfers and heterolytic bond strengths, such as hydride $\left(2 e^{-} / 1 \mathrm{H}^{+}\right)$transfers, although the same type of analysis can be applied. A recent and elegant example can be found in the work of DuBois et al. using of the thermochemistry of $\mathrm{H}^{-}, \mathrm{H}^{\cdot}, \mathrm{H}^{+}$and $e^{-}$ transfers to develop new transition metal-hydride catalytic processes.5

These $\mathrm{H}^{+} / e^{-}$transfer processes all fall under the general term 'proton-coupled electron transfer' or PCET. This term has come to encompass any redox process where the rate or energetics are affected by one or more protons, including processes in which protons and electrons transfer among one or more reactants, by concerted or stepwise mechanisms, and processes in which protons modulate ET processes even if they do not transfer.6 This very broad definition is not what Meyer and co-workers intended when they coined the term in 1981,7 and many current researchers in the field use 'PCET' to mean something more specific. However, examination of the large literature citing 'PCET' - over 200 papers from 2006 to 20098 - shows that the broad usage has taken hold. Therefore in our view, 'PCET' can no longer be used to refer to a single reaction class, and the mechanistic implications of this term have often been diluted. Thus, we support the broad use of PCET given above. We note that Meyer and Costentin have also recently emphasized this broad definition of PCET. 1,3

As 'PCET' has been used to describe many different redox reactions, researchers have coined new and more specific terms, which has led to some confusion in this area. The variety of nomenclature, while unfortunate, reflects the surge of interest in the field by workers from quite different disciplines, and the variety of PCET phenomena that have been investigated. 


\subsection{Concerted Proton-Electron Transfer (CPET) vs. stepwise pathways}

As originally conceived, 7 'PCET' referred to reactions where a proton and electron are transferred in a single, concerted step. Since PCET has lost this mechanistic connotation, Savéant and coworkers have proposed a new term, 'concerted proton-electron transfer' (CPET), that makes the mechanistic implication explicit.9 We support using this term to refer to any chemical reaction where one $\mathrm{H}^{+}$and one $e^{-}$are transferred in a single kinetic step. CPET is equivalent to the 'CEP' term (concerted electron/proton) used by Hammarström and coworkers, 10 and the 'EPT' moniker (electron/proton transfer) used by Meyer et al.1a CPET (/CEP/EPT) processes contrast with stepwise processes involving either initial ET followed by PT, or PT followed by ET, as shown in Scheme 1. In this and the other Schemes in this review, proton transfer processes are horizontal lines, ET processes are vertical lines, and processes that involve protons and electrons are diagonal lines. Readers should be aware that other workers have chosen other representations that better illustrate their particular concerns ( $c f$. , ref. 5).

The stepwise pathways in Scheme 1 for $1 \mathrm{H}^{+} / 1 e^{-}$transfer reactions are proton transfer followed by electron transfer (PT-ET) and ET-PT. Many examples of PT-ET, ET-PT, and concerted reactions are known. For instance, the groups of Ingold and Foti have shown that acidic phenols can react by a PT-ET type mechanism termed 'sequential proton-loss electron transfer' or SPLET (adding to the list of acronyms).11-1213 Hammarström et al. have shown that the aqueous ruthenium-tyrosine complexes can undergo ET-PT, CPET, or PT-ET processes depending on the $\mathrm{pH} .10$,14 ET-PT pathways are particularly well documented in the electrochemical literature, where they are a type of EC mechanism (electrochemical then chemical). 15 The factors that determine which path is followed are discussed in Section 6, below.

\subsection{Hydrogen Atom Transfer (HAT)}

Hydrogen atom transfer has been studied by physical and organic chemists for over a century.16 It is key to the rate and selectivity of a variety of free radical reactions, including radical chains as in autoxidation and combustion. The abstraction of $\mathrm{H}^{\bullet}$ from organic compounds by peroxyl radicals has been especially widely discussed and researched because they are important to disease states, aging and food preservation. 17

In the older physical-organic literature there was no need to define HAT, as it was selfevident that this referred to reactions involving concerted transfer of $\mathrm{H}^{\bullet}$ from a donor $(\mathrm{XH})$ to an acceptor (Y, Scheme 2).18 We will use this definition here, noting that 'concerted' implies a single kinetic step for transfer of the two particles but does not necessarily imply synchronous transfer. By this definition, HAT is one class of CPET reactions.

In the last 25 years it has been recognized that transition metal coordination complexes and metalloenzymes can undergo HAT reactions, and that there is overlap between traditional HAT reactions and PCET. This has led to the appearance of a number of new definitions and new thinking about HAT.192021 ${ }^{-} 22$ For instance, computationally there is a clear orbital distinction between degenerate $\mathrm{H}^{*}$ exchange between toluene and benzyl radical, versus exchange between phenol and phenoxyl radical.19 In toluene, the $\mathrm{H}^{+}$and $e^{-}$start in the same bond and end in the same bond. In the phenol/phenoxyl reaction, however, the proton is in the molecular plane but the transferring electron is in an orthogonal $\pi$ symmetry orbital. 19 To deal with such distinctions, Meyer et al. have proposed to restrict HAT to reactions where "the transferring electron and proton come from the same bond." 1,20 This contrasts with his earlier definition that "the term ' $\mathrm{H}$-atom transfer' refers to what is transferred between reactants in the net sense and not to the mechanism of the event."18 However, the restrictive definition is problematic in many cases. For instance, often the two particles come 
from the same bond but are not in the same bond in the product. One example is hydrogen atom abstraction from $\mathrm{C}-\mathrm{H}$ bonds by compound $\mathrm{I}$ in cytochrome $\mathrm{P} 450$ enzymes, where the proton transfers from carbon to the oxygen of the ferryl $(\mathrm{Fe}=\mathrm{O})$ group but the electron is transferred to the porphyrin radical cation.23 Under the restrictive "same bond" definition the reaction would be HAT in the forward direction but not in the reverse, which is a problem. Furthermore, it is often difficult to determine whether the electron and proton are "in the same bond." In removing $\mathrm{H}^{\bullet}$ from phenols, for example, the $e^{-}$and $\mathrm{H}^{+}$are in the same bond when the $\mathrm{O}-\mathrm{H}$ bond lies in a plane perpendicular to the aromatic ring, but they are not in the same bond when the $\mathrm{O}-\mathrm{H}$ lies in the plane of the aromatic ring. In phenol itself the hydrogen is in the plane, but how would reactions of the common 2,6-di-tert-butylsubstituted phenols be classified? Similarly, classification of $\mathrm{H}^{\bullet}$ removal from the vanadyl hydroxide complex $\left[(\mathrm{bpy})_{2} \mathrm{~V}^{\mathrm{IV}}(\mathrm{O})(\mathrm{OH})\right]^{+}$would depend on the $\mathrm{O} \equiv \mathrm{V}-\mathrm{O}-\mathrm{H}$ torsion angle.24 In the minimum energy structure, the $\mathrm{O}-\mathrm{H}$ bond is calculated to have a torsion angle of $45^{\circ}$ $v s$. the orbital with the transferring electron, which precludes conclusions about 'being in the same bond.' To avoid these confusions, we prefer the definition implied in Scheme 2, that 'hydrogen atom transfer' indicates concerted transfer of $\mathrm{H}^{+}$and $e^{-}$from a single donor to a single acceptor.

\subsection{Separated CPET}

There are also concerted transfers of $1 e^{-}+1 \mathrm{H}^{+}$in which the proton and electron transfer to (or from) different reagents. In Scheme 3, for instance, $\mathrm{XH}$ is oxidized with the electron being transferred to oxidant $\mathrm{Y}$ while the proton is transferred to base B. One of the more widely discussed biological examples is the photosynthetic oxidation of tyrosine- $Z$ where an electron is transferred to a photoexcited chlorophyll $\left(\mathrm{P} 680^{+}\right)$as the phenolic proton is thought to transfer to a nearby H-bonded histidine residue.25 Babcock's discussion of the thermochemistry of this process is a landmark in the development of biological PCET chemistry.26 Such 'separated CPET' reactions are clearly distinct from HAT reactions. These have also been termed "multisite EPT." 1 a However, there are an increasing number of reactions that fall in a grey area between HAT and separated CPET, such as the reaction in eq 3.27 This reaction involves concerted transfer of $e^{-}$and $\mathrm{H}^{+}\left(\mathrm{H}^{*}\right)$ from the $\mathrm{O}-\mathrm{H}$ bond of 2,4,6-tri-t-butylphenol to a ruthenium(III) complex, so this reaction could formally be called HAT. From another perspective, however, the proton is transferred to a carboxylate oxygen that is $11 \AA$ removed from the ruthenium center that accepts the electron, and there is essentially no communication between these sites, 27 so in some ways this is better described as a separated CPET process.

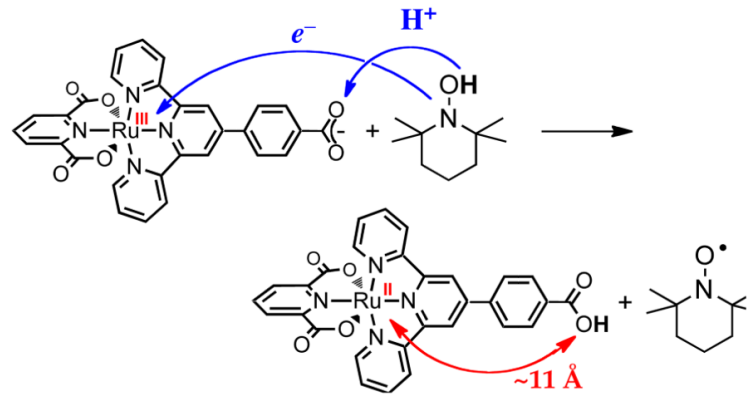

\section{Thermochemical Background}

The thermochemistry of a $1 \mathrm{H}^{+} / 1 e^{-} \mathrm{PCET}$ reagent $\mathrm{XH}$ in a given solvent is described by five parameters, as shown in Scheme 4. These are: the acidity/basicity of the oxidized and 
reduced forms, given by the $\mathrm{p} K_{\mathrm{a}}$ s of $\mathrm{XH}^{\bullet+} / \mathrm{X}^{\bullet}$ and $\mathrm{XH} / \mathrm{X}^{-}$pairs; the reduction potentials of the protonated and deprotonated substrate, $E^{\circ}\left[\mathrm{XH}^{\bullet+} / \mathrm{XH}\right]$ and $E^{\circ}\left[\mathrm{X}^{\bullet} / \mathrm{X}^{-}\right]$, and the homolytic bond dissociation free energy, the BDFE (see below). All of these parameters are free energies, and it is simple to convert them all into the same units (eqs 4 and 5, where $\mathrm{R}$ is the gas constant, $\mathrm{T}=$ temperature, and $F=$ Faraday constant). The $E^{\circ}$ is a free energy for the chemical reaction that is the sum of the half reaction of interest, such as $\mathrm{X}^{\cdot}+e^{-} \rightarrow \mathrm{X}^{-}$, and the half reaction for the standard redox couple (NHE for aqueous values). For a reaction such as $\mathrm{HX}+\mathrm{Y} \rightarrow \mathrm{X}+\mathrm{HY}$, the $\mathrm{p} K_{\mathrm{a}}$ and $E^{\circ}$ values for the $\mathrm{HX}$ and $\mathrm{HY}$ systems determine the free energies of PT, ET, and $\mathrm{H}^{\bullet}$ transfer steps.

$$
\begin{aligned}
\begin{aligned}
\Delta G_{\mathrm{PT}}^{\circ} & =-\mathrm{RT} \ln \left(K_{\mathrm{a}}\right)=2.303 \mathrm{RT}\left(\mathrm{p} K_{\mathrm{a}}\right) \\
& =-\left(1.37 \mathrm{kcal} \mathrm{mol}^{-1}\right) \mathrm{p} K_{\mathrm{a}}=-\left(5.73 \mathrm{~kJ} \mathrm{~mol}^{-1}\right) \mathrm{p} K_{\mathrm{a}} \quad(\text { at } 298 \mathrm{~K})
\end{aligned} \\
\begin{aligned}
\Delta G_{\mathrm{ET}}^{\circ}= & -F \mathrm{E}^{\circ}=-\left(23.06 \mathrm{kcal} \mathrm{mol}^{-1} \mathrm{~V}^{-1}\right) E^{\circ}=-\left(96.48 \mathrm{~kJ} \mathrm{~mol}^{-1} \mathrm{~V}^{-1}\right) E^{\circ}
\end{aligned}
\end{aligned}
$$

The $\mathrm{p} K_{\mathrm{a}}$ values in many cases can be determined by titration either versus $\mathrm{pH}$ (in aqueous media) or versus a standard acid or base (in organic solvents). As discussed below in more detail, there are extensive acid/base data available in organic solvents from the respective work of Izutsu,28 Bordwell29 and Kütt.30 The redox potentials are typically determined electrochemically. The average of the anodic and cathodic peaks in the cyclic voltammogram, $E_{1 / 2}$, is typically used as a good measure of the thermodynamic potential $E^{\circ}$. 31 Parenthetically, we note that it is strongly preferred to reference non-aqueous potentials to the ferrocene $\left(\mathrm{Cp}_{2} \mathrm{Fe}^{+/ 0}\right)$ couple. 32 Aqueous potentials are reference to normal hydrogen (NHE) in this review. Useful conversions between common electrochemical references are available for acetonitrile 33 and water34 and potentials of $\mathrm{Cp}_{2} \mathrm{Fe}^{+/ 0}$ in organic solvents versus aqueous NHE have been reviewed.35

The thermodynamic parameters $E^{\circ}$ and $\mathrm{p} K_{\mathrm{a}}$, if they are to be used in the same Scheme or equation, should be determined under conditions that are as similar as possible. For instance, if the electrochemical data are determined using solutions containing supporting electrolyte (as is typical), then the $\mathrm{p} K_{\mathrm{a}}$ values should ideally be determined in the presence of the same electrolyte. Because the data tabulated below often come from different sources and different types of measurements, this requirement for similar conditions is not always met, which introduces some (usually relatively small) uncertainty into any composite values. A valuable check on the consistency of the data can be obtained using Hess' law, which states that the energy change is independent of path, and that the energy change around any closed cycle is zero. This means that there are actually only 3 independent parameters in Scheme 4. It also implies, perhaps counter-intuitively, that in free energy terms the change in the $\mathrm{p} K_{\mathrm{a}}$ values upon oxidation is identical to the change in redox potential upon deprotonation (eq $6)$.

$$
\text { 2.303RT }\left[\mathrm{p} K_{\mathrm{a}}\left(\mathrm{XH}^{\bullet+}\right)-\mathrm{p} K_{\mathrm{a}}(\mathrm{XH})\right]=F\left[E^{\circ}\left(\mathrm{X}^{\bullet /-}\right)-E^{\circ}\left(\mathrm{XH}^{\bullet+/ 0}\right)\right]
$$

\subsection{X-H Bond Dissociation Free Energies}

HAT reactions have historically been analyzed using the Bell-Evans-Polyani relation, 36 which uses bond dissociation enthalpies (BDEs, which are not exactly the same as bond dissociation energies37). It is, however, more appropriate to use bond dissociation free energies (BDFEs) because all modern theories of ET, PT, and CPET use free energies rather than enthalpies. Our group has shown, for an iron system where the BDE and BDFE are 
quite different, that CPET reactivity correlates with the free energy and not the enthalpy. 38,39 The use of BDFEs rather than BDEs is especially important for transition metal complexes because they can have large entropic contributions to the driving force for a PCET reaction. 39,40

One of the goals of this review is to encourage the use of solution BDFEs because these directly connect with the free energy of reaction which is the correct driving force. We discourage the (common) use of reduction potentials to describe PCET reagents because the $E^{\circ}$ or $E_{1 / 2}$ value does not indicate the proton stoichiometry. As noted above, a reduction potential is the free energy for a particular process and it is strictly speaking meaningful only when the stoichiometry of that process is well defined.

This review tabulates both solution BDFEs and BDEs. Most of the BDFEs are determined from known $\mathrm{p} K_{\mathrm{a}}$ and $E^{\circ}$ following methods developed by Bordwell41 for organic compounds and later extended by Parker and Wayner 42 and by Tilset 43 (eq 7). The methods are essentially identical, but Bordwell's method was derived explicitly to calculate BDEs while Tilset's derivation perhaps more clearly distinguishes between BDEs and BDFEs. Bordwell and coworkers were the first to popularize this approach and apply it to a range of compounds. They provide valuable discussion of the assumptions and potential errors involved,41 which were later analyzed in more detail by Parker and Tilset 44 and others. 45 It should also be noted that there are examples of the use of $\mathrm{p} K_{\mathrm{a}}$ and $E^{\circ}$ values to derive bond strengths prior to Bordwell's broad use, including work by Breslow as early as 196946 and by Wiberg in 1961.47 Similar thermochemical cycles have also been used in gas-phase thermochemical studies for some time.37

This approach to calculating BDFEs uses Hess' Law and the $\mathrm{p} K_{\mathrm{a}}$ and $E^{\circ}$ values on adjacent sides of a square scheme (Scheme 4, eqs 4 and 5). Essentially the same equation can be used for BDEs, with a constant denoted $C_{\mathrm{H}}$ (but see the comments in the next paragraph). The constants $C_{\mathrm{G}}$ and $C_{\mathrm{H}}$ were derived explicitly as described by Tilset, 43 and a similar derivation was given earlier by Parker.48 A number of slightly different values of $C_{\mathrm{H}}$ can be found in the literature, depending on the assumptions and values used in the derivation. $414243^{-} 44$ The differences between these values are typically smaller than the estimated uncertainties in the bond strengths derived from this analysis, as briefly discussed in Section 4.1 below.

$C_{\mathrm{G}}$ in a given solvent is equivalent to the $\mathrm{H}^{+} / \mathrm{H}^{\bullet}$ standard reduction potential in that solvent (see Section 5.8.3). Following Tilset, $43 C_{\mathrm{G}}$ includes the free energy for formation of $\mathrm{H}^{\bullet}\left(\Delta G_{f}^{\circ}\left(\mathrm{H}_{\mathrm{g}}{ }_{\mathrm{g}}\right)=48.59 \mathrm{kcal} \mathrm{mol}^{-1}\right), 49$ the free energy of solvation of $\mathrm{H}^{\bullet}\left(\Delta G_{\text {solv }^{\circ}}{ }^{\circ}\left(\mathrm{H}^{\bullet}\right)\right)$, as well as the nature of the reference electrode. In Parker's early analysis, $48 \Delta G_{\text {solv }}{ }^{\circ}\left(\mathrm{H}^{\circ}\right)$ was approximated using solvation energies of the noble gases. Roduner has now shown that the solvation of $\mathrm{H}^{\bullet}$ is better approximated as that of $\mathrm{H}_{2} .50$ On that basis, we have calculated revised values for $C_{\mathrm{G}}$ in several different solvents (Table 1),39,51 using known values of $\Delta G_{\text {solv }}{ }^{\circ}\left(\mathrm{H}_{2}\right) .52^{-} 5354$ The values for $C_{\mathrm{G}}$ and $C_{\mathrm{H}}$ in water in Table 1 are also different from those reported previously because we have corrected the standard state for $\Delta G_{\text {solv }}{ }^{\circ}\left(\mathrm{H}^{*}\right)(\cong$ $\left.\Delta G_{\text {solv }}{ }^{\circ}\left(\mathrm{H}_{2}\right)\right)$ from $1 \mathrm{~atm}$ to $1 \mathrm{M} .55$ These $C_{\mathrm{G}}$ and $C_{\mathrm{H}}$ values are, to the best of our abilities, the most accurate available, and they have been confirmed by comparison with BDEs and BDFEs derived from other methods such as equilibration or calorimetry. Readers should note that the constants in Table 1 in organic solvents are for redox potentials referenced to $\mathrm{Cp}_{2} \mathrm{Fe}^{+/ 0}$, because we feel that these are more directly useful than those given previously $v s$. the standard hydrogen electrode. 43

$$
\mathrm{BDEF}_{\mathrm{sol}}(\mathrm{X}-\mathrm{H})=1.37 \mathrm{p} K_{\mathrm{a}}+23.06 E^{\circ}+C_{\mathrm{G}, \text { sol }}
$$


The calculation of bond dissociation enthalpies from free energy measurements $\left(\mathrm{p} K_{\mathrm{a}}\right.$ and $E$ ${ }^{\circ}$ ) is accurate only when there are no significant entropic effects. Specifically, this analysis requires that the entropies of $\mathrm{HX}$ and $\mathrm{X}^{\circ}$ are essentially equal $\left[S^{\circ}(\mathrm{HX})_{\text {solv }}=S^{\circ}\left(\mathrm{X}^{\circ}\right)_{\text {solv }}\right] .39^{-}$ 40414243 This issue was discussed early on by Bordwell, Parker and Tilset, $41^{-} 4243$ and entropic contributions were found to be small for the organic and organometallic systems they studied.37,39-40414243 Recently, however, it has been shown that $S^{\circ}(\mathrm{HX})_{\text {solv }}$ and $S^{\circ}$ $\left(\mathrm{X}^{\circ}\right)_{\text {solv }}$ can be very different when the compounds contain high-spin transition metal ions. 39,40 For such species, BDEs cannot be determined from $\mathrm{p} K_{\mathrm{a}}$ and $E^{\circ}$ values. With the assumption that $\mathrm{S}^{\circ}(\mathrm{HX})_{\text {solv }}=\mathrm{S}^{\circ}\left(\mathrm{X}^{\circ}\right)_{\text {solv }}$, the solution BDE can be calculated from $\mathrm{p} K_{\mathrm{a}}$ and $E$ ${ }^{\circ}$ values or from the $\mathrm{BDFE}_{\mathrm{sol}}$ (eqs 8, 9), with the constant $C_{\mathrm{H}}$ given by $C_{\mathrm{G}}-\mathrm{T} \Delta S^{\circ}\left(\mathrm{H}^{*}\right)_{\text {solv }}$.

Assuming $S^{\circ}{ }_{\text {sol }}(\mathrm{HX})=S^{\circ}{ }_{\text {sol }}\left(\mathrm{X}^{\circ}\right)$, then

$$
\mathrm{BDE}_{\mathrm{sol}}(\mathrm{X}-\mathrm{H})=1.37 \mathrm{p} K_{\mathrm{a}}+23.06 E^{\circ}+C_{\mathrm{H} . \mathrm{sol}}
$$

$$
\mathrm{BDE}_{\mathrm{sol}}(\mathrm{X}-\mathrm{H})=\mathrm{BDFE}_{\mathrm{sol}}(\mathrm{X}-\mathrm{H})+\left(C_{\mathrm{H}, \mathrm{sol}}-C_{\mathrm{G}, \mathrm{sol}}\right)
$$

Equations 7 and 8 use the thermochemical standard potentials $E^{\circ}$ which are typically very close to the $E_{1 / 2}$ values measured by cyclic voltammetry. Bordwell has also shown that useful values can also often be obtained using electrochemical peak potentials from irreversible cyclic voltammograms.41 However, this introduces an additional uncertainty into the derived values (see Section 4.1). In the thermochemical tables below, it is explicitly noted when the BDFE or BDFE value has been derived using an irreversible peak potential.

A more direct way to determine a BDFE is by equilibration with a standard reagent, for instance, measurement of $K_{\text {eq }}$ for $\mathrm{XH}+2,4,6-{ }^{t} \mathrm{Bu}_{3} \mathrm{ArO}^{\bullet} \rightleftarrows \mathrm{X}^{\bullet}+2,4,6-{ }^{t} \mathrm{Bu}_{3} \mathrm{ArOH}$. $\mathrm{RT} \ln \left(K_{\mathrm{eq}}\right)$ is then the difference between the BDFEs of $\mathrm{XH}$ and the standard reagent. This approach works very well for stable species such as aminoxyl radicals (Section 5.1) and transition metal complexes (Section 5.10), or for reactions of transients that reach equilibrium faster than they decay. Pedulli and co-workers, for instance, has used this approach to measure the bond strengths in a variety of phenols.56 Kreevoy et al. used equilibration to measure the relative hydride affinities of NAD+ analogs (a type of heterolytic bond strength). 57

3.1.1 Solution vs. Gas Phase Bond Strengths-CPET reactivity in solution should be analyzed with solution BDFEs, but common tabulations of bond strengths are gas phase BDEs (as in many organic chemistry textbooks58). A very extensive tabulation of such BDEs can be found in the recent book by Luo.59 Gas phase BDEs are related to gas phase BDFEs by eq 10 , using $S_{\mathrm{g}}^{\circ}\left(\mathrm{H}^{*}\right)=27.42 \mathrm{cal} \mathrm{K}^{-1} \mathrm{~mol}^{-1} .49$ As noted above, for small molecules and organic molecules, $S^{\circ}\left(\mathrm{X}^{\circ}\right) \cong S^{\circ}(\mathrm{XH})$ because the species are roughly the same size and structure. 37,40 For instance, $\left\{S_{\mathrm{g}}^{\circ}\left(\mathrm{HO}^{\circ}\right)-S_{\mathrm{g}}^{\circ}\left(\mathrm{H}_{2} \mathrm{O}\right)\right\}=-1.2 \mathrm{cal} \mathrm{mol}^{-1} \mathrm{~K}^{-1,49}, 60$ and $\left\{S_{\mathrm{g}}^{\circ}\left(\mathrm{PhO}^{\circ}\right)-S_{\mathrm{g}}^{\circ}(\mathrm{PhOH})\right\}=-0.8 \mathrm{cal} \mathrm{mol}^{-1} \mathrm{~K}^{-1}, 61$ so in both cases the magnitude of the $\mathrm{T}\left\{S^{\circ}\left(\mathrm{X}^{\circ}\right)-S^{\circ}(\mathrm{XH})\right\}$ term is less than $0.4 \mathrm{kcal} \mathrm{mol}^{-1}$. Note that when $S^{\circ}\left(\mathrm{X}^{\circ}\right)=S^{\circ}(\mathrm{XH})$, $\mathrm{BDFE}_{\mathrm{g}}(\mathrm{XH})$ is $8.17 \mathrm{kcal} \mathrm{mol}^{-1}$ less than the corresponding $\mathrm{BDE}_{\mathrm{g}}(\mathrm{XH})$.

$$
\mathrm{BDFE}_{\mathrm{g}}(\mathrm{XH})=\mathrm{BDE}_{\mathrm{g}}(\mathrm{XH})-\mathrm{T}^{\circ}\left(\mathrm{H}^{\bullet}\right)-\mathrm{T}\left\{S^{\circ}\left(\mathrm{X}^{\bullet}\right)-S^{\circ}(\mathrm{XH})\right\}
$$

Gas phase BDFEs are related to solution BDFEs as shown in Scheme 5 and eq 11. Determining the solution BDFE from the gas phase value requires (i) the free energy of solvation of $\mathrm{H}^{\bullet}$ and (ii) the difference in the solvation free energies of $\mathrm{X}^{\bullet}$ and $\mathrm{XH} . \Delta G_{\text {solv }}{ }^{\circ}$ $\left(\mathrm{H}^{\circ}\right)$ is approximated as that of $\mathrm{H}_{2}$ (see above). 


$$
\mathrm{BDFE}_{\text {solv }}(\mathrm{XH})=\mathrm{BDFE}_{\mathrm{g}}(\mathrm{XH})+\Delta G_{\text {solv }}^{\circ}\left(\mathrm{H}^{\bullet}\right)+\Delta G_{\text {solv }}^{\circ}\left(\mathrm{X}^{\bullet}\right)-\Delta G_{\text {solv }}^{\circ}(\mathrm{XH})
$$

For hydrocarbons and other relatively nonpolar substrates, the free energies of solvation of $\mathrm{X}^{\bullet}$ and $\mathrm{XH}$ are close because the closed shell and radical species are approximately the same size and have the same charge. For this situation, $\Delta G_{\text {solv }^{\circ}}(\mathrm{XH})=\Delta G_{\text {solv }}{ }^{\circ}\left(\mathrm{X}^{\bullet}\right)$, the difference between the solution and gas phase BDFEs is $\Delta G_{\text {solv }}{ }^{\circ}\left(\mathrm{H}^{\circ}\right)$ which is $\cong \Delta G_{\text {solv }}{ }^{\circ}\left(\mathrm{H}_{2}\right)$ (see above). This is, for example, $5.12 \mathrm{kcal} \mathrm{mol}^{-1}$ in MeCN.52 For substrates with one H-bond donating/accepting group such as phenol, $\left[\Delta G_{\text {solv }}{ }^{\circ}\left(\mathrm{X}^{\bullet}\right)-\Delta G_{\text {solv }}{ }^{\circ}(\mathrm{XH})\right]$ can be approximated as the difference in solvation of the hydroxyl/oxyl moiety. Following Ingold, 62 this difference in solvation can be accurately estimated using Abraham's empirical hydrogen bonding model.63-6465 This model relates the hydrogen bond acidity $\left(\alpha_{2}{ }^{\mathrm{H}}\right)$ and the hydrogen bond basicity $\left(\beta_{2}{ }^{\mathrm{H}}\right)$ to the strength of a hydrogen bond (eq 12) and its application to estimate $\left[\Delta G_{\text {solv }}{ }^{\circ}\left(\mathrm{R}^{\bullet}\right)-\Delta G_{\text {solv }}{ }^{\circ}(\mathrm{RH})\right]$ is given in eq 13 . We have shown that this procedure gives accurate solution BDFEs for several mono-hydroxylic substrates in several solvents.66 However, given the approximations involved, this method should only be used when the relevant thermochemical data for the solvent of interest are not available. This method has been used sparingly in the Tables below and any BDFE estimated in this fashion is given in (parentheses).

$$
\Delta G_{\mathrm{HB}}^{\circ}=-10.02 \alpha_{2}{ }^{\mathrm{H}} \beta_{2}{ }^{\mathrm{H}}+1.492
$$

$\Delta G_{\text {solv }}^{\circ}\left(\mathrm{R}^{\bullet}\right)-\Delta G_{\text {solv }}^{\circ}(\mathrm{RH})=-10.02 \alpha_{2}{ }^{\mathrm{H}}($ solv $) \beta_{2}{ }^{\mathrm{H}}\left(\mathrm{RO}{ }^{\bullet}\right)+10.02 \alpha_{2}{ }^{\mathrm{H}}(\mathrm{ROH}) \beta_{2}{ }^{\mathrm{H}}($ solv $)$

\subsection{PCET Thermochemistry in Aqueous Solutions}

In aqueous solution, proton transfer is extremely rapid and electrochemical measurements often give reduction potentials for half reactions including any proton addition or loss. The potential for a half reaction as a function of $\mathrm{pH}$ is given by the Nernst equation (eq 14). The Nernst factor RT/F is $59 \mathrm{mV}$ at $298 \mathrm{~K}$, so the potential of a one-electron, one-proton couple $(n=m=1)$ varies $59 \mathrm{mV}$ per $\mathrm{pH}$ unit. For such a $1 e^{-} / 1 \mathrm{H}^{+}$couple, the BDFE is simply given by the potential at $\mathrm{pH} 0$ by eq 15 , in which the $\mathrm{p} K_{\mathrm{a}}$ is not needed because $E^{\circ}\left(\mathrm{X}^{\bullet} / \mathrm{XH}\right)$ includes the free energy of addition of the proton. For measurements at other $\mathrm{pH}$ 's, the BDFE is given by eq 16 . The $1.37(\mathrm{pH})$ term in eq 16 in effect extrapolates a $1 e^{-} / 1 \mathrm{H}^{+}$ potential at a given $\mathrm{pH}$ to the standard state of $\mathrm{pH} 0$.

$$
\begin{aligned}
& \text { For: } \mathrm{A}+n e^{-}+m \mathrm{H}^{+} \rightarrow \mathrm{H}_{m} \mathrm{~A}^{(n-m)-} \\
& \qquad E=E^{0}-\frac{\mathrm{RT}}{n \mathrm{~F}} \ln \frac{\left[\mathrm{H}_{m} \mathrm{~A}^{(n-m)-}\right]}{[\mathrm{A}]\left[\mathrm{H}^{+}\right]^{m}}
\end{aligned}
$$

or:

$$
E=E^{0}-\frac{\mathrm{RT}}{n \mathrm{~F}} \ln \frac{\left[\mathrm{H}_{m} \mathrm{~A}^{(n-m)-}\right]}{[\mathrm{A}]}-\frac{\mathrm{RT}}{\mathrm{F}} \frac{m}{n} \mathrm{pH}
$$

For a $1 e^{-} / 1 \mathrm{H}^{+}$redox couple using $E^{\circ}$ at $\mathrm{pH}=0$ : 
For a $1 e^{-} / 1 \mathrm{H}^{+}$redox couple using $E^{\circ}$ at another $\mathrm{pH}$ :

$$
\operatorname{BDFE}(\mathrm{XH})=23.06\left[E_{\mathrm{pH}}\left(\mathrm{X}^{\bullet} / \mathrm{XH}\right)\right]+1.37(\mathrm{pH})+57.6 \mathrm{kcal} \mathrm{mol}^{-1}
$$

Pourbaix diagrams, which plot potential vs. $\mathrm{pH}$, are one form of the thermochemical map described above, and an elegant application of the Nernst equation. Pourbaix assembled a compendium of these diagrams, describing the aqueous redox chemistry of each element.67 Figure 1 shows a recent example of a Pourbaix diagram, constructed by Llobet and coworkers for a ligated dimeric ruthenium-aquo complex from electrochemical measurements. 68 Horizontal and diagonal lines on the diagram indicate the potentials separating the $E / \mathrm{pH}$ regions in which the various stable species predominate. As per eq 14, the lines have the slope of $\mathrm{m} / \mathrm{n}$ and therefore indicate the proton/electron stoichiometry of the electrochemical measurements. For the $1 e^{-} / 1 \mathrm{H}^{+}$couples, the BDFEs can be determined directly from the Pourbaix diagram from eq 16. Vertical lines (and points where diagonal lines change slope) indicate the $\mathrm{p} K_{\mathrm{a}}$ values of the species to the left of the line.

\section{Introduction to the Thermochemical Tables}

The following sections present an overview of the PCET reactivity of different classes of compounds, such as phenols, hydrocarbons, or transition metal-oxo/hydroxo/aquo complexes. Each section has brief comments about the importance of PCET reactivity of this class of compounds, and then provides an overview and highlights of the data available. Each section concludes with an extensive data Table. To assist the reader looking for a PCET reagent with a particular bond dissociation free energy (BDFE), and to give an overview of the following, this section has a Table with selected compounds from each class and their BDFE values.

The Table in each of the following sections present thermochemical data for PCET reagents from ascorbate to xanthene. They give, when available, the $E^{\circ}\left(\mathrm{XH}^{\bullet+} / \mathrm{XH}\right), E^{\circ}\left(\mathrm{X}^{\circ} / \mathrm{X}^{-}\right)$, $\mathrm{p} K_{\mathrm{a}}\left(\mathrm{XH}^{\bullet+}\right), \mathrm{p} K_{\mathrm{a}}(\mathrm{XH})$, and the solution BDFE and BDE in various solvents ( $c f .$, Scheme 4 above). All of the potentials in this review are reduction potentials, though arrows in the "square schemes" may appear to indicate oxidation. When the only redox potentials available are irreversible peak potentials from cyclic voltammetry $(\mathrm{CV})$, the values are indicated by italics in the Tables. BDFEs and BDEs derived from such irreversible peak potentials should be viewed as more uncertain than those values derived from reversible $E_{1 / 2}$ measurements. Irreversible peak potentials often depend on the kinetics of the step preceding or following electron transfer and therefore are not necessary characteristic of the thermodynamics. While this is a concern, Bordwell addressed this issue in his early papers 41,69 and showed that, at least for the systems studied, the use of irreversible potentials gave BDE values in agreement with those from other sources. In some cases, such as for hydrocarbons, gas phase bond strengths are given and the "solvent" is identified as "gas."

Any value in the Tables below that is taken from the literature has a reference associated with it. Values without citations have been calculated from the other values in the Table; as noted above, there are only three unique values among the five free energy parameters for each compound (listed in a row of a Table or depicted in a square scheme). Typically, the $\mathrm{p} K_{\mathrm{a}}$ and $E^{\circ}$ values are experimentally determined and we have calculated the solution BDFE and $\mathrm{BDE}$ from those values using eqs $7,8,15$ or 16 above. When $E^{\circ}$ and $\mathrm{p} K_{\mathrm{a}}$ values are 
given in [square brackets], they have been calculated from the other values in the row using Hess' law (eqs 6, 7).

We note that some of the BDEs and BDFEs shown in this review have been revised from those previously reported. This may be due to new values of the $\mathrm{p} K_{\mathrm{a}}$ or $E_{1 / 2}$, or more often to revision of the constants $C_{\mathrm{G}}$ and $C_{\mathrm{H}}$ as discussed above. A few BDFEs measured by equilibration with a standard reagent have been revised because the best BDFE value for the standard has be reevaluated. For instance, BDFEs derived from $K_{\text {eq }}$ for $\mathrm{XH}+$ $2,4,6-{ }^{t} \mathrm{Bu}_{3} \mathrm{ArO}^{\bullet} \rightleftarrows \mathrm{X}^{\bullet}+2,4,6-{ }^{t} \mathrm{Bu}_{3} \mathrm{ArOH}$ may be revised to reflect the updated solution $\mathrm{BDFE}$ for $2,4,6-{ }^{t} \mathrm{Bu}_{3} \mathrm{ArOH}$. Our goal has been to assemble a consistent set of values.

Most of the earlier data are reported as BDEs, but based on our recent discovery of large entropic contributions to PCET, we now encourage the use of BDFEs.39,40 Readers are urged to pay close attention to this distinction. If only a BDE or a BDFE has been reported, the Tables give the other value calculated using the difference between $C_{\mathrm{H}}$ and $C_{\mathrm{G}}$ (eq 9). As described above, this connection of a bond dissociation enthalpy (BDE) with measurements of free energies (BDFE, $E^{\circ}$, and $\mathrm{p} K_{\mathrm{a}}$ ) requires the assumption that the entropies of $\mathrm{HX}$ and $\mathrm{X}^{\circ}$ are equal (eqs 8,9 ). Because this assumption does not hold well for some transition metal complexes, the calculation of BDEs in this fashion has not been done in Table 21. In some cases, a BDFE in one solvent has been estimated from a BDFE in a different solvent, using the Abraham model (eq 13); again, in these cases the BDFE is given in (parentheses).

\subsection{Estimated Errors}

The thermochemical data given here come from a wide variety of sources and are derived from a variety of different measurements. It is beyond the scope of this review to provide error analyses for each value presented (particularly in light of the occurrence of systematic errors that have at times affected measurements of BDEs70). Instead, we roughly estimate that typical uncertainties in the solution BDFE values given in this review of $\pm 2 \mathrm{kcal} \mathrm{mol}^{-1}$. Accuracies may be better for well-studied, small molecules, particularly in their gas-phase bond dissociation enthalpies. For BDFEs derived from $\mathrm{p} K_{\mathrm{a}}$ and $E_{1 / 2}$ measurements (eq 7 above), our error estimate is based on typical uncertainties in these values, and the uncertainties in the $C_{\mathrm{G}}$ constant. Relative values may be more accurate, as the uncertainty in $C_{\mathrm{G}}$ is eliminated. Bordwell estimated somewhat larger errors $\left(\leq \pm 3 \mathrm{kcal} \mathrm{mol}^{-1}\right)$ when irreversible peak potentials are used.41 In some cases, these estimated accuracies may be optimistic. We encourage the interested reader to examine the primary literature. All of the bond strengths are reported here to one decimal place to eliminate ambiguity due to rounding.

\section{Thermochemistry of PCET Reagents}

\subsection{Hydroxylamines}

Hydroxylamines and their $1 e^{-} / 1 \mathrm{H}^{+}$oxidized partners, aminoxyl radicals, also known as nitroxyl radicals or nitroxides, 71 have received considerable attention in the past 20 years. 72 Thermochemical data for proton, electron, and $\mathrm{H}^{*}$ transfers from hydroxylamines are given in Table 3. This section is focused on three of the most well studied hydroxylamine/ aminoxyl radical pairs: 2,2'-6,6'-tetramethypiperidine-1-ol (TEMPOH), $N, N$-di-tertbutylhydroxylamine ( ${ }^{t} \mathrm{Bu}_{2} \mathrm{NOH}$ ) and $\mathrm{N}$-hydroxyphthalimide (NHPI) (Scheme 6).

5.1.1 TEMPO(H) and ${ }^{t} \mathrm{Bu}_{2} \mathbf{N O}(\mathbf{H})$-The 2,2'-6,6'-tetramethypiperidine-1-oxyl radical, TEMPO, and related derivatives have been widely used as spin labels, spin traps, MRI contrast agents, free radical polymerization promoters, and 'green' oxidation catalysts. 73 
The radicals are typically air-stable, isolable, and commercially available (while the hydroxylamine 2,2'-6,6'-tetramethypiperidine-1-ol, TEMPOH, is reactive with air). The TEMPO/TEMPOH and related redox couples are particularly valuable for PCET studies because of the their low $\mathrm{O}-\mathrm{H}$ bond strengths, and their strong thermochemical bias towards concerted $\mathrm{H}^{\bullet}$ transfer reactions (as discussed in greater detail below). HAT pseudo-selfexchange reactions of TEMPO and related alkyl aminoxyl radicals have been found to involve significant hydrogen tunneling (as do some cross reactions), in contrast to the related reactions of aryl aminoxyl radicals.74,75

The BDFE and BDE of TEMPOH will serve as benchmarks for some of the following discussion. We have recently critically evaluated the BDE and BDFE of TEMPOH in $\mathrm{MeCN}$ and $\mathrm{C}_{6} \mathrm{H}_{6}$ solvents, using both reported calorimetric measurements 76 and $E^{\circ}$ and $\mathrm{p} K_{\mathrm{a}}$ data (Table 3). 40 The calorimetric measurements, for diphenylhydrazine +2 TEMPO $\rightarrow$ azobenzene +2 TEMPOH, were reinterpreted using the recently revised heat of formation of azobenzene. 77

The other noteworthy redox reaction of TEMPO is its oxidation to the corresponding nitrosonium cation. The nitrosonium cation has received attention for its superoxide dismutase-type reactivity 78 and catalytic alcohol oxidations, 79 both of which can be described as PCET processes. In water $E^{\circ}\left(\mathrm{TEMPO}^{\circ /+}\right)=0.74 \mathrm{~V}(v s$. NHE),80,81 and in $\mathrm{MeCN} E^{\circ}\left(\mathrm{TEMPO}^{\circ /+}\right)=0.61 \mathrm{~V} 82$ (vs. SCE; better: $0.24 \mathrm{~V}$ vs. $\left.\mathrm{Cp}_{2} \mathrm{Fe}^{+/ 0} 33\right)$.

Several 4-substituted derivatives of TEMPO have been investigated, including 4-oxo-, 4methoxy-, 4-amino-, and 4-hydroxy-TEMPO. Bond strengths for these and other aminoxyls in hexane have been reported by Malievskii et al. from kinetic and equilibrium measurements, 83 but little acidity or redox potential data are available for these other TEMPO derivatives.

As noted above, the TEMPO $(\% / \mathrm{H}) 1 \mathrm{H}^{+} / 1 e^{-}$couple is an excellent example of a PCET reagent that favors concerted $\mathrm{H}^{*}$ transfer over stepwise ET-PT or PT-ET pathways. TEMPOH $\left(\mathrm{p} K_{\mathrm{a}}=41\right.$ in MeCN) is a very poor acid and TEMPO $\left(\mathrm{p} K_{\mathrm{a}} \sim-4\right)$ is a poor base. Likewise, it is difficult to oxidize TEMPOH to TEMPOH ${ }^{\bullet+}\left(E_{\mathrm{p}, \mathrm{a}}=0.71 \mathrm{~V} v s . \mathrm{Cp}_{2} \mathrm{Fe}^{+/ 0}\right)$ and quite difficult to reduce TEMPO to TEMPO ${ }^{-}\left(E_{\mathrm{p}, \mathrm{c}}=-1.95 \mathrm{~V}\right)$. These data indicate that under typical conditions, TEMPO ${ }^{-}$and TEMPOH ${ }^{*+}$, the species at the top right and bottom left of the TEMPO square scheme (see Scheme 4), are high-energy species.

The preference for concerted transfer of $\mathrm{H}^{\bullet}$ in reactions of TEMPO and TEMPOH can be illustrated by examining the energetics for the different pathways for the TEMPOH + TEMPO self exchange reaction (Scheme 7). HAT from TEMPOH to TEMPO has $\Delta G^{\circ}=0$ because it is a degenerate process. In MeCN, initial PT from TEMPOH to TEMPO gives $\mathrm{TEMPO}^{-}+\mathrm{TEMPOH}^{\bullet+}$. This reaction has an equilibrium constant of $10^{-45}$ based on the $\mathrm{p} K_{\mathrm{a}} \mathrm{s}$ of 41 and $\sim-4$ respectively (Table 3 ), indicating a very unfavorable free energy, $\Delta G$ ${ }_{\mathrm{PT}} \sim+60 \mathrm{kcal} \mathrm{mol}^{-1}$. Initial ET from TEMPOH to TEMPO is uphill by the same amount $(\sim 2.7 \mathrm{~V}$ from the redox potentials). Note that for the unique case of a self-exchange reaction $\mathrm{XH}+\mathrm{X}$, these two values must be the same, because initial PT and ET both make the same intermediate state, $\mathrm{XH}^{+}+\mathrm{X}^{-} .84$ Thus, there is a very large $\left(60 \mathrm{kcal} \mathrm{mol}^{-1}\right)$ bias favoring concerted transfer of $e^{-}$and $\mathrm{H}^{+}$. The self-exchange reaction occurs readily, proceeding on the stopped flow timescale with an Eyring barrier $\Delta G^{\ddagger}=16.5 \mathrm{kcal} \mathrm{mol}^{-1}$ in MeCN.38,74 On this basis, the self-exchange cannot be proceeding through an intermediate state that is $60 \mathrm{kcal} \mathrm{mol}^{-1}$ above the ground state; the two particles must transfer together. This type of thermochemical argument, probably first applied to PCET by Meyer and coworkers, 1 is quite powerful and is discussed in more detail for cross reactions in Section 6. 
5.1.2 N-hydroxyphthalimide (NHPI)/phthalimide- $\mathrm{N}$-oxyl radical (PINO)-The PINO radical has been broadly explored in organic free radical oxidations, 85,86 especially as a 'green' alternative to the bromide co-catalyst in transition metal-catalyzed autoxidations.87 Catalytic oxidations in PINO-containing systems are thought to proceed through a series of H-atom abstraction steps. Despite the wide attention that NHPI/PINO has received, relatively few thermochemical data are available. Koppel and co-workers have determined $\mathrm{p} K_{\mathrm{a}}$ values for NHPI in water and DMSO, 88 and the DMSO value can be used to estimate a $\mathrm{p} K_{\mathrm{a}}$ in MeCN.89 NHPI is much more acidic than dialkyl hydroxylamines, as would be expected for a phthalimide.

There is little consensus between the published electrochemical studies of NHPI. In MeCN in the absence of base, a broad quasi-reversible oxidation is observed at $+1.2 \mathrm{~V} v s$. $\mathrm{Cp}_{2} \mathrm{Fe}^{+/ 0} .90$ Addition of pyridine bases caused a shift to much lower potentials, which was attributed to the oxidation of deprotonated NHPI (the NHPI ${ }^{\circ-}$ couple). $90^{-} 919293$ However, this assignment is unlikely since the pyridine bases used $\left(\mathrm{p} K_{\mathrm{a}}=12-16\right.$ in MeCN30) are not basic enough to deprotonate NHPI to any great extent ( $\mathrm{p} K_{\mathrm{a}}=23.5$ in MeCN, see Table 3). Furthermore, the potentials vary with the strength of the added base, with stronger bases leading to lower potentials - by roughly $59 \mathrm{mV}$ per unit change in the pyridine $\mathrm{p} K_{\mathrm{a}}$, as would be expected for a PCET reaction.90-919293 These data all suggest that the electrochemical process removes $1 \mathrm{H}^{+}$and $1 e^{-}$from NHPI, not simply an electron. We estimate, based on the reported electrochemical data extrapolated to $\mathrm{p} K_{\mathrm{a}}(\mathrm{NHPI})=23.5$ (59 $\mathrm{mV}$ per $\left.\mathrm{p} K_{\mathrm{a}}\right), E^{\circ}\left(\mathrm{NHPI}^{\circ /-}\right)=-0.1 \mathrm{~V}$ and $\mathrm{BDFE}=84.8 \mathrm{kcal} \mathrm{mol}^{-1}$ in $\mathrm{MeCN}$.

Lucarini, Pedulli and co-workers have employed their EPR radical equilibration technique to determine bond strengths (BDEs) of NHPI, substituted NHPI derivatives and other related hydroxylamines.94,95 The BDE of NHPI was determined to be $88.1 \mathrm{kcal} \mathrm{mol}^{-1}$ in ${ }^{t} \mathrm{BuOH}$ solvent.94 Later, bond strengths for substituted NHPI derivatives were determined in $\mathrm{CH}_{3} \mathrm{CN}$ with respect to the parent NHPI, again using the EPR equilibration technique.95 The reference BDE used in that study was $88.1 \mathrm{kcal} \mathrm{mol}^{-1}$, the BDE of NHPI in ${ }^{t} \mathrm{BuOH}$. However, based on the $E^{\circ}$ and $\mathrm{p} K_{\mathrm{a}}$ data for NHPI in $\mathrm{MeCN}$, we conclude that the $\mathrm{BDE}_{\mathrm{MeCN}}$ of NHPI is $1.2 \mathrm{kcal} \mathrm{mol}^{-1}$ higher than the corresponding BDE in ${ }^{t} \mathrm{BuOH}$. Thus, BDEs for substituted NHPI derivatives have been adjusted upward by $1.2 \mathrm{kcal} \mathrm{mol}^{-1}$ such that they are relative to the $\mathrm{BDE}$ of NHPI in MeCN determined here. One of the great advantages of the EPR equilibration technique is that the BDEs are usually very accurate with respect to each other, so that the uncertainty in the absolute BDE is essentially only dependent upon the accuracy of the reference compound BDE.

\subsection{Phenols, Hydroquinones, Catechols and Ascorbate}

This section presents thermochemical data for hydroxylic compounds where the $\mathrm{OH}$ group is attached to an unsaturated $\left(\mathrm{sp}^{2}\right)$ carbon. The redox chemistry of such compounds phenols, quinones, ascorbate, etc. - has been the subject of intense interest for more than a half century. To give just a few examples, PCET reactions of these compounds are integral to biological energy production (e.g. quinone cycling in photosystems I and II and the $b c_{1}$ complex; tyrosine $\mathrm{Z}$ in photosystem II),106 107108 biosynthesis (ribonucleotide reductases), 109 antioxidant activity (tocopherols),110,111 and food preservation (butylated hydroxytoluene). 112 The coverage in this section is not intended to be complete, but is rather focused on representative cases where there are extensive $\mathrm{p} K_{\mathrm{a}}, E$, and bond strength data. A reader interested in a particular substituted derivative that does not appear in Table 4 is encouraged to check the references cited there, and reference 56, as many of the primary papers cover a range of substituents. 
5.2.1 Phenol (PhOH)—Phenol has been widely studied as the simplest of the aromatic hydroxylic compounds. The gas-phase O-H BDE in phenol has been a subject of much discussion.62, 113,114 Heats of formation from the NIST Chemistry WebBook, $\Delta H_{\mathrm{f}}^{\circ}{ }_{\text {gas }}\left(\mathrm{PhO}^{\circ}\right)=13 \pm 1 \mathrm{kcal} \mathrm{mol}^{-}$and $\Delta H_{\mathrm{f}}^{\circ}{ }_{\text {gas }}\left(\mathrm{PhOH}=-23.03 \pm 0.14 \mathrm{kcal} \mathrm{mol}^{-1}\right.$, give $\mathrm{BDE}_{\mathrm{g}}(\mathrm{PhOH})=88.0 \pm 1 \mathrm{kcal} \mathrm{mol}^{-1} .49,70$ This value is in between alternative values of $86.7 \mathrm{kcal} \mathrm{mol}^{-1} 114$ and $88.7 \mathrm{kcal} \mathrm{mol}^{-1} .62 \mathrm{~A}$ clearer value for this important benchmark compound would be valuable.

A wealth of thermochemical data is available for phenols, in particular their acidity $\left[\mathrm{p} K_{\mathrm{a}}(\mathrm{ArOH})\right]$ and the phenoxyl radical $/$ phenoxide reduction $\left[E^{\circ}\left(\mathrm{ArO}^{\circ /-}\right)\right]$. Protonated phenoxyl radicals are typically high energy species with aqueous $\mathrm{p} K_{\mathrm{a}}$ values $>0.115$ The most extensive studies of $E^{\circ}\left(\mathrm{ArO}^{\circ /-}\right)$ are by Bordwell et al. for DMSO solutions 116 and by Lind et al. and Steenken and Neta in aqueous media.117,118 The aqueous measurements take advantage of the phenol potential becoming independent of $\mathrm{pH}$ above its $\mathrm{p} K_{\mathrm{a}}$ (see Section 3.2 above).

Phenols readily react by hydrogen atom transfer (HAT) and this pathway is implicated in the antioxidant properties of phenols both in vivo and in vitro (see below). 119 For the more acidic phenols, or under basic conditions, a mechanism of sequential proton loss then electron transfer (SPLET) can occur.11-1213 It is less common for phenols to react by initial outer-sphere electron transfer because of the high $E^{\circ}\left(\mathrm{PhOH}^{*+/ 0}\right)$ potentials. The $\mathrm{ArO} \%$ ArOH potentials (or, better, BDFEs) are often above the thermodynamic requirement for water oxidation, as is necessary for the function of Tyrosine $\mathrm{Z}$ in photosystem II, mediating hole transfer from the chlorophyll radical cation to the oxygen evolving complex.

5.2.2 2,4,6-Tri-tert-butylphenol ( $\left.{ }^{t} \mathrm{Bu}_{3} \mathrm{PhOH}\right)$-4-Substituted-2,6-di-tert-butyl-phenols are widely used in the research lab and as food preservatives, especially 'butylated hydroxytoluene' (BHT, 4-Me) and 'butylated hydroxyanisole' (BHA, 4-MeO). $2,4,6-{ }^{t} \mathrm{Bu}_{3} \mathrm{PhOH}$ is an especially interesting and useful reagent for studies of PCET reactions because of the exceptional stability of the phenoxyl radical $\left({ }^{t} \mathrm{Bu}_{3} \mathrm{PhO}^{*}\right) .120$ The radical is easily prepared from the corresponding phenol using $\mathrm{NaOH}$ and $\mathrm{K}_{3} \mathrm{Fe}(\mathrm{CN})_{6}$, and can be isolated as dark blue crystals.120 As discussed for TEMPOH above, we have recently reevaluated the solution $\mathrm{BDE}$ of ${ }^{t} \mathrm{Bu}_{3} \mathrm{PhO}^{\circ}$ in $\mathrm{C}_{6} \mathrm{H}_{6}$ to account for recent revision of the thermochemistry of the originally used diphenylhydrazine/azobenzene couple.40 Our preferred value is $81.6 \pm 0.4 \mathrm{kcal} \mathrm{mol}^{-1}$.

The ${ }^{t} \mathrm{Bu}_{3} \mathrm{PhO}(/ \mathrm{H})$ PCET couple is a very useful benchmark for the determination of bonds strengths in other phenols. The clearest example is Pedulli and co-workers' EPR method to measure equilibrium constants for $\mathrm{ArOH}+{ }^{t} \mathrm{Bu}_{3} \mathrm{PhO}^{\cdot} .121$ Please note that here and in Table 4, we have slightly adjusted Pedulli's reported BDEs to reflect our recent critical evaluation of the $\mathrm{BDE}$ (and the BDFE) of ${ }^{t} \mathrm{Bu}_{3} \mathrm{PhOH} .40$ The EPR equilibration method provides a high degree of precision and the values are, in general, internally consistent.122 The values obtained agree very well with those from other methods, such as from $E^{\circ}$ and $\mathrm{p} K_{\mathrm{a}}$ measurements. For example, the adjusted Pedulli values for $\mathrm{BDFE}(\mathrm{PhOH})$ and $\operatorname{BDFE}\left(2,6-{ }^{t} \mathrm{Bu}_{2} \mathrm{PhOH}\right)$ in $\mathrm{C}_{6} \mathrm{H}_{6},=83.8$ and $78.3 \mathrm{kcal} \mathrm{mol}^{-1}$ (Table 4), agree very closely with our conversion of Bordwell's BDFEs in DMSO (from $E^{\circ}$ and $\mathrm{p} K_{\mathrm{a}}$ values) 116 to $\mathrm{C}_{6} \mathrm{H}_{6}$ using the Abraham method, 83.7 and $78.1 \mathrm{kcal} \mathrm{mol}^{-1}$, respectively.

5.2.3 Tyrosine-Redox reactions of the amino acid tyrosine are involved in biological energy transduction, charge transport, oxidative stress, and enzymatic catalysis.123 The $1 \mathrm{H}^{+} / 1 e^{-}$oxidized form, the tyrosyl radical, has been implicated in a variety of enzymatic systems, including ribonucleotide reductases, 109 photosystem II,106 galactose oxidase, 124 prostaglandin-H-synthase 125 and perhaps cytochrome $c$ oxidase.126 Furthermore, tyrosine 
oxidation products are thought to play deleterious roles in various disease states, including atherosclerosis and aging.127

The proton-coupled redox chemistry of tyrosine $(\mathrm{TyrOH})$ and related compounds has been widely reported.128-129130131 In aqueous solutions, the Pourbaix diagram shows a clear $59 \mathrm{mV}$ per $\mathrm{pH}$ dependence for the oxidation of tyrosine below $\mathrm{pH} 10$, indicative of a $1 e^{-} /$ $1 \mathrm{H}^{+}$redox couple. As for phenol, above $\mathrm{p} K_{\mathrm{a}}$ (tyrosine) the redox potential does not depend on $\mathrm{pH}$ because this is the proton-independent $\mathrm{TyrO}^{\bullet} / \mathrm{TyrO}^{-}$redox couple. Other, more detailed, discussions of aspects of proton-coupled redox chemistry of tyrosine can be found in other contributions to this issue. As an aside, we encourage biochemical studies of PCET to use a nomenclature that explicitly shows the proton, such as 'TyrOH' for tyrosine, to avoid ambiguity. For instance, the commonly used "Y"" for tyrosyl radicals could refer either to neutral radical $\mathrm{TyrO}^{\bullet}$ or to the typically high-energy radical cation $\mathrm{TyrOH}^{\bullet+}$.

5.2.4 $\alpha$-Tocopherol and Related Phenols- $\alpha$-Tocopherol (a main component of Vitamin E) is thought to be a key chain breaking antioxidant in biological systems. Since its discovery in 1922,132 vitamin $\mathrm{E}$ has received considerable attention from chemists, biologists, and clinicians, among others.110 Due to its insolubility in water, several small water soluble analogs such as Trolox $C(( \pm)-6$-hydroxy-2,5,7,8-tetramethylchromane-2carboxylic acid) and HPMC (6-hydroxy-2,2-5,7,8-pentamethylchroman) have been developed (Scheme 8; see references 133 and 134). As shown in Table 4, these three phenols show similar thermochemistry in the same solvent. This is in good agreement with their solution kinetic behavior and indicates that the analogs lacking the greasy phytyl tails are good models for the redox chemistry of tocopherol. The BDFEs of these phenols are much lower than those of other phenols, by more than $10 \mathrm{kcal} \mathrm{mol}^{-1} v s$. unsubstituted phenol and by $\sim 2 \mathrm{kcal} \mathrm{mol}^{-1} v s .{ }^{t} \mathrm{Bu}_{3} \mathrm{PhOH}$ in the same solvent. This relatively weak bond is the origin of the good biological reducing power of vitamin $\mathrm{E}$. The weak bond is a result of the electron-donating substituents, which also reduces the acidity of these phenols. The combination of a weak $\mathrm{O}-\mathrm{H}$ bond, low acidity, and a high outer-sphere redox potential $\left[E^{\circ}\right.$ $\left.\left(\mathrm{ArOH}^{\bullet+/ 0}\right)\right]$ give these molecules a strong preference to react by concerted transfer of $e^{-}$ and $\mathrm{H}^{+}$(HAT). Njus and Kelley used such reasoning to conclude that Vitamin E donates $\mathrm{H}^{\bullet}$ as opposed to $e^{-}$in biological reactions.135 A characteristic of these and other systems that prefer to transfer $\mathrm{H}^{\bullet}$ rather than react by stepwise paths ( $c f$., TEMPOH above) is the very large shift of the $\mathrm{p} K_{\mathrm{a}}$ upon redox change and (equivalently) the large shift of $E^{\circ}$ upon protonation: for $\alpha$-tocopherol, the $\mathrm{p} K_{\mathrm{a}}$ changes by 25 units and $E^{\circ}$ changes by $1.5 \mathrm{~V}$.

5.2.5 Quinones, Hydroquinones and Catechols-The PCET chemistry of hydroquinones and catechols (1,4- and 1,2-dihydroxybenzenes, respectively) is somewhat similar to that of 4-substituted phenols, but more extensive because there are two transferable hydrogen atoms and removal of both leads to stable quinones. This means that instead of the four species of the standard 'square scheme' that are formed upon PT, ET, or CPET from HX (Scheme 4), there are nine species derived from $\mathrm{H}_{2} \mathrm{Q}$, as shown in Figure 2. This is also the case for flavins, which are discussed below. In practice, the cationic forms, $\mathrm{H}_{2} \mathrm{Q}^{\bullet+}, \mathrm{H}_{2} \mathrm{Q}^{2+}$ and $\mathrm{HQ}^{+}$, are not involved in typical PCET reactivity because they are high energy species under normal conditions.

In the reactions of the first $\mathrm{O}-\mathrm{H}$ bond, hydroquinones follow the patterns outlined above for phenols. In general, the $\mathrm{p} K_{\mathrm{a}}$ values for $\mathrm{H}_{2} \mathrm{Q}$ and the oxidation potential of $\mathrm{HQ}^{-}$fit on Hammett correlations with other 4-substituted phenols, both in aqueous117 and in organic media.116 For example, the BDFE of the first $\mathrm{O}-\mathrm{H}$ bond in hydroquinone is $2-3 \mathrm{kcal} \mathrm{mol}^{-1}$ weaker than that of $p$-methoxyphenol. With hydroquinones and catechols, however, loss of $\mathrm{H}^{\bullet}$ yields the semiquinone radical that has a high propensity to lose a second $\mathrm{H}^{\bullet} .148$ Semiquinones and related species were among the first free radicals to be investigated in 
detail: Michaelis' 1935 review in this journal points out that many systems commonly understood as $1 e^{-}$systems can actually undergo $1 e^{-}$or $1 \mathrm{H}^{+} / 1 e^{-}$redox chemistry, and that the redox properties of semiquinone-type radicals are dependent upon $\mathrm{pH}-$ a very early recognition of the importance of PCET in biology.149

While hydroquinones have reactivity patterns that are in part similar to phenols, with preferential loss of $\mathrm{H}^{\circ}$, quinones have a different PCET behavior, especially in water. Quinones are typically easily reduced to semiquinone radical anions in water, without the assistance of protons, and the $\mathrm{Q}^{\bullet-}$ anions are not particularly basic (Table 6). Therefore quinone cofactors can readily mediate stepwise PCET reactions, with initial electron transfer followed by proton transfer. $\mathrm{Q} / \mathrm{Q}^{--}$interconversion is well understood using semi-classical ET theory.150 Such stepwise mechanisms have been discussed,151 and an example of stepwise PT-ET of quinones in biology is discussed in Section 6 below.

The aqueous $2 \mathrm{H}^{+} / 2 e^{-}$potentials of many quinones have been reported, because they are easily measured and because they are important biological cofactors (ubiquinone, for instance, is so named because it is ubiquitous). Their electrochemistry is generally well behaved,153 although there is still much to be learned in this area.154 The electrochemical data directly give an average BDFE/BDE for each quinone system (Table 5). Interestingly, the average bond strength for most quinones lies between the relatively narrow range of 68 to $75 \mathrm{kcal} \mathrm{mol}^{-1}$.

The average $\mathrm{O}-\mathrm{H}$ bond strengths in Table 5 do not, however, always parallel the individual $\mathrm{O}-\mathrm{H}$ bond strengths. Using the known $\mathrm{p} K_{\mathrm{a}} \mathrm{s}$ and reduction potentials for the quinones and semiquinones, the BDFEs (and BDEs) for many hydroquinones can be calculated (Table 6). The power of the thermochemical cycles (Hess' Law) is illustrated by the calculation of the $\mathrm{HQ}^{*} / \mathrm{HQ}^{-}$reduction potentials (Figure 2 ), which are difficult to obtain directly because of the rapid disproportionation of semiquinone radicals. 156 It should also be noted that the BDFEs of these quinones do not necessarily reflect the $1 e^{-}$quinone/semiquinone reduction potentials. For example, tetrachloro- $p$-benzoquinone is $0.5 \mathrm{~V}$ more oxidizing than $p$ benzoquinone, 157 even though the average BDFEs are not too different. One electron potentials for a variety of quinones in several different organic solvents are available in reference 157.

The ortho-substituted quinone/catechol redox couple has reactivity and thermochemistry that is somewhat distinct from the para-quinone/hydroquinone couple. Ortho-quinones and catechols (1,2-hydroxybenzenes) are also key biological cofactors, the most widely known of which are the catecholamines dopamine, epinephrine and norepinepherine.167 The antioxidant and anti-cancer activities of ortho-quinone derivatives, known as 'catachins,' have recently received considerable attention.168 Unfortunately, the data available for catechols are more limited than those for hydroquinones, and thus, the double square scheme in Figure 3 cannot be completely filled in. Still, sufficient results are available to show the important differences between hydroquinones and catechols.

The aqueous $2 \mathrm{H}^{+} / 2 e^{-}$potential of catechol 155 indicates an average O-H BDFE of $75.9 \mathrm{kcal}$ $\mathrm{mol}^{-1}$, slightly higher than that of 1,4-hydroquinone $\left(73.6 \mathrm{kcal} \mathrm{mol}^{-1}\right)$. From the known $\mathrm{p} K_{\mathrm{a}}$ of the semiquinone 169 and the one electron potential of ortho-benzoquinone, the second BDFE is $65.4 \mathrm{kcal} \mathrm{mol}^{-1}$, using eq 7. Thus, the first BDFE in catechol must be $86.2 \mathrm{kcal}$ $\mathrm{mol}^{-1}$ in water. The second O-H BDFEs for the hydroquinone and catechol semiquinones are very similar, $65.5 \mathrm{kcal} \mathrm{mol}^{-1}$ and $65.4 \mathrm{kcal} \mathrm{mol}^{-1}$, respectively.

The thermochemistry of catechols is different from hydroquinones partially due to the availability of an internal hydrogen bond (Scheme 9). The first $\mathrm{p} K_{\mathrm{a}}$ of catechol $(9.26170)$ is not too different from the first $\mathrm{p} K_{\mathrm{a}}$ in hydroquinone (9.85), and for both the second $\mathrm{p} K_{\mathrm{a}}$ is 
larger, as expected for deprotonation of an anion. However, the second $\mathrm{p} K_{\mathrm{a}}$ for catechol (13.4170) is two $\mathrm{p} K_{\mathrm{a}}$ units larger than that of hydroquinone (11.4), because the catecholate is stabilized by the strong intramolecular hydrogen bond.

The intramolecular hydrogen bond appears to be more important in the gas phase and in non-hydrogen bond accepting solvents where it does not compete with hydrogen bonding to solvent. Theoretical work indicates that the intramolecular hydrogen bond in catechol has a free energy of about $-4 \mathrm{kcal} \mathrm{mol}^{-1}$ and, importantly, that the analogous $\mathrm{H}$-bond in the monoprotonated semiquinone radical is about twice as strong (Scheme 9).171,172 Thus the reactivity of catechols can be quite different in non-hydrogen bond accepting solvents $v s$. water. Lucarini173 and Foti174 have each shown that in non-hydrogen bond-accepting solvents, compounds with intramolecular hydrogen bonds are better $\mathrm{H}^{\bullet}$ donors than analogous species without intramolecular hydrogen bonding. This is opposite to the thermochemistry in water where BDFE(catechol) > BDFE(hydroquinone).

5.2.6 Ascorbate-Ascorbic acid (Vitamin C) is a ubiquitous biological cofactor that is necessary for human health.175 Ascorbate has traditionally been thought of as a oneelectron reductant, but redox reactions of ascorbate almost always involve the loss of an electron and a proton (or a hydrogen atom), so it is really a PCET reagent. Njus176 and Tsubaki177 have shown that ascorbate donates hydrogen atoms in its reactions with cytochrome $b_{561}$. Njus has also demonstrated this for other ascorbate utilizing enzyme systems.178 Ascorbate is also likely oxidized by loss of $\mathrm{H}^{+}+e^{-}$in the catalytic cycle of ascorbate peroxidase (APX).179 HAT from ascorbate may play a role in regeneration of vitamin E (tocopherol) radicals.135, 180 Investigations from our group have shown that 5,6isoproylidene ascorbate, a convenient, commercially available organic-soluble analog of ascorbate, reacts with TEMPO, ${ }^{t} \mathrm{Bu}_{3} \mathrm{PhO}^{\bullet}$ and iron-porphyrin models via concerted transfer of $\mathrm{H}^{\bullet} .181,182$

The aqueous thermochemistry of ascorbate is well understood (Figure 4).135,183,184 In principle, a nine-membered square could be constructed for ascorbic acid because two electrons and two protons can be removed to make dehydroascorbate. However, similar to hydroquinones, the oxidized forms that have not lost a proton are high-energy species (very acidic) and are not relevant to ascorbate chemistry. Ascorbic acid becomes a stronger reducing agent at higher $\mathrm{pH}$ as it is converted to ascorbate $\left(\mathrm{AscH}^{-}\right)$and then the doubly deprotonated form $\left(\mathrm{Asc}^{2-}\right) .184,185$ At physiological $\mathrm{pH}, \mathrm{AscH}^{-}$is the predominant species and the ascorbyl radical $\left(\mathrm{Asc}^{\circ-}\right.$ ) is deprotonated (the $\mathrm{p} K_{\mathrm{a}}$ of $\mathrm{AscH}^{\bullet+}$ is -0.45 ). Therefore, the most important reaction is $\mathrm{AscH}^{-} \rightarrow \mathrm{Asc}^{\bullet-}+\mathrm{H}^{+}+e^{-}$. The thermochemical data for ascorbate and isopropylidene ascorbate in a few different solvents is given in Table 7 . The ascorbyl radical rapidly disproportionates with consumption of a proton to give one equivalent of dehydroascorbate (Asc) and ascorbate, 186 so the very weak O-H BDFE of the ascorbyl radical is typically not relevant. Disproportionation is, however, much slower in 'anhydrous' solvents. 182

\subsection{Alcohols and Water}

Aliphatic alcohols and water have quite different PCET chemistry than the 'enols' discussed above (phenols, hydroquinones, catechols and ascorbate). $\mathrm{O}-\mathrm{H}$ bonds in alcohols are much stronger than those in phenolic compounds (because the enolic $\pi$ resonance stabilizes the oxyl radical much more than the $\sigma$-bond hyperconjugation). Thus, the gas phase $\mathrm{O}-\mathrm{H}$ BDE in methanol $\left(96.4 \mathrm{kcal} \mathrm{mol}^{-1}\right) 188$ is ca. $8 \mathrm{kcal} \mathrm{mol}^{-1}$ stronger that the analogous BDE in phenol ( $88 \mathrm{kcal} \mathrm{mol}^{-1}$, see above). The alcohol O-H bond is usually stronger than the $\mathrm{C}-\mathrm{H}$ bonds in the same molecule. Again using methanol as an example, the $\mathrm{O}-\mathrm{H} \mathrm{BDE}$ is more than $8 \mathrm{kcal} \mathrm{mol}^{-1}$ stronger than the $\mathrm{C}-\mathrm{H} \mathrm{BDFE}$ for $\mathrm{H}_{-} \mathrm{CH}_{2} \mathrm{OH}, 87.9 \mathrm{kcal} \mathrm{mol}^{-1} .37$ For this 
reason, hydrogen atom abstractors react with alcohols to give a hydroxyalkyl radical such as ${ }^{\circ} \mathrm{CH}_{2} \mathrm{OH}$, rather than the alkoxyl radical $\left(\mathrm{CH}_{3} \mathrm{O}^{\circ}\right)$.

5.3.1 tert-Butanol and tert-Butoxyl Radical-The tert-butoxyl radical ( $\left.{ }^{t} \mathrm{BuO}{ }^{\circ}\right)$ has received considerable attention, in part because it does not have any easily abstracted $\alpha \mathrm{C}-\mathrm{H}$ bonds. ${ }^{t} \mathrm{BuO}{ }^{\bullet}$ radicals can be generated via photolysis of ${ }^{t} \mathrm{BuOO}{ }^{t} \mathrm{Bu}$ in the gas phase 189 or in solution, 190 and by photolysis or thermal decomposition of tert-butylhyponitrite $\left({ }^{t} \mathrm{BuONNO}{ }^{t} \mathrm{Bu}\right), 191$ tert-butylhypochlorite, 192 or tert-butylperoxalate. $193 \mathrm{The} \mathrm{O}-\mathrm{H}$ bond in tert-butanol $\left({ }^{t} \mathrm{BuOH}\right)$ is quite strong, with a gas-phase BDFE of $106.3 \mathrm{kcal} \mathrm{mol}^{-1,37}$ so ${ }^{t} \mathrm{BuO}^{\bullet}$ is a quite reactive $\mathrm{H}$-atom abstractor. Photochemically generated ${ }^{t} \mathrm{BuO}{ }^{\bullet}$ is therefore useful to rapidly form other oxyl radicals, such as phenoxyls, often within the duration of a nanosecond laser pulse.194-195196 A large number of rate constants are available for HAT from various substrates to ${ }^{t} \mathrm{BuO}{ }^{\circ} .197$ With less reactive $\mathrm{X}-\mathrm{H}$ bonds, however, HAT must compete with $\beta$-scission of ${ }^{t} \mathrm{BuO}^{\circ}$ to give methyl radical and acetone.198 In neat acetonitrile, for instance, only $\beta$-scission is observed, because of the low reactivity of the $\mathrm{H}-\mathrm{CH}_{2} \mathrm{CN}$ bonds. 198

BDFEs for ${ }^{t} \mathrm{BuOH}$ in water and DMSO have been estimated using Abraham's empirical method, described in Section 3.1.1 above. Combining these values with the known $\mathrm{p} K_{\mathrm{a}}$ values provides estimates of the $1 e^{-}$reduction potentials of ${ }^{t} \mathrm{BuO}{ }^{\bullet}$ in these solvents. The estimated $E\left({ }^{t} \mathrm{BuO}^{\circ-}\right)$ in DMSO is in reasonable agreement with Bordwell's estimate, 100 from the complex electrochemical response of ${ }^{t} \mathrm{BuO}^{-}$in DMSO (Table 8). In water, ${ }^{t} \mathrm{BuO}{ }^{\bullet}$ is very oxidizing, substantially more than phenoxyl $\left(1.2 \mathrm{~V}\right.$ versus $0.78 \mathrm{~V}$ for the $\mathrm{RO}^{\circ /}$ couple). Electron transfer reactions of ${ }^{t} \mathrm{BuO}^{\bullet}$ have been briefly commented on, 199 although the product of these reactions is ${ }^{t} \mathrm{BuOH}$, apparently formed by protonation of the quite basic tert-butoxide anion.

5.3.2 Water/Hydroxyl radical-The first $\mathrm{O}-\mathrm{H}$ bond in water is, to our knowledge, the strongest known O-H bond. It has a gas-phase BDFE of $110.64 \mathrm{kcal} \mathrm{mol}^{-1}\left(\mathrm{a} \mathrm{BDE}_{\mathrm{g}}\right.$ of $\left.118.81 \mathrm{kcal} \mathrm{mol}^{-1}\right) .37,200$ In aqueous solution, we calculate the BDFE(HO-H) to be 122.7 $\mathrm{kcal} \mathrm{mol}^{-1}$ based on the $\mathrm{OH}^{\bullet /-}$ redox potential and $\mathrm{p} K_{\mathrm{a}}$. The very high $\mathrm{HO}-\mathrm{H}$ bond strength is due, at least in part, to the absence of any resonance or hyperconjugative stabilization in $\mathrm{OH}^{*}$. The hydroxyl radical is therefore a very high energy species capable of extracting $\mathrm{H}$ atoms from essentially all aliphatic $\mathrm{C}-\mathrm{H}$ bonds ( $\mathrm{C}-\mathrm{H}$ bonds with an $\mathrm{sp}^{3}$-hybridized carbon). $\mathrm{OH}^{\bullet}$ is also a potent $1 e^{-}$oxidant and can add to unsaturated organic compounds, for instance converting benzene to phenol. The $\mathrm{O}-\mathrm{H}$ bond in the hydroxyl radical (the second $\mathrm{O}-\mathrm{H}$ bond in water) is significantly weaker, as given in Table 8 and shown in the square Scheme in Figure 5a.

\subsection{Compounds with O-O Bonds}

5.4.1 Overview of Dioxygen PCET Chemistry-PCET reactions involving dioxygen are of considerable research interest. The four electron/four proton reduction of $\mathrm{O}_{2}$ to water is key to biological aerobic metabolism203 and is the "oxygen reduction reaction" (ORR) in fuel cells.204 The oxidation of water to dioxygen is an important component in many proposals for storage of electrical energy.205 The abundance and low environmental impact of dioxygen make it an attractive oxidant in industrial chemical processes.206 However, all $4 e^{-}$and $4 \mathrm{H}^{+}$cannot be added or removed at the same time, so the intermediate species of dioxygen reduction are also of great importance. These species, $\mathrm{O}_{2}{ }^{--}, \mathrm{HO}_{2}{ }^{\bullet}, \mathrm{HO}_{2}{ }^{-}, \mathrm{H}_{2} \mathrm{O}_{2}$, $\mathrm{HO}^{\circ}$, and $\mathrm{O}^{\circ-}$, are all high-energy intermediates as can be seen in the Frost diagrams in Figure 6, and are known collectively as reactive oxygen species (ROS). In biology, ROS damage lipids, proteins, nucleic acids, and carbohydrates, and have been implicated in various diseases and aging.203,207,208 Many of these species are highly reactive with 
organic molecules, making it difficult to study their chemistry in non-aqueous solvents. However, the aqueous thermochemistry of oxygen species has been studied extensively, and has been reviewed by Sawyer 209 and Afanas'ev.210 The properties of the species without an $\mathrm{O}-\mathrm{O}$ bond have been summarized above; the PCET thermochemistry of the $\mathrm{O}-\mathrm{O}$ bonded species are given in Table 9 and Figure 6.

The Pourbaix diagram for water (Figure 6c) does not show most of the reactive oxygen species. This is because, other than $\mathrm{H}_{2} \mathrm{O}_{2}$ and $\mathrm{HO}_{2}{ }^{-}$, the ROS are not the most thermodynamically stable species at any point in the diagram, at any $\mathrm{pH}$ or redox potential. The standard ( $\mathrm{pH} 0$ ) potential for the $4 e^{-} / 4 \mathrm{H}^{+}$reduction of $\mathrm{O}_{2}$ is always given as $1.23 \mathrm{~V}$ (eq 17) but from some perspectives it can be better to think about $\mathrm{O}_{2}$ reduction or water oxidation as transferring hydrogen atoms. The free energy in these terms, following eqs 15 or 16 above, is given in eq 18 both for the full $4 e^{-} / 4 \mathrm{H}^{+}$process and per hydrogen atom, as an effective BDFE. Thus, oxidizing water to $\mathrm{O}_{2}$, requires a 'system' with an effective BDFE of greater than $86 \mathrm{kcal} \mathrm{mol}^{-1}$. Such a system could be a hydrogen atom abstracting reagent, or a combination of an oxidant and a base (Section 5.9 below). In photosystem II, the oxidizing equivalents pass through the tyrosine/tyrosyl radical couple which in aqueous solution has a BDFE of $87.8 \mathrm{kcal} \mathrm{mol}^{-1}$ from Table 4 . While this BDFE could be different within the protein, it shows that the tyrosyl radical has just enough free energy to accomplish water oxidation and shows the remarkable catalytic activity of the oxygen evolving complex at low overpotential.

$$
\mathrm{O}_{2}+4 e^{-}+4 \mathrm{H}^{+} \rightarrow 2 \mathrm{H}_{2} \mathrm{O} \quad E^{\circ}=1.23 \mathrm{~V}
$$

$\mathrm{O}_{2}+4 \mathrm{H}^{\bullet} \rightarrow 2 \mathrm{H}_{2} \mathrm{O} \quad-\Delta G^{\circ}=344 \mathrm{kcol} \mathrm{mol}^{-1}$ or BDFE average $=86 \mathrm{kcal} \mathrm{mol}^{-1}$

5.4.2 Dioxygen-While the overall proton-coupled reduction of $\mathrm{O}_{2}$ to water is quite favorable, transfer of the first electron is far less favorable. Dioxygen is a poor one-electron outer-sphere oxidant, with $E^{\circ}$ for reduction to superoxide $\left(\mathrm{O}_{2}{ }^{\circ-}\right)=-0.16 \mathrm{~V}$ vs. NHE in $\mathrm{H}_{2} \mathrm{O} .209$ Superoxide is also not very basic (aqueous $\mathrm{p} K_{\mathrm{a}}=4.9$ ), so this combination of a low potential and low $\mathrm{p} K_{\mathrm{a}}$ means that $\mathrm{HO}_{2}{ }^{\circ}$ (hydroperoxyl) has a very low O-H BDFE, $60.4 \mathrm{kcal}$ $\mathrm{mol}^{-1}$ in water. Because of this low BDFE, $\mathrm{O}_{2}$ is not an effective $\mathrm{H}$-atom abstractor (so the large majority of organic molecules are 'air stable'). It should be emphasized that $\mathrm{H}$-atom abstracting ability typically correlates with the $\mathrm{X}-\mathrm{H}$ BDFE that an oxidant can form and does not correlate with the 'radical character'.211 Thus, dioxygen is a triplet diradical but is quite unreactive toward HAT, while permanganate $\left(\mathrm{MnO}_{4}{ }^{-}\right)$with no unpaired spins is a reactive $\mathrm{H}$-atom abstractor because it can form an $\mathrm{O}-\mathrm{H}$ bond with a BDFE of $80.7 \mathrm{kcal}$ $\mathrm{mol}^{-1}$ (Section 5.10). In contrast, oxene (O), a neutral triplet radical like $\mathrm{O}_{2}$, is a far more potent $\mathrm{H}$-atom abstractor because of the high BDFE of ${ }^{\bullet} \mathrm{O}-\mathrm{H}, 106.9 \mathrm{kcal} \mathrm{mol}^{-1}$ (Table 8).

5.4.3 Superoxide/Hydroperoxyl-Superoxide radical anion $\left(\mathrm{O}_{2}{ }^{-}\right)$and its protonated form (the neutral perhydroxyl radical, $\mathrm{HO}_{2}{ }^{\circ}$ ) are considered reactive oxygen species but do not undergo the chemistry typical of oxygen radicals.212 Superoxide generally does not act as a direct one electron oxidant due to the relatively high energy of the solvated peroxide dianion $\left(\mathrm{O}_{2}{ }^{2-}\right) .213$ Similarly, $\mathrm{O}_{2}{ }^{--}$does not usually react as a direct $\mathrm{H}$-atom abstractor since it forms a relatively weak $\mathrm{O}-\mathrm{H}$ bond (aqueous BDFE $(-\mathrm{OO}-\mathrm{H})=81.6 \mathrm{kcal} \mathrm{mol}^{-1}$ ). The neutral perhydroxyl radical $\mathrm{HO}_{2}{ }^{-}$is a more reactive oxidant, in part because it forms a stronger $\mathrm{O}-\mathrm{H}$ bond: $E\left(\mathrm{HO}_{2}{ }^{\bullet-}\right)=0.76 \mathrm{~V}$ and $\mathrm{BDFE}_{\mathrm{aq}}(\mathrm{HOO}-\mathrm{H})=91.0 \mathrm{kcal} \mathrm{mol}^{-1}$ (Table 9). Thus, it is perhydroxyl, present in small quantities at biological $\mathrm{pH}\left(\mathrm{pK}_{\mathrm{a}} \mathrm{HO}_{2}{ }^{\circ}=4.9\right), 209$ that is responsible for much of the oxidative damage associated with biological fluxes of 
superoxide. Some of this damage also results from the $\mathrm{H}_{2} \mathrm{O}_{2}$ produced by superoxide dismutation or by HAT to $\mathrm{HO}_{2}{ }^{*}$. Perhydroxyl, because of its high BDFE, can abstract $\mathrm{H}$ atoms from weak $\mathrm{C}-\mathrm{H}$ bonds such as the allylic $\mathrm{C}-\mathrm{H}$ 's in cyclohexadiene214,215 or linoleic acid.216 Superoxide HAT reactions have also been reported with $\mathrm{H}$-atom donors such as ascorbic acid217 and di-tert-butylcatechol.218

Superoxide is fairly stable to disproportionation in the absence of protons because the peroxide $\left(\mathrm{O}_{2}{ }^{2-}\right)$ product is a high energy species. In the presence of protons, however, it rapidly decays to $\mathrm{H}_{2} \mathrm{O}_{2}$ and $\mathrm{O}_{2}\left(k=1.0 \times 10^{8} \mathrm{M}^{-1} \mathrm{~s}^{-1}\right.$ at $\mathrm{pH}$ 7). This reaction likely occurs by the reaction of superoxide with perhydroxyl radicals to give hydroperoxide and dioxygen, which is a highly favorable process (eq 19).219 This reaction has been described as the reduction of $\mathrm{HO}_{2}{ }^{\bullet}$ by superoxide, in other words as an ET reaction, but it could also occur by HAT from $\mathrm{HO}_{2}{ }^{\circ}$ by superoxide, a net oxidation of $\mathrm{HO}_{2}{ }^{\bullet}$ that gives the same products. Superoxide disproportionation forms $\mathrm{HO}_{2}{ }^{-}$which is a moderate base $\left(\mathrm{p} K_{\mathrm{a}} 11.6\right), 220$ so aqueous superoxide in effect acts as a base despite its relatively low dissociation constant.

$$
\mathrm{HO}_{2}{ }^{-}+\mathrm{O}_{2}{ }^{-} \rightarrow \mathrm{HO}_{2}{ }^{-}+\mathrm{O}_{2} \quad K=4 \times 10^{20} \text { in water at } \mathrm{pH} 7
$$

5.4.4 Hydrogen Peroxide-Peroxides are two-electron reduced from dioxygen. The peroxide dianion $\left(\mathrm{O}_{2}{ }^{2-}\right)$ is found in ionic solids but is very basic, such that the two-electron electrochemical reduction of oxygen in DMSO produces deprotonated DMSO $\left(\mathrm{p} K_{\mathrm{a}, \mathrm{DMSO}}=\right.$ 3529) and hydroperoxide.221 Hydroperoxide $\left(\mathrm{HO}_{2}{ }^{-}\right)$is moderately basic in water $\left[\mathrm{p} K_{\mathrm{a}}\left(\mathrm{H}_{2} \mathrm{O}_{2}\right)=11.6\right]$. In typical organic solvents such as DMSO, DMF, or acetonitrile, the $\mathrm{p} K_{\mathrm{a}}$ of $\mathrm{H}_{2} \mathrm{O}_{2}$ cannot be directly measured because $\mathrm{HO}_{2}{ }^{-}$readily reacts with sulfoxides, amides, and nitriles.221,222

Hydrogen peroxide is increasingly attractive as a "green" oxidant and is being produced on a very large scale.223 It is almost always used as an aqueous solution. $224 \mathrm{H}_{2} \mathrm{O}_{2}$ is unstable with respect to disproportionation to water and dioxygen, but this is slow in the absence of light or a catalyst. The most famous example is the Fenton reaction, in which iron salts catalyze the decomposition in part by the inner-sphere reduction of $\mathrm{H}_{2} \mathrm{O}_{2}$ by $\mathrm{Fe}$ (II) (eq 20) which yields the very reactive hydroxyl radical ( $\left.\mathrm{HO}^{*}\right) .225,226$ This and related reactions are a connection between the compounds with $\mathrm{O}-\mathrm{O}$ bonds discussed in this section and the water/hydroxyl radical PCET chemistry described above. The proton-coupled reduction of $\mathrm{H}_{2} \mathrm{O}_{2}$ to $\mathrm{H}_{2} \mathrm{O}+\mathrm{OH}^{\bullet}$ is thermodynamically quite favorable (eq 21). In practice, however, cleavage of $\mathrm{H}_{2} \mathrm{O}_{2}$ by outer-sphere electron donors and hydrogen atom donors often has a large kinetic barrier, likely associated with the cleavage of the $\mathrm{O}-\mathrm{O}$ bond.227

$$
\mathrm{Fe}(\mathrm{II})+\mathrm{H}_{2} \mathrm{O}_{2} \rightarrow \mathrm{Fe}(\mathrm{III}) \mathrm{OH}+\mathrm{OH}^{\bullet}
$$

$$
\begin{array}{ll}
\mathrm{H}_{2} \mathrm{O}_{2}+e^{-}+\mathrm{H}^{+} \rightarrow \mathrm{H}_{2} \mathrm{O}+\mathrm{OH}^{\bullet} & E^{\circ}=0.80 \mathrm{~V} \\
\mathrm{H}_{2} \mathrm{O}_{2}+\mathrm{H}^{\bullet} \rightarrow \mathrm{H}_{2} \mathrm{O}+\mathrm{OH}^{\bullet} & \Delta G^{\circ}=-76 \mathrm{kcal} \mathrm{mol}^{-1}
\end{array}
$$

5.4.5 Organic Hydroperoxides-Organic hydroperoxides have received considerable attention for their roles in synthesis, catalysis, and biochemical processes. Like $\mathrm{H}_{2} \mathrm{O}_{2}$, the free radical chemistry of $\mathrm{ROOH}$ containing systems can proceed either by $\mathrm{O}-\mathrm{O}$ or $\mathrm{O}-\mathrm{H}$ homolysis. Here we only discuss the chemistry of the $\mathrm{O}-\mathrm{H}$ bond; the interested reader is pointed to a review of the radiation and photochemistry of peroxides, which discusses a variety of $\mathrm{O}-\mathrm{O}$ bond homolysis reactions.230 PCET reactions of organic peroxyl radicals have almost always been understood as HAT reactions, especially the chain propagating step 
in autoxidation.17 This makes sense because of the strong ROO-H bonds, while PT-ET or ET-PT pathways are disfavored by the low basicity of ROO` and the moderate ROO/potentials (Table 10).

The most commonly employed organic hydroperoxide is tert-butyl hydroperoxide. The gas phase thermochemistry of organic peroxides has been widely discussed. Simmie et al.231 recently gave $\Delta H_{f}{ }^{\circ}\left({ }^{t} \mathrm{BuOO}^{\circ}\right)=-24.69 \mathrm{kcal} \mathrm{mol}^{-1}$, which, together with $\Delta H_{f}{ }^{\circ}\left(\mathrm{H}^{\circ}\right)=52.103$ $\mathrm{kcal} \mathrm{mol}{ }^{-1} 232$ and $\Delta H_{f}^{\circ}\left({ }^{t} \mathrm{BuOOH}\right)=-56.14 \mathrm{kcal} \mathrm{mol}^{-1} 233$, gives $\mathrm{BDE}_{\mathrm{g}}\left({ }^{(} \mathrm{BuOOH}\right)=83.6$ kcal mol ${ }^{-1} .234$

The $\mathrm{p} K_{\mathrm{a}} \mathrm{s}$ of several alkyl hydroperoxides and peracids have long been known,235 and $\mathrm{p} K_{\mathrm{a}}$ values for several peroxybenzoic acid have been reported.236 However, until recently, the reduction potentials of the corresponding peroxyl radicals have remained elusive. Das and co-workers indirectly measured the $\mathrm{ROO}^{\bullet /-}$ couple for several peroxyl compounds in water (Table 10).237 Their value for $E^{\circ}\left({ }^{t} \mathrm{BuOO}^{-/ 0}\right)$ is in good agreement with an earlier estimate made using kinetic and $\mathrm{p} K_{\mathrm{a}}$ data.238 In contrast, very little data exists on the redox potentials of percarboxylate anions. Peracids have gas phase BDFEs that are a little higher, and they are more acidic than the corresponding alkyl peroxides, which indicate that the $\mathrm{RC}(\mathrm{O}) \mathrm{OO}^{\circ /-}$ potentials are probably more oxidizing $(\geq 1 \mathrm{~V}) .239$ Jonsson's estimate of $E^{\circ}$ $\left(\mathrm{CH}_{3} \mathrm{C}(\mathrm{O}) \mathrm{OO}^{\circ /-}\right)=1.14 \mathrm{~V} 240$ is in agreement with this estimate. Jonsson has also estimated thermochemical data for a variety of other peroxides but these need to be used with caution as they were extracted from electron transfer kinetic data240 and some of these values do not agree with those determined via more direct methods (e.g., Jonsson gives $E^{\circ}$ $\left(\mathrm{Cl}_{3} \mathrm{COO}^{\circ-}\right)=1.17 \mathrm{~V}$ while and Das reports $\left.E^{\circ}\left(\mathrm{Cl}_{3} \mathrm{COO}^{\circ-}\right)=1.44 \mathrm{~V} 237\right)$.

\subsection{Simple Nitrogen Compounds: Dinitrogen to Ammonia, Amines, and Arylamines}

The previous sections all focused on reagents with reactive $\mathrm{O}-\mathrm{H}$ bonds. With this section we shift to $\mathrm{N}-\mathrm{H}$ bonds, and those below deal with $\mathrm{S}-\mathrm{H}$ and $\mathrm{C}-\mathrm{H}$ bonds. While the same principles apply, there are some important differences. $\mathrm{N}-\mathrm{H}$ bonds are less acidic than comparable $\mathrm{O}-\mathrm{H}$ bonds, and in general $\mathrm{N}$-lone pairs are higher in energy so nitrogen compounds are more basic and more easily lose an electron to form the radical cation. Therefore, stepwise PCET reactions of amines typically involve aminium radical cations $\left(\mathrm{R}_{3} \mathrm{~N}^{\bullet+}\right)$, particularly for arylamines, while those of alcohols and phenols involve alkoxides and phenoxides. We start with the simple gas phase species from $\mathrm{N}_{2}$ to ammonia, then progress to alkyl and aryl amines, and finally to more complex aromatic heterocycles of biological interest.

5.5.1 Dinitrogen, Diazine, and Hydrazine-Dinitrogen $\left(\mathrm{N}_{2}\right)$ is one of the most abundant compounds on earth, making it an almost unlimited feedstock for the production of reduced nitrogen species such as ammonia. The overall reduction of dinitrogen to ammonia by dihydrogen is thermodynamically favorable under standard conditions both in the gas phase and in aqueous solution. However, this is a $6 \mathrm{H}^{+} / 6 e^{-}$reaction and cannot occur in one step. 243 The energetics of the intermediates are therefore important. Industrially, dinitrogen is reduced to ammonia via the Haber-Bosch process which is carried out at high temperatures and high pressures by an iron catalyst. The high temperature is needed to overcome the kinetic barrier, but makes the reaction less favorable so high pressures are needed. Combining the production of the $\mathrm{H}_{2}$ and the operation of the Haber-Bosch process, it is said that industrial $\mathrm{N}_{2}$-fixation accounts for $1 \%$ or more of the total human energy consumption.244 In biology, $\mathrm{N}_{2}$-fixation is accomplished by nitrogenase enzymes in solution at room temperature using reduced ferredoxins and ATP.243 Most biochemical studies and biomimetic models for nitrogen fixation propose sequential single-electron and single-proton transfers to metal-bound nitrogen species, but the thermochemistry of these 
steps is not experimentally known (only in the Schrock/Yandulov cycle is there good evidence for each of the various intermediates).245,246 Much less is known about the solution thermochemistry of simple $\mathrm{N}_{x} \mathrm{H}_{y}{ }^{z \pm}$ species compared with the oxygen analogs. The known aqueous values are provided by Stanbury, 247 and Koper has recently reviewed electrochemical studies. 248

Dinitrogen is one of the most inert chemical compounds. The addition of a proton or an electron is not very favorable: $\mathrm{N}_{2}$ has a gas phase proton affinity of $5.12 \mathrm{eV}$, slightly less than methane, and its electron affinity is negative $(-1.8 \mathrm{eV}) .243$ The BDE of NN-H is estimated to be close to or less than $0 \mathrm{kcal} / \mathrm{mol}$ (Table 11).249 These values make it unlikely that reduction of free dinitrogen can proceed through a free one-electron reduced species. The two $\mathrm{H}$-atom reduced species of dinitrogen is diazene $(\mathrm{HN}=\mathrm{NH})$, also called diimide. Diazene is unstable, as it is powerful $\mathrm{H}$-atom transfer agent with a first BDE of only $\sim 60$ $\mathrm{kcal} / \mathrm{mol} .49$ The average gas phase BDFE for Z-diazene to $\mathrm{N}_{2}+2 \mathrm{H}^{*}$ is only $19.5 \mathrm{kcal} \mathrm{mol}^{-1}$ (average $\mathrm{BDE}=26.7 \mathrm{kcal} \mathrm{mol}^{-1}$ ), so decomposition to $\mathrm{N}_{2}$ and $\mathrm{H}_{2}$ is very favorable.49 Moreover, diazene is thought to transfer both hydrogens in a concerted fashion to alkenes and alkynes, a very rare example of a $2 e^{-} / 2 \mathrm{H}^{+}$reaction. 250 Diazene, like dinitrogen, is a very poor base, with a $\mathrm{p} K_{\mathrm{a}}$ of the conjugate acid of less than zero.251

The reduction of diazene by one $\mathrm{H}$-atom gives the hydrazyl radical $\left(\mathrm{HNNH}_{2}\right)$, a high-energy species with a very weak $\mathrm{N}-\mathrm{H}$ bond. Hydrazyl is capable of abstracting an $\mathrm{H}$-atom to yield the more stable hydrazine $\left(\mathrm{H}_{2} \mathrm{NNH}_{2}\right)$ with $\mathrm{BDFE}_{\mathrm{aq}(\mathrm{H} 2 \mathrm{NNH} 2)}=83 \mathrm{kcal} \mathrm{mol}^{-1}$. In the gas phase the average BDFE for $\mathrm{H}_{2} \mathrm{NNH}_{2}$ to $Z$-diazene $+2 \mathrm{H}^{\circ}$ is $58.7 \mathrm{kcal} \mathrm{mol}^{-1}$ (average BDE $\left.=66.2 \mathrm{kcal} \mathrm{mol}^{-1}\right) .49$ Like peroxides, hydrazine has a week $\mathrm{N}-\mathrm{N}$ bond $(\mathrm{BDE}=66.2 \mathrm{kcal}$ $\mathrm{mol}^{-1}$ ) and can undergo homolytic $\mathrm{N}-\mathrm{N}$ bond cleavage as well as PCET reactions.

Hydrazine's lone pairs make it moderately basic, with a first $\mathrm{p} K_{\mathrm{a}}$ of the conjugate acid similar to the $\mathrm{p} K_{\mathrm{a}}$ of ammonium, though the addition of a second proton is very unfavorable. 247 Electron transfer oxidation of tetraalkylhydrazines have been examined by Nelsen and others. 252 Hydrazine is a powerful, but kinetically slow oxidant, undergoing $2 e^{-} / 2 \mathrm{H}^{+}$ reduction to give two molecules of ammonium with $E^{\circ}=1.2 \mathrm{~V}$ in acidic aqueous solution. 253 Hydrazine has also been used as a mild reducing agent in aprotic media, though the proton containing products are not clear.254

5.5.2 Ammonia and Alkylamines-Ammonia is the simplest amine and a critical commodity chemical; in 2005 global ammonia production was estimated at 168 million tons. 258 Ammonia is a good base $\left(\mathrm{p} K_{\mathrm{a}}\left(\mathrm{NH}_{4}{ }^{+}\right)_{\mathrm{H} 2 \mathrm{O}}=9.24259\right)$ so it primarily exists as ammonium salts at normal physiological conditions. The gas phase homolytic bond strengths for $\mathrm{NH}_{3}, \mathrm{NH}_{4}^{+}$, and $\mathrm{NH}_{3}{ }^{*+}$ are very high (Table 12). $\mathrm{H}$-abstraction from $\mathrm{NH}_{3}$ requires very high energy species, such as hydroxyl radical.260 The $\mathrm{p} K_{\mathrm{a}}$ of $\mathrm{NH}_{3}$ has been estimated to be 38,261 similar to that for $\mathrm{H}_{2}$ (see below).

As indicated above, alkylamines can often be oxidized by one $e^{-}$to the protonated aminium radical cation $\mathrm{R}_{2} \mathrm{NH}^{\bullet+}$ (Table 12), which is substantially less acidic than a protonated alkoxyl radical. As with alcohols, the $\mathrm{N}-\mathrm{H}$ bonds in alkylamines are significantly stronger than the $\alpha-\mathrm{C}-\mathrm{H}$ bonds (because of dative stabilization of the carbon radical by the nitrogen lone pair). This is evident, for instance, in the $\mathrm{N}-\mathrm{H}$ and $\mathrm{C}-\mathrm{H}$ alkylamine BDEs in MeCN and $\mathrm{C}_{6} \mathrm{H}_{6}$ reported by Lalevée and co-workers. 262

5.5.3 Arylamines and arylhydrazines-Arylamines are more easily oxidized to radical cations than phenols, because $-\mathrm{NH}_{2}$ is a more electron-donating substituent to the aromatic ring than $-\mathrm{OH}$ (in both cases the electron is lost from a $\pi$-symmetry orbital in large part on the aromatic ring). Therefore, for anilines the potential for oxidation of the neutral $\mathrm{ArNH}_{2}$ is experimentally accessible $E^{\circ}\left(\mathrm{ArNH}_{2}{ }^{++/ 0}\right)$, whereas for phenols the accessible outer-sphere 
potential involves the phenoxide $E^{\circ}\left(\mathrm{PhO}^{\circ /-}\right)$. Monoaryl and diaryl aminium radical cations are transient, but triarylaminium radical cations with para-substituents are isolable and very useful, for instance as chemical reagents 254 and as 'hole-transport' electronic materials.270 Bordwell has tabulated data for complete 'square schemes' for several substituted anilines and diphenylamines.271 Furthermore, Jonsson, Lind and Merényi have determined reduction potentials for anilinium radical cations, and $\mathrm{p} K_{\mathrm{a}} \mathrm{s}$ for the corresponding radical cations in water.268,272,273 Selected data are shown in Table 13, but other examples are available in both DMSO and water in each respective reference.

The $\mathrm{N}-\mathrm{H}$ BDE of aniline $\left(\mathrm{PhNH}_{2}\right)$ in $\mathrm{C}_{6} \mathrm{H}_{6}$ has been measured by MacFaul et al. using photoacoustic calorimetry (PAC), and they calculated the gas phase BDE using estimated solvation enthalpies.274 These values are consistent with the BDE derived from the reported $E^{\circ}$ and $\mathrm{p} K_{\mathrm{a}}$ data in DMSO when we extrapolate it to $\mathrm{C}_{6} \mathrm{H}_{6}$ using Abraham's model.275,276 For diphenylamine, a number of slightly different BDEs have been reported,274,277,278 as summarized by Pratt et al; 278 at this time we see no clear reason to favor one value.122

The stable, isolable radical 2,2-diphenyl-1-picrylhydrazyl (DPPH) has long been used to study the antioxidant properties of organic compounds.11,12,279 DPPH-H (1,1-diphenyl-2picrylhydrazine) has a bond strength $c a .80 \mathrm{kcal} \mathrm{mol}^{-1}$ making it well suited for studies of many antioxidants, such as phenols and thiols. The BDFE of DPPH-H is perhaps best known in benzene from the calorimetric determination by Ingold and co-workers.76 Thermochemical data in other solvents are also shown in Table 13. From the work of Bordwell in DMSO,280 the bond strengths of aryl hydrazines are less than the BDFEs of arylamines, presumably because of stabilization of the radical by the delocalized $\pi$ system.

\subsection{Tryptophan, Flavins and Nucleosides}

The nitrogen containing heterocycles tryptophan, flavin and the nucleotide guanine are important in biological redox chemistry. Tryptophan is thought to be important in longrange electron transfer in proteins123,285 and its oxidation products are often observed in oxidatively stressed proteins.286 Guanine is the most easily oxidized nucleoside and is therefore implicated in the much-studied long-range hole transfer through DNA. Guanine oxidation is also thought to be important in DNA damage/repair.287 Flavins are critical biological cofactors that mediate charge transfer in a variety of proteins.288,289 Although these cofactors are widely discussed in terms of electron transfer, their $\mathrm{pH}$ dependent redox potentials indicate that they should be viewed as PCET reagents, at least in certain circumstances.

5.6.1 Indole and Tryptophan-The biological importance of electron transfer reactions of tryptophan has prompted thorough studies of its solution thermochemistry (Table 14). Merényi and co-workers have reported aqueous redox potentials and $\mathrm{p} K_{\mathrm{a}}$ values for a series of indoles, 290 although their measurement of $E^{\circ}\left(\mathrm{TrpH}^{++/ 0}\right)$ is different from the value reported by both Harriman 128 and from DeFilippis.131 (Table 14 does not give the $\mathrm{p} K_{\mathrm{a}} \mathrm{s}$ for the amine or the carboxylate moieties of tryptophan.) Indoles and tryptophan are more acidic than alkylamines and anilines, but are still less acidic than phenols [in DMSO, $\mathrm{p} K_{\mathrm{a}}($ indole $)=$ 20.9291 while $\mathrm{p} K_{\mathrm{a}}(\mathrm{phenol})=18.0116($ see Tables 4 and 14 for more extensive data $\left.)\right]$. The more striking difference between indole and phenol is the acidity of the radical cation: $\mathrm{PhOH}^{\bullet+}$ is a very strong acid (aqueous $\mathrm{p} K_{\mathrm{a}}=-2115$ ) while indole ${ }^{\circ+}$ is a weak acid (aqueous $\mathrm{p} K_{\mathrm{a}}=4.9290$ ). Thus oxidations of indoles and tryptophan often form the radical cation (like the amines discussed above), while oxidations of phenols typically form the neutral phenoxyl radical.

This comparison of indole and phenol is particularly interesting because tryptophan and tyrosine are the most important redox-active amino acids, and their thermochemistry proves 
the framework for understanding their roles in biological catalysis and charge transfer. Tyrosine radical cations $\left(\mathrm{TyrOH}^{\circ+}\right.$ ) are too high in energy to be involved in a biological system, even in photosystem II that is said to contain the strongest oxidant in biology.292 Thus, in biological systems (and in the large majority of chemical systems as well) tyrosine and other phenols are oxidized to the neutral phenoxyl radical. However, $\operatorname{TrpH}^{\bullet+}$ is a much more accessible species, being much less acidic than $\mathrm{TyrOH}^{\circ+}$ and having a reduction potential $0.25 \mathrm{~V}$ lower than that of $\mathrm{TyrOH}^{*+}$. Therefore oxidations of tryptophan (and indoles) often involve the radical cation. In this way, indoles resemble the alkylamines and anilines discussed in Section 5.5.3. While tryptophan is easier to oxidize by outer-sphere electron transfer, tyrosine is easier to oxidize by PCET because its BDFE is about $3 \mathrm{kcal}$ $\mathrm{mol}^{-1}$ weaker than the N-H BDFE in tryptophan. Again, given the critical importance of the proton in these chemical transformations, we strongly encourage those working on redoxactive amino acids to not just refer to the oxidized forms as, for instance, $\mathrm{Y}^{*}$ or $\mathrm{W}^{*}$, but to explicitly show the proton, for instance as $\mathrm{TyrO}^{\bullet} v s$. $\mathrm{TrpH}^{\bullet+}$.

5.6.2 Flavins-Flavin is the common name for a family of 7,8-dimethyl-substituted isoalloxazines (isoalloxazine $=10$-substituted alloxazine). The reader should be warned that the current IUPAC flavin numbering scheme is different from much of the flavin literature published before $c a$. 1980.295 There are four biologically relevant flavins, which differ only in the nature of the alkyl substituent at N10: lumiflavin, riboflavin, flavin mononucleotide (FMN) and flavin adenine dinucleotide (FAD) (Scheme 10).296 These cofactors exhibit essentially identical redox 155 and acid/base chemistry (Figure 7). Both the fully oxidized and fully reduced forms are stable, and are typically referred to using nomenclature analogous to quinones/hydroquinones.289 For example, the fully reduced form can be referred to as the "flavohydroquinone." Flavins also exhibit stable "flavosemiquinone" radicals at low pH.289 Also like hydroquinones, flavins can undergo $2 \mathrm{H}^{+} / 2 e^{-}$chemistry, thus a 9-membered square scheme is needed to describe the PCET thermodynamics.

The proton-coupled redox chemistry of flavins has long been known. Michaelis in the late 1930s297,298 and Lowe in 1956299 reported that lumiflavin, FMN, and FAD all have the Nernstian dependence of the redox potential on $\mathrm{pH}\left(\sim 60 \mathrm{mV}\right.$ per $\mathrm{pH}$ unit) below the $\mathrm{p} K_{\mathrm{a}}$ of the flavohydroquinone, which indicates that they can undergo $1 e^{-} / 1 \mathrm{H}^{+}$and $2 e^{-} / 2 \mathrm{H}^{+}$PCET reactions. Starting from the reduced anion, flavins can also mediate $1 \mathrm{H}^{+} / 2 e^{-}$(hydride) transfer to give the fully oxidized form. The net hydride transfer from $\mathrm{NAD}(\mathrm{P}) \mathrm{H}$ to a flavin is a fundamental biological reaction that can be found in nearly any biochemistry text book. PCET chemistry of NADH and related compounds is discussed below. There is evidence that the mechanism of such net hydride transfers can be concerted in some instances.300 A recent study of the enzyme glucose oxidase, using chemically modified flavin-type cofactors, concluded that glucose is most likely oxidized by concerted hydride $\left(2 e^{-} / \mathrm{H}^{+}\right)$ transfer.301 Flavins can also mediate single electron transfer reactions, such as has been implicated in the electron transport chain of NADPH oxidase, to name just one example.302 The flavin cofactor in glucose oxidase has been shown to react with $\mathrm{O}_{2}$ by electron transfer, showing the power of using a series of modified flavins in mechanistic studies.303 The interested reader is directed to these references for the thermochemical properties of flavins, deazaflavins and related derivatives. While electron and hydride transfer reactions of flavins are well known, to our knowledge single hydrogen atom transfer reactions of flavins have not been widely discussed.

The acid/base chemistry of flavins has been extensively studied. The first $\mathrm{p} K_{\mathrm{a}} \mathrm{s}$ of flavins are generally much lower than that of many quinones, and are below neutral $\mathrm{pH}$, so that they are mostly ionized under biological conditions. The $\mathrm{p} K_{\mathrm{a}}$ for the flavohydroquinone and the

flavosemiquinone have not been drastically revised since their first reports in the early $20^{\text {th }}$ century.289,297-298299 Land and Swallow reported a $K_{\mathrm{a}}$ of 0.25 for protonation of 
oxidized riboflavin and $\mathrm{p} K_{\mathrm{a}}=2.3$ for protonation of the flavin semiquinone. 304 We note that $\mathrm{p} K_{\mathrm{a}} \mathrm{s}$ of the transient flavosemiquinones, like those of most transient radicals, are not simple to determine; the values quoted here are the most widely employed. Many reports of pH 7 midpoint one electron potentials for flavins have emerged, but perhaps the most widely accepted values were reported by Anderson.305 Those data were later used to fit $E$ versus $\mathrm{pH}$ data for flavins and obtain $1 \mathrm{H}^{+} / 1 e^{-}$potentials at $\mathrm{pH} 0.306$ Using the known dissociation constants (Figure 7) we have calculated the standard $1 e^{-}$(not proton-coupled) reduction potentials shown along the vertical arrows in Figure 7. The derived bond strengths are in excellent agreement with the average bond strength calculated from the $\mathrm{pH} 7$ midpoint potential $(-0.21 \mathrm{~V}, 155$ equivalent to $+0.2 \mathrm{~V}$ at $\mathrm{pH} 0$ upon extrapolation with the Nernstian $59 \mathrm{mV}$ per $\mathrm{pH})$.

The free energy to lose $1 \mathrm{H}^{+} / 2 e^{-}$(or $\mathrm{H}^{-}$) is also shown in Figure 7, as the long steep diagonal. As with BDFEs, hydride affinities can be determined from thermodynamic square schemes. 5 In a given solvent, the hydride affinity is calculated from the sum of two free energies for reduction/oxidation $\left(23.06 E^{\circ}\right)$, the free energy for protonation/deprotonation $\left(1.37 \mathrm{p} K_{\mathrm{a}}\right)$, and $23.06 E^{\circ}\left(\mathrm{H}^{+/-}\right)\left(=23.06\left(E^{\circ}\left(\mathrm{H}^{+/ \circ}\right)+E^{\circ}\left(\mathrm{H}^{\circ /-}\right)\right)\right.$, see Table 19 and Section 5.8.3, below). 5 By Hess' law, it does not matter which two reduction potentials and $\mathrm{p} K_{\mathrm{a}}$ are used to calculate a hydride affinity so long as together they connect the two species differing by $\mathrm{H}^{-}$.

The $2 \mathrm{H}^{+} / 2 e^{-}$potentials for non-biological substituted flavins do not vary drastically with respect to substitution, 155,307 ranging from $E^{\circ}=0.30 \mathrm{~V}$ to $E^{\circ}=0.19 \mathrm{~V}$ (the later for the biological flavins discussed above). This implies a range of average N-H BDFEs from 64.5 $\mathrm{kcal} \mathrm{mol}{ }^{-1}$ to $62 \mathrm{kcal} \mathrm{mol}^{-1}$. Unfortunately, there are no individual $\mathrm{p} K_{\mathrm{a}} / E^{\circ}$ data for many of these compounds, precluding construction of complete thermochemical cycles.

As noted above, the thermochemistry of flavins allows them to mediate a wide range of redox reactions, including hydride transfers and single electron transfers. The ability of flavins to transfer $\mathrm{H}^{-}$is in contrast with hydroquinones, which do not normally react by hydride transfer presumably because the hydroquinone anion $\left(\mathrm{HQ}^{-}\right)$is a high energy species, and difficult to generate under typical conditions (see above). In contrast, the reduced flavin anion is much lower in energy. In this way flavins are also unique from the other nitrogen containing compounds discussed above. Inspection of Figure 7 shows that the thermochemical landscape for flavins is more "flat" than other compounds discussed here. Because the redox potentials of flavins are less sensitive to their acid/base chemistry (and vice versa), they are able to mediate a wider range of reactions, and are not limited to $\mathrm{H}^{*}$ transfer like phenols or ascorbate.

5.6.3 Nucleosides-The redox chemistry of nucleotides, nucleosides, and nucleobases has been of great interest because of its relevance to the effects of free radicals, oxidants, and ionizing radiation on DNA, and to understand long-range change transport along DNA. 308 This section summarizes the PCET thermochemistry of individual nucleosides. These data are a foundation for understanding the redox chemistry of DNA, although the properties of the nucleosides can be different within the DNA helix. There is some evidence that charge transport along DNA can be a PCET process.308f,309

Guanine is the most easily oxidized nucleobase and therefore has received the most attention. At pH 7, one-electron oxidation of guanine occurs with loss of the N1 proton (Scheme 11; the radical density in the product is mostly at O6, as drawn). The most authoritative value for this redox potential is $1.29 \mathrm{~V}$ at $\mathrm{pH} 7.310 \mathrm{It}$ should be emphasized that this is the potential for a $1 \mathrm{H}^{+} / 1 e^{-}$transfer process and cannot be used in analyses of 
pure electron transfer - although this has been done. The nature of the charge carrier in oxidized DNA is still a matter of debate, as summarized in a very recent review:308e

"in the context of hopping and drift, the nature of the states that mediate charge transport vary with the sequence and sequence-dependent dynamics. What these states are, localized radical cations, localized neutral radicals, large polarons, delocalized domains, or a combination, will be different on the basis of the properties of the specific donor, DNA bridge, and acceptor."

Table 15 gives the PCET thermochemical data for the four nucleosides at $\mathrm{pH} 7$ and the bond strengths derived from these values. Steenken also extrapolated these measured $\mathrm{pH} 7$ potentials for guanosine and adenosine to standard $\mathrm{pH} 0 E^{\circ}$ values, accounting for the complex pH dependence of the neutral and radical species.310 The bond strengths are quite high, and highlight the propensity of the nucleobases to undergo reactions other than HAT with powerful oxidants, such as $\mathrm{OH}^{\bullet}$ addition to guanosine to produce 8-oxo-guanosine. Reagents that abstract hydrogen atoms tend to react with the weak $\mathrm{C}-\mathrm{H}$ bonds in the ribose portion of DNA. The nucleobase $\mathrm{N}-\mathrm{H}$ bonds may also be kinetically unreactive because those hydrogen atoms are in strong hydrogen bonds, a possible effect analogous to Ingold's kinetic solvent for HAT from $\mathrm{O}-\mathrm{H}$ bonds in small molecules in solution.11

\subsection{Thiols}

The redox chemistry of thiols is important in many areas of biology. The oxidation of the thiol side chain of the amino acid cysteine, ${ }^{-} \mathrm{O}_{2} \mathrm{CCH}\left(\mathrm{NH}_{3}{ }^{+}\right) \mathrm{CH}_{2} \mathrm{SH}$, forms disulfide linkages that are critical to the proper folding and function of peptides and proteins. Thiols are also important to the function of the hormone insulin to catalysis by ribonucleotide reductases to the structural keratin in hair and other biomaterials. Thiols are important biological antioxidants, with the prototypical example being glutathione (GSH), a tripeptide of glycine, cysteine and glutamic acid.313 GSH has long been understood as an important biological antioxidant, and it has more recently been shown to have other important biological roles. 314 The redox chemistry of thiols typically involves net $\mathrm{H}^{*}$ loss to give the thiyl radical RS*, with subsequent disulfide formation or oxidation to sulfenic (RSOH), sulfinic $[\mathrm{RS}(\mathrm{O}) \mathrm{OH}]$ and/or sulfonic acids $\left[\mathrm{RS}(\mathrm{O})_{2} \mathrm{OH}\right]$.

Thiols are in general more acidic than corresponding alcohols, more easily oxidized, and have weaker $\mathrm{X}-\mathrm{H}$ bonds. For example, in DMSO thiophenol is $7.7 \mathrm{p} K_{\mathrm{a}}$ units more acidic and $\mathrm{PhS}^{-}$is $35 \mathrm{mV}$ easier to oxidize than phenol and phenoxide, which results in an $11 \mathrm{kcal}$ $\mathrm{mol}^{-1}$ weaker BDFE (Tables 4 and 16). In water, the differences are less because $\mathrm{PhS}^{-}$is not as strongly solvated as $\mathrm{PhO}^{-}$: the differences are $3.4 \mathrm{p} K_{\mathrm{a}}$ units, $0.1 \mathrm{~V}$ in $E^{\circ}\left(\mathrm{PhE}^{\circ /-}\right)$, and $7 \mathrm{kcal} \mathrm{mol}^{-1}$ in BDFE $\left(\mathrm{E}=\mathrm{S}\right.$ or $\mathrm{O}$ ). Extensive $\mathrm{p} K_{\mathrm{a}}$ data available for thiols 315 but fewer redox potentials are known, presumably because of the rapid dimerization of thiyl radicals. Representative available data are given in Table 16 for selected compounds. We can find no data for thiol radical cations, which suggests that these are high energy species with $E^{\circ}$ $\left(\mathrm{RSH}^{\bullet+/ 0}\right)>1 \mathrm{~V}$ and $\mathrm{p} K_{\mathrm{a}}\left(\mathrm{RSH}^{\bullet+}\right)<0$ in water.

Armstrong and Surdhar used gas phase RS-H BDEs, estimated heats of solution and the $\mathrm{p} K_{\mathrm{a}} \mathrm{s}$ to calculate $\mathrm{RS}^{\bullet /-}$ redox couples in water. 316 They used $\mathrm{BDE}(\mathrm{RS}-\mathrm{H})=81.2 \mathrm{kcal}$ $\mathrm{mol}^{-1}$, but these values have since then been determined to be larger, $c a .87 \mathrm{kcal} \mathrm{mol}^{-1}$ (Table 16). Using Armstrong's thermochemical cycle with the revised gas phase BDFEs shown in Table 16 gives $E^{\circ}\left(\mathrm{MeS}^{\circ /-}\right)=0.73 \mathrm{~V}$ and $E^{\circ}\left(\mathrm{EtS}^{\circ /-}\right)=0.74 \mathrm{~V}$. These values are in good agreement with later estimates of $E^{\circ}\left(\mathrm{RS}^{\bullet /-}\right)$ for deprotonated $\beta$-mercaptoethanol (= $\left.\mathrm{HOCH}_{2} \mathrm{CH}_{2} \mathrm{SH}\right) 317$ and cysteine. 318

$\beta$-mercaptoethanol has better solubility in water than other alkyl thiols, and serves as a reasonable model of aqueous thiol chemistry since the thiol and alcohol moieties are not too 
near to each other. The aqueous potential for $\mathrm{HOCH}_{2} \mathrm{CH}_{2} \mathrm{~S}^{\bullet}+\mathrm{H}^{+}+e^{-} \rightarrow \mathrm{HOCH}_{2} \mathrm{CH}_{2} \mathrm{SH}$ is $E^{\circ}=1.33 \pm 0.02 \mathrm{~V}\left(\mathrm{HOCH}_{2} \mathrm{CH}_{2} \mathrm{SH}=\beta\right.$-mercaptoethanol $) .317$ Applying eq 15 above gives $\mathrm{BDFE}_{\mathrm{H} 2 \mathrm{O}}\left(\mathrm{HOCH}_{2} \mathrm{CH}_{2} \mathrm{~S}-\mathrm{H}\right)=88.3 \mathrm{kcal} \mathrm{mol}^{-1}\left(\right.$ and $\mathrm{BDE}_{\mathrm{H} 2 \mathrm{O}}\left(\mathrm{HOCH}_{2} \mathrm{CH}_{2} \mathrm{~S}-\mathrm{H}\right)=86.5 \mathrm{kcal}$ mol $^{-1}$ with the assumption that $S^{\circ}{ }_{2} \mathrm{O}\left(\mathrm{HOCH}_{2} \mathrm{CH}_{2} \mathrm{~S}^{\circ}\right)=\mathrm{S}^{\circ} \mathrm{H} 2 \mathrm{O}\left(\mathrm{HOCH}_{2} \mathrm{CH}_{2} \mathrm{SH}\right)$, see above). This value is in excellent agreement with the bonds strengths calculated above from thermochemical cycles.

The $\mathrm{p} K_{\mathrm{a}}$ of the $\mathrm{S}-\mathrm{H}$ group in cysteine has long been known319 and was recently determined as a function of temperature and ionic strength. 320 It is very similar to the $\mathrm{p} K_{\mathrm{a}}$ of other alkyl thiols, 315 which is not surprising since the side chain is fairly separated from the amine and carboxylate groups. The $\mathrm{RS}^{\bullet}+\mathrm{H}^{+}+e^{-} \rightarrow \mathrm{RSH}$ redox potential of cysteine, determined by Prütz and co-workers, is also very similar to the values determined by Surdhar and Armstrong (see above). Thus, the PCET thermochemistry of cysteine, glutathione, and alkyl thiols are very similar. Like phenols and ascorbate, the intermediates of single proton or electron transfer of RSH species are high in energy, indicating that thiols preferentially lose $\mathrm{H}^{\bullet}$ under normal physiological conditions.

\subsection{C-H bonds and $\mathrm{H}_{2}$}

Bell, Evans, and Polanyi showed in the 1930s that the facility of hydrogen atom abstraction from hydrocarbons parallels the gas phase homolytic BDE of the $\mathrm{C}-\mathrm{H}$ bond being cleaved. Ever since then, BDEs have been central to organic free radical chemistry, and have been widely used for solution as well as gas-phase radical reactions: the gas phase BDE is the typical starting point for understanding the reactivity of $\mathrm{C}-\mathrm{H}$ bonds. However, it should be noted that other factors besides $\mathrm{C}-\mathrm{H}$ bond strength affect radical reactivity. For instance, the polar effect 328 of electron withdrawing substituents makes $\mathrm{C}-\mathrm{H}$ bonds much less reactive towards electrophilic radicals such as ${ }^{t} \mathrm{BuO}{ }^{*}$, as illustrated above in the lack of reactivity of acetonitrile solvent with this radical.198

This portion of the review is divided into three subsections. The first presents selected thermochemical data for simple hydrocarbons and small alkylaromatic compounds. Readers interested in a wider range of compounds are referred to specialized reviews on the acidities, redox potentials, and bond dissociation energies of organic compounds. In particular, Bordwell and co-workers measured $\mathrm{p} K_{\mathrm{a}} \mathrm{s}$ in DMSO for many compounds with weak C-H bonds, as well as a number of redox potentials of the corresponding anions.29,69,329 One version of this is available online.29 Kochi and others have discussed outer-sphere electron transfer reactions of organic compounds330 and Eberson's book on electron transfer in organic chemistry is particularly useful.331 Recently, Luo has assembled an excellent and very extensive monograph on bond dissociation energies (which is also in part available online).59 The second section below discusses the thermochemistry of nicotinamide derivatives and analogs, which are perhaps the most important biological PCET reagents with reactive $\mathrm{C}-\mathrm{H}$ bonds. There are a number of other redox-active $\mathrm{C}-\mathrm{H}$ bonds in biology that we would like to include, such as the glycine that is oxidized to a glycyl radical in the catalytic cycle of pyruvate formate-lyase activating enzyme 332 and the adenosine methyl $\mathrm{C}-\mathrm{H}$ bond that is formed and cleaved in the catalytic cycles of vitamin $\mathrm{B}_{12}$ and radical-SAM enzymes.333 However, little experimental thermochemistry is available for these systems; the interested reader is referred to computational studies.334 Finally, this section concludes with a discussion of the PCET thermochemistry of $\mathrm{H}_{2}$.

5.8.1 Hydrocarbons-Gas phase $\mathrm{C}-\mathrm{H}$ BDEs of hydrocarbons have been repeatedly reviewed, but the reader is cautioned that the "best" values have changed over time (the reasons for this are nicely explained by Tsang70). Two of the more valuable current sources are a review by Blanksby and Ellison of gas phase BDEs of common organic and inorganic 
compounds 37 and Luo's monograph mentioned above.59 Table 17 presents some of these data for hydrocarbons (and xanthene), as well as a few $\mathrm{p} K_{\mathrm{a}}$ and $E$ values. For a number of entries in the Table, the solution bond strength has been calculated from the gas phase value using Abraham's model, which is expected to work well here. In the absence of strong hydrogen bonding, the energies of solution are small and the differences in these energies should be very small $\left[\right.$ e.g., $\left.\Delta G_{\text {solv }}{ }^{\circ}\left(\mathrm{R}^{\circ}\right)-\Delta G_{\text {solv }}{ }^{\circ}(\mathrm{RH}) \cong 0\right]$. This means that the solution bond strengths differ from the gas phase values primarily by the different solvation energies of $\mathrm{H}^{\bullet}$ (see eq 11 above). Using this method, we estimate $\mathrm{BDFE}\left(\mathrm{H}_{3} \mathrm{C}-\mathrm{H}\right) \cong 106 \mathrm{kcal} \mathrm{mol}^{-1}$ in water and, using eq $16, E^{\circ}\left(\mathrm{CH}_{3}{ }^{\circ-}\right)=-0.7 \mathrm{~V}$ vs. NHE.

For several aromatic hydrocarbons, redox potentials $E\left(\mathrm{R}^{\cdot+/ 0}\right)$ are available in $\mathrm{MeCN}$ solvent. 335 For toluene, $p$-xylene and fluorene there are also data for the reduction of the neutral radical $\mathrm{R}^{*}$, and estimates can be made of the $\mathrm{p} K_{\mathrm{a}} \mathrm{s}$ in $\mathrm{MeCN}$. Thus, a complete cycle can be made for these reagents. However, readers should be cautioned that potentials and $\mathrm{p} K_{\mathrm{a}} \mathrm{s}$ that are very high or very low are difficult to measure and may have larger errors.

These hydrocarbons, as exemplified by toluene, are extreme examples of reagents that prefer to react by $\mathrm{H}^{\bullet}$ transfer rather than the stepwise paths of ET-PT or PT-ET. Few reagents are basic or oxidizing enough to mediate single electron or single proton transfers with toluene and other alkyl aromatics, yet the toluene $\mathrm{C}-\mathrm{H}$ is of modest strength and is relatively easily abstracted. As discussed in more detail below, toluene is oxidized by a variety of transition metal complexes and most of these reactions must proceed via concerted transfer of $\mathrm{H}^{\bullet}$ because the stepwise electron transfer or proton transfer intermediates are simply too far uphill. However, an interesting exception involving stepwise ET-PT is also discussed in Section 6, below. As noted above for hydroxylamines and phenols, one of the hallmarks of a reagent that prefers to transfer an electron and proton together is that the $\mathrm{p} K_{\mathrm{a}}$ of the changes dramatically upon redox change (and, equivalently, the $E^{\circ}$ changes dramatically upon deprotonation). For toluene, the $\mathrm{pK}_{\mathrm{a}} \mathrm{s}$ of $\mathrm{PhCH}_{3}$ and $\mathrm{PhCH}_{3}{ }^{\circ+}$ differ by more than 50 orders of magnitude!

5.8.2 Nicotinamide derivatives-One of the archetypal biological redox reactions of $\mathrm{C}$ $\mathrm{H}$ bonds is the $\mathrm{H}^{+} / 2 e^{-}$couple in reactions of nicotinamide adenine nucleotide $\left(\mathrm{NAD}^{+} / \mathrm{H}\right)$ and nicotinamide adenine dinucleotide phosphate $\left(\mathrm{NADP}^{+} / \mathrm{H}\right.$, Figure 8$)$. As noted above, NADH and NADPH commonly transfer hydride to flavins in many different enzyme catalytic cycles. Kreevoy and coworkers have beautifully explored the hydride transfer chemistry of NADH analogs, and shown that the kinetics of these reactions are related to the thermochemistry of hydride transfer.57 More recently, other cellular roles of nicotinamides have been uncovered.349 In vitro, nicotinamide derivatives and analogs can undergo electron transfer, hydrogen atom transfer, and hydride transfer reactions (similar to flavins), as has been shown in a number of studies. 350

The reactivity of NADH and related compounds, such as $N$-benzyl-1,4-dihydronicotinamide (BNAH) and 10-methyl-9,10-dihydroacridine $\left(\mathrm{AcrH}_{2}\right)$, has been widely studied, and there are a few reports of the redox potential and $\mathrm{p} K_{\mathrm{a}}$ data necessary to draw complete thermochemical scheme. Nicotinamides are oxidized by two electrons with loss of one proton, to give the corresponding pyridinium ion, so a double square scheme is needed to describe each system (Figure 9). Nicotinamide radical cations are quite acidic, like the hydrocarbon radical cations discussed above, and the closed shell (reduced) nicotinamides are very poor acids, highlighting the typical preference of these compounds to undergo PCET rather than ET or PT. Cheng et al. have presented thermochemical data for aqueous NADH351 and for 10-methyl-9,10-dihydroacridine $\left(\mathrm{AcrH}_{2}\right)$ in DMSO352 and MeCN (Figure 9),353 although questions have been raised about some of these results.354 For $\mathrm{AcrH}_{2}$ in $\mathrm{MeCN}$, there is reasonable agreement between Cheng's values and those reported 
earlier by Savéant and Neta, but there is a substantial disagreement in the values for BNAH. 355 There is also a discrepancy between Cheng et al.'s data351 and other literature values356,357 for $\mathrm{NADH}$ in water. The $E^{\circ}$ and $\mathrm{p} K_{\mathrm{a}}$ data can be converted to BDFEs and hydride affinities $\left(\Delta G^{\circ}\left(\mathrm{H}^{-}\right)\right)$, as discussed above. The derived hydride affinities for $\mathrm{AcrH}_{2}$ and benzyl nicotinamide BNAH (Figure 8) in $\mathrm{MeCN}$ are in reasonable agreement with those obtained from equilibrium measurements, 358 and the difference between them similarly agrees with the relative hydride affinities reported by Wayner.359 Methylated BNAH derivatives show thermochemistry that is similar to the parent compound in MeCN.360

5.8.3 Hydrogen-The $\mathrm{H}-\mathrm{H}$ bond in dihydrogen is in many ways very similar to the $\mathrm{C}-\mathrm{H}$ bond in methane. The gas phase BDE361 and BDFE49 of $\mathrm{H}_{2}$ are known (Table 19). These gas phase values are within $1 \mathrm{kcal} \mathrm{mol}^{-1}$ of methane. These BDEs and BDFEs, along with the known enthalpies and entropies of solution, are used to calculate BDEs and BDFEs in various solvents, using Roduner's 2005 demonstration that the solvation of $\mathrm{H}^{\bullet}$ is energetically roughly equal to that of $\mathrm{H}_{2} .50$ As described in Section 3.1 above, use of this approximation has led to revision of the $\mathrm{H}^{+} / \mathrm{H}^{\bullet}$ reduction potentials in different solvents. The $\mathrm{H}^{\circ} / \mathrm{H}^{-}$reduction potentials in water362 and in DMSO and MeCN363 have been reported, allowing the $\mathrm{p} K_{\mathrm{a}}$ of $\mathrm{H}_{2}$ to be estimated by eq $22 . \mathrm{H}_{2}$ is very weakly acidic, though significantly more acidic than methane. Recently Kelly has proposed new values for $\mathrm{p} K_{\mathrm{a}}\left(\mathrm{H}_{2}\right)$ and $E^{\circ}\left(\mathrm{H}^{\bullet /-}\right)$, some of which are very different from the values that have long been used.364

$\mathrm{p} K_{\mathrm{a}}\left(\mathrm{H}_{2}\right)_{(\text {solv })}=\left[\operatorname{BDFE}\left(\mathrm{H}_{2}\right)_{\text {solv }}-F\left[E^{\circ}\left(\mathrm{H}^{\bullet} / \mathrm{H}^{+}\right)_{\text {solv }}+E^{\circ}\left(\mathrm{H}^{\bullet} / \mathrm{H}^{-}\right)_{\text {solv }}\right]\right] / 1.37$

\subsection{Separate Proton and Electron Donors/Acceptors}

This review primarily deals with PCET reagents, that is individual chemical compounds that can donate or accept proton(s) and electron(s). From a thermodynamic perspective, this is equivalent to two reagents, one of which accepts or donates proton(s) and the other of which accepts or donates electrons. For instance, ferrocene-carboxylic acid is a single PCET reagent that can donate $e^{-}+\mathrm{H}^{+}\left(\mathrm{H}^{*}\right)$ to give the zwitterionic ferrocene carboxylate, with an effective BDFE of $68 \mathrm{kcal} \mathrm{mol}^{-1}$ in $80 / 20 \mathrm{MeCN} / \mathrm{H}_{2} \mathrm{O}$ solvent [assuming that $C_{\mathrm{G}}(\mathrm{MeCN}) \sim$ $\left.C_{\mathrm{G}}\left(\mathrm{MeCN} / \mathrm{H}_{2} \mathrm{O}\right)\right] .365$ Similarly, the combination of ferrocene and benzoic acid can donate $e^{-}+\mathrm{H}^{+}$. One can even define a formal BDFE for the $\mathrm{Cp}_{2} \mathrm{Fe}+$ benzoic acid combination in $\mathrm{MeCN}, 83.3 \mathrm{kcal} \mathrm{mol}^{-1}$, using the same eq 7 as used above for a single PCET reagent. The thermodynamic calculation is independent of whether the proton and electron come from a single reagent or two reagents. The most famous example of a separate outer-sphere oxidant and a base accomplishing a PCET reaction is the oxidation of tyrosine $\mathrm{Z}$ in photosystem II, in which the proton is transferred from tyrosine $\mathrm{Z}$ to a nearby histidine while the electron is transferred to the chlorophyll radical cation $\mathrm{P} 680^{+\bullet}$ about $14 \AA$ away.108

The use of a "BDFE" for two separated reagents is perhaps a bit peculiar, because there is no $\mathrm{X}-\mathrm{H}$ bond that is being homolytically cleaved. It is, however, a very useful way to characterize the thermochemistry of a PCET system, and it emphasizes the thermodynamic equivalence of $\mathrm{H}^{+} / e^{-}$acceptors and $\mathrm{H}^{\bullet}$ acceptors $\left[\mathrm{H}^{+} / e^{-}\right.$donors and $\mathrm{H}^{\bullet}$ donors $]$. The literature for water oxidation, for example, typically quantifies the free energy required as a minimum redox potential of $E^{\circ}=1.23 \mathrm{~V}(\mathrm{pH} 0)$. However, this puts emphasis on the electron, while the thermochemistry depends equally on the $e^{-}$and the $\mathrm{H}^{+}$. What is needed to convert $\mathrm{H}_{2} \mathrm{O}$ to $\mathrm{O}_{2}$ is a PCET reagent or PCET system with an average BDFE of $\geq 86$ $\mathrm{kcal} \mathrm{mol}^{-1}$ (eq 18, described above). This free energy can be obtained with a single PCET reagent or with a combination of an oxidant and a base. The required free energy can be obtained with a strong oxidant plus a weak base, or a weak oxidant plus a strong base. While 
this area has not received the same detailed study as traditional H-atom transfer reactions, we believe that it is a very important and versatile approach to PCET, and will prove to be widely used in biology and valuable in the development of new chemical processes.

A huge number of possibilities are possible for oxidant/base combinations ( $\mathrm{H}^{\bullet}$ acceptors) and reductant/acid combinations ( $\mathrm{H}^{\bullet}$ donors). This is because there are many one-electron redox reagents and a huge number of possible acids/bases. A few examples are listed in Table 20, with an emphasis on $\mathrm{H}^{\bullet}$ acceptors in $\mathrm{MeCN}$, based on our experience ( $c f$., reference 366 ). The same principles should apply to other solvents and to " $\mathrm{H}^{\bullet}$ donors." Listings are available of stable, isolable one-electron oxidants and reductants and their potentials in $\mathrm{MeCN}, 254$ as well as tabulations of organic acids and bases and their $\mathrm{p} K_{\mathrm{a}} \mathrm{s}$. 28,30,89 There are, however, practical limitations at both the extremes of strong $\mathrm{H}^{\circ}$ acceptors (high BDFEs) and strong $\mathrm{H}^{\bullet}$ donors (low BDFEs). In general, bases are electronrich and can be oxidized, and in our experience this limits the combinations that are available at high BDFE. Similarly, strong reductants are electron rich and are often protonated by acids, and acids are often easily reduced to $\mathrm{H}_{2}$. Some of the challenges are illustrated by the Schrock/Yandulov nitrogen reduction system, which uses decamethylchromocene as the very strong reductant $\left(E^{\circ}\right.$ for $\mathrm{CrCp}_{2}=-1.47 \mathrm{~V}$ in THF $v s$. $\left.\mathrm{Cp}_{2} \mathrm{Fe}^{+/ 0}\left[\mathrm{Cp}^{*}=\mathrm{C}_{5} \mathrm{Me}_{5}\right]\right)$ and [2,6-lutidinium $] \mathrm{BAr}_{4}^{\prime}\left[\mathrm{Ar}^{\prime}=3,5-\left(\mathrm{CF}_{3}\right)_{2} \mathrm{C}_{6} \mathrm{H}_{3}\right]$ as the acid. 245b As Schrock wrote: "Heptane was chosen as the solvent to minimize the solubility of [2,6-lutidinium] $\mathrm{BAr}_{4}$ and thereby minimize direct reduction of protons by $\mathrm{CrCp}_{2}{ }_{2}$ in solution. Slow addition of the reducing agent in heptane to an Mo complex and [2,6lutidinium] $\mathrm{BAr}_{4}{ }_{4}$ in heptane (over a period of $6 \mathrm{~h}$ with a syringe pump) was chosen to minimize exposure of protons to $\mathrm{CrCp}_{2}$ at a high concentration." $245 \mathrm{~b}$

Waidmann et al. have explored combinations of triarylaminium oxidants and substituted pyridine bases as strong $\mathrm{H}^{*}$ acceptors in $\mathrm{CH}_{2} \mathrm{Cl}_{2} .366$ One of the key observations in these studies is that trace reducing impurities in the pyridine base can lead to decay of the aminium oxidant. Thus, careful purification of the base appears to be important. Furthermore, some oxidant-base combinations may not be compatible. For example, the $\mathrm{N}\left(4-\mathrm{Br}-\mathrm{C}_{6} \mathrm{H}_{4}\right)_{3}{ }^{++}\left(E_{1 / 2}=0.67 \mathrm{~V}\right.$ versus $\mathrm{Cp}_{2} \mathrm{Fe}^{+/ 0}$ in MeCN254) is stable in the presence of pyridine $\left(\mathrm{p} K_{\mathrm{a}}=12.530\right)$ at $298 \mathrm{~K}$, but decays in the presence of 4-NH $-\mathrm{NH}_{2}$-pyridine $\left(\mathrm{p} K_{\mathrm{a}}=\right.$ 17.630). [For the reader not accustomed to this electrochemical scale, $\mathrm{Cp}_{2} \mathrm{Fe}^{+/ 0}$ in $\mathrm{MeCN}$ is roughly $+0.63 \mathrm{~V} v s$. aqueous NHE.33] By using different combinations of oxidant and base, effective BDFEs ranging from 76 to $100 \mathrm{kcal} \mathrm{mol}^{-1}$ can be achieved (Table 20). Roughly the same BDFE can often be achieved with different combinations of oxidants and bases, which allows flexibility in selecting oxidant/base combinations based on the requirements or limitations of a given PCET system and which can be a valuable mechanistic test.

The discussion above has emphasized the thermodynamics of oxidant/base and reductant/ acid combinations of reagents, and that they are equivalent to the thermochemistry of single PCET reagents. However, equivalent BDFEs does not necessarily mean that the kinetic behavior will be the same for single PCET reagents $v s$. combinations, or even that similar pathways - stepwise vs. concerted - will be followed. A few studies have shown that two separate reagents can accomplish concerted transfer of $\mathrm{H}^{+}$and $e^{-}$, termed separated CPET (or multisite EPT). In perhaps the first clear example, Linschitz and co-workers oxidized phenols hydrogen-bonded to pyridines, using photogenerated triplet $\mathrm{C}_{60}$ as the oxidant (eq 23).367 They showed that proton transfer to the pyridine is concerted with electron transfer to the oxidant. Hammarström and Nocera have studied reactions in which a tethered tyrosine is oxidized by a photoexcited transition metal complex ( $\mathrm{Ru}$ or $\mathrm{Re}$ ), with proton transfer to an intramolecular carboxylate or to the aqueous solvent or buffer.10,14,368 Both separated CPET and stepwise proton transfer then electron transfer mechanisms have been observed. Rhile, Markle and co-workers have examined oxidations of phenols with an attached base, 
in which outer-sphere electron transfer to an oxidant $\mathrm{A}^{+}$is concerted with intramolecular proton transfer (eq 24).369 Hammarström and Savéant have examined similar systems. $368 \mathrm{~b}, \mathrm{e}, \mathrm{f}, 370$ Costentin has very thoroughly and clearly reviewed electrochemical CPET reactions, in which electron transfer to/from an electrode is concerted with proton transfer. 3

$$
\mathrm{PhOH} \cdots \mathrm{py}^{3} \mathrm{C}_{60}{ }^{*} \rightarrow \mathrm{PhO}^{\bullet} \cdots \mathrm{Hpy}^{+}+\mathrm{C}_{60}{ }^{-}
$$

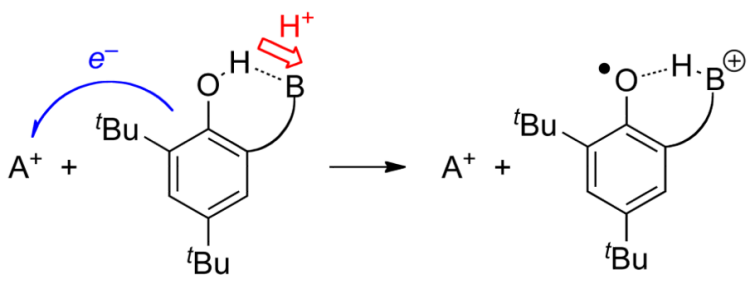

The examples in the previous paragraph show that combinations of oxidant and base, or reductant and acid, can in some circumstances accomplish concerted transfer of an electron and a proton. Thus, considering these combinations as having an 'effective BDFE' is reasonable. More studies are needed to examine the generality and utility of these combination PCET reagents. In addition, as illustrated in the next section, the distinction between a single PCET reagent and two separate reagents is not always so clear.

\subsection{Selected Transition Metal Systems}

The PCET chemistry of a wide range of transition metal systems has been investigated over the last few decades. No individual system has received the scrutiny of many of the classic organic systems discussed above, such as phenol, but there are examples for most of the transition metals that readily undergo one-electron redox change. A comprehensive account of all known transition metal PCET systems is beyond the scope of this review, which just presents selected examples, particularly from our laboratories.

Transition metal containing systems can mediate a range of PCET reactions. Most of these systems undergo redox change at the metal coupled to protonation or deprotonation at a ligand. A classic example is the interconversion of a metal hydroxide complex with a oneelectron oxidized metal-oxo compound (eq 25). This could be viewed as analogous to the oxidation of a phenol to a phenoxyl radical, in which the aromatic ring is oxidized by $1 e^{-}$. HAT reactions involving metal hydride complexes, which are well known, are somewhat different because both the redox and acid/base chemistry occur at the metal center. In some ways, HAT from metal hydrides is similar to that of $\mathrm{C}-\mathrm{H}$ bonds.

$$
\mathrm{L}_{x} \mathrm{M}^{n+}(\mathrm{OH}) \rightarrow \mathrm{L}_{x} \mathrm{M}^{(n+1)+}(\mathrm{O})+\mathrm{H}^{+}+e^{-}\left(\text {or } \mathrm{H}^{\bullet}\right)
$$

The thermochemistry of transition metal PCET reagents is typically determined by $\mathrm{p} K_{\mathrm{a}}$ and $E^{\circ}$ measurements (Scheme 12), and sometimes by equilibration with other PCET reagents. In the same manner as done above, these free energy measurements yield BDFE values using eqs 7,15 , or 16, as listed in Table 21 below. Unlike the data for organic reagents above, data are typically available for a given transition metal system only in one solvent, because of experimental limitations. BDFEs can not be adjusted as above because the Abraham model is untested and difficult to apply for metal complexes. Table 21 also does 
not include data for BDEs unless they have been directly measured via calorimetry or van't Hoff analysis. This is because, as discussed in Section 3.1, ground state entropy changes in transition metal PCET systems can be substantial. Thus, use of BDFEs is especially important in these cases.

5.10.1 Metal-Oxo and Hydroxo Complexes-The aqueous redox chemistry of transition metal ions has long been known to be critically dependent on the solution $\mathrm{pH}$, and to involve aquo, hydroxo, and oxo species. Pourbaix first assembled a compendium of diagrams summarizing the aqueous behavior of each metal in 1945.67 There are two excellent books on the properties of aqueous metal ions. 372 The chemical reactivity of transition metal-oxo complexes in particular have been of special interest to chemists and biochemists for many years. 373 Compounds such as $\mathrm{KMnO}_{4}, \mathrm{OsO}_{4}$ and $\mathrm{RuO}_{4}$ are important reagents for organic oxidations, 374 and many of their reactions are proton coupled. Metaloxo intermediates are similarly implicated in a range of biological oxidations, in particularly the oxo-iron(IV) (ferryl) intermediates found in the catalytic cycles of peroxidases, cytochromes P450, and many other heme and non-heme iron enzymes.375 The dissolution/ precipitation of many oxide/hydroxide minerals in the environment can also be a PCET process.376 For these reasons and others, there may be more interest in PCET reactions of the metal-oxo/hydroxo/aquo complexes than any other class of compounds.

For the simple aquo ions of metal cations, and for oxyanions of both main-group and transition-metal elements, most redox processes are proton-coupled.67 A simple example is the oxidation of aqueous ferrous ion, $\left[\mathrm{Fe}\left(\mathrm{H}_{2} \mathrm{O}\right)_{6}\right]^{2+}$, in mildly acidic solutions to give - at least in principle - the ferric hydroxo ion $\left[\mathrm{Fe}(\mathrm{OH})\left(\mathrm{H}_{2} \mathrm{O}\right)_{5}\right]^{2+}$. This transformation is loss of $\mathrm{H}^{\bullet}$ and has a BDFE of $79.5 \mathrm{kcal} \mathrm{mol}^{-1}$ based on the well-known $\mathrm{Fe}\left(\mathrm{H}_{2} \mathrm{O}\right)_{6}{ }^{3+/ 2+}$ aqueous redox potential $(0.77 \mathrm{~V})$ and the $\mathrm{p} K_{\mathrm{a}}$ of aqueous $\mathrm{Fe}^{\mathrm{III}} .372$ In practice, such reactions are challenging to study because of the hydrolysis of the cations - the $\left[\mathrm{Fe}(\mathrm{OH})\left(\mathrm{H}_{2} \mathrm{O}\right)_{5}\right]^{2+}$ product under most conditions loses additional protons and precipitates a hydrous oxide/ hydroxide. Using transient methods, Bakac has studied aqueous PCET reactions of simple metal-oxo aquo ions, for example showing that oxidations of organics by $\mathrm{Fe}^{\mathrm{IV}} \mathrm{O}^{2+}$ occurs by either HAT or hydride transfer.377 The chromium(III) superoxo complex $\left(\mathrm{H}_{2} \mathrm{O}\right) \mathrm{CrOO}^{2+}$ was found to undergo various PCET reactions and, starting from Anson's $1 \mathrm{H}^{+} / 1 e^{-}$ electrochemical data,378 a bond strength for $\left(\mathrm{H}_{2} \mathrm{O}\right)_{5} \mathrm{CrOO}_{-} \mathrm{H}^{2+}\left(\mathrm{BDFE}=81.4 \mathrm{kcal} \mathrm{mol}^{-1}\right)$ was determined.379 Bakac has also discussed the BDFEs in $\left(\mathrm{H}_{2} \mathrm{O}\right)_{5} \mathrm{CrO}-\mathrm{H}^{2+},\left(\mathrm{Me}_{6}\right.$ cyclam $)$ $\left(\mathrm{H}_{2} \mathrm{O}\right) \mathrm{Rh}(\mathrm{OO}-\mathrm{H})^{2+},\left(\mathrm{Me}_{6}\right.$ cyclam $)\left(\mathrm{H}_{2} \mathrm{O}\right) \mathrm{Co}(\mathrm{OO}-\mathrm{H})^{2+}$, and $(1,4,8,11-$ tetraazacyclotetradecane $)\left(\mathrm{H}_{2} \mathrm{O}\right) \mathrm{Co}(\mathrm{OO}-\mathrm{H})^{2+},\left(\mathrm{Me}_{6}\right.$ cyclam $=$ meso-hexamethylcyclam $)$. 380,381 The BDFEs given for these species in Table 21 are slightly different than those in Bakac's original reports because of reevaluation of the value for $E^{\circ}\left(\mathrm{H}^{+} / \mathrm{H}^{*}\right)_{\mathrm{aq}}\left[C_{\mathrm{G}}\left(\mathrm{H}_{2} \mathrm{O}\right)\right]$ as noted in Sections 3.1 and 5.8.3.

Probably the best studied metal PCET system, and one of the earliest studied in detail, is the ruthenium polypyridyl complex $\left[\text { cis- }(\text { bpy })_{2}(\mathrm{py}) \mathrm{Ru}^{\mathrm{IV}} \mathrm{O}\right]^{2+}\left(\right.$ abbreviated $\left.\left[\mathrm{Ru}^{\mathrm{IV}} \mathrm{O}\right]\right)$, developed by Meyer and coworkers (bpy $=2,2^{\prime}$-bipyridine, py = pyridine) .382 An extensive 2007 Chemical Reviews article is focused on this and other closely related complexes.1b Various reactions have been investigated including ET,383 PCET,384 C-H bond oxidations by HAT, 385 and by hydride abstraction, 386 HAT from O-H bonds, 387 and others. 388 Related compounds are of much current as catalysts for the oxidation of water to $\mathrm{O}_{2} .68,389$ The thermochemical landscape of this system has been thoroughly worked out by Meyer and coworkers383,390 and is summarized in Figure 10 and Table 21. $\left[\mathrm{Ru}^{\mathrm{IV}} \mathrm{O}\right]$ has a very strong preference to accept $\mathrm{H}^{+}$and $e^{-}$together; no well defined $\mathrm{p} K_{\mathrm{a}}$ for its protonation or $E^{\circ}$ for its non-proton-coupled reduction could be determined.383 The limits on these values are included in Figure 10 in parentheses. The relatively large bond strengths in the $\left[\mathrm{Ru}^{\mathrm{IV}} \mathrm{O}\right]$ system allow it to oxidize a number of strong bonds $\mathrm{C}-\mathrm{H}$ bonds via $\mathrm{H}$-atom abstraction. 
The PCET properties of a number of other transition metal oxo complexes have been examined. Borovik and co-workers have prepared unusual non-heme manganese and iron hydroxo/oxo systems stabilized by a hydrogen-bonding ligand, and has reported a number of O-H bond strengths.391,392 Stack et. al. have determined O- $\mathrm{H}$ bond strengths for $\mathrm{H}_{2} \mathrm{O}-$ ligated or $\mathrm{MeOH}-$ ligated iron and manganese complexes $(\mathrm{Py} 5) \mathrm{M}(\mathrm{ROH})^{2+}$ as models for lipoxygenase enzymes which use a non-heme iron(III) hydroxide to oxidize fatty acids by an HAT mechanism (Py5 = 2,6-bis(bis(2-pyridyl)methoxymethane)-pyridine).393394-395

Oxidized iron-heme active sites are perhaps the most important and most studied PCET reagents. The so-called "compound I" and "compound II" intermediates are the reactive species in the catalytic cycles of cytochromes P450, peroxidases, and other enzymes that accomplish a wide range of important transformations.396 Compound I species are two redox levels above the iron(III) resting state, and are usually described as iron(IV)-oxo complexes with an oxidized ligand, usually a porphyrin radical cation. Compound II species are one-electron oxidized and were traditionally viewed all as iron(IV)-oxo compounds. However, Green and co-workers have recently described a number of lines of evidence that some Compound II's are basic ( $\left.\mathrm{p} K_{\mathrm{a}}>8.2\right)$ and are actually iron(IV)-hydroxo species. 397,398 In these cases, the conversion of compound I to compound II is an unusual PCET process, in which the proton is transferred to the oxo group and the electron to the porphyrin radical cation (Scheme 13). Based on the apparent $\mathrm{p} K_{\mathrm{a}}$ values for of compound II in myoglobin, horseradish peroxidase, cytochrome $c$ peroxidase and catalase, it was concluded that only thiolate-ligated Compound IIs have substantial basicity. As should be clear to readers of this review, the basicity of Compound II is a key component of the free energy of PCET or HAT to compound I. Thus, the ability of cytochrome P450 enzymes to abstract $\mathrm{H}^{*}$ from strong $\mathrm{C}-\mathrm{H}$ bonds is intimately tied to the basicity of Compound II, as well as its redox potential. Behan and Green have also estimated, using equation 7 above, the minimum redox potentials and $\mathrm{p} K_{\mathrm{a}} \mathrm{s}$ necessary for ferryl containing systems to achieve a BDE of $99 \mathrm{kcal}$ $\mathrm{mol}^{-1}$ (so that HAT from cyclohexane would be isothermal).398

Small-molecule metal-oxo porphyrin species have been widely studied, both as models for heme proteins and as reactive intermediates in catalytic oxidation processes. These systems are very oxidizing, reacting via ET, PCET, oxygen atom transfer and other pathways, which makes direct determination of redox and acid/base properties challenging. Groves et al. have reported aqueous $\mathrm{p} K_{\mathrm{a}}$ values for manganese $(\mathrm{V})$-oxo-hydroxo complexes with water-soluble porphyrins, 7.5 for the tetra-( $N$-methyl-2-pyridyl)porphyrin (complex and 8.6 for the isomeric $N$-methyl-4-pyridyl (4TMPy) derivative. 399 They have also estimated, using rate constants for HAT reactions and the Brønsted-Evans-Polanyi relationship, $\mathrm{O}-\mathrm{H}$ bond dissociation enthalpies of $\sim 100 \mathrm{kcal} \mathrm{mol}^{-1}$ for $[(5,10,15,20$-tetra( $N$-methyl-4'pyridylporphyrin) $\left.) \mathrm{Fe}^{\mathrm{IV}} \mathrm{OH}\right]^{5+}, \sim 92 \mathrm{kcal} \mathrm{mol}^{-1}$ for $[(5,10,15,20-$

tetra(mesityl)porphyrin) $\left.\mathrm{Fe}^{\mathrm{IV}} \mathrm{OH}\right]^{+}$, and $\sim 86 \mathrm{kcal} \mathrm{mol}^{-1}$ for $[(5,10,15,20-$ tetra(pentafluorophenyl)]porphyrin) $\left.\mathrm{Fe}^{\mathrm{IV}} \mathrm{OH}\right]^{+} .400$ Shaik et al. have computed an O-H BDE of $\sim 86 \mathrm{kcal} \mathrm{mol}^{-1}$ for a gas-phase $\mathrm{Fe}^{\mathrm{IV}} \mathrm{OH}$ complex of a simplified protoporphyrin IX model.396a'401 Goldberg's porphyrinoid $\mathrm{Mn}^{\mathrm{V}} \mathrm{O}$ (corrolazine) complex has a relatively low redox potential in $\mathrm{MeCN}\left(E_{1 / 2}\left(\mathrm{Mn}^{\mathrm{V} / \mathrm{IV}}\right)=-0.43 \mathrm{~V} v s . \mathrm{Cp}_{2} \mathrm{Fe}^{+/ 0}\right)$ yet is able to abstract $\mathrm{H}^{*}$ from fairly strong phenolic O-H bonds. 402 Based on these results and eq 7, they concluded that the reduced $\mathrm{Mn}^{\mathrm{IV}} \mathrm{O}$ species must be quite basic.

Related ruthenium compounds with porphyrin, salen or tetramine macrocycles have also been studied in detail, as has been reviewed elsewhere.403 For instance, Lau and coworkers have studied in detail oxidation reactions of trans- $\left[\mathrm{Ru}^{\mathrm{VI}}(\mathrm{tmc})(\mathrm{O})_{2}\right]^{2+}$, trans- $\left[\mathrm{Ru}^{\mathrm{IV}}(\mathrm{tmc})(\mathrm{O})\right.$ $($ solv $)]^{2+}$, and trans- $\left[\mathrm{Ru}^{\mathrm{II}}(\mathrm{tmc})\left(\mathrm{H}_{2} \mathrm{O}\right)_{2}\right]^{2+}$, where tmc is the macrocyclic tertiary amine ligand 1,4,8,11-tetramethyl-1,4,8,11-tetraazacyclotetradecane.404 A full Pourbaix diagram was developed from aqueous electrochemical data, which indicates BDFEs of $74.3 \mathrm{kcal} \mathrm{mol}^{-1}$ 
for $\mathrm{Ru}^{\mathrm{V}}(\mathrm{O})(\mathrm{O}-\mathrm{H})$ and $82.5 \mathrm{kcal} \mathrm{mol}^{-1}$ for $\mathrm{Ru}^{\mathrm{IV}}(\mathrm{O})(\mathrm{HO}-\mathrm{H}) .405$ Consistent with these values, this and related complexes abstract $\mathrm{H}^{\bullet}$ from alkylaromatic compounds.406 Lau et al. have also shown that Lewis acids can greatly enhance the ability of oxo reagents to abstract $\mathrm{H}^{\bullet}$ from $\mathrm{C}-\mathrm{H}$ bonds, due to the stabilization of the reduced oxidant by the Lewis acid and therefore the larger O-H BDFE in the presence of the acid.407

The first studies of metal-mediated HAT in our labs involved chromyl chloride $\left(\mathrm{CrO}_{2} \mathrm{Cl}_{2}\right)$ and permanganate.211,408,409 The known aqueous $E^{\circ}\left(\mathrm{MnO}_{4}{ }^{2-I-}\right)=0.564 \mathrm{~V}$ and $\mathrm{p} K_{\mathrm{a}}\left(\mathrm{HMnO}_{4}^{-}\right)=7.4$ give, using equation $7, \operatorname{BDFE}\left(\mathrm{O}_{3} \mathrm{MnO}-\mathrm{H}^{-}\right)=80.7 \mathrm{kcal} \mathrm{mol}^{-1}$ (which was reported originally as a BDE of $80 \pm 3 \mathrm{kcal} \mathrm{mol}^{-1}$ ). The ability of $\mathrm{CrO}_{2} \mathrm{Cl}_{2}$ and $\mathrm{MnO}_{4}{ }^{-}$ to abstract $\mathrm{H}^{\bullet}$ from hydrocarbons was rationalized on the basis of this bond strength, which is high for isolable, stable species. More recently, $\mathrm{H}$-transfer reactions of cis-vanadium dioxo complexes, (bpy ${ }_{2} \mathrm{~V}^{\mathrm{V}}(\mathrm{O})_{2}{ }^{+}$, have been examined,24 and a VO-H BDFE of $70.6 \mathrm{kcal}$ $\mathrm{mol}^{-1}$ was obtained by equilibration with 2,6-di-tert-butyl-4-methoxyphenol. This system has unusually large barriers to HAT which are due to the substantial inner-sphere reorganization that occurs between $(\mathrm{bpy})_{2} \mathrm{~V}^{\mathrm{V}}(\mathrm{O})_{2}{ }^{+}$and $(\mathrm{bpy})_{2} \mathrm{~V}^{\mathrm{IV}}(\mathrm{O})(\mathrm{OH})^{+} .24$

Bridging oxo and hydroxo ligands can also be involved in PCET reactions. Pecoraro, Baldwin, and Caudle,410,411 and independently Brudvig, Crabtree and Thorp,412 showed that dimeric $\mu$-oxo manganese compounds such as $\left[(\text { phen })_{2} \mathrm{Mn}^{\mathrm{IV}}(\mu-\mathrm{O})_{2} \mathrm{Mn}^{\mathrm{III}}(\text { phen })_{2}\right]^{3+}$ $\left(\left[\mathrm{Mn}^{\mathrm{IV}} \mathrm{Mn}^{\mathrm{III}}{ }_{2}(\mathrm{O})_{2}\right]^{3+}\right.$, phen = 1,10-phenanthroline) are reduced with addition of protons to make $\left[\mathrm{Mn}_{2}{ }_{2}(\mathrm{O})(\mathrm{OH})\right]^{3+}$ and $\left[\mathrm{Mn}^{\mathrm{III}} \mathrm{Mn}^{\mathrm{II}}(\mathrm{OH})_{2}\right]^{3+}$. Pecoraro et al. derived $\mathrm{BDE}$ values and showed that these hydroxide complexes could donate $\mathrm{H}^{*}$ to a phenoxyl radical, and thus suggested that these are potential models for the manganese cluster in Photosystem II (the oxygen evolving cluster) which is oxidized by the nearby tyrosine $\mathrm{Z}$ radical. A more recent report has described transfer of $\mathrm{H}^{*}$ from a $\mu$-hydroxide to $2,4,6-{ }^{t} \mathrm{Bu}_{3} \mathrm{PhO}^{*} .413$ It was later shown that $\left(\left[\mathrm{Mn}^{\mathrm{IV}} \mathrm{Mn}^{\mathrm{III}}{ }_{2}(\mathrm{O})_{2}\right]^{3+}\right.$ can abstract $\mathrm{H}^{\bullet}$ from alkylaromatic hydrocarbons with weak $\mathrm{C}-\mathrm{H}$ bonds, consistent with the thermochemistry summarized in Figure 11.414 The more highly oxidized dimer, $\left[\mathrm{Mn}^{\mathrm{IV}}{ }_{2}(\mathrm{O})_{2}\right]^{4+}$, has a much higher $1 e^{-}$redox potential and oxidizes aromatic hydrocarbons either by ET or by hydride abstraction. $415 \mathrm{H}^{\bullet}$ abstraction by $\left[\mathrm{Mn}^{\mathrm{IV}}{ }_{2}(\mathrm{O})_{2}\right]^{4+}$ is not observed because the one-electron reduced product $\left[\mathrm{Mn}^{\mathrm{IV}} \mathrm{Mn}^{\mathrm{III}}{ }_{2}(\mathrm{O})_{2}\right]^{3+}$ is not basic, and therefore the thermodynamics are not favorable to form " $\left[\mathrm{Mn}_{2}(\mathrm{O})(\mathrm{OH})\right]^{4+"} .416$ More recently, a number of laboratories have shown that dimeric $\mathrm{Cu}^{\mathrm{III}}-\mu$-oxo complexes abstract $\mathrm{H}^{*}$ from $\mathrm{C}-\mathrm{H}$ and $\mathrm{O}-\mathrm{H}$ bonds, as has been reviewed and discussed elsewhere.417 Unfortunately, this system has not proven amenable to detailed thermodynamic measurements, despite considerable effort.417

5.10.2 Metal Complexes with $\mathbf{N}-\mathbf{H}$ Bonds-Metal-imido, -amide, and -amine complexes, $\mathrm{MNR}, \mathrm{MNR}_{2}$ and $\mathrm{MNR}_{3}$, are isoelectronic with metal-oxo, -hydroxo, and aquo species. These appear to undergo analogous PCET processes, although far fewer systems have been examined. The nitrogen derivatives have an additional substituent and are therefore more sterically encumbered than their oxygen relatives. Che, 418 Holland 419 and others have shown that metal-imido species can abstract $\mathrm{H}^{\bullet}$ from $\mathrm{C}-\mathrm{H}$ bonds, analogous to the oxo complexes above, but little thermochemical data are available. In principle, oxidizing metal amide complexes $\mathrm{MNR}_{2}$ could be good $\mathrm{H}^{\bullet}$ acceptors due to the basicity of the amide ligand. For instance, De Santis and co-workers have reported $E^{\circ}$ and $\mathrm{p} K_{\mathrm{a}}$ data for $\mathrm{Ni}^{\mathrm{II}}$ (cyclam) which indicate $\mathrm{BDFE}=89.1 \mathrm{kcal} \mathrm{mol}^{-1}$ to give the $\mathrm{Ni} \mathrm{iII}^{\mathrm{II}}$ with a deprotonated cyclam ligand.420 However, the amide ligand itself is often susceptible to oxidation, losing hydrogen from the $\alpha$-carbon to form imines or nitriles. 421 Che has used the oxidationprotected 2,3-diamino-2,3-dimethylbutane ligand $\left(\mathrm{H}_{2} \mathrm{NCMe}_{2} \mathrm{CMe}_{2} \mathrm{NH}_{2}\right)$ to prepare oxidizing $\mathrm{Ru}^{\mathrm{IV}}$ amides (and reported their Pourbaix diagrams). 422 
Anilido ligands, $\mathrm{NHAr}^{-}$, can not be oxidized by loss of $\alpha$-hydrogens (but they can be susceptible to nucleophilic attack in oxidizing compounds423). The $\mathrm{Os}^{\mathrm{IV}}$ anilido complex $\mathrm{TpOs}(\mathrm{NHPh}) \mathrm{Cl}_{2}\left(\mathrm{Tp}=\right.$ hydrotris $\left(1\right.$-pyrazolyl)borate, $\left.\mathrm{HBpz}_{3}\right)$ converts to the $\mathrm{Os}^{\mathrm{III}}$-aniline derivative $\mathrm{TpOs}\left(\mathrm{NH}_{2} \mathrm{Ph}\right) \mathrm{Cl}_{2}$ on addition of one electron and one proton.424 In the thermochemical square scheme in $\mathrm{MeCN}$, there is a remarkably large shift of the $\mathrm{p} K_{\mathrm{a}}$ of the aniline ligand from -3 when bound to $\mathrm{Os}^{\mathrm{IV}}$ to 22.5 on $\mathrm{Os}^{\mathrm{III}}$. The redox potential shifts from strongly oxidizing for the protonated forms, $E_{1 / 2}\left(\mathrm{TpOs}\left(\mathrm{NH}_{2} \mathrm{Ph}_{\mathrm{Cl}} \mathrm{Cl}_{2}{ }^{+/ 0}\right)=+0.48 \mathrm{~V} v\right.$ s. $\mathrm{Cp}_{2} \mathrm{Fe}^{+/ 0}$, to quite reducing for the anilide, $E\left(\mathrm{TpOs}(\mathrm{NHPh}) \mathrm{Cl}_{2}{ }^{0 /-}\right)=-1.05 \mathrm{~V}$. The $1.53 \mathrm{shift}$ in potential is, in free energy terms, exactly the same as 25 unit shift in $\mathrm{p} K_{\mathrm{a}}$, as it has to be by Hess' Law since these are all part of the same square scheme (Scheme 12). This large shift is reminiscent of the $\left[c i s-(\mathrm{bpy})_{2}(\mathrm{py}) \mathrm{Ru}^{\mathrm{IV}} \mathrm{O}\right]^{2+}$ system (Figure 10) and probably has the same origin, that the oxidized form has a metal-ligand $\pi$ bond that is disrupted upon reduction. In the osmium system, the rate constants for degenerate ET, PT, and HAT selfexchange were all obtained. 424

There are a number of metal-imidazole and related PCET systems where protonation/ deprotonation occurs at the nitrogen not bound to the redox-active metal center. In such systems there is a formal separation between the redox and the acid/base sites (see also Section 6): there are 3 chemical bonds and $\sim 4$ A separation between the metal center and the acidic/basic nitrogen (Figure 12). Even with this separation the redox and acid/base chemistry is still coupled. In general, protonation/deprotonation of metal-imidazole complexes results in a change of 0.3 to $0.5 \mathrm{~V}$ in reduction potential (Table 21 and reference 425). Even though this 'thermochemical communication' is substantially less than in compounds where the proton is bound to an atom directly bonded to the metal, as discussed above, imidazole complexes are still able to mediate concerted H-transfer reactions.

Of these systems perhaps the most well explored are the iron(II)tris(2-2'-biimidazoline $)^{2+}$ ( $\mathrm{Fe}^{\mathrm{II}} \mathrm{H}_{2}$ bip) and iron(II)tris(2,2'-(tetrahydro)pyrimidine) ${ }^{2+}\left(\mathrm{Fe}^{\mathrm{II}} \mathrm{H}_{2}\right.$ bip). $84,426^{-} 427428$ The $\mathrm{Fe}^{\mathrm{II}}\left(\mathrm{H}_{2}\right.$ bim $)$ and $\mathrm{Fe}^{\mathrm{II}}\left(\mathrm{H}_{2}\right.$ bip $)$ systems have similar acid/base properties in MeCN, with $\mathrm{p} K_{\mathrm{a}}=$ 17.5. The systems have slightly different redox potentials in $\mathrm{MeCN}, E_{1 / 2}\left(\mathrm{Fe}^{\mathrm{III} / \mathrm{II}}\left(\mathrm{H}_{2} \mathrm{bim}\right)\right)=$ $-0.31 \mathrm{~V} 84$ and $E_{1 / 2}\left(\mathrm{Fe}^{\mathrm{III} / \mathrm{II}}\left(\mathrm{H}_{2} \mathrm{bip}\right)\right)=-0.55 \mathrm{~V} 428$ (both $v s$. $\left.\mathrm{Fc}^{+/ 0}\right)$. Application of eq 7 gives $\mathrm{BDFE}\left(\mathrm{Fe}^{\mathrm{II}} \mathrm{H}_{2} \mathrm{bim}\right)=71.7 \mathrm{kcal} \mathrm{mol}^{-1}$ and $\mathrm{BDFE}\left(\mathrm{Fe}^{\mathrm{II}} \mathrm{H}_{2} \mathrm{bip}\right)=66.2 \mathrm{kcal} \mathrm{mol}^{-1}$. The $\mathrm{Fe}^{\mathrm{II}} \mathrm{H}_{2}$ bip and $\mathrm{Fe}^{\mathrm{III}} \mathrm{H}_{2}$ bip compounds are both mixtures of high-spin and low-spin forms at ambient temperatures in $\mathrm{MeCN}$, which indirectly affects their hydrogen atom self-exchange rate. 427 The related cobalt- $\mathrm{H}_{2}$ bim complexes have similar thermochemistry, with a BDFE of $70.5 \mathrm{kcal} \mathrm{mol}^{-1} .429 \mathrm{In}$ this system, $\mathrm{Co}^{\mathrm{II}} \mathrm{H}_{2}$ bim is high spin while $\mathrm{Co}^{\mathrm{II}} \mathrm{H}_{2}$ bim is low spin, and HAT reactions that interconvert these two are very slow.428,429 These iron and cobalt $\mathrm{H}_{2}$ bim and $\mathrm{H}_{2}$ bip systems all have large ground-state entropy changes $\left(\Delta S^{\circ}\right)$ associated with their $1 e^{-} / 1 \mathrm{H}^{+}$redox couples, so the initial analyses of these systems using BDEs has been revised.39, 40

Related ruthenium systems have been developed using a bidentate 2-(2'-pyridyl)-imidazole ligand (py-imH) and with either acac (2,4-pentanedionato) or 1,1,1,5,5,5-hexafluoro-acac (hfacac) as supporting ligands.430 In both sets of compounds, deprotonation of the imidazole reduces the redox potential by $0.36 \mathrm{~V}$ (and, equivalently, oxidation from $\mathrm{Ru}^{\mathrm{II}}$ to $\mathrm{Ru}^{\mathrm{III}}$ makes the imidazole proton more acidic by $6.1 \mathrm{p} K_{\mathrm{a}}$ units). The BDFEs in (acac) ${ }_{2} \mathrm{Ru}^{\mathrm{II}}(\mathrm{py}-\mathrm{imH})$ and in $\mathrm{TpOs}^{\mathrm{III}}\left(\mathrm{NH}_{2} \mathrm{Ph}\right) \mathrm{Cl}_{2}, 62.1$ and $61.5 \mathrm{kcal} \mathrm{mol}^{-1}$ respectively, are unusually low for $\mathrm{N}-\mathrm{H}$ bonds. HAT reactions of $(\mathrm{acac})_{2} \mathrm{Ru}^{\mathrm{II}}(\mathrm{py}-\mathrm{imH})$ show large $\mathrm{H} / \mathrm{D}$ kinetic isotope effects and involve substantial hydrogen tunneling.75

Replacing acac with hfacac increases the BDFE by a remarkable $17.6 \mathrm{kcal} \mathrm{mol}^{-1} .430$ This is principally the result of differences in the reduction potentials; the $\mathrm{p} K_{\mathrm{a}}$ of the imidazole ligand is not strongly affected. This illustrates that the effect off ligands and substituents on 
BDFEs is not always straightforward. Electron-withdrawing groups, for instance, will make a complex more oxidizing but also more acidic, and these two effects are in opposite directions in terms of the BDFE. This is perhaps most clearly illustrated for substituted toluenes, where substituents strongly affect $E^{\circ}$ and $\mathrm{p} K_{\mathrm{a}}$ values, but the benzylic $\mathrm{C}-\mathrm{H}$ bond strengths are much more constant.346 In phenols, however, electron donating substituents lower the redox potential more than they raise the $\mathrm{p} K_{\mathrm{a}}$, and therefore these substituents lower the BDFE (Table 4). This is probably because the "hole" created upon oxidation of phenols resides mostly on the aromatic ring, rather than on the phenolic oxygen. Similarly, replacing $-\mathrm{CH}_{3}$ for $-\mathrm{CF}_{3}$ in the acac ligands of $(\mathrm{acac})_{2} \mathrm{Ru}$ (I) $(\mathrm{py}-\mathrm{imH})$ has a much larger effect on the ruthenium center than the distant imidazole ligand.430

The PCET chemistry of metal-imidazole compounds has been extended to models for biologically important bis(histidine) ligated hemes. Starting from initial studies of Quinn, Nappa, and Valentine on meso-tetraphenylporphyrin-iron complexes with 4methylimidazole, (TPP) $\mathrm{Fe}^{\mathrm{III}}(\mathrm{MeImH})_{2}{ }^{+}, 431$ we have generated all of the compounds in the $\mathrm{Fe}^{\mathrm{II} / \mathrm{III}}$ imidazole/imidazolate square scheme. 181 The thermochemistry and concerted $\mathrm{H}$ transfer reactivity is similar to the $\mathrm{Fe}^{\mathrm{II}} \mathrm{H}_{2}$ bip, $\mathrm{Fe}^{\mathrm{II}} \mathrm{H}_{2}$ bim and (acac) ${ }_{2} \mathrm{Ru}{ }^{\mathrm{II}}$ py-imH systems discussed above.

5.10.3 Separating the Redox and Protonation Sites-In the metal-oxo systems above, the oxo group that accepts the proton is only one bond away from the metal center that formally accepts the proton. In the imidazole compounds, the two sites are three bonds and $c a .4 \AA$ removed. It is interesting to ask how far the two sites can be separated in a PCET reagent. From one perspective this is related to the issues raised in the discussion of PCET by separate proton and electron donors in Section 5.9 above. These concerns are probably very relevant to biological PCET, where proton acceptors may be able to be placed somewhat distant from redox cofactors.

Ruthenium systems developed by Manner et al., shown in Scheme 14, are perhaps the clearest examples of a proton-electron accepting reagent with a long and fixed separation between the redox and acid/base sites. The complex with a trpy-carboxylate ligand, $\mathrm{Ru}^{\mathrm{III}} \mathrm{COO}$, has a $6.9 \AA$ separation between the ruthenium and the carboxylate oxygen atoms, 27 and in the trpy-benzoate analog $\mathrm{Ru}^{\mathrm{III}} \mathrm{PhCOO}$ the distance is $c a$. $11 \AA$ (trpy $=2,2^{\prime} ; 6^{\prime}, 2^{\prime \prime}$ terpyridine). 432 As this distance gets larger, there is less 'communication' between the redox and acid/base sites, as indicated by the thermochemical measurements. For $\mathrm{Ru}^{\mathrm{III}} \mathrm{CO}_{2} \mathrm{H}$ the redox potential decreases by only $0.13 \mathrm{~V}$ upon deprotonation and for $\mathrm{RuPhCO}_{2} \mathrm{H}$ the changes is only $0.02 \mathrm{~V}$ and the $\mathrm{p} K_{\mathrm{a}}$ of the carboxylate is almost the same as that for benzoic acid in MeCN. However, even though the two sites behave essentially independently, $\mathrm{Ru}^{\mathrm{III}} \mathrm{PhCOO}$ is still able to undergo concerted $\mathrm{H}^{\bullet}$ transfer from TEMPOH (see below).

5.10.4 Selected Metal Hydrides-Metal hydride complexes can transfer $e^{-}, \mathrm{H}^{+}, \mathrm{H}^{\bullet}$, or $\mathrm{H}^{-}$to substrates, and therefore they can be considered to be PCET reagents. Metal hydrides are key intermediates in various homogeneous catalytic processes involved in the production of petrochemicals to fine chemicals as well as laboratory-scale reactions. Their thermochemistry has been investigated by a number of groups, especially by Parker, Tilset, 43 Norton,433 Bullock,434 DuBois,5,435 and Hoff.436 The cited references provide excellent reviews of these data; in Table 21 we include only a few examples that illustrate some general features of metal hydride systems. In general, metal hydrides have $\mathrm{M}-\mathrm{H}$ bond strengths that are somewhat weaker than the $\mathrm{X}-\mathrm{H}$ bond strengths summarized above.

Furthermore, $\mathrm{H}^{+}$and $e^{-}$transfers of many metal hydrides are highly coupled, meaning that there is a large change in $\mathrm{p} K_{\mathrm{a}}$ with reduction/oxidation of the metal, and that the redox potential drops dramatically upon deprotonation. For example, the oxidation/reduction of 
$\mathrm{CpCr}(\mathrm{CO})_{3} \mathrm{H}$ changes the $\mathrm{p} K_{\mathrm{a}}$ by more than 20 orders of magnitude. These very large changes in acidity with redox state are reminiscent of the chemistry of $\mathrm{C}-\mathrm{H}$ bonds, above.

\section{Mechanistic Implications}

The thermochemistry of individual PCET reagents provides a foundation for understanding cross reactions between two potential PCET reagents. The following sections address how the individual $E^{\circ}, \mathrm{p} K_{\mathrm{a}}$, and BDFE values are informative about the mechanism of a reaction, whether it occurs by PT, ET, HAT, or otherwise (e.g., hydride transfer). The discussion above indicated that, in general, reagents that exhibit a large change in $\mathrm{p} K_{\mathrm{a}}$ upon redox change (equivalently, a large change in $E^{\circ}$ upon protonation state change) preferentially undergo concerted rather than stepwise transfer of $\mathrm{H}^{+}$and $e^{-}$. In two examples emphasized above, TEMPOH and toluene, the $\mathrm{p} K_{\mathrm{a}}$ values in MeCN change more than 40 orders of magnitude upon oxidation/reduction and these reagents in most cases react by HAT.

The following sections outline situations where concerted $\mathrm{H}^{\bullet}$ transfer or stepwise $\mathrm{H}^{+} / e^{-}$ transfers are more likely based on thermochemical arguments. One example is also discussed in which thermochemical arguments do not give a clear indication of mechanism. We emphasize here that it is best to use of solution bond dissociation free energies to understand solution hydrogen atom transfer reactions, despite the century-old use of gasphase bond enthalpies for this purpose. For all-organic PCET reactions this is usually a minor concern, as the entropic change is usually small, however this is not the case for some metal mediated PCET reactions.39,40

\subsection{Using Thermochemical Data to Understand PCET Mechanisms}

In any net one-electron/one-proton transfer reaction, there are three simple mechanisms, as shown in Scheme 1 at the start of this review: proton transfer (PT) followed by electron transfer (ET), ET followed by PT, and concerted transfer of the two particles (CPET or HAT). The thermochemical data in the Tables above can be used to calculate the ground state free energy changes, $\Delta G^{\circ}$, for each of these mechanisms, following eqs 26-28. The activation energies $\Delta G^{\ddagger}$ must be at least as high as these free energy changes, so the $\Delta G^{\circ}$ values are a conservative lower limit to $\Delta G^{\ddagger}$. It should be noted that electron transfer theories use a slightly different free energy barrier, $\Delta G^{*}$, because a different pre-exponential factor is used.442 Since this prefactor is smaller than the Eyring $k \mathrm{~T} / h$, the ET $\Delta G^{*}$ is always higher than the Eyring $\Delta G^{\ddagger}$, and $\Delta G^{\circ}$ is still a good conservative lower limit.

For $\mathrm{X}-\mathrm{H}+\mathrm{Y}$,

$$
\Delta G^{\circ}(\mathrm{PT})=-\mathrm{RT} \ln \left(K_{\mathrm{eq}}\right)=-\left(1.37 \mathrm{kcal} \mathrm{mol}^{-1}\right)\left[\mathrm{p} K_{\mathrm{a}}\left(\mathrm{YH}^{+}\right)-\mathrm{p} K_{\mathrm{a}}(\mathrm{XH})\right]
$$

$\Delta G^{\circ}(\mathrm{ET})=-F E^{\circ}=-\left(23.06 \mathrm{kcal} \mathrm{mol}^{-1} \mathrm{~V}^{-1}\right)\left[E^{\circ}\left(\mathrm{XH}^{+/ 0}\right)-E^{\circ}\left(\mathrm{Y}^{0 /-}\right)\right]$

$$
\left.\Delta G^{\circ}(\mathrm{CPET})=\mathrm{BDFE}(\mathrm{X}-\mathrm{H})-\operatorname{BDFE}(\mathrm{Y}-\mathrm{H})\right]
$$

The reaction of $\mathrm{Fe}^{\mathrm{II}} \mathrm{H}_{2} \mathrm{bim}^{2+}+$ TEMPO will serve to illustrate this approach (Figure 13). The analysis uses the thermochemical data in MeCN for TEMPOH (Table 3) and $\mathrm{Fe}^{\mathrm{II}} \mathrm{H}_{2}$ bim (Table 21). Initial PT from $\mathrm{Fe}^{\mathrm{II}} \mathrm{H}_{2}$ bim $^{2+}$ to TEMPO to yield $\mathrm{Fe}^{\mathrm{II}} \mathrm{Hbim}^{+}+\mathrm{TEMPOH}^{\bullet+}$ has $\Delta G^{\circ}=+41 \mathrm{kcal} \mathrm{mol}^{-1}$ from the relevant $\mathrm{p} K_{\mathrm{a}}$ values. Similarly, $\Delta G^{\circ}$ for initial ET to give $\mathrm{Fe}^{\mathrm{III}} \mathrm{H}_{2} \mathrm{bim}^{3+}+\mathrm{TEMPO}^{-}$, from the redox potentials, is $+52 \mathrm{kcal} \mathrm{mol}^{-1}$. The observed 
Eyring barrier $\left(\Delta G^{\ddagger}\right)$ is much lower, only $17.7 \mathrm{kcal} \mathrm{mol}^{-1}$, so the reaction cannot be going through either of the stepwise pathways. Thus, the reaction of $\mathrm{Fe}^{\mathrm{II}} \mathrm{H}_{2} \mathrm{bim}+\mathrm{TEMPO}$ most likely proceeds via concerted proton-electron transfer (CPET). This same treatment can be applied to any $\mathrm{H}$-transfer reaction, provided the relevant reduction potentials and $\mathrm{p} K_{\mathrm{a}} \mathrm{s}$ are known.

It should be noted that Figure 13 is a simplification of the actual multi-dimensional free energy surface for a PCET reaction. The stepwise intermediates are in different regions of the multi-dimensional space, particularly when the solvent coordinates are included. This has been discussed by Hammes-Schiffer443 and Truhlar444 and is mentioned in other contributions to this special issue.

Many studies have used this thermochemical approach to show that the transfer of an electron and a proton must occur in the same kinetic step. This section is meant to be illustrative, not comprehensive. A particularly elegant example is the comproportionation of related ruthenium oxo and -aquo complexes to make the hydroxo derivative (eq 29), which has an H/D kinetic isotope effect of 16.1.7,18,445 The aquo complex has an aqueous $\mathrm{p} K_{\mathrm{a}}$ of 10.3 and the oxo species is not protonated even in strong acid (Figure 10 above), so initial proton transfer is to endoergic to account for the observed rate. In this case, the large kinetic isotope effect and its linear dependence on the mole fraction of deuterium provide strong additional evidence against a mechanism of initial electron transfer and for a CPET pathway. The pseudo-self exchange reaction between the aquo complex and a related hydroxo complex (eq 30) proceeds by a similar mechanism, except at high $\mathrm{pH}$ when the aquo complex is deprotonated and the reaction becomes a pure electron transfer.

$$
\left[\mathrm{Ru}(\mathrm{bpy})_{2}(\mathrm{py})\left(\mathrm{OH}_{2}\right)\right]^{2+}+\left[\mathrm{Ru}(\mathrm{bpy})_{2}(\mathrm{py})(\mathrm{O})\right]^{2+} \rightarrow 2\left[\mathrm{Ru}(\mathrm{bpy})_{2}(\mathrm{py})(\mathrm{OH})\right]^{2+}+
$$

$$
\left[\mathrm{Ru}(\mathrm{bpy})_{2}(\mathrm{py})\left(\mathrm{OH}_{2}\right)\right]^{2+}+[\mathrm{Ru}(\mathrm{tpy})(\mathrm{bpy})(\mathrm{OH})]^{2+} \rightarrow\left[\mathrm{Ru}(\mathrm{bpy})_{2}(\mathrm{py})(\mathrm{OH})\right]^{2+}+\left[\mathrm{Ru}(\mathrm{typ})(\mathrm{bpy})\left(\mathrm{OH}_{2}\right)\right]^{2+}
$$

Reducing PCET reactions to the three mechanistic alternatives of Figure 13, eqs 26-28 and Scheme 1 is also a simplification. First of all, many PCET reagents form hydrogen bonds to solvent, and Ingold and co-workers have shown that for reagents such as phenols, this hydrogen bond must be broken prior to HAT.11,12 Second, the reaction of two PCET reagents likely involves precursor and successor complexes, by analogy to electron transfer theory, whether the reaction proceeds by ET, PT, or HAT/CPET. Such complexes may have hydrogen bonds and be energetically significant.446 In addition, one can envision a stepwise path of initial ET, for instance, which forms a successor complex that undergoes PT prior to dissociation to the products. The energetics of this situation are more complicated to analyze than eqs 26-28 above, as described in reference 447 . Finally, PCET reactions can be mechanistically more complex, for instance being catalyzed by trace acid or base, or trace oxidant or reductant, as in the mechanism shown in eq 31.424 Thermochemical analysis of a reaction such as eq 31 requires the $\mathrm{p} K_{\mathrm{a}}$ of the catalytic acid, as well as the properties of the $\mathrm{HY}$ and HX systems.

$$
\mathrm{Y}+\mathrm{XH} \stackrel{\mathrm{H}^{+}}{\longrightarrow} \mathrm{YH}^{+}+\mathrm{XH} \stackrel{\mathrm{ET}}{\longrightarrow} \mathrm{YH}+\mathrm{XH}^{+} \stackrel{\mathrm{H}^{+}}{\longrightarrow} \mathrm{YH}+\mathrm{X}
$$




\subsection{Characteristics and Examples of Concerted vs. Stepwise Pathways}

In general, the concerted mechanism is favored when one or both of the reagents have strong 'thermodynamic coupling' between the proton and the electron, as indicated by large changes in $\mathrm{p} K_{\mathrm{a}}$ upon oxidation/reduction and large changes in $E^{\circ}$ upon protonation/ deprotonation. In the $\mathrm{Fe}^{\mathrm{II}} \mathrm{H}_{2}$ bim $^{2+}+$ TEMPO case analyzed in Figure 13, in the rutheniumoxo system in eq 29, and in the TEMPOH/TEMPO self-exchange reaction analyzed in Scheme 7, both reagents have large $\Delta \mathrm{p} K_{\mathrm{a}}$ and $\Delta E^{\circ}$ values. It is not necessary, however, for both reagents to have this property. For instance, TEMPOH transfers $\mathrm{H}^{\bullet}$ in a concerted fashion to the ruthenium carboxylate complexes in Scheme 14, even though the Ru complexes have very little thermodynamic 'communication.' The very strong preference for CPET by TEMPOH is sufficient to make the PT-ET and ET-PT paths very high in energy. 27,432

On the other hand, stepwise mechanisms for net PCET occur when there is a good match between the $\mathrm{p} K_{\mathrm{a}} \mathrm{s}$ of $\mathrm{HX}$ and $\mathrm{HY}^{+}$, or between the $E^{\circ}$ 's of $\mathrm{HX}^{+/ 0}$ and $\mathrm{Y}^{0 /-}$. If the two $\mathrm{p} K_{\mathrm{a}} \mathrm{s}$ are similar, then initial proton transfer will be accessible. A particularly clear example of this comes from Ingold's studies of acidic phenols + the DPPH radical (DPPH $=2,2$ diphenyl-1-picryhydrazyl radical).11,12 In MeCN, DMSO and THF there is a $\mathrm{p} K_{\mathrm{a}}$ mismatch and proton transfer is thermodynamically unfavorable, so a CPET mechanism is operative. In alcohol solvents, however, the mismatch is much smaller and the reaction proceeds by initial $\mathrm{H}^{+}$transfer. These thermodynamic effects are compounded in this case by the unusual kinetic facility of proton transfer in hydroxylic solvents. As this example illustrates, solvent can alter the $E^{\circ} / \mathrm{p} K_{\mathrm{a}}$ properties of a compound, so that there is no one set of mechanistic "rules" for a given PCET reagent.

Eberson has described a particularly clear example of a stepwise ET/PT mechanism, in the oxidation of aromatic hydrocarbons by polyoxometallates containing $\mathrm{Co}^{\mathrm{III}}$ ions such as $\mathrm{Co}^{\mathrm{III}} \mathrm{W}_{12} \mathrm{O}_{40}{ }^{5-} 448$ (Jönsson has extended these studies to $\mathrm{Ni}^{\mathrm{IV}}$ and $\mathrm{Mn}^{\mathrm{IV}}$ containing oxidants.449) Although these reactions show primary H/D kinetic isotope effects, consistent with CPET, they actually occur via fast, pre-equilibrium electron transfer, followed by rate limiting proton transfer (the origin of the isotope effect). The hallmark of this mechanism is that the reactions are inhibited by addition of the reduced $\mathrm{Co}^{\mathrm{II}}$ species, which shifts the preequilibrium toward the reactants.448b This is an excellent example of the limits of thermochemical analyses, as this ET-PT mechanism would have been eliminated without the careful kinetics studies, and without considering the unusual stabilization of the ET successor complex by the strong attraction between the aromatic cation radical and the polyanionic polyoxometallate.

In biology, perhaps the clearest example of a stepwise PCET reaction is the $2 \mathrm{H}^{+} / 2 e^{-}$ reduction of the quinone $\mathrm{Q}$ at the end of the ET cascade in the reaction centers of photosynthetic bacteria.450 The first electron transfer $\left(\mathrm{Q}+e^{-} \rightarrow \mathrm{Q}^{--}\right)$occurs via conformational gating, as indicated by the absence of a driving force dependence for this step.451 The second reducing equivalent is added in a PCET process, $\mathrm{Q}^{--}+\mathrm{H}^{+}+e^{-} \rightarrow$ $\mathrm{QH}^{-}$, which was indicated to occur by fast, pre-equilibrium proton transfer, followed by rate limiting electron transfer, PT-ET.450a The cycle is completed by the addition of one proton, not coupled to electron transfer $\left(\mathrm{QH}^{-}+\mathrm{H}^{+} \rightarrow \mathrm{QH}_{2}\right)$.

Finally, this section would be remiss without mentioning electrochemical PCET processes, which have been examined in detail by Savéant, Costentin, Robert, Finklea, Evans, and others.3,9,15,142,154b,452 Often, the electrochemical reactions of organic molecules proceed by electrochemical-chemical (EC) mechanisms, akin to a ET-PT mechanism (and often by more complex paths such as ECE etc.). However, some electrochemical processes 
have recently been shown to occur by concerted transfer of $e^{-}$and $\mathrm{H}^{+}$, as summarized in an excellent recent review in this journal.3

\section{Conclusions}

The primary goals of this review are (1) to assemble thermochemical data - reduction potentials, $\mathrm{p} K_{\mathrm{a}}$ values, and bond dissociation free energies and enthalpies - from disparate sources, and (2) to illustrate the utility of these data in understanding proton-coupled redox chemistry. We hope to have illustrated the value and power of thermochemical cycles ("square schemes"), and made them accessible to readers. For example, the square schemes for tyrosine and tryptophan indicate why biochemical oxidations of tyrosine residues form tyrosyl radicals directly, while those of tryptophan residues typically proceed via indole radical cations. The square schemes are particularly valuable in analyzing mechanistic pathways for H-transfers. A detailed knowledge of all of the microscopic steps (ET, PT and $\mathrm{H}^{\bullet}$ transfer) is a key part of understanding a PCET process. We hope that this review will have value for workers developing and understanding proton-coupled redox phenomena. This area has grown tremendously in scope and depth in the past 25 years, and there is still much to be learned about PCET in chemistry and biology, and much to be done utilizing PCET processes in chemical synthesis and chemical energy transduction.

\section{Acknowledgments}

We are grateful to the many coworkers and colleagues who have measured values and contributed in other ways to the field of PCET. In particular, Dr. Christopher R. Waidmann undertook studies of separated CPET reagents with support from the National Science Foundation funded Center for Enabling New Technologies through Catalysis and Prof. David Stanbury provided valuable comments on the manuscript, as did Ms. Sophia Tran, Dr. Adam Tenderholt, Dr. Mauricio Cattaneo, Dr. Lisa S. Park-Gehrke, and Dr. Michael P. Lanci. Prof. Andreja Bakac directed us to an important value. We gratefully acknowledge the financial support of the U.S. National Institutes of Health (grant GM50422 supporting J.J.W. and (in part) J.M.M.) and the Center for Molecular Electrocatalysis, an Energy Frontier Research Center funded by the U.S. Department of Energy, Office of Science, Office of Basic Energy Sciences (supporting T.A.T. and (in part) J.M.M.) and the U.S. National Science Foundation Center for Enabling New Technologies through Catalysis (in part supporting J.M.M.).

\section{References}

1. (a) Huynh MHV, Meyer TJ. Chem. Rev. 2007; 107:5004. [PubMed: 17999556] (b) Meyer TJ, Huynh MHV. Inorg. Chem. 2003; 42:8140. [PubMed: 14658865]

2. Hynes, JT.; Klinman, JP.; Limback, H-H.; Schowen, RL., editors. Hydrogen-Transfer Reactions. Weinheim: Wiley-VCH; 2007.

3. Costentin C. Chem. Rev. 2008; 108:2145. [PubMed: 18620365]

4. Stock, JS.; Orna, MV., editors. Electrochemistry, past and present. Washington, DC: American Chemical Society; 1989. ACS Symposium Series 390

5. Cf., Appel AM, Lee S-J, Franz JA, DuBois DL, DuBois MR. J. Am. Chem. Soc. 2009; 131:5224. [PubMed: 19309157]

6. Cf., (a) Young ER, Rosenthal J, Hodgkiss JM, Nocera DG. J. Am. Chem. Soc. 2009; 131:7678. [PubMed: 19489645] (b) Cukier RI, Nocera DG. Annu. Rev. Phys. Chem. 1998; 49:337. [PubMed: 9933908]

7. Binstead RA, Moyer BA, Samuels GJ, Meyer TJ. J. Am. Chem. Soc. 1981; 103:2897.

8. SciFinder search for the term "proton-coupled electron transfer" performed Jan. 4, 2010.

9. Costentin C, Evans DH, Robert M, Savéant J-M, Singh PS. J. Am. Chem. Soc. 2005; 127:12490. [PubMed: 16144387]

10. Sjödin M, Styring S, Åkermark B, Sun L, Hammarström L. J. Am. Chem. Soc. 2000; 122:3932.

11. Litwinienko G, Ingold KU. J. Org. Chem. 2003; 68:3433. [PubMed: 12713343]

12. Litwinienko G, Ingold KU. J. Org. Chem. 2004; 69:5888. [PubMed: 15373474]

13. Foti MC, Daquino C, Geraci C. J. Org. Chem. 2004; 69:2309. [PubMed: 15049623] 
14. (a) Sjödin M, Styring S, Wolpher H, Xu Y, Sun L, Hammarström L. J. Am. Chem. Soc. 2005; 127:3855. [PubMed: 15771521] (b) Irebo T, Reece SY, Sjödin M, Nocera DG, Hammarström L. J. Am. Chem. Soc. 2007; 129:15462. [PubMed: 18027937]

15. Savéant, J-M. Elements of Molecular and Biomolecular Electrochemistry. New Jersey: WileyInterscience; 2006. especially pp 96-102, 140-158, 182-250

16. (a) Kochi, JK., editor. Free Radicals. New York: Wiley; 1973. (b) Perkins, MJ. Free Radical Chemistry. New York: Ellis Horwood; 1994.

17. Cf. (a) Burton GW, Ingold KU. Acc. Chem. Res. 1986; 19:194. (b) Gutteridge JMC, Halliwell B. Trends Biochem. Sci. 1990; 15:129. [PubMed: 2187293]

18. Binstead RA, Meyer TJ. J. Am. Chem. Soc. 1987; 109:3287.

19. (a) Mayer JM, Hrovat DA, Thomas JL, Borden WT. J. Am. Chem. Soc. 2002; 124:11142. [PubMed: 12224962] (b) Lingwood M, Hammond JR, Hrovat DA, Mayer JM, Borden WT. J. Chem. Theory Comput. 2006; 2:740. [PubMed: 18725967]

20. Binstead RA, McGuire ME, Dovletoglou A, Seok WK, Roecker LE, Meyer TJ. J. Am. Chem. Soc. 1992; 114:173.

21. Tishchenko O, Truhlar DG, Ceulemans A, Nguyen MT. J. Am. Chem. Soc. 2008; 130:7000. [PubMed: 18465862]

22. Hammes-Schiffer S, Soudackov AV. J. Phys. Chem. B. 2008; 112:14108. [PubMed: 18842015]

23. Meunier B, de Visser SP, Shaik S. Chem. Rev. 2004; 104:3947. [PubMed: 15352783]

24. Waidmann CR, Zhou X, Tsai EA, Kaminski W, Hrovat DA, Borden WT, Mayer JM. J. Am. Chem. Soc. 2009; 131:4729. [PubMed: 19292442]

25. McEvoy JP, Brudvig GW. Chem. Rev. 2006; 106:4455. [PubMed: 17091926]

26. Tommos C, Babcock GT. Acc. Chem. Res. 1988; 31:18.

27. Manner VW, DiPasquale AG, Mayer JM. J. Am. Chem. Soc. 2008; 130:7210. [PubMed: 18479096]

28. Izutsu, K. Acid-Base Dissociation Constants in Dipolar Aprotic Solvents. Oxford U.K.: Blackwell Scientific; 1990. Chemical Data Series No. 35

29. Bordwell FG. Acc. Chem. Res. 1988; 21:456. (b) Many of Bordwell's p $K_{\mathrm{a}}$ measurements in DMSO have been collected on the web (including references): http://www.chem.wisc.edu/areas/reich/pkatable/

30. Kaljurand I, Kütt A, Sooväli L, Rodima T, Mäemets V, Leita, Koppel IA. J. Org. Chem. 2005; 70:1019. [PubMed: 15675863]

31. Bard, AJ.; Faulkner, LR. Electrochemical Methods: Fundamentals and Applications. 2nd Ed.. New Jersey: John Wiley and Sons; 2001. p. 178-180.

32. Gritzner G, Kuta J. (IUPAC Commission on Electrochemistry) Pure Appl. Chem. 1984; 56:461.

33. Pavlishchuk VV, Addison AW. Inorg. Chim. Acta. 2000; 298:97.

34. Reference 31, see inside back cover for electrochemical references. See also: Sawyer, DT.; Sobkowiak, A.; Roberts, JL, Jr.. Electrochemistry for Chemists. 2nd ed.. New York: John Wiley and Sons; 1995.

35. Kolthoff IM, Chantooni MK Jr. J. Phys. Chem. 1972; 76:2024.

36. References 16a, b and (a) Lowry, TH.; Richardson, KS. Mechanism and Theory in Organic Chemistry. 3rd ed.. New York: Harper and Row; 1987. (b) Shaik, SS.; Schlegel, HB.; Wolfe, S. Theoretical Aspects of Physical Organic Chemistry: The $S_{\mathrm{N}} 2$ Mechanism. New York: Wiley; 1992. p. 11-23.

37. Blanksby SJ, Ellison GB. Acc. Chem. Res. 2003; 36:255. [PubMed: 12693923]

38. Mader EA, Larsen AS, Mayer JM. J. Am. Chem. Soc. 2004; 126:8066. [PubMed: 15225018]

39. Mader EA, Davidson ER, Mayer JM. J. Am. Chem. Soc. 2007; 129:5153. [PubMed: 17402735]

40. Mader EA, Manner VW, Markle TF, Wu A, Franz JA, Mayer JM. J. Am. Chem. Soc. 2009; 131:4335. [PubMed: 19275235]

41. Bordwell FG, Cheng J-P, Harrelson JA Jr. J. Am. Chem. Soc. 1988; 110:1229.

42. Wayner DM, Parker VD. Acc. Chem. Res. 1993; 26:287. 
43. Tilset, M. Electron Transfer in Chemistry. Balzani, V., editor. Weinheim: Wiley-VCH; 2001. p. 677-713.

44. (a) Tilset M, Parker VD. J. Am. Chem. Soc. 1989; 111:6711. and 1990, 112, 2843. (b) Parker VD, Handoo KL, Roness F, Tilset M. J. Am. Chem. Soc. 1991; 113:7493.

45. (a) Wang D, Angelici RJ. J. Am. Chem. Soc. 1996; 118:935. (b) Eisenberg DC, Norton JR. Isr. J. Chem. 1991; 31:55. (c) References 39, 42, and 51. (d) Kiss G, Zhang K, Mukerjee SL, Hoff CD, Roper GC. J. Am. Chem. Soc. 1990; 112:5657. (e) McDonough JE, Weir JJ, Carlson MJ, Hoff CD, Kryatova OP, Rybak-Akimova EV, Clough CR, Cummins CC. Inorg. Chem. 2005; 44:3127. [PubMed: 15847418]

46. (a) Breslow R, Balasubramanian K. J. Am. Chem. Soc. 1969; 91:5182. (b) Breslow R, Chu W. J. Am. Chem. Soc. 1973; 95:411. (c) Jaun B, Schwarz J, Breslow R. J. Am. Chem. Soc. 1980; 102:5741.

47. Wiberg KB, Foster G. J. Am. Chem. Soc. 1961; 83:423. (the thermochemical cycle is on p. 425).

48. Parker VD. J. Am. Chem. Soc. 1992; 114:7458.

49. Afeefy, HY.; Liebman, JF.; Stein, SE. Neutral Thermochemical Data in NIST Chemistry WebBook, NIST Standard Reference Database Number 69, Eds. Linstrom, P. J., Mallard, W. G. Gaithersburg MD: National Institute of Standards and Technology; p. 20899http://webbook.nist.gov (retrieved May 21, 2009)

50. Roduner E. Radiat. Phys. Chem. 2005; 72:201.

51. Mader, EA. Ph.D. dissertation. Seattle, WA: University of Washington; 2007 December. Hydrogen Atom Transfer Reactions of Iron and Cobalt Tris Alpha-Diimines: A Study of Intrinsic and Thermodynamic Effects.

52. Brunner E. J. Chem. Eng. Data. 1985; 30:269.

53. Young, CL., editor. IUPAC Solubility Data Series. Vol. Vols. 5/6. New York: Permagon; 1981. 'Hydrogen and Deuterium'.

54. Wilhelm E, Battino R. Chem. Rev. 1973; 73:1.

55. The revised calculation of $C_{\mathrm{G}}$ and $C_{\mathrm{H}}$ in water is from reference 39 and its Supporting Information. Unfortunately, a subtraction error in the final line of the derivation leads to an erroneous value of $\Delta S^{\circ}$ solvation $\left(\mathrm{H}^{\bullet}\right)_{\mathrm{H}_{2} \mathrm{O}}$, as shown in reference 51 . The correct value for $\Delta S$ ${ }_{\text {solvation }}\left(\mathrm{H}^{\bullet}\right)_{\mathrm{H}_{2} \mathrm{O}}$ is $-33.35 \mathrm{cal} \mathrm{K}^{-1} \mathrm{~mol}^{-1}$.

56. Lucarini M, Pedrielli P, Pedulli GF, Cabiddu S, Fattuoni C. J. Am. Chem. Soc. 1996; 61:9259.

57. (a) Roberts RMG, Ostovic D, Kreevoy MM. Faraday Discuss. Chem. Soc. 1982; 74:257. (b) Lee ISH, Ostovic D, Kreevoy M. J. Am. Chem. Soc. 1988; 110:3989. and references therein.

58. Cf. Organic Chemistry. 5th ed.. Hill: McGraw-Hill; 2003. p. 170

59. Luo, Y-R. Comprehensive Handbook of Chemical Bond Energies. Boca Raton: CRC Press; 2007. (b) Portions of this book are available online: http://books.google.com

60. Ruscic B, Boggs JE, Burcat A, Csázszár AG, Demaison J, Martin JML, Morton ML, Rossi MJ, Stanton JF, Szalay PG, Westmoreland PR, Zabel F, Bérces T. J. Phys, Chem. Ref. Data. 2005; 34:573.

61. Burcat, A.; Ruscic, B. TAE Report No. 960; Technical Report. 2005. (ftp://ftp.technion.ac.il/pub/supported/aetdd/thermodynamics)

62. Mulder P, Korth H-G, Pratt DA, DiLabio GA, Valgimigli L, Pedulli GF, Ingold KU. J. Phys. Chem. A. 2005; 109:2647. [PubMed: 16833571]

63. Abraham MH, Grellier PL, Prior DV, Taft RW, Morris JJ, Taylor PJ, Laurence C, Berthelot M, Doherty RM, Kamlet MJ, Abboud J-LM, Sraidi K, Guihéneuf G. J. Am. Chem. Soc. 1988; 110:8534.

64. Abraham MH, Grellier PL, Prior DV, Duce PP, Morris JJ, Taylor PJ. J. Chem. Soc. Perkin Trans. 2. 1989; 1989:699.

65. Abraham MH, Grellier PL, Prior DV, Morris JJ, Taylor PJ. J. Chem. Soc. Perkin Trans. 2. 1990; 1990:521.

66. Warren JJ, Mayer JM. Proc. Natl. Acad. Sci. U. S. A. 2010; 107:5282. [PubMed: 20215463] 
67. Pourbaix, M. Atlas of Electrochemical Equilibria in Aqueous Solutions. 2nd English ed.. Houston, Texas: National Association of Corrosion Engineers; 1974. (b) According to the Preface of this volume, the first version of this atlas was Pourbaix's 1945 Ph.D thesis

68. Bozoglian F, Romain S, Ertem MZ, Todorova TK, Sens C, Mola J, Rodríguez M, Romero I, Benet-Buchholz J, Fontrodona X, Cramer CJ, Gagliardi L, Llobet A. J. Am. Chem. Soc. 2009; 131:15176. [PubMed: 19791789]

69. Bordwell FG, Cheng J-P, Ji G-Z, Satish AV, Zhang X. J. Am. Chem. Soc. 1991; 113:9790.

70. Tsang, W. "Heats of Formation of Organic Free Radicals by Kinetic Methods" Chapter 2. In: Martinho Simões, JA.; Greenberg, Arthur; Liebman, Joel F., editors. Energetics of Organic Free Radicals. New York: Chapman and Hall; 1996. p. 22-58.

71. McNaught, AD.; Wilkinson, A., compilers. IUPAC currently recommends the name 'aminoxyl radical' for compounds of the general form $\mathrm{R}_{2} \mathrm{~N}-\mathrm{O}^{\circ}$, although 'nitroxyl radical' and 'nitroxide' are more common: IUPAC. Compendium of Chemical Terminology, 2nd ed. (the "Gold Book"). Oxford: Blackwell Scientific Publications; 1997 [Accessed 20 October 2009]. http://goldbook.iupac.org

72. Rappoport, Z.; Liebman, JF., editors. The Chemistry of Hydroxylamines, Oximes and Hydroxamic Acids. Wiley: West Sussex; 2009. Parts 1 \& 2

73. Galli C. Nitroxyl radicals. In reference 72: pp 705-750.

74. Wu A, Mader EA, Datta A, Hrovat DA, Borden WT, Mayer JM. J. Am. Chem. Soc. 2009; 131:11985. and references therein. [PubMed: 19618933]

75. Wu A, Mayer JM. J. Am. Chem. Soc. 2008; 130:14745. [PubMed: 18841973]

76. Mahoney LR, Mendenhall GD, Ingold KU. J. Am. Chem. Soc. 1973; 95:8610.

77. Pratt DA, Blake JA, Mulder P, Walton JC, Korth H-G, Ingold KU. J. Am. Chem. Soc. 2004; 126:10667. [PubMed: 15327325]

78. Goldstein S, Merényi G, Russo A, Samuni A. J. Am. Chem. Soc. 2003; 125:789. [PubMed: 12526680]

79. Sheldon RA, Arends IWCE, Brink G-JT, Dijksman A. Acc. Chem. Res. 2002; 35:774. [PubMed: 12234207]

80. Maeda H, Wu H-Y, Yamauchi Y, Ohmori H. J. Org. Chem. 2005; 70:8338. [PubMed: 16209576]

81. Israeli A, Patt M, Oron M, Samuni A, Kohen R, Goldstein S. Free Radical Bio. Med. 2005; 38:317. [PubMed: 15629861]

82. Marx L, Schöllhorn B. New. J. Chem. 2006; 30:430.

83. Malievskii AD, Koroteev SV, Shapiro AB. Kinet. Catal. 2005; 46:859.

84. Roth JP, Lovell S, Mayer JM. J. Am. Chem. Soc. 2000; 122:5486.

85. Recupero F, Punta C. Chem. Rev. 2007; 107:3800. [PubMed: 17848093]

86. Sheldon RA, Arends IWCE. Adv. Synth. Catal. 2004; 346:1051.

87. Coseri S. Cataly. Rev. 2009; 51:218.

88. Koppel I, Koppel J, Leito J, Pihl V, Grehn L, Ragnarsson U. J. Chem. Res.-S. 1993; 11:3008.

89. Kütt A, Leito I, Kaljurand I, Sooväli L, Vlasov VM, Yagupolskii LM, Koppel IA. J. Org. Chem. 2006; 71:2829. [PubMed: 16555839]

90. Kishioka S, Yamada A. J. Electroanal. Chem. 2005; 578:71.

91. Gorgy K, Lepretre J-C, Saint-Aman E, Einhorn C, Einhorn J, Marcadal C, Pierre J-L. Electrochim. Acta. 1998; 44:385.

92. Masui M. Stud. Org. Chem. 1987; 30:137.

93. Kishioka S, Yamada A. Electrochim. Acta. 2006; 51:4582.

94. Amorati R, Lucarini M, Mugnaini V, Pedulli GF, Minisci F, Recupero F, Fontana F, Astofli P, Greci L. J. Org. Chem. 2003; 68:1747. [PubMed: 12608787]

95. Annunziatini C, Gerini MF, Lanzalunga O, Lucarini M. J. Org. Chem. 2004; 69:3431. [PubMed: 15132553]

96. Lind J, Merényi G. J. Phys. Chem. A. 2006; 110:192. [PubMed: 16392855]

97. Bonner FT, Wang N-Y. Inorg. Chem. 1986; 25:1858.

Chem Rev. Author manuscript; available in PMC 2011 December 8. 
98. The closest available analogy is the $\mathrm{p} K_{\mathrm{a}}$ for diethylhydroxylamine.99 As expected, this $\mathrm{p} K_{\mathrm{a}}$ is slightly less than the $\mathrm{p} K_{\mathrm{a}}$ of hydroxylamine $\left(\mathrm{H}_{2} \mathrm{NOH}, \mathrm{p} K_{\mathrm{a}}=13.7\right) .97$

99. Colthurst MJ, Kanagoasooriam AJSS, Wong MSO, Contini C, Williams A. Can. J. Chem. 1998; 76:678.

100. Bordwell FG, Liu W-Z. J. Am. Chem. Soc. 1996; 118:10819.

101. Mori Y, Sakaguchi Y, Hayashi H. J. Phys. Chem. A. 2000; 104:4896.

102. Semmelhack MF, Chou CS, Cortes DA. J. Am. Chem. Soc. 1983; 105:4492.

103. Bordwell FG, Liu W-Z. J. Am. Chem. Soc. 1996; 118:8777.

104. Xu F, Deusen H-JW, Lopez B, Lam L, Li K. Eur. J. Biochem. 2001; 268:4169. [PubMed: 11488909]

105. Koshino N, Cai Y, Espenson JH. J. Phys. Chem. A. 2003; 107:4262.

106. (a) Feher G, Allen JP, Okamura MY, Rees DC. Nature. 1989; 339:111. (b) Okamura MY, Paddock ML, Graige MS, Feher G. Biochim. Biophys. Acta. 2000; 1458:148. [PubMed: 10812030]

107. (a) Berry EA, Guergova-Kuras M, Huang L-S, Crofts AR. Ann. Rev. Biochem. 2000; 69:1005. [PubMed: 10966481] (b) Osyczka A, Moser CC, Dutton PL. Trends Biochem. Sci. 2005; 30:176. [PubMed: 15817393]

108. (a) Barber J. Inorg. Chem. 2008; 47:1700. [PubMed: 18330964] (b) Meyer TJ, Huynh MHV, Thorp HH. Angew. Chem. Int. Ed. 2007; 46:5284.

109. Stubbe J, Nocera DG, Yee CS, Chang MCY. Chem. Rev. 2003; 103:2167. [PubMed: 12797828]

110. Packer, L.; Fuchs, J., editors. Vitamin E in Health and Disease. New York: Marcel Dekker; 1993.

111. Packer L, Kagan VE. In reference 110; pp 173-192.

112. Ingold KU. Chem. Rev. 1961; 61:563.

113. Borges dos Santos RM, Martinho Simões JA. J. Phys. Chem. Ref. Data. 1998; 27:707.

114. Borges dos Santos RM, Costa Cabral BJ, Martinho Simões JA. Pure Appl. Chem. 2008; 79:1369.

115. Dixon WT, Murphy D. J. Chem. Soc. Faraday Trans. 2. 1976; 76:1221.

116. Bordwell FG, Cheng J-P. J. Am. Chem. Soc. 1991; 113:1736.

117. Lind J, Shen X, Eriksen TE, Merényi G. J. Am. Chem. Soc. 1990; 112:479.

118. Steenken S, Neta P. J. Phys. Chem. 1982; 86:3661.

119. Cf. (a) Barclay, LRC.; Vinquist, MR. The chemistry of phenols. Rappoport, Z., editor. West Sussex: John Wiley and Sons; 2003. p. 839-908. (b) Steenken S, Neta P. ibid. :1107-1152.

120. (a) Altwicker ER. Chem. Rev. 1967; 67:475. (b) Manner VW, Markle TF, Freudenthal JH, Roth JP, Mayer JM. Chem. Commun. 2008; 2008:256.

121. Lucarini M, Pedrielli P, Pedulli GF. J. Org. Chem. 1996; 61:9259. (b) See also reference 56.

122. The EPR equilibration technique used by Pedulli and Lucarini can be complicated by the radical species decaying on the timescale of the experiment, but it is validated by the very good agreement between the values from this technique and other methods. Occasional disagreements between this method and others (e.g., for $\mathrm{BDE}\left(\mathrm{Ph}_{2} \mathrm{~N}-\mathrm{H}\right)$, Section 5.5.3) could also result from uncertainty in the bond strength of the reference compound used.

123. (a) Stubbe J, van der Donk WA. Chem. Rev. 1998; 98:705. [PubMed: 11848913] (b) Pesavento RP, van der Donk WA. Adv. Prot. Chem. 2001; 58:317.

124. Whittaker JW. Chem. Rev. 2003; 103:2347. [PubMed: 12797833]

125. Tsai A-L, Kulmacz RJ, Palmer G. J. Biol. Chem. 1995; 270:10503. [PubMed: 7737984]

126. Proshlyakov DA, Pressler MA, DeMaso C, Leykam JF, DeWitt DL, Babcock GT. Science. 2000; 290:1588. [PubMed: 11090359]

127. Heinecke JW. Free Radical Bio. Med. 2002; 32:1090. [PubMed: 12031894]

128. Harriman A. J. Phys. Chem. 1987; $91: 6102$.

129. Jovanovic SV, Harriman A, Simic MG. J. Phys. Chem. 1986; 90:1935.

130. Tommos C, Skalicky JJ, Pilloud DL, Wand AJ, Dutton PL. Biochemistry. 1999; 38:9495. [PubMed: 10413527] 
131. DeFelippis MR, Murthy CP, Broitman F, Weinraub D, Faraggi M, Klapper MH. J. Phys. Chem. 1991; 95:3416.

132. Evans HM, Bishop KS. Science. 1922; 56:650. [PubMed: 17838496]

133. Gregor W, Grabner G, Adelwöhrer C, Rosenau T, Gille L. J. Org. Chem. 2005; 70:3472. [PubMed: 15844980]

134. Mukai K. In reference 110; pp 97-139.

135. Njus D, Kelley PM. FEBS Lett. 1991; 283:147. [PubMed: 1647978]

136. Kimura M, Kaneko Y. J. Chem. Soc. Dalton Trans. 1984:341.

137. Serjeant, EP.; Dempsey, B. Ionisation Constants of Organic Acids in Aqueous Solution. Oxford: Permagon; 1979.

138. Das TN, Neta P. J. Phys. Chem. A. 1998; 102:7081.

139. Bernhard K, Geimer J, Canle-Lopez M, Reynisson J, Beckert D, Gleiter R, Steenken S. Chem. Eur. J. 2001; 7:4640.

140. Bordwell FG, Zhang X-M. J. Phys. Org. Chem. 1995; 8:529.

141. Williams LL, Webster RD. J. Am. Chem. Soc. 2004; 126:12441. [PubMed: 15453778]

142. Costentin C, Loualt C, Robert M, Savéant J-M. J. Am. Chem. Soc. 2008; 130:15817. [PubMed: 18975863]

143. $\mathrm{p} K_{\mathrm{a}}\left({ }^{t} \mathrm{Bu}_{3} \mathrm{PhOH}\right)=13$ is in good agreement with an independent measurement in aqueous ethanol $\left(\mathrm{p} K_{\mathrm{a}}=14\right)$. See: Gersmann HR, Bickel AF. J. Chem. Soc. 1959; 1959:2711.

144. $E_{1 / 2}\left({ }^{t} \mathrm{Bu}_{3} \mathrm{PhO}^{\circ-}\right)$ is an average of two independently measured values: $-0.689 \mathrm{~V} 145$ and -0.707 V.146

145. Grampp G, Landgraf S, Muresanu C. Electrochim. Acta. 2004; 49:537.

146. Niyazymbetov ME, Evans DH. J. Chem. Soc. Perkin Trans. 2. 1993; 1993:1333.

147. Osako T, Ohkubo K, Taki M, Tachi Y, Fukuzumi S, Itoh S. J. Am. Chem. Soc. 2003; 125:11027. [PubMed: 12952484]

148. For an review of semiquinone chemistry see: Neta, P. The chemistry of quinoid compounds, Vol. 2, Part 1. Patai, S.; Rappoport, Z., editors. Chichester: John Wiley and Sons; 1988. p. 879-898.

149. Michaelis L. Chem. Rev. 1935; 16:243.

150. Meisel D, Fessenden RW. J. Am. Chem. Soc. 1976; 98:7505.

151. (a) Rich PR. Biochim. Biophys. Acta. 1981; 637:28. (b) Rich PR. Biochim. Biophys. Acta. 2004; 1658:165. [PubMed: 15282188]

152. Laviron E. J. Electroanal. Chem. 1984; 164:213.

153. Chambers, JQ. The chemistry of the quinoid compound Vol. 2, Part 1. Patai, S.; Rappoport, Z., editors. Chichester: John Wiley and Sons; 1988. p. 719-757.

154. Cf., (a) Quan M, Sanchez D, Wasylkiw MF, Smith DK. J. Am. Chem. Soc. 2007; 129:12847. [PubMed: 17910453] (b) Savéant J-M. J. Am. Chem. Soc. 2008; 130:4732. [PubMed: 18345668] (c) Hui Y, Chng ELK, Chng CYL, Poh HL, Webster RD. J. Am. Chem. Soc. 2009; 131:1523. [PubMed: 19132833]

155. Clark, WM. Oxidation Reduction Potentials of Organic Systems. Baltimore: Williams and Wilkins; 1960.

156. (a) Wong SK, Sytnyk W, Wan JKS. Can. J. Chem. 1972; 50:3052. (b) Alegría AE, López M, Guevara N. J. Chem. Soc., Faraday Trans. 1996; 92:4965.

157. Sasaki K, Kashimura T, Ohura M, Ohsaki Y, Ohta N. J. Electrochem. Soc. 1990; 137:2437.

158. Bailey SI, Ritchie IM, Hewgill FR. J. Chem. Soc. Perkin Trans. II. 1983; 1983:645.

159. Baxendale JH, Hardy HR. Trans. Faraday Soc. 1953; 49:1140.

160. Youngblood MP. J. Am. Chem. Soc. 1989; 111:1843.

161. Bishop CA, Tong LKJ. J. Am. Chem. Soc. 1965; 87:501.

162. Ilan YA, Czapski G, Meisel D. Biochim. Biophys. Acta. 1976; 430:209. [PubMed: 179587]

163. Adams GE, Michael BD. Trans. Faraday Soc. 1967; 63:1171.

164. Rao PS, Hayon E. J. Phys. Chem. 1973; 77:2274.

165. Patel KB, Willson RL. J. Chem. Soc. Faraday Trans. I. 1973; 69:814. 
166. Meisel D, Czapski G. J. Phys. Chem. 1975; 79:1503.

167. Purves, D.; Augustine, GJ.; Fitzpatrick, D.; Hall, WC.; LaMantia, A-S.; McNamara, JO.; White, LE., editors. Neuroscience. 4th ed.. Sunderland, MA: Sinauer Associates; 2008. p. 137-143.

168. Yao LH, Jiang YM, Shi J, Tomás-Barberán FA, Datta N, Singanusong R, Chen SS. Plant Food Hum. Nutr. 2004; 113:113.

169. Steenken S, O’Neill P. J. Phys. Chem. 1977; 81:505.

170. Kennedy JA, Munro MHG, Powel HKJ, Porter LJ, Foo LY. Aust. J. Chem. 1984; 37:885.

171. Korth H-G, de Heer MI, Mulder P. J. Phys. Chem. A. 2002; 106:8779.

172. Wright JS, Johnson ER, DiLabio GA. J. Phys. Chem. A. 2001; 123:1173.

173. Lucarini M, Mugnaini V, Pedulli GF. J. Org. Chem. 2002; 67:928. [PubMed: 11856039]

174. Foti MC, Barclay LRC, Ingold KU. J. Am. Chem. Soc. 2002; 124:12881. [PubMed: 12392436]

175. Packer, L.; Fuchs, J., editors. Vitamin C in Heath and Disease. Vol. Vol. 5. New York: MarcelDekkar; 1997.

176. Njus D, Wigle M, Kelley PM, Kipp BH, Schlegel HB. Biochemistry. 2001; 40:11905. [PubMed: 11570891]

177. Nakanishi N, Takeuchi F, Tsubaki M. J. Biochem. 2007; 142:553. [PubMed: 17905810]

178. Njus D, Kelley PM. Biochim. Biophys. Acta. 1993; 1144:235. [PubMed: 8399278]

179. MacDonald IK, Badyal SK, Ghamsari L, Moodey PCE, Raven EL. Biochemistry. 2006; 45:7808. [PubMed: 16784232]

180. Bisby RH, Parker AW. Arch. Biochem. Biophys. 1995; 317:170. [PubMed: 7872780]

181. Warren JJ, Mayer JM. J. Am. Chem. Soc. 2008; 130:2774. [PubMed: 18257574]

182. Warren JJ, Mayer JM. J. Am. Chem. Soc. 2008; 130:7546. [PubMed: 18505256]

183. Creutz C. Inorg. Chem. 1981; 20:4449.

184. Williams NH, Yandell JK. Aust. J. Chem. 1982; 35:1133.

185. Macartney DH, Sutin N. Inorg. Chim. Acta. 1983; 74:221.

186. Bielski BHJ, Allen AO, Schwarz HA. J. Am. Chem. Soc. 1981; 103:3516.

187. Laroff GP, Fessenden RW, Schuler RH. J. Am. Chem. Soc. 1972; 94:9062. [PubMed: 4345160]

188. Ervin KM, DeTuri VF. J. Phys. Chem. A. 2002; 106:9947.

189. Dorfman LM, Salsburg ZW. J. Am. Chem. Soc. 1951; 73:255.

190. Cf. Paul H, Small RD Jr. Scaiano JC. J. Am. Chem. Soc. 1978; 100:4520.

191. Kiefer H, Traylor TG. Tet. Lett. 1966; 7:6163.

192. Walling C. Pure. Appl. Chem. 1967; 15:69.

193. Bartlett PD, Benzing EP, Pincock RE. J. Am Chem. Soc. 1960; 82:1762.

194. Cf. Foti M, Ingold KU, Lusztyk J. J. Am. Chem. Soc. 1994; 116:9440.

195. Cf. Wong PC, Griller D, Scaiano JC. J. Am Chem. Soc. 1982; 104:5106.

196. Fischer, H., editor. Radical Reaction Rates in Liquids Radical Reaction Rates in Liquids; Subvol. II-18-D1, Landolt-Börnstein New Series. Berlin: Springer; 1997.

197. For an extensive listing of reactions of ${ }^{t} \mathrm{BuO}{ }^{\bullet}$ see: Lusztyk J. in reference 196; pp 1-228.

198. For rates of $\beta$-scission in different solvents, see: Tsentalovich YP, Kulik LV, Gritsan NP, Yurkovskaya AV. J. Phys. Chem. A. 1998; 102:7975.

199. Hopkins AS, Ledwith A. J. Chem. Soc. D, Chem. Commun. 1971; 1971:830.

200. Ruscic B, Wagner AF, Harding LB, Asher RL, Feller D, Dixon DA, Peterson KA, Song Y, Qian X, Ng C-Y, Lui J, Chen W, Schwenke DW. J. Phys. Chem. A. 2002; 106:2727.

201. Olmstead WN, Margolin Z, Bordwell FG. J. Org. Chem. 1980; 45:3295-3299.

202. Mollin J, Pavelek Z, Schneiderová A, Vičar J, Šimánek V, Lasovský J. Collect. Czech. Chem. C. $1983 ; 48: 2156$.

203. Valentine JS, Wertz DL, Lyons TJ, Liou L-L, Goto JJ, Gralla EB. Curr. Opin. Chem. Biol. 1998; 2:253. [PubMed: 9667937] 
204. (a) Vielstich, W.; Lamm, A.; Gasteiger, H., editors. Handbook of Fuel Cells-Fundamentals, Technology, and Applications. Chichester, UK: Wiley; 2003. (b) Winter M, Brodd RJ. Chem. Rev. 2004; 104:4245. [PubMed: 15669155]

205. Forum on Making Oxygen (a) Eisenberg, R.; Gray, HB., editors. Inorg. Chem. Vol. 47. 2008. (b) Eisenberg R, Gray HB. Inorg. Chem. 2008; 47:1697. [PubMed: 18330963]

206. Lenoir D. Angew. Chem. Int. Ed. 2006; 45:3206.

207. Afanas'ev, IB. Superoxide Ion: Chemistry and Biological Implications. Vol. Vol. 2. Boca Raton, Florida: CRC Press; 1991.

208. Dröge W. Physiol. Rev. 2002; 82:47. [PubMed: 11773609]

209. Sawyer, DT. Oxygen Chemistry. New York: Oxford University Press; 1991.

210. Afanas'ev, IB. Superoxide Ion: Chemistry and Biological Implications. Vol. Vol. 1. Boca Raton: CRC Press; 1989.

211. Mayer JM. Acc. Chem. Res. 1998; 31:441.

212. Sawyer DT, Valentine JS. Acc. Chem. Res. 1981; 14:393.

213. Sawyer DT, Gibian MJ, Morrison MM, Seo ET. J. Am. Chem. Soc. 1978; 100:627.

214. Howard JA, Ingold KU. Can. J. Chem. 1967; 45:785.

215. Sawyer DT, MacDowell MS, Yamaguchi KS. Chem. Res. Toxicol. 1988; 1:97. [PubMed: 2979721]

216. Bielski BHJ, Arudi RL, Sutherland MW. J. Biol. Chem. 1983; 258:4759. [PubMed: 6833274]

217. Sawyer DT, Chiericato G Jr. Tsuchiya T. J. Am. Chem. Soc. 1982; 104:6273.

218. (a) Nanni EJ Jr. Sawyer DT. J. Am. Chem. Soc. 1980; 102:7593. (b) Sawyer DT, Calderwood TS, Johlman CL, Wilkins CL. J. Org. Chem. 1985; 50:1409.

219. Sawyer DT, Gibian MJ. Tetrahedron. 1979; 35:1471.

220. Lide, DR., editor. CRC Handbook of Chemistry and Physics. 90th ed.. Boca Raton, Florida: CRC Press; 2009.

221. Goolsby AD, Sawyer DT. Anal. Chem. 1968; 40:83.

222. Roberts JL Jr. Morrison MM, Sawyer DT. J. Am. Chem. Soc. 1978; 100:329.

223. Cf., (a) Goti, A.; Cardona, F. Green Chemical Reactions. Tundo, P.; Esposito, V., editors. Dordrecht, Netherlands: Springer; 2008. p. 191-212. (b) http://www.chemicals-technology.com/projects/BASF-HPPO (c) http://www.highbeam.com/doc/1G1-166955737.html (d) Clerici M. Oil Gas Eur. Mag. (Int. Ed. Erdöl Erdgas Kohle). 2006; 32:77.

224. Dilute anhydrous $\mathrm{H}_{2} \mathrm{O}_{2}$ can be prepared in $\mathrm{CH}_{2} \mathrm{Cl}_{2}$ solvent. See: DiPasquale AG, Mayer JM. J. Am. Chem. Soc. 2008; 130:1812. [PubMed: 18198874]

225. Walling C. Acc. Chem. Res. 1975; 8:125.

226. (a) Cheng Z, Li Y. Chem. Rev. 2007; 107:748. [PubMed: 17326688] (b) ibid. 2007; 107:2165.

227. For a related discussion of ET and O-O bond cleavage, see Donkers RL, Maran F, Wayner DDM, Workentin MS. J. Am. Chem. Soc. 1999; 121:7239.

228. Ruscic B, Pinzon RE, Morton ML, Srinivasan NK, Su M-C, Sutherland JW, Michael JV. J. Phys. Chem. A. 2006; 110:6592. [PubMed: 16722670]

229. Andrieux CP, Hapiot P, Savéant J-M. J. Am. Chem. Soc. 1987; 109:3768.

230. Ogata, Y.; Tomizawa, K.; Furata, K. The Chemistry of peroxides. Patai, S., editor. Chichester: John Wiley and Sons; 1983. p. 711-775.

231. Simmie JM, Black G, Curran HJ, Hinde JP. J. Phys. Chem. A. 2008; 112:5010. [PubMed: 18461912]

232. Chase MW Jr. NIST-JANAF Thermochemical Tables, Fourth Edition, J. Phys. Chem. Ref. Data, Monograph 9. 1998 1-1951.

233. Khursan SL, Martem'yanov VS. Russ. J. Phys. Chem. (Engl. Transl.). 1991; 65:321.

234. This value is consistent with that from another recent measurement of $\Delta H_{f}{ }^{\circ}\left({ }^{t} \mathrm{BuOO}^{\circ}\right), 205 \mathrm{a}$ with the $\mathrm{BDE}_{\mathrm{g}}\left({ }^{t} \mathrm{BuOOH}\right)=85 \pm 2 \mathrm{kcal} \mathrm{mol}^{-1}$ derived by Clifford et al. using gas phase measurements of the ionization energy and gas phase acidity,205b and with recent DFT calculations using CBS-QB3 or CBS-APNO basis sets that gave $\mathrm{BDE}_{\mathrm{g}}\left({ }^{t} \mathrm{BuOOH}\right)=84.85 \mathrm{kcal}$ 
$\mathrm{mol}^{-1}$ and BDE $\mathrm{g}\left({ }^{t} \mathrm{BuOOH}\right)=83.89 \mathrm{kcal} \mathrm{mol}^{-1}$, respectively.205c See: (a) Blanksby SJ, Ramond TM, Davico GE, Nimlos MR, Kato S, Bierbaum VM, Lineberger WC, Ellison GB, Okumura M. J. Am. Chem. Soc. 2001; 123:9585. [PubMed: 11572679] (b) Clifford EP, Wenthold PG, Gareyev R, Lineberger WC, DePuy CH, Bierbaum VM, Ellison GB. J. Chem. Phys. 1998; 109:10293.

235. Everett AJ, Minkoff GJ. Trans. Faraday Soc. 1953; 49:410.

236. Jones P, Davies DM. J. Org. Chem. 1978; 43:769.

237. Das TN, Dhanasekaran T, Alfassi ZB, Neta P. J. Phys. Chem. A. 1998; 102:280.

238. Merényi G, Lind J, Engman L. J. Chem. Soc. Perkin Trans. 2. 1994; 1994:2551.

239. This assumes that the aqueous free energies of solvation for alkylhydroperoxides and peracids are similar.

240. Jonsson M. J. Phys. Chem. 1996; 100:6814.

241. Villano SM, Eyet N, Wren SC, Ellison GB, Bierbaum VM, Lineberger WC. J. Phys. Chem. A. 2010; 114:191. [PubMed: 19827803]

242. Janoschek R, Rossi MJ. Int. J. Chem. Kinet. 2004; 36:661.

243. (a) Burgess BK, Lowe DJ. Chem. Rev. 1996; 96:2983. [PubMed: 11848849] (b) Bazhenova TA, Shilov AE. Coord. Chem. Rev. 1995; 144:69. (c) Rees DC, Tezcan FA, Haynes CA, Walton MY, Andrade S, Einsle O, Howard JB. Philos. Trans. R. Soc. London, Ser. A. 2005; 363:971. (d) Seefeldt LC, Hoffman BM, Dean DR. Annu. Rev. Biochem. 2009; 78:701. [PubMed: 19489731] (e) Peters, JC.; Mehn, MP. Activation of Small Molecules. Tolman, WB., editor. New York: Wiley; 2006. p. 81-120.

244. Smith BE. Science. 2002; 297:1654. [PubMed: 12215632]

245. (a) Schrock RR. Phil. Trans. R. Soc. A. 2005; 363:959. [PubMed: 15901545] (b) Schrock RR. Acc. Chem. Res. 2005; 38:955. [PubMed: 16359167]

246. Cf., (a) Neese F. Angew. Chem. Int. Ed. 2006; 45:196. (b) Hoffman BM, Dean DR, Seefeldt LC. Acc. Chem. Res. 2009; 42:609. [PubMed: 19267458]

247. Stanbury DM. Prog. Inorg. Chem. 1998; 47:511.

248. Rosca V, Duca M, de Groot MT, Koper MTM. Chem. Rev. 2009; 109:2209. [PubMed: 19438198]

249. Walch SP, Duchovic RJ. J. Chem. Phys. 1989; 90:3230.

250. (a) van Tamelen EE, Dewey RS, Lease MF, Pirkle WH. J. Am. Chem. Soc. 1961; 83:4302.(b) Pasto, DJ. Comprehensive Organic Synthesis: Selectivity, Strategy and Efficiency in Modern Organic Chemistry. Trost, BM.; Fleming, I., editors. Oxford: Pergamon Press; 1991. p. 472-478. (c) Tang HR, McKee ML, Stanbury DM. J. Am. Chem. Soc. 1995; 117:8967. and references therein.

251. McKee ML. J. Phys. Chem. 1993; 97:13608.

252. Nelsen SF. Adv. Phys. Org. Chem. 2006; 41:183. and references therein.

253. (a) Bard, AJ.; Parsons, R.; Jordan, J., editors. Standard Potentials in Aqueous Solution. New York: Marcel Dekkar; 1985. p. 134(b) Latimer, WM. The Oxidation States of the Elements and Their Potentials in Aqueous Solutions. 2nd ed.. New York: Prentice-Hall; 1952. p. 99-100.

254. Connelly NG, Geiger WE. Chem. Rev. 1996; 96:877. [PubMed: 11848774]

255. Bauer N. J. Phys. Chem. 1969; 64:833.

256. Ruscic B, Berkowitz J. J. Chem. Phys. 1991; 95:4378.

257. Buxton GV, Stuart CR. J. Chem. Soc. Faraday Trans. 1996; 92:1519.

258. Appl, M. Ullman's Encyclopedia of Industrial Chemistry. Weinheim: Wiley-VHC; 2006. DOI 10.1002/14356007.a02_143.pub2

259. March, J. Advanced Organic Chemistry. 4th ed.. New York: John Wiley and Sons; 1992. p. 248-253.

260. (a) Stephens RD. J. Phys. Chem. 1984; 88:3308. (b) Jeffries JB, Smith GP. J. Phys. Chem. 1986; 90:487.

261. Buncel E, Menon B. J. Organomet. Chem. 1977; 141:1.

262. Lalevée J, Allonas X, Fouassier J-P. J. Am. Chem. Soc. 2002; 124:9613. [PubMed: 12167057]

Chem Rev. Author manuscript; available in PMC 2011 December 8. 
263. Song Y, Qian X-M, Lau K-C, Ng CY, Liu J, Chen W. J. Chem. Phys. 2001; 115:2582.

264. Dixon DA, Gutowski M. J. Phys. Chem. A. 2005; 109:5129. [PubMed: 16833867]

265. Mordaunt DH, Ashfold MNR, Dixon RN. J. Chem. Phys. 1996; 104:6460.

266. Colussi, AJ. Chemical Kinetics of Small Organic Molecules. Alfassi, ZB., editor. Vol. Vol. 1. Boca Raton, FL: CRC Press; 1988. p. 25-43.

267. Bourdelande JL, Gallardo I, Guirado G. J. Am. Chem. Soc. 2007; 129:2817. [PubMed: 17298061]

268. Jonsson M, Wayner DDM, Lusztyk J. J. Phys. Chem. 1996; 100:17539.

269. Mann, CK.; Barnes, KK. Electrochemical Reactions in Nonaqueous Systems. New York: Marcell Dekker; 1970. p. 259-296.

270. $C f$., (a) Shirota Y, Kageyama H. Chem. Rev. 2007; 107:953. [PubMed: 17428022] (b) Weiss DS, Abkowitz M. Chem. Rev. 2010; 110:479. [PubMed: 19848380]

271. Bordwell FG, Zhang X-M, Cheng J-P. J. Org. Chem. 1993; 58:6410.

272. Jonsson M, Lind J, Eriksen TE, Merényi G. J. Am. Chem. Soc. 1994; 116:1423.

273. Jonsson M, Lind J, Merényi G, Eriksen TE. J. Chem. Soc. Perkin Trans. 2. 1995; 1995:61.

274. MacFaul PA, Wayner DDM, Ingold KU. J. Org. Chem. 1997; 62:3413. [PubMed: 11671733]

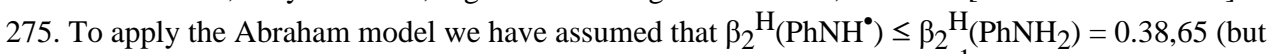
varying this parameter by \pm 0.2 changes the BDE less than $1 \mathrm{kcal} \mathrm{mol}^{-1}$ ).

276. Meot-Ner (Mautner), M. J. Am. Chem. Soc. 1982, 104, 5 gives a gas phase BDE for aniline that is almost $4 \mathrm{kcal} \mathrm{mol}^{-1}$ lower than MacFaul's value; given the agreement with the DMSO data + Abraham's model,275 we prefer McFaul's value.

277. Lucarini M, Pedrielli P, Pedulli GF, Valgimigli L, Gigmes D, Tordo P. J. Am. Chem. Soc. 1999; 121:11546.

278. Pratt DA, DiLabio GA, Valgimigli L, Pedulli GF, Ingold KU. J. Am. Chem. Soc. 2002; 124:11085. [PubMed: 12224956]

279. Blois MS. Nature. 1958; 181:1199.

280. Zhao Y, Bordwell FG, Cheng J-P, Wang D. J. Am. Chem. Soc. 1997; 119:9125.

281. Cauquis G, Delhomme H, Serve D. Tet. Lett. 1971; 12:4113.

282. Milardovic S, Iveković D, Rumenjak V, Grabarić BS. Electroanal. 2005; 17:1847.

283. Friaa O, Brault D. Org. Biomol. Chem. 2006; 4:2417. [PubMed: 16763687]

284. Foti MC, Daquine C. Chem. Commun. 2006:3252.

285. Shih C, Museth AK, Abrahamson M, Balnci-Rodriguez AM, Di Bilio AJ, Sudhamso J, Crane BR, Ronayne KL, Towrie M, Vlečk A Jr. Richards JH, Winkler JR, Gray HB. Science. 2008; 320:1760. [PubMed: 18583608]

286. Bertlett BS, Stadtman ER. J. Biol. Chem. 1997; 272:20313. [PubMed: 9252331]

287. Burrows CJ, Muller JG. Chem. Rev. 1998; 98:1109. [PubMed: 11848927]

288. Cf. (a) Walsh C. Acc. Chem. Res. 1980; 13:148. (b) Bruice TC. Acc. Chem. Res. 1980; 13:256. (c) Klinman JP. Acc Chem. Res. 2007; 40:325. [PubMed: 17474709] (d) Fitzpatrick PF. Acc. Chem. Res. 2001; 34:299-307. [PubMed: 11308304]

289. Müller, F. Chemistry and Biochemistry of Flavoenzymes. Müller, F., editor. Vol. Vol. 1. Boca Raton: CRC Press; 1991. p. 1-71.

290. Merényi G, Lind J, Shen X. J. Phys. Chem. 1988; 92:134.

291. Bordwell FG, Zhang Z, Cheng J-P. J. Org. Chem. 1991; 56:3216.

292. Nelson N, Ben-Shem A. Nat. Rev. Mol. Cell Bio. 2004; 5:971. [PubMed: 15573135]

293. The potential for indole in DMSO had been converted to NHE reference in DMSO, however we prefer the use of $\mathrm{Fc}^{+/ 0}$. For the original conversion see: Bordwell FG, Harrelson JA Jr. Satish AV. J. Org. Chem. 1989; 54:3101.

294. Remers, RA. Heterocyclic Compounds: Indoles, Part 1. Houlihan, WJ., editor. New York: WileyInterscience; 1972. p. 14

295. For current flavin numbering see: McNaught, AD.; Wilkinson, A., compilers. IUPAC. Compendium of Chemical Terminology, 2nd ed. (the "Gold Book"). Oxford: Blackwell Scientific Publications; 1997 [Accessed 08 January 2010]. http://goldbook.iupac.org 
296. Hemmerich P, Veeger C, Wood HCS. Angew. Chem. Int. Edit. 1965; 4:671.

297. Michaelis L, Schubert MP, Smythe CV. J. Biol. Chem. 1936; 116:587.

298. Michaelis L, Schwarzenbach G. J. Biol. Chem. 1938; 123:527.

299. Lowe HJ, Clark WM. J. Biol. Chem. 1956; 221:983. [PubMed: 13357492]

300. Pang J, Hay S, Scrutton NS, Sutcliffe MJ. J. Am. Chem. Soc. 2008; 130:7092. [PubMed: 18470990]

301. Brinkley DW, Roth JP. J. Am. Chem. Soc. 2005; 127:15720. [PubMed: 16277511]

302. Vignais PV. Cell. Mol. Life Sci. 2002; 59:1428. [PubMed: 12440767]

303. (a) Roth JP, Klinman JP. Proc. Natl. Acad. Sci. U. S. A. 2003; 100:62. [PubMed: 12506204] (b) Roth JP, Wincek R, Nodet G, Edmondson DE, McIntire WS, Klinman JP. J. Am. Chem. Soc. 2004; 126:15120. [PubMed: 15548009]

304. Land EJ, Swallow AJ. Biochemistry. 1969; 8:2117. [PubMed: 5785230]

305. Anderson RF. Biochim. Biophys. Acta. 1983; 722:158. [PubMed: 6824643]

306. Mayhew SJ. Eur. J. Biochem. 1999; 265:698. [PubMed: 10504402]

307. Hasford JJ, Rizzo CJ. J. Am. Chem. Soc. 1998; 120:2251.

308. Cf., (a) Burrows CJ, Muller JG. Chem. Rev. 1998; 98:1109. [PubMed: 11848927] (b) Burrows, CJ. "Surviving an Oxygen Atmosphere: DNA Damage and Repair,". In: Zaikowski, L.; Friedrich, JM.; Seidel, SR., editors. Chemical Evolution II: From Origins of Life to Modern Society. Washington, DC: ACS Symposium Series; 2009. (c) Pogozelski WK, Tullius TD. Chem. Rev. 1998; 98:1089. [PubMed: 11848926] (d) Kanvah S, Joseph J, Schuster GB, Barnett RN, Cleveland CL, Landman U. Acc. Chem. Res. 2010; 43:280. [PubMed: 19938827] (e) Genereux JC, Barton JK. Chem. Rev. 2010; 110:1642. [PubMed: 20214403] (f) Giese B. Top. Curr. Chem. 2004; 236:27.

309. Cf., (a) Weatherly SC, Yang IV, Armistead PA, Thorp HH. J. Phys. Chem. B. 2003; 107:372. (b) Boussicault F, Robert M. Chem. Rev. 2008; 108:2622. [PubMed: 18563937] (c) Yamagami R, Kobayashi K, Tagawa S. J. Am. Chem. Soc. 2008; 130:14772. [PubMed: 18841971] (d) Szyperska A, Rak J, Leszczynski J, Li X, Ko YJ, Wang H, Bowen K. J. Am. Chem. Soc. 2009; 131:2663. [PubMed: 19170629] (e) Raytchev M, Mayer E, Amann N, Wagenknecht H-A, Fiebig T. ChemPhysChem. 2004; 5:706. [PubMed: 15179723] (f) Shafirovich V, Dourandin A, Geacintov NE. J. Phys. Chem. B. 2001; 105:8431. (g) Shinde SS, Maroz A, Hay MP, Anderson RF. J. Am. Chem. Soc. 2009; 131:5203. [PubMed: 19320486]

310. Steenken S, Jovanovic SV. J. Am. Chem. Soc. 1997; 119:617.

311. Candeias LP, Steenken S. J. Am. Chem. Soc. 1989; 111:1094.

312. Steenken S. Chem. Rev. 1989; 89:503.

313. Sies H. Free Rad. Biol. Med. 1999; 27:916. [PubMed: 10569624]

314. Pompella A, Visvikis A, Paolicchi A, De Tata V, Casini AF. Biochem. Pharmacol. 2003; 66:1499. [PubMed: 14555227]

315. For a review of thiol $\mathrm{p} K_{\mathrm{a}} \mathrm{s}$ and hydrogen bonding see: Crampton, MR. The chemistry of the thiol group. Patai, S., editor. London: John Wiley and Sons; 1974. p. 379-415.

316. Surdhar PS, Armstrong DA. J. Phys. Chem. 1986; 90:5915.

317. Surdhar PS, Armstrong DA. J. Phys. Chem. 1987; 91:6532.

318. Prütz WA, Butler J, Land EJ, Swallow AJ. Free Rad. Res. Com. 1986; 2:69.

319. Benesch RE, Benesch R. J. Am. Chem. Soc. 1955; 77:5877.

320. Sharma VK, Casteran F, Millero FJ, De Stefano C. J. Solution Chem. 2002; 31:783.

321. Berkowitz J, Ellison GB, Gutman D. J. Phys. Chem. 1994; 98:2744.

322. Pedley, JB.; Naylor, RD.; Kirby, SP. Thermochemical Data of Organic Compounds. 2nd ed.. New York: Chapman and Hall; 1986.

323. Reed DR, Hare MC, Fattahi A, Chung G, Gordon MS, Kass SR. J. Am. Chem. Soc. 2003; 125:4643. [PubMed: 12683837]

324. Madej E, Wardman P. Arch. Biochem. Biophys. 2007; 462:94. [PubMed: 17466930]

325. Tajc SG, Tolbert BS, Basavappa R, Miller BL. J. Am. Chem. Soc. 2004; 126:10508. [PubMed: 15327286] 
326. Borges dos Santos RM, Muralha VSF, Correia CF, Guedes RC, Costa Cabral BJ, Martinho Simões JA. J. Phys. Chem. A. 2002; 106:9883.

327. Armstrong DA, Sun Q, Schuler RH. J. Phys. Chem. 1996; 100:9892.

328. Tedder JM. Angew. Chem. Int. Ed. Engl. 1982; 21:401.

329. Bordwell FG. Pure. Appl. Chem. 1977; 49:963.

330. (a) Kochi, JK. Comprehensive Organic Synthesis. Trost, BM., editor. Vol. Vol. 7. New York: Permgamon; 1991. p. 849-886. (b) Miller LL, Nordblom GD, Mayeda EA. J. Org. Chem. 1972; 37:916.

331. Eberson, LE. Electron Transfer Reactions In Organic Chemistry. Berlin: Springer; 1987.

332. Buis JM, Broderick JB. Arch. Biochem. Biophys. 2005; 433:288. [PubMed: 15581584]

333. (a) Frey PA, Hegeman AD, Reed GH. Chem. Rev. 2006; 106:3302. [PubMed: 16895329] (b) Ragsdale SW. Chem. Rev. 2006; 106:3317. [PubMed: 16895330] (c) Brown KL. Chem. Rev. 2005; 105:2075. [PubMed: 15941210] (d) Frey PA, Hegeman AD, Ruzicka FJ. Crit. Rev. Biochem. Mol. Biol. 2008; 43:63. [PubMed: 18307109] (e) Booker SJ. Curr. Opin. Chem. Biol. 2009; 13:58. [PubMed: 19297239]

334. Cf., (a) Yu D, Rauk A, Armstrong DA. J. Am. Chem. Soc. 1995; 117:1789. (b) Armstrong DA, Yu D, Rauk A. Can. J. Chem. 1996; 74:1192. (c) Gil A, Simon S, Rodríguez-Santiago L, Bertrán J, Sodupe M. J. Chem. Theory Comput. 2007; 3:2210. (d) Sandala GM, Smith DM, Marsh ENG, Radom L. J. Am. Chem. Soc. 2007; 129:1623. [PubMed: 17249667] (e) Sandala GM, Smith DM, Radom L. Acc. Chem. Res. 2010; 43:642. [PubMed: 20136160]

335. (a) Kochi, JK. Comprehensive Organic Synthesis. Trost, BM., editor. Vol. Vol. 7. New York: Permgamon; 1991. p. 849-886. (b) Miller LL, Nordblom GD, Mayeda EA. J. Org. Chem. 1972; 37:916.

336. Ruscic B, Litorja M, Asher RL. J. Phys. Chem. A. 1999; 103:8265.

337. Seakins PW, Pilling MJ, Niiranen JT, Gutman D, Krasnoperov LN. J. Phys. Chem. 1992; 96:9847.

338. Ervin KM, DeTuri VF. J. Phys. Chem. A. 2002; 106:9947.

339. Mordaunt DH, Ashfold MNR. J. Chem. Phys. 1994; 101:2630.

340. Roy K, Braun-Unkhoff M, Frank P, Just T-H. Int. J. Chem. Kinet. 2001; 33:821.

341. Streitwieser A Jr. Nebenzahl LL. J. Am. Chem. Soc. 1976; 98:2188.

342. Tsang W. J. Phys. Chem. 1986; 90:1152.

343. Ellison GB, Davico GE, Bierbaum VM, DePuy CH. Int. J. Mass Spectrom. Ion Processes. 1996; 156:109.

344. Wayner DDM, McPhee DJ, Griller D. J. Am Chem. Soc. 1988; 110:132.

345. Schlesener CJ, Amatore C, Kochi JK. J. Phys. Chem. 1986; 90:3747.

346. Sim BA, Griller D, Wayner DDM. J. Am. Chem. Soc. 1989; 111:754.

347. Streitwieser A Jr. Taylor DR. J. Chem. Soc. D. 1970; 1970:1248.

348. Streitwieser A Jr. Ni JX. Tet. Lett. 1985; 51:6317.

349. (a) Pollak N, Dölle C, Ziegler M. Biochem. J. 2007; 402:205. [PubMed: 17295611] (b) Belenky P, Bogna KL, Brenner C. Trends Biochem. Sci. 2007; 32:12. [PubMed: 17161604]

350. Cf., (a) Mauzerall D, Westheimer FH. J. Am. Chem. Soc. 1955; 77:2261. (b) Reference57. (c) Yasui S, Ohno A. Bioorg. Chem. 1986; 14:70. (d) Chan PC, Bielski BHJ. J. Biol. Chem. 1975; 250:7266. [PubMed: 170258] (e) Pestovsky O, Bakac A, Espenson JH. J. Am. Chem. Soc. 1998; 120:13422. (f) Pestovsky O, Bakac A, Espenson JH. Inorg. Chem. 1998; 37:1616. (g) Fukuzumi S, Fujioka N, Kotani H, Ohkubo K, Lee Y-M, Nam W. J. Am. Chem. Soc. 2009; 131:17127. [PubMed: 19888722] (h) Yuasa J, Fukuzumi S. J. Am. Chem. Soc. 2006; 128:14281. [PubMed: 17076501] (i) Fukuzumi S, Kotani H, Lee Y-M, Nam W. J. Am. Chem. Soc. 2008; 130:15134. [PubMed: 18937476] (j) Yuasa J, Yamada S, Fukuzumi S. J. Am. Chem. Soc. 2008; 130:5808. [PubMed: 18386924] (k) Matsuo T, Mayer JM. Inorg. Chem. 2005; 44:2150. [PubMed: 15792449]

351. Zhu X-C, Yang Y, Zhang M, Cheng J-P. J. Am. Chem. Soc. 2003; 125:15298. [PubMed: 14664567] 
352. (a) Cheng J-P, Lu Y. J. Phys. Org. Chem. 1997; 10:577. (b) Cheng J-P, Lu Y, Zhu X, Mu L. J. Org. Chem. 1998; 63:6108. [PubMed: 11672236]

353. Zhu X-Q, Li H-R, Li Q, Ai T, Lu J-Y, Yang Y, Cheng J-P. Chem. Eur. J. 2003; 9:871.

354. Stanbury, D. M., personal communication 2010, questions the C-H BDEs in MeCN in Table 2 of ref. 353 because their derivation depends on $E_{1 / 2}$ (TMPA), and the latter appears to be in error due to an incorrect assignment of the CV waves for TMPA [TMPA $\left.=1,4-\mathrm{C}_{6} \mathrm{H}_{4}\left(\mathrm{NMe}_{2}\right)_{2}\right]\left(E_{1 / 2}=\right.$ $-0.27 \mathrm{~V}$ versus $\mathrm{Cp}_{2} \mathrm{Fe}^{+/ 0}$ in MeCN. See: Hu, K.; Evans, D. H. J. Electroanal. Chem. 1997, 423, 29) The aqueous BDEs for NADH in ref. 351 also depends on $E_{1 / 2}$ (TMPA), and the value used $(0.520 \mathrm{~V})$ differs, for an unknown reason, from that reported by Steenken and Neta $(0.27 \mathrm{~V}) .118$

355. Anne A, Hapiot P, Moiroux J, Neta P, Savéant J-M. J. Am. Chem. Soc. 1992; 114:4694.

356. Farrington JA, Land EJ, Swallow AJ. Biochim. Biophys. Acta. 1980; 590:273. [PubMed: 6445204]

357. Carlson BW, Miller LL, Neta P, Grodkowski J. J. Am. Chem. Soc. 1984; 106:7233.

358. Ellis WW, Raebiger JW, Curtis CJ, Bruno JW, DuBois DL. J. Am. Chem. Soc. 2004; 126:2738. [PubMed: 14995190]

359. Klippenstein J, Arya P, Wayner DDM. J. Org. Chem. 1991; 56:6736.

360. Anne A, Moiroux J. Can. J. Chem. 1995; 73:531.

361. Zhang YP, Cheng CH, Kim JT, Stanojevic J, Eyler EE. Phys. Rev. Lett. 2004; 92:1. (Article No. 203003).

362. Pearson RG. J. Am. Chem. Soc. 1986; 108:6109.

363. (a) Zhang X-M, Bruno JW, Enyinnaya E. J. Org. Chem. 1998; 63:4671. (b) Handoo KL, Cheng JP, Parker VD. J. Am. Chem. Soc. 1993; 115:5067.

364. Kelly CA, Rosseinsky DR. Phys. Chem. Chem. Phys. 2001; 3:2086.

365. De Santis G, Fabbrizzi L, Licchelli M, Pallavicini P. Inorg. Chim. Acta. 1994; 225:239.

366. Waidmann, CR. PhD. Thesis. Seattle, WA: University of Washington; 2009 October. Investigating Proton Coupled Electron Transfers in Oxovanadium and Dimeric Copper-Oxo Systems: The Importance of Intrinsic Barriers and Reaction Driving Force.

367. (a) Biczók L, Linschitz H. J. Phys. Chem. 1995; 99:1843. (b) Gupta N, Linschitz H, Biczók L. Fullerene, Sci. Technol. 1997; 5:343. (c) Biczók L, Gupta N, Linschitz H. J. Am. Chem. Soc. 1997; 119:12601.

368. Cf. (a) Sjödin M, Irebo T, Utas JE, Lind J, Merényi G, Åkermark B, Hammarström L. J. Am. Chem. Soc. 2006; 128:13076. [PubMed: 17017787] (b) Irebo T, Johansson O, Hammarström L. J. Am. Chem. Soc. 2008; 130:9194. [PubMed: 18582051] (c) Johannissen LO, Irebo T, Sjödin M, Johansson O, Hammarström L. J. Phys. Chem. B. 2009; 113:16214. [PubMed: 20000384] (d) Reece SY, Nocera DG. J. Am. Chem. Soc. 2005; 127:9448. [PubMed: 15984872]

369. (a) Rhile IJ, Mayer JM. J. Am. Chem. Soc. 2004; 126:12718. [PubMed: 15469234] (b) Rhile IJ, Markle TF, Nagao H, DiPasquale AG, Lam OP, Lockwood MA, Rotter K, Mayer JM. J. Am. Chem. Soc. 2006; 128:6075. [PubMed: 16669677] (c) Markle TF, Rhile IJ, DiPasquale AG, Mayer JM. Proc. Natl. Acad. Sci. USA. 2008; 105:8185. [PubMed: 18212121] (d) Markle TF, Mayer JM. Angew. Chem. Int. Ed. 2008; 47:738.

370. (a) Costentin C, Robert M, Savéant J-M. J. Am. Chem. Soc. 2006; 128:4552. [PubMed: 16594674] (b) Costentin C, Robert M, Savéant J-M. J. Am. Chem. Soc. 2007; 129:9953. [PubMed: 17637055]

371. Geiger WE Jr. J. Am. Chem. Soc. 1974; 96:2632.

372. (a) Richens, DT. The Chemistry of Aqua Ions. New York: John Wiley and Sons; 1997. p. 366(b) Baes, CF., Jr.; Mesmer, RE. The Hydrolysis of Cations. New York: Wiley; 1976. p. 226-229.

373. Nugent, WA.; Mayer, JM. Metal-Ligand Multiple Bonds. New York: Wiley-Interscience; 1988.

374. Mijs, WJ.; de Jonge, CRHI., editors. Organic Synthesis by Oxidation with Metal Compounds. New York: Plenum; 1986.

375. $C f$., (a) Ortiz de Montellano, PR., editor. Cytochrome P450: Structure, Mechanism and Biochemistry. 3rd Ed.. New York: Kluwer Academic/Plenum; 2005. (b) Dunford, HB. Heme Peroxidases. New York: Wiley-VCH; 1999. (c) Abu-Omar MM, Loaiza A, Hontzeas N. Chem. 
Rev. 2005; 105:2227. [PubMed: 15941213] (d) Costas M, Mehn MP, Jensen MP, Que L Jr. Chem. Rev. 2004; 104:939. [PubMed: 14871146]

376. Stumm, W.; Morgan, JJ. Aquatic Chemistry. 3rd Ed.. New York: Wiley-Interscience; 1996. especially Chapters 8-11

377. Pestovsky O, Bakac A. J. Am. Chem. Soc. 2004; 126:13757. [PubMed: 15493935]

378. Kang C, Anson FC. Inorg. Chem. 1994; 33:2624.

379. Nemes A, Bakac A. Inorg. Chem. 2001; 40:746. [PubMed: 11225118]

380. Bakac A. J. Am. Chem. Soc. 2000; 122:1092.

381. Szajna-Fuller E, Bakac A. Inorg. Chem. 2007; 46:10907. [PubMed: 17985876]

382. Moyer BA, Meyer TJ. J. Am. Chem. Soc. 1978; 100:3601.

383. Lebeau EL, Binstead RA, Meyer TJ. J. Am. Chem. Soc. 2001; 123:10535. [PubMed: 11673985]

384. Binstead RA, McGuire ME, Dovletoglou A, Seok WK, Roecker LE, Meyer TJ. J. Am. Chem. Soc. 1992; 114:173.

385. (a) Bryant JR, Mayer JM. J. Am. Chem. Soc. 2003; 125:10351. [PubMed: 12926960] (b) Bryant JR, Matsuo T, Mayer JM. Inorg. Chem. 2004; 43:1587. [PubMed: 14966998]

386. Roecker L, Meyer TJ. J. Am. Chem. Soc. 1986; 108:4066.

387. Gilbert J, Roecker L, Meyer TJ. Inorg. Chem. 1987; 26:1126.

388. E.g., oxygen atom transfer chemistry: Seok WK, Meyer TJ. J. Am. Chem. Soc. 1988; 110:7358.

389. (a) Liu F, Concepcion JJ, Jurss JW, Cardolaccia T, Templeton JL, Meyer TJ. Inorg. Chem. 2008; 47:1727. [PubMed: 18330966] (b) Hurst JK, Cape JL, Clark AE, Das S, Qin C. Inorg. Chem. 2008; 47:1753. [PubMed: 18330967] (c) Concepcion JJ, Tsai M-K, Muckerman JT, Meyer TJ. J. Am. Chem. Soc. 2010; 132:1545. [PubMed: 20085264]

390. Moyer BA, Meyer TJ. Inorg. Chem. 1981; 20:436.

391. (a) Rupta R, MacBeth CE, Young VG Jr. Borovik AS. J. Am. Chem. Soc. 2002; 124:1136. [PubMed: 11841259] (b) Gupta R, Borovik AS. J. Am. Chem. Soc. 2003; 125:13234. [PubMed: 14570499]

392. Parsell TH, Yang M-Y, Borovik AS. J. Am. Chem. Soc. 2009; 131:2762. [PubMed: 19196005]

393. Goldsmith CR, Cole AP, Stack TDP. J. Am. Chem. Soc. 2005; 127:9904. [PubMed: 15998097]

394. Goldsmith CR, Jonas RT, Stack TDP. J. Am. Chem. Soc. 2002; 124:83. [PubMed: 11772065]

395. Goldsmith CR, Stack TDP. Inorg. Chem. 2006; 45:6048. [PubMed: 16842013]

396. Cf. (a) Shaik S, Cohen S, Wang Y, Chen H, Kumar D, Theil W. Chem. Rev. 2010; 110:949. [PubMed: 19813749] (b) Ortiz de Montellano PR. Chem. Rev. 2010; 110:932. [PubMed: 19769330] (c) Denisov IG, Makris TM, Sligar SG, Schlichting I. Chem. Rev. 2005; 105:2253. [PubMed: 15941214] (d) Sono M, Roach MP, Coulter ED, Dawson JH. Chem. Rev. 1996; 96:2841. [PubMed: 11848843]

397. Green MT, Dawson JH, Gray HB. Science. 2004; 304:1653. [PubMed: 15192224]

398. (a) Behan RK, Green MT. J. Inorg. Biochem. 2006; 100:448. [PubMed: 16500711] (b) Green MT. Curr. Op. Chem. Biol. 2009; 13:84.

399. Angelis FD, Jin N, Car R, Groves JT. Inorg. Chem. 2006; 45:4268. [PubMed: 16676990] 400. Bell SR, Groves JT. J. Am. Chem. Soc. 2009; 131:9640. [PubMed: 19552441]

401. (a) Shaik S, Kumar D, de Visser SP. J. Am. Chem. Soc. 2008; 130:10128. [PubMed: 18616242] (b) ibid. 2008; 130:14016.

402. (a) Lansky DE, Goldberg DP. Inorg. Chem. 2006; 45:5119. [PubMed: 16780334] (b) Goldberg DP. Acc. Chem. Res. 2007; 40:626. [PubMed: 17580977]

403. (a) Che C-M, Yam VWM. Adv. Inorg. Chem. 1992; 39:233. (b) Griffith WP. Chem. Soc. Rev. 1992; 21:179. (c) Arends IWCE, Kodama T, Shledon RA. Topics Organomet. Chem. 2004; 11:277.

404. Lam WWY, Man W-L, Leung C-F, Wong C-Y, Lau T-C. J. Am. Chem. Soc. 2007; 129:13646. [PubMed: 17929922]

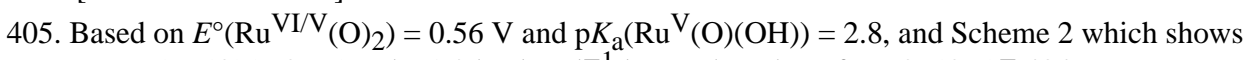
$\mathrm{BDFE}\left(\mathrm{Ru}(\mathrm{O})(\mathrm{HO}-\mathrm{H})\right.$ to be $1.8 \mathrm{kcal} \mathrm{mol}^{-1}$ larger than that of $\mathrm{MnO}_{3}(\mathrm{OH})^{-} .404$ 
406. C.f., references 1' 403, and Lam WWY, Yiu S-M, Yiu DTY, Lau T-C, Yip W-P, Che C-M. Inorg. Chem. 2003; 42:8011. [PubMed: 14632520]

407. (a) Lam WWY, Yiu S-M, Lee JMN, Yau SKY, Kwong H-K, Lau T-C, Liu D, Lin Z. J. Am. Chem. Soc. 2006; 128:2851. [PubMed: 16506763] (b) Yiu S-M, Wu Z-B, Mak C-K, Lau T-C. J. Am. Chem. Soc. 2004; 126:14921. [PubMed: 15535719]

408. (a) Cook GK, Mayer JM. J. Am. Chem. Soc. 1994; 116:1855. and erratum ibid., 8859. (b) Cook GK, Mayer JM. J. Am. Chem. Soc. 1995; 117:7139. (c) Wang K, Mayer JM. J. Org. Chem. 1997; 62:4248. [PubMed: 11671743]

409. Gardner KA, Kuehnert LL, Mayer JM. Inorg. Chem. 1997; 36:2069. [PubMed: 11669825]

410. Baldwin MJ, Vincent L, Pecoraro VL. J. Am. Chem. Soc. 1996; 118:11325.

411. Caudle MT, Pecoraro VL. J. Am. Chem. Soc. 1997; 119:3415.

412. (a) Thorp HH, Sarneski JE, Brudvig GW, Crabtree RH. J. Am. Chem. Soc. 1989; 111:9249. (b) Manchanda R, Thorp HH, Brudvig GW, Crabtree RH. Inorg. Chem. 1991; 30:494. (c) Efros LL, Thorp HH, Brudvig GW, Crabtree RH. Inorg. Chem. 1992; 31:1722.

413. Jensen KB, McKenzie CJ, Pedersen JZ. Inorg. Chem. 2001; 40:2760.

414. Wang K, Mayer JM. J. Am. Chem. Soc. 1997; 119:1470. 1997.

415. (a) Lockwood MA, Wang K, Mayer JM. J. Am. Chem. Soc. 1999; 121:11894. (b) Larsen AS, Wang K, Lockwood MA, Rice GL, Won T-J, Lovell S, Sadílek M, Tureček F, Mayer JM. J. Am. Chem. Soc. 2002; 124:10112. [PubMed: 12188675]

416. Mayer JM, Larsen AS, Bryant JR, Wang K, Lockwood M, Rice G, Won T-J. Activation and Functionalization of C-H Bonds, Chapter 21. 2004:356-369. ACS Symposium Series, Volume 885.

417. (a) Lewis EA, Tolman WB. Chem. Rev. 2004; 104:1047. [PubMed: 14871149] (b) Shearer J, Zhang CX, Zakharov LN, Rheingold AL, Karlin KD. J. Am. Chem. Soc. 2005; 127:5469. [PubMed: 15826184] (c) Osako T, Ohkubo K, Taki M, Tachi Y, Fukuzumi S, Itoh S. J. Am. Chem. Soc. 2003; 125:11027. [PubMed: 12952484] (d) Cole AP, Mahadevan V, Mirica LM, Ottenwaelder X, Stack TDP. Inorg. Chem. 2005; 44:7345. [PubMed: 16212361]

418. Leung SK-Y, Tsui W-M, Huang J-S, Che C-M, Liang J-L, Zhu N. J. Am. Chem. Soc. 2005; 127:16629. [PubMed: 16305252]

419. Eckert NA, Vaddadi S, Stoian S, Lachicotte RJ, Cundari TR, Holland PL. Angew. Chem. Int. Ed. 2006; 45:6868.

420. De Santis G, Fabbrizzi L, Poggi A, Taglietti A. Inorg. Chem. 1994; 33:134.

421. Keene FR. Coord. Chem. Rev. 1999; 187:121.

422. Chiu W-H, Peng S-M, Che C-M. Inorg. Chem. 1996; 35:3369. [PubMed: 11666540]

423. Soper JD, Saganic E, Weinberg D, Hrovat DA, Benedict JB, Kaminsky W, Mayer JM. Inorg. Chem. 2004; 43:5804. [PubMed: 15360229]

424. Soper JD, Mayer JM. J. Am. Chem. Soc. 2003; 125:12217. [PubMed: 14519007]

425. Cf., (a) Stuoka G, Gremaud L, Williams AF. Helv. Chim. Acta. 2005; 88:487. (b) Brewer C, Brewer G, Luckett C, Marbury GS, Viragh C, Beatty AM, Scheidt WR. Inorg. Chem. 2004; 43:2402. [PubMed: 15046517] (c) Lambert F, Policar C, Durot S, Cesario M, Yuwei L, KorriYoussoufi H, Keita B, Nadjo L. Inorg. Chem. 2004; 43:4178. [PubMed: 15236529]

426. Roth JP, Mayer JM. Inorg. Chem. 1999; 38:2760. [PubMed: 11671018]

427. Yoder JC, Roth JP, Gussenhoven EM, Larsen AS, Mayer JM. J. Am. Chem. Soc. 2003; 125:2629. [PubMed: 12603151]

428. Roth JP, Yoder JC, Won T-J, Mayer JM. Science. 2001; 294:2524. [PubMed: 11752572]

429. (a) Manner, VW. PhD Thesis. Seattle, WA: University of Washington; 2009 April. Concerted Proton-Electron Transfer Reactions of Ruthenium and Cobalt Complexes: Studies on Distance Dependence and Spin Effects. (b) Manner VW, Lindsay AD, Mader EA, Harvey JN, Mayer JM. manuscript in preparation. (c) The $\mathrm{BDFE}\left(\mathrm{Co} \mathrm{II}_{\mathrm{H}_{2}}\right.$ bim) derived from the thermochemical data in reference 429 is in good agreement with the direct equilibrium measurements reported in reference 40.

430. Wu A, Masland J, Swartz RD, Kaminsky W, Mayer JM. Inorg. Chem. 2007; 46:11190. [PubMed: 18052056] 
431. Quinn R, Nappa M, Valentine JS. J. Am. Chem. Soc. 1982; 104:2588.

432. Manner VW, Mayer JM. J. Am. Chem. Soc. 2009; 131:9874. [PubMed: 19569636]

433. Eisenberg DC, Norton JR. Isr. J. Chem. 1991; 31:55.

434. Bullock RM. Comments Inorg. Chem. 1991; 12:1.

435. DuBois DL, DuBois MR. Chem. Soc. Rev. 2009; 38:62. [PubMed: 19088965]

436. (a) Kiss G, Zhang K, Mukerjess SL, Hoff CD, Roper GC. J. Am. Chem. Soc. 1990; 112:5657. (b) Hoff CD. Coord. Chem. Rev. 2000; 206-207:451.

437. Tilset M, Parker VD. J. Am. Chem. Soc. 1989; 111:6711.

438. Ryan OB, Tilset M, Parker VD. J. Am. Chem. Soc. 1990; 112:2618.

439. Jordan RF, Norton JR. J. Am. Chem. Soc. 1982; 104:1255.

440. Moore EJ, Sullivan JM, Norton JR. J. Am. Chem. Soc. 1986; 108:2257.

441. Kiss G, Zhang K, Mukerjee SL, Hoff CD. J. Am. Chem. Soc. 1990; 112:5657.

442. (a) Marcus RA, Sutin N. Biochim. Biophys. Acta, Rev. Bioenerg. 1985; 811:265. (b) Sutin N. Prog. Inorg. Chem. 1983; 30:441.

443. Hammes-Schiffer S, Soudackov AV. J. Phys. Chem. B. 2008; 112:14108. [PubMed: 18842015]

444. Tishchenko O, Truhlar DG, Ceulemans A, Nguyen MT. J. Am. Chem. Soc. 2008; 130:7000. [PubMed: 18465862]

445. Binstead RA, Stultz LK, Meyer TJ. Inorg. Chem. 1995; 34:546.

446. (a) Mader EA, Mayer JM. Inorg. Chem. 2010; 49:3685. [PubMed: 20302273] (b) Reference 51.

447. See the last page of the Supporting Information of reference 369a.

448. (a) Eberson L, Wistrand L-G. Acta Chem. Scand. 1980; B34:349. (b) Eberson L. J. Am. Chem. Soc. 1983; 105:3192.

449. Jönnson L. Acta Chem. Scand. 1983; B37:761.

450. (a) Graige MS, Paddock ML, Bruce JM, Feher G, Okamura MY. J. Am. Chem. Soc. 1996; 118:9005. (b) Paddock ML, Feher G, Okamura MY. Biochemistry. 1997; 36:14238. [PubMed: 9369497] (c) Okamura MY, Paddock ML, Graige MS, Feher G. Biochim. Biophys. Acta. 2000; 1458:148. [PubMed: 10812030]

451. Graige MS, Feher G, Okamura MY. Proc. Natl. Acad. Sci. USA. 1998; 95:11679. [PubMed: 9751725]

452. (a) Madhiri N, Finklea HO. Langmuir. 2006; 22:10643. [PubMed: 17129042] (b) Singh PS, Evans DH. J. Phys. Chem. B. 2006; 110:637. [PubMed: 16471577]

\section{Biographies}

Jeff Warren was born in Spokane, WA in 1982. He received his Bachelor of Science Degree in Chemistry from Washington State University in 2005, at which time he joined Professor James M. Mayer's research group at the University of Washington. He earned his $\mathrm{PhD}$ in March, 2010 and is currently a Postdoctoral Scholar in Chemistry at Caltech under the mentorship of Harry Gray. He is currently interested in understanding biological redox reactions, especially coupled redox reactions, using a combination of small molecule and biochemical tools.

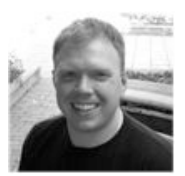

Tristan Tronic was born in Falls Church, Virginia in 1985. He received his B. S. in chemistry from the College of William and Mary in 2007, performing undergraduate research with Robert Pike. He then joined the group of James Mayer at the University of Washington, where he is currently studying redox reactions related to catalytic dioxygen/ water interconversion.

Chem Rev. Author manuscript; available in PMC 2011 December 8. 


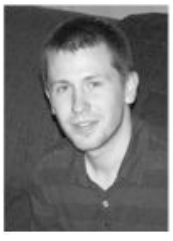

James Mayer was born in New York City in 1958 and did undergraduate research at Hunter College with Edwin Abbott, and with William Klemperer while earning his A.B. at Harvard. He completed a PhD at Caltech under the direction of John Bercaw in 1982, and after two years as a Visiting Scientist at DuPont moved to the University of Washington, where he is now Alvin L. and Verla R. Kwiram Professor of Chemistry. His interests in redox chemical reactions span inorganic, bioinorganic, organometallic, and physical organic chemistry.

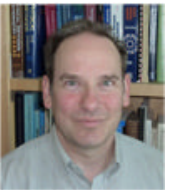




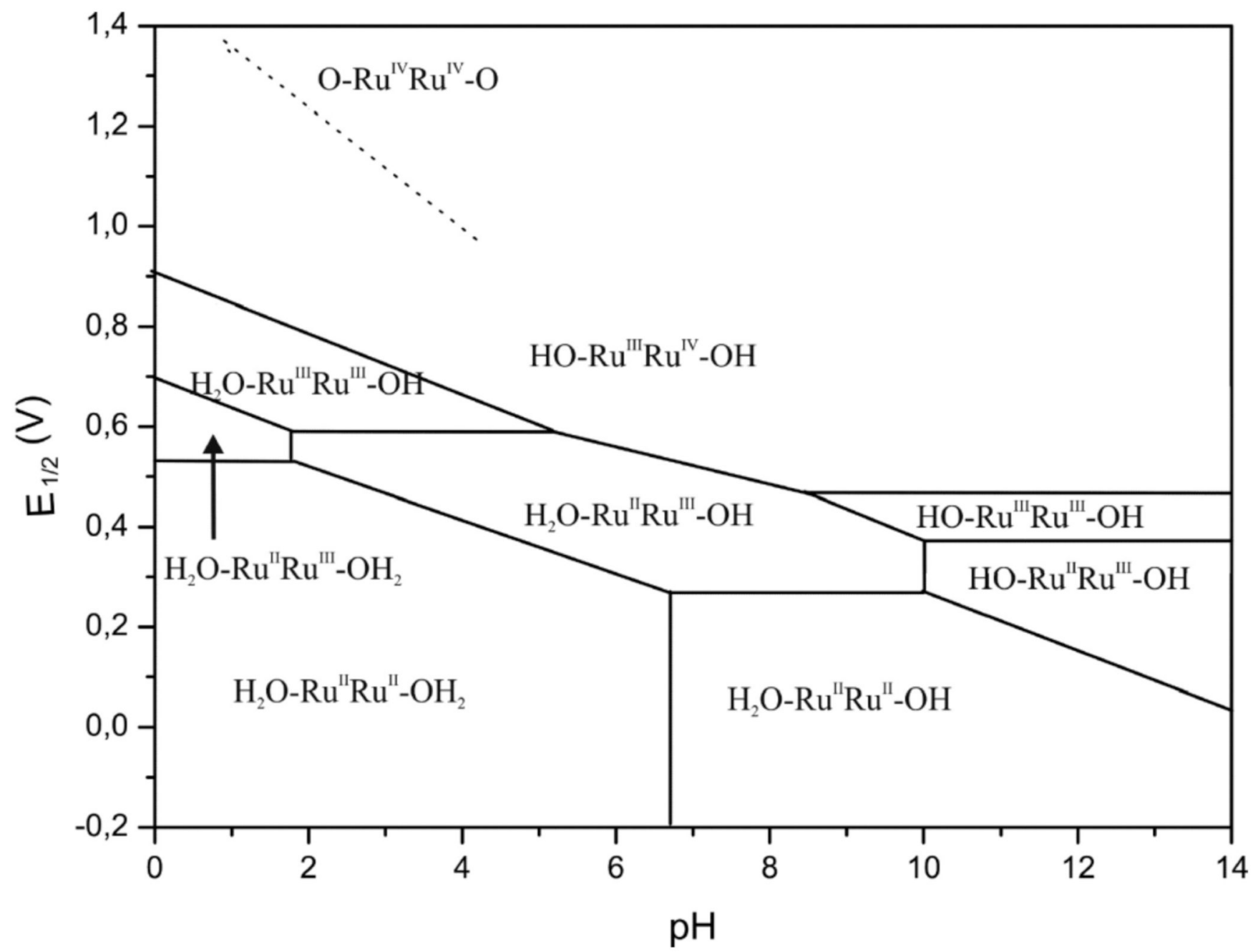

Figure 1.

Pourbaix diagram for the in, in $-\left\{\left[\mathrm{Ru}^{\mathrm{II}}(\operatorname{trpy})\left(\mathrm{H}_{2} \mathrm{O}\right)\right]_{2}(\mu \text {-bpp })\right\}^{3+}$ water oxidation catalyst (trpy is $2,2^{\prime}: 6^{\prime}, 2^{\prime \prime}$-terpyridine, bpp is bis(2-pyridyl)-3,5-pyrazolate)). Reprinted with permission from Ref. 68. (C) 2009 American Chemical Society. 
(a)<smiles>O=C(O)c1cc(O)ccc1O</smiles>

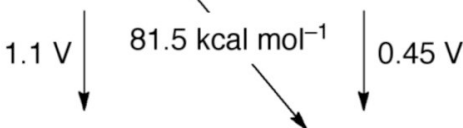<smiles></smiles><smiles>COc1ccc([O-])cc1</smiles><smiles>Oc1ccc(O)cc1</smiles>

$(2.4 \mathrm{~V})$

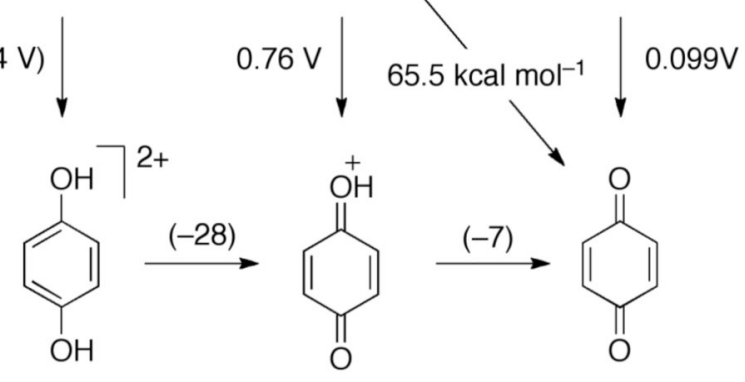

average $\mathrm{BDFE}=73.6 \mathrm{kcal} \mathrm{mol}{ }^{-1}$ (b)

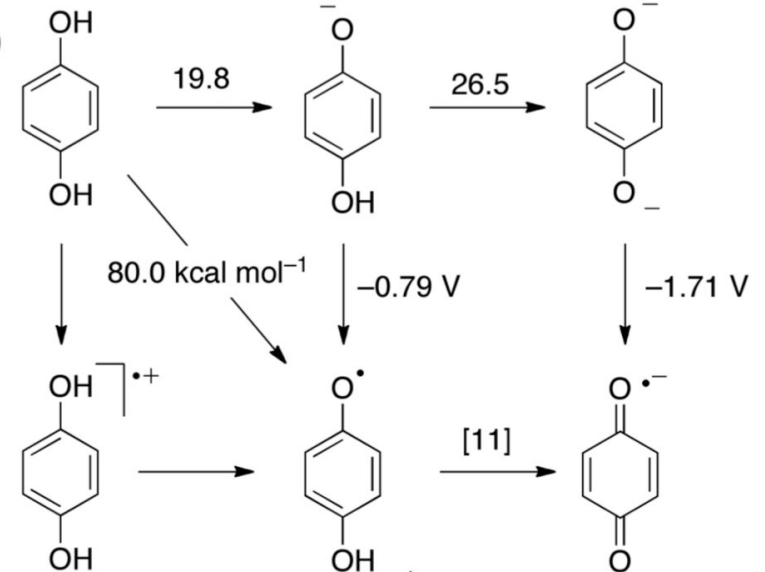

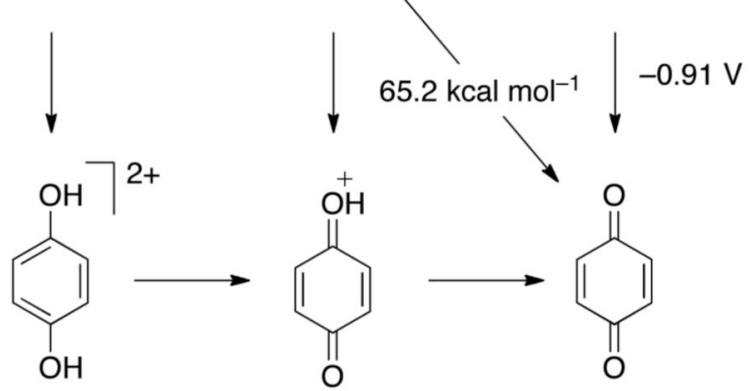

average $\mathrm{BDFE}=72.6 \mathrm{kcal} \mathrm{mol}^{-1}$

Figure 2.

Thermochemistry of the hydroquinone/benzoquinone system (a) in water and (b) in DMSO, from Table 6. Numbers above horizontal arrows give $\mathrm{p} K_{\mathrm{a}}$ values; numbers beside vertical arrows give electrochemical potentials (vs. NHE in water and vs. $\mathrm{Cp}_{2} \mathrm{Fe}^{+/ 0}$ in DMSO); numbers bisecting diagonal lines are BDFEs in $\mathrm{kcal} \mathrm{mol}^{-1}$. In (a), the values in parentheses were estimated by Laviron;152 in (b) the values in square brackets are estimates using eq 7 and Hess' Law. 


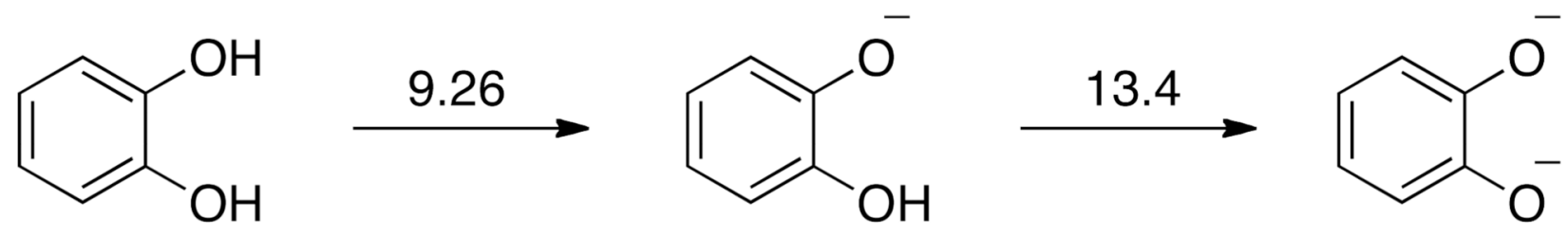<smiles>Oc1ccccc1O</smiles>

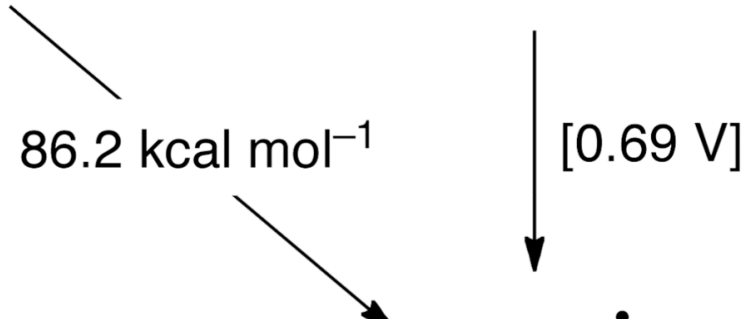<smiles>Oc1ccccc1Oc1ccccc1</smiles><smiles>O=C1CC=CCC1=[OH+]</smiles><smiles>[O-]c1ccccc1O</smiles><smiles>CC1C=CC=CC(=O)C1</smiles><smiles>CC</smiles>
$65.4 \mathrm{kcal} \mathrm{mol}^{-1}$

\section{Average BDFE $=75.9 \mathrm{kcal} \mathrm{mol}^{-1}$}

Figure 3.

Thermochemistry of the catechol/ortho-quinone system in water, with $\mathrm{p} K_{\mathrm{a}}$ values above horizontal arrows, redox potentials (in V vs. NHE) beside vertical arrows, and BDFE values (in $\mathrm{kcal} \mathrm{mol}^{-1}$ ) bisecting diagonal lines. The values in square brackets are estimates using eq 7 and Hess' Law. 

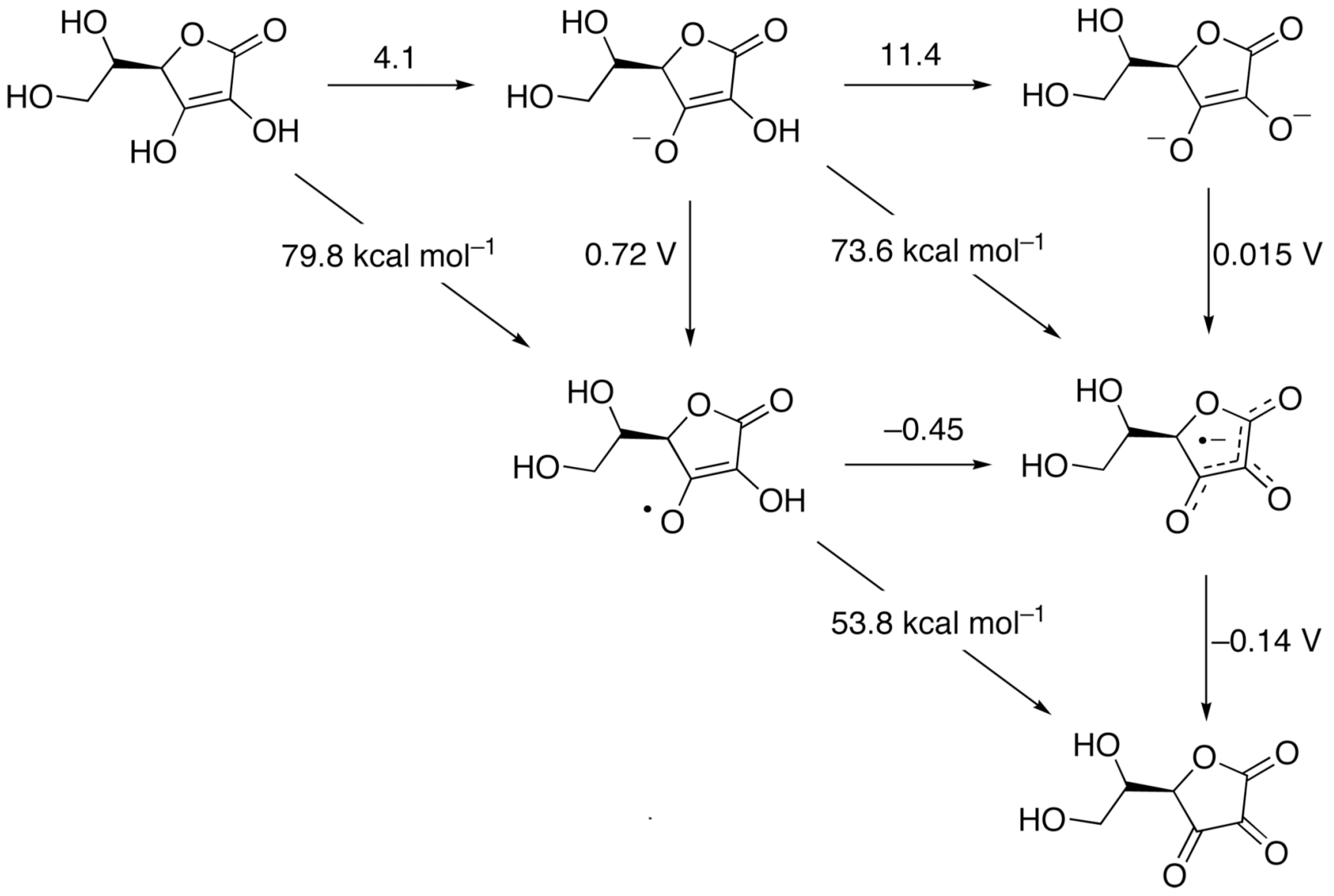

Figure 4.

Aqueous thermochemistry of ascorbic acid, with $\mathrm{p} K_{\mathrm{a}}$ values above horizontal arrows, redox potentials (in V vs. NHE) beside vertical arrows, and BDFE values (in $\mathrm{kcal} \mathrm{mol}^{-1}$ ) bisecting diagonal lines. Data from references 135, 183, 184 and 187 (see Table 7). 
(a)

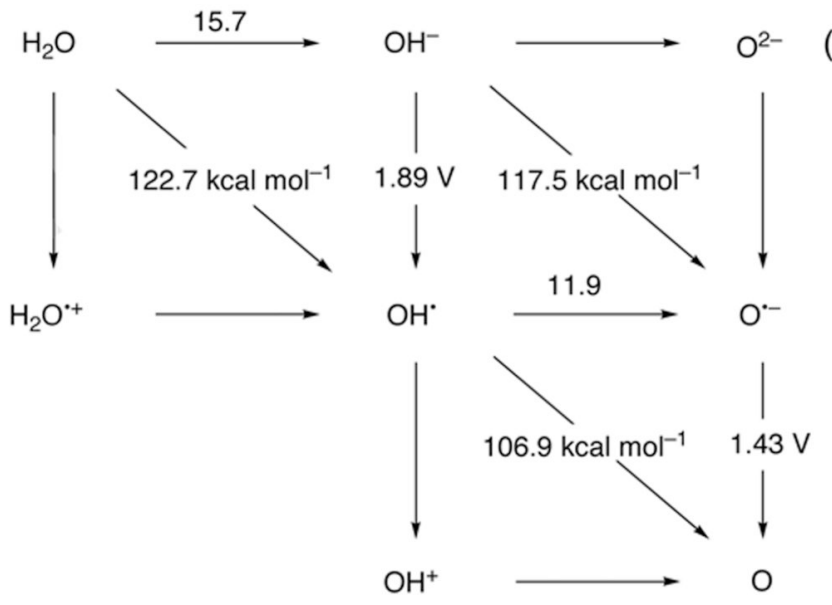

Average BDFE $=114.8 \mathrm{kcal} \mathrm{mol}^{-1}, \mathrm{E}^{\circ}\left(\mathrm{O} / \mathrm{H}_{2} \mathrm{O}\right)=2.48 \mathrm{~V}$ (b)

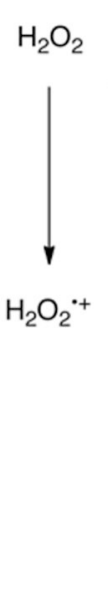

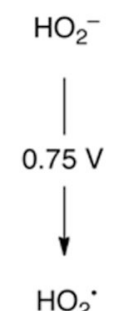
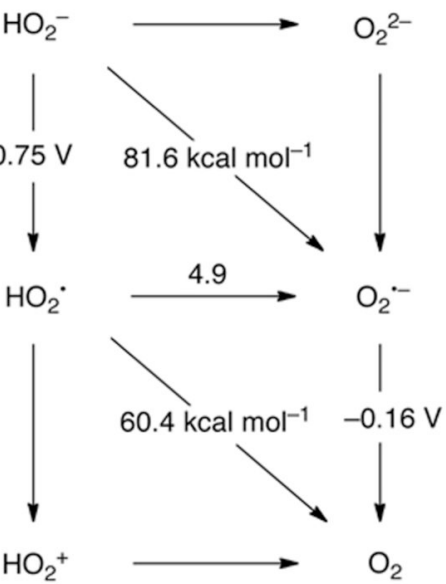

Average $B D F E=75.6 \mathrm{kcal} \mathrm{mol}^{-1}$

Figure 5.

Aqueous PCET thermochemistry of (a) aqueous $\mathrm{H}_{2} \mathrm{O}$ and (b) aqueous hydrogen peroxide, with $\mathrm{p} K_{\mathrm{a}}$ values above horizontal arrows, redox potentials (in V vs. NHE) beside vertical arrows, and BDFE values (in $\mathrm{kcal} \mathrm{mol}^{-1}$ ) bisecting diagonal lines. 

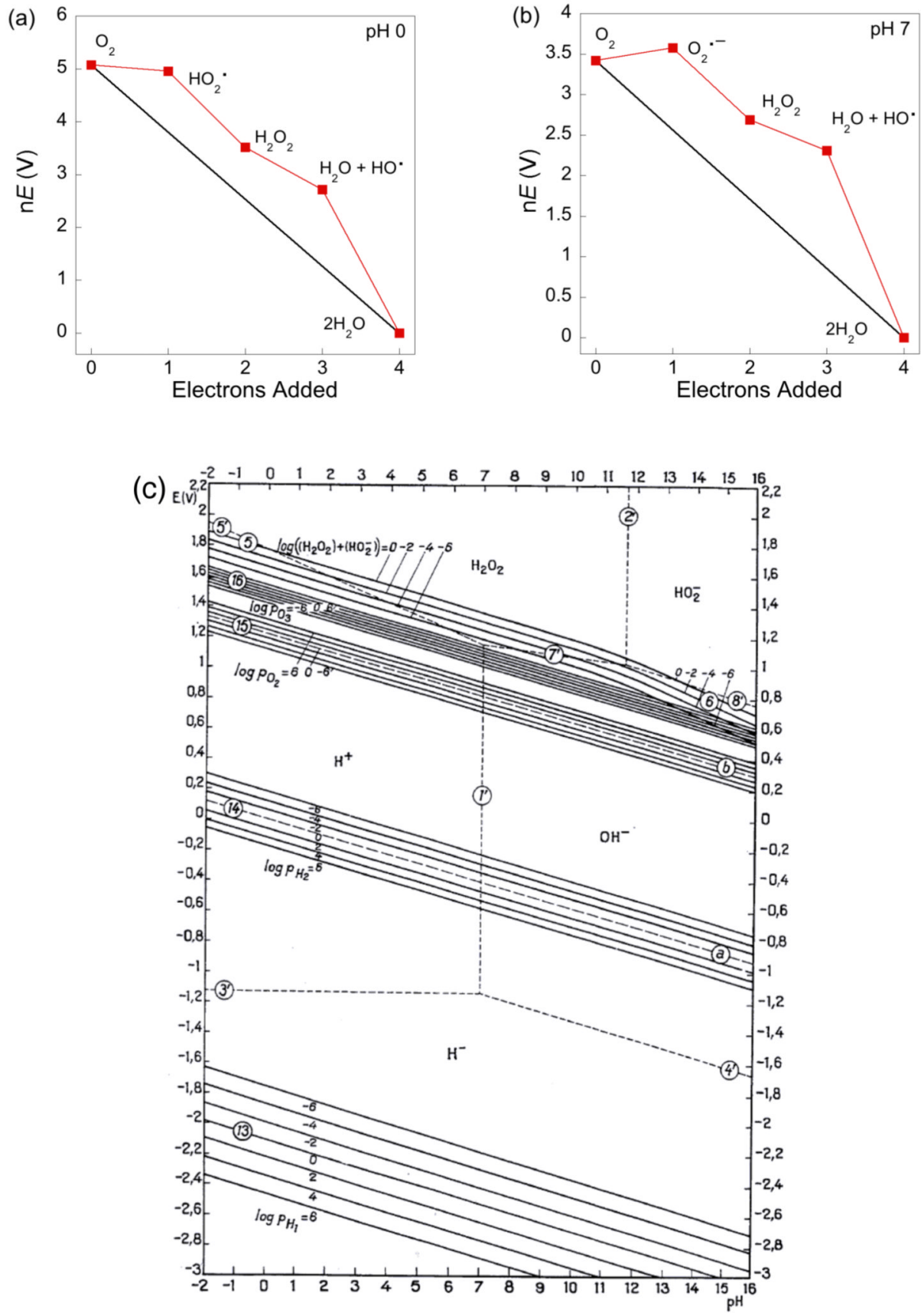

Figure 6.

Frost diagram for dioxygen reduction to water showing the free energy $(\mathrm{n} E)$ of the various reactive oxygen species at (a) $\mathrm{pH} 0$ and (b) $\mathrm{pH}$ 7. (c) Pourbaix diagram for water, showing the potentials for oxidation to $\mathrm{O}_{2}$ and reduction to $\mathrm{H}_{2}$ as a function of $\mathrm{pH}$ and the pressure of $\mathrm{O}_{2}$ and $\mathrm{H}_{2}$ (from M. Pourbaix, Atlas of Electrochemical Equilibria in Aqueous Solutions, reference 67, with permission, (C) NACE International 1974). 
<smiles></smiles><smiles></smiles><smiles>Cc1cc2c(cc1C(C)C)nc1c(=O)[nH]c(=O)nc-1n2C</smiles><smiles>[14CH3][V]</smiles><smiles>[14CH3][V]</smiles><smiles></smiles><smiles>[R]n1c2nc(=O)[nH]c(=O)c-2nc2cc(C)c(C)cc21</smiles><smiles>[R]n1c2nc(=O)[nH]c(=O)c-2nc2cc(C)c(C)cc21</smiles>

Figure 7.

Double square scheme showing the PCET thermochemistry of flavins. While only one resonance form is drawn for each species, many are better described by multiple structures. Numbers above horizontal arrows give $\mathrm{p} K_{\mathrm{a}}$ values; numbers beside vertical arrows give electrochemical potentials $v s$. NHE in water; numbers bisecting diagonal lines are BDFEs in $\mathrm{kcal} \mathrm{mol}^{-1}$. The values in square brackets are estimates using eq 7 and Hess' Law. For definitions of R, see Scheme 10. References for the values in this scheme, and descriptions of how they were derived, are given in the text. 

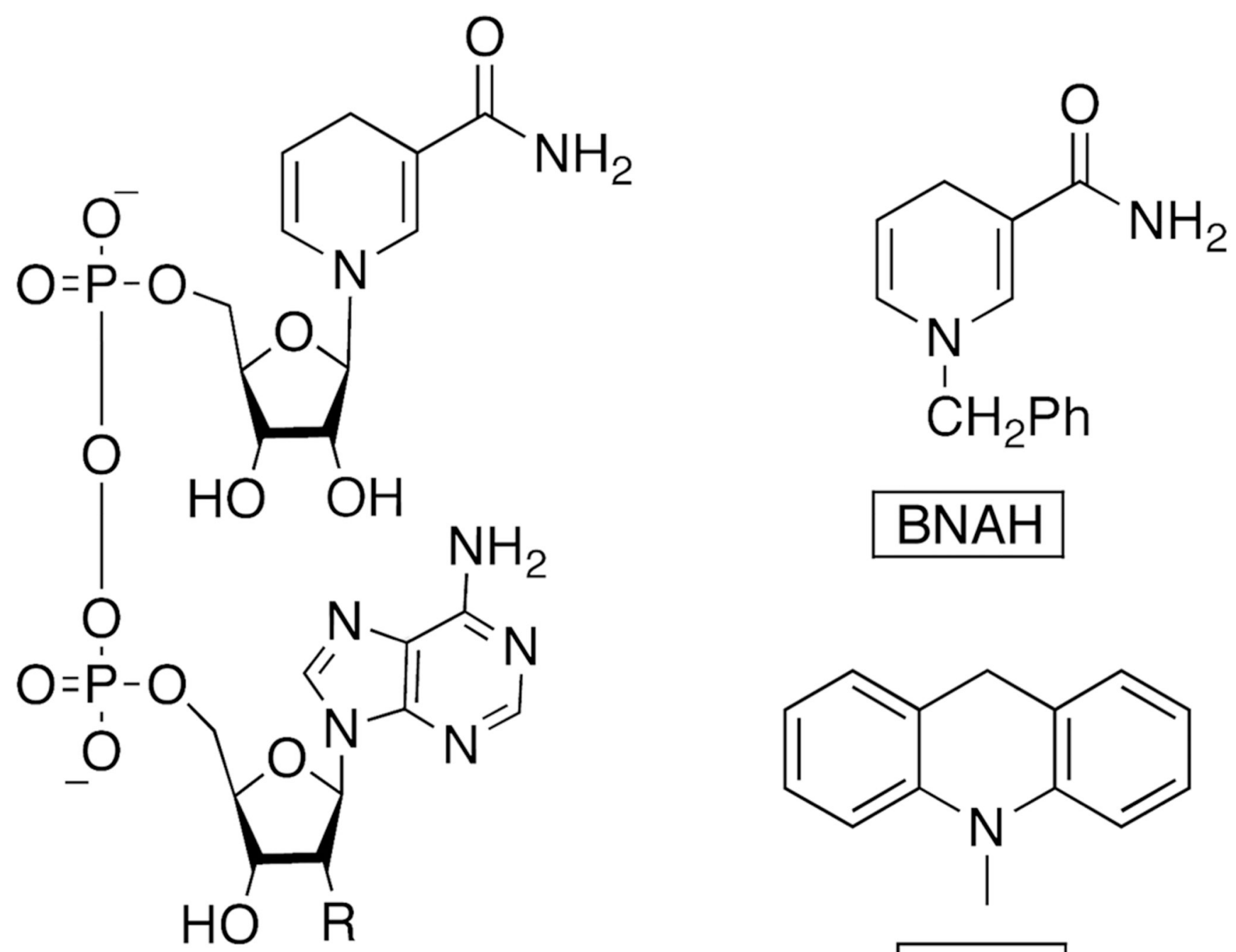

\section{$\mathrm{R}=\mathrm{OH}(\mathrm{NADH})$ $\mathrm{OPO}_{3}{ }^{2-}(\mathrm{NADPH})$}

$\mathrm{AcrH}_{2}$

Figure 8.

Structures of nicotinamide adenine nucleotide (NADH), nicotinamide adenine dinucleotide phosphate (NADPH) and the model complexes $N$-benzyl-1,4-dihydronicotinamide (BNAH) and 10-methyl-9,10-dihydroacridine $\left(\mathrm{AcrH}_{2}\right)$. 
(a)

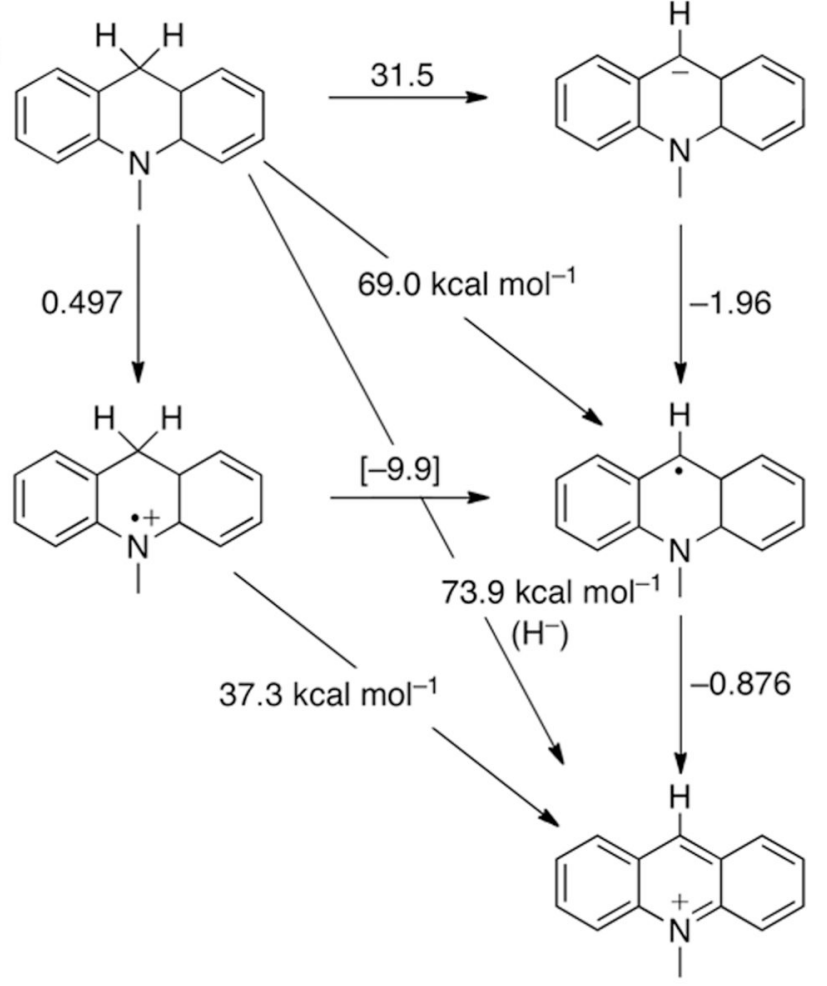

(b)<smiles>CN1c2ccccc2CC2C=CC=CC21</smiles><smiles>C1CC[GeH2]C1</smiles><smiles>CN1c2ccccc2C=C2C=CC=CC21</smiles><smiles>[3H]C1c2ccccc2N(C)C2C=CC=CC12</smiles><smiles>CCCCC</smiles>

4]

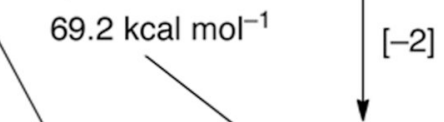

[-2]

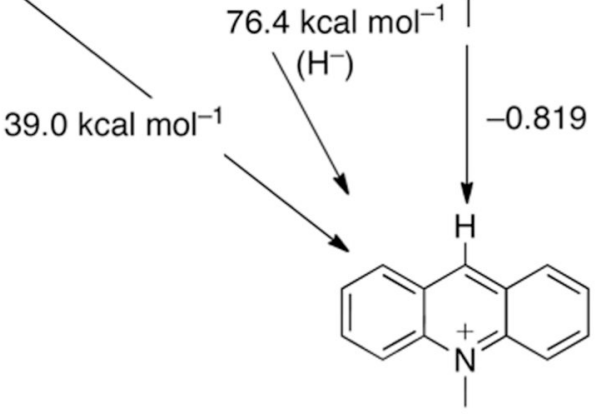

Figure 9.

Square schemes showing the PCET thermochemistry of 10-methyl-9,10-dihydroacridine $\left(\mathrm{AcrH}_{2}\right)$ in (a) DMSO and (b) MeCN from Cheng;352,353 see text. Values above horizontal arrows give $\mathrm{p} K_{\mathrm{a}}$ values; numbers beside vertical arrows give electrochemical potentials $v s$. $\mathrm{Cp}_{2} \mathrm{Fe}^{+/ 0}$; numbers bisecting diagonal lines are BDFEs in $\mathrm{kcal} \mathrm{mol}^{-1}$; and numbers along the steep diagonals are hydride affinities. The values in square brackets are estimates using eq 7 and Hess' Law. For definitions of R, see Figure 8. 


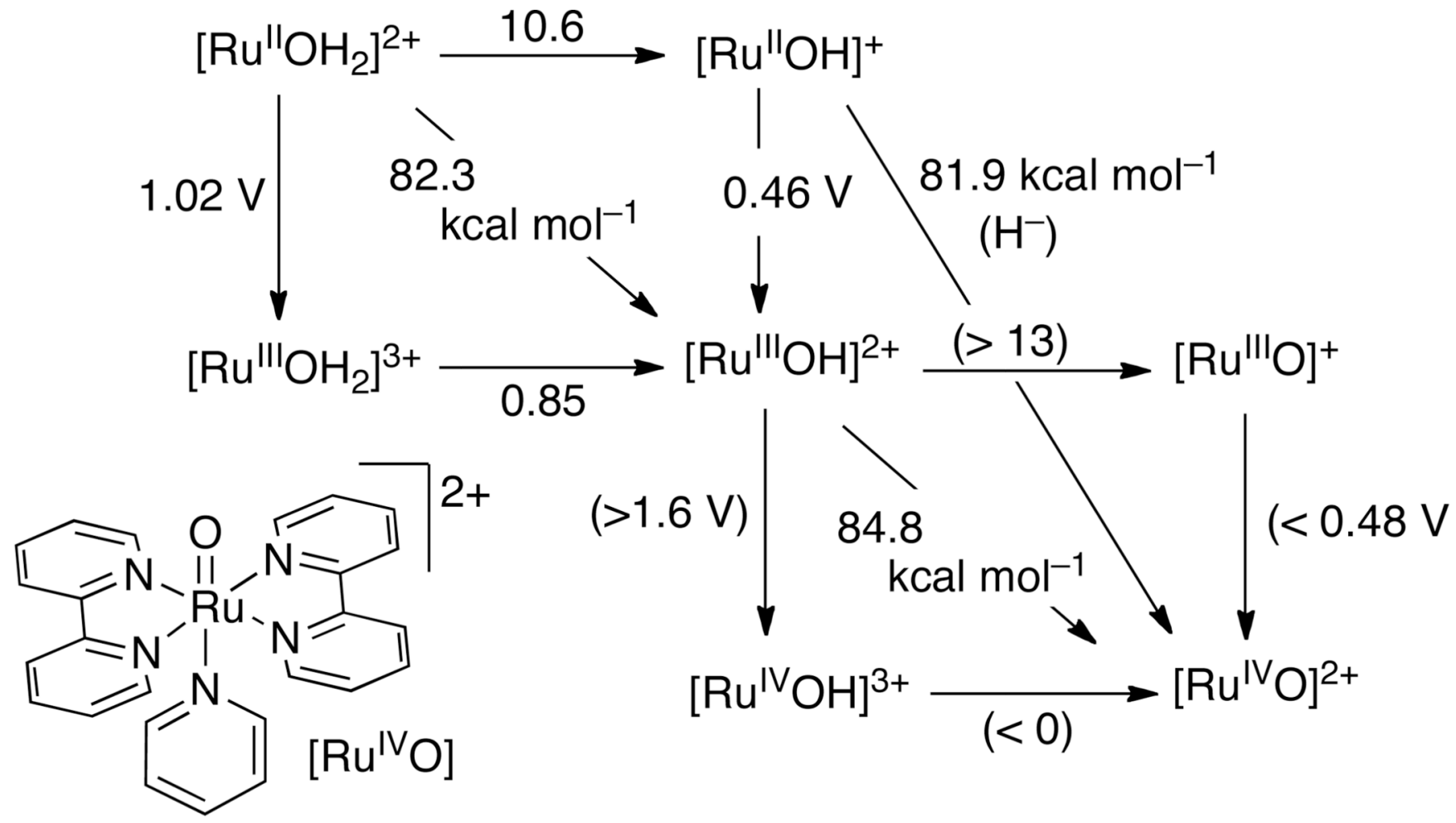

Figure 10.

Double square scheme showing the PCET thermochemistry of $\left[\text { cis-(bpy) } 2(\mathrm{py}) \mathrm{RuOH}_{x}\right]^{n+}$ from reference(s) 383 and 390. Numbers above horizontal arrows give $\mathrm{p} K_{\mathrm{a}}$ values; numbers beside vertical arrows give electrochemical potentials $v s$. NHE in water; numbers bisecting diagonal lines are BDFEs in $\mathrm{kcal} \mathrm{mol}^{-1}$ except for the long diagonal at left which is a hydride affinity, determined following reference 385a. Values in (parentheses) are limits derived from experimental results in 383 . 

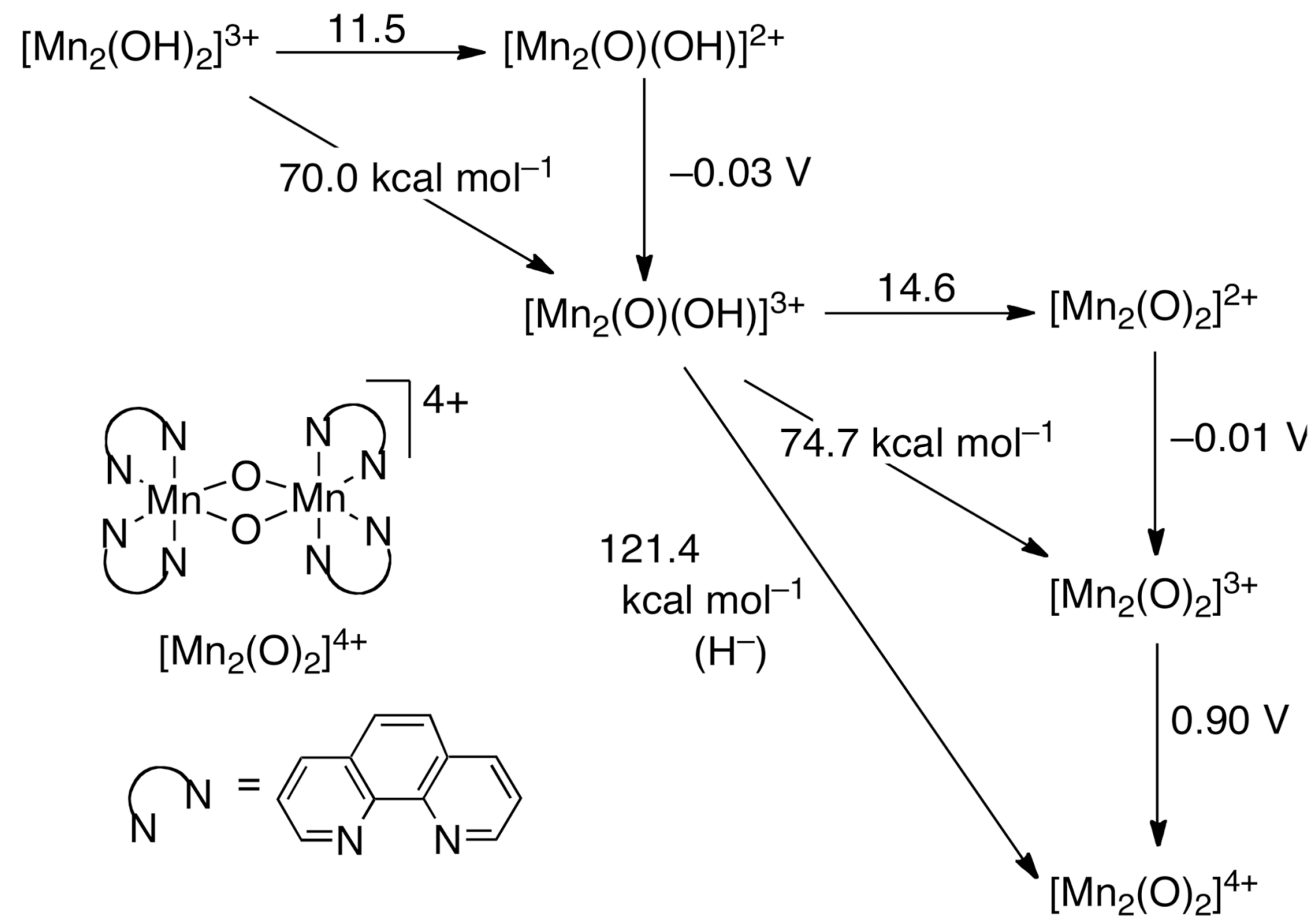

Figure 11.

PCET thermochemistry of the $\left[(\mathrm{phen})_{4} \mathrm{Mn}_{2}(\mathrm{O})_{2}\right]^{3+}$ system in MeCN, from reference 415.

The phen ligands are omitted from the formulae for brevity. Numbers above horizontal arrows give $\mathrm{p} K_{\mathrm{a}}$ values; numbers beside vertical arrows give electrochemical potentials $v s$. $\mathrm{Cp}_{2} \mathrm{Fe}^{+/ 0}$; numbers bisecting diagonal lines are BDFEs in $\mathrm{kcal} \mathrm{mol}^{-1}$ except for the long diagonal at left which is a hydride affinity. 


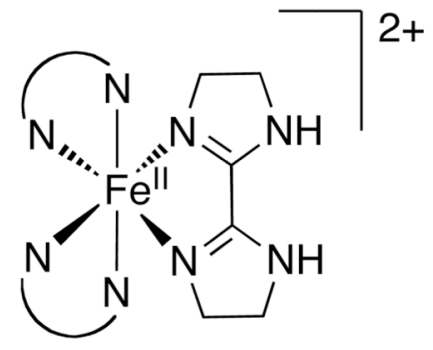

$\mathrm{Fe}^{\mathrm{Il}} \mathrm{H}_{2} \mathrm{bim}$
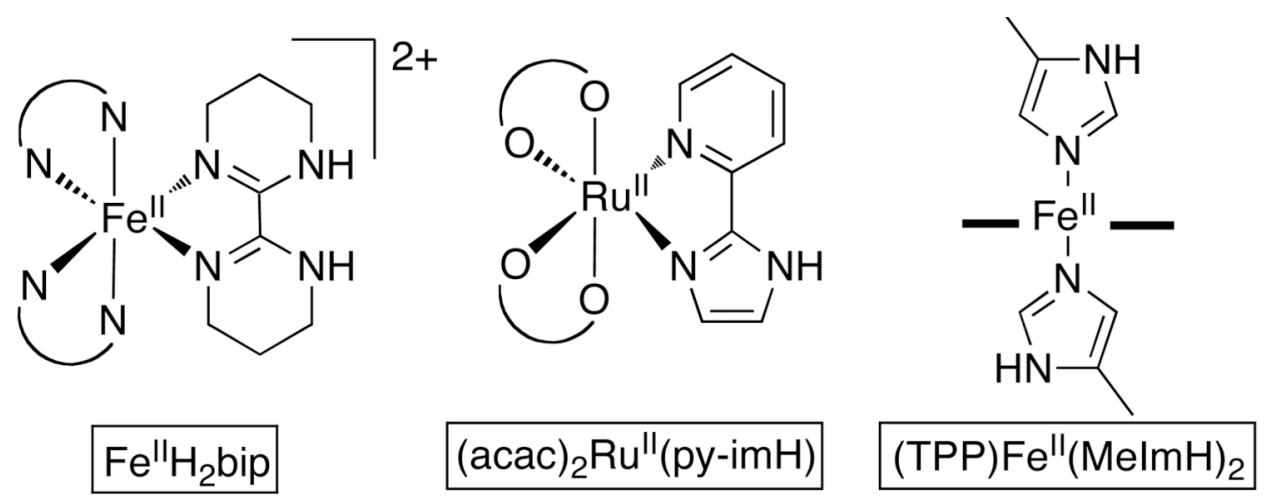

Figure 12.

Examples of transition metal PCET systems with three bonds between the redox site and acid/base site. The ancillary ligands in $\mathrm{Fe}^{\mathrm{II}} \mathrm{H}_{2}$ bim and $\mathrm{Fe}^{\mathrm{II}} \mathrm{H}_{2}$ bip are the same as the ligand shown in full. The ancillary O-O ligands are acac $(=2,4$-pentanedionato). The black bar in (TPP)Fe ${ }^{\mathrm{II}}(\mathrm{MeImH})_{2}$ represents meso-tetraphenylporphyrin. 


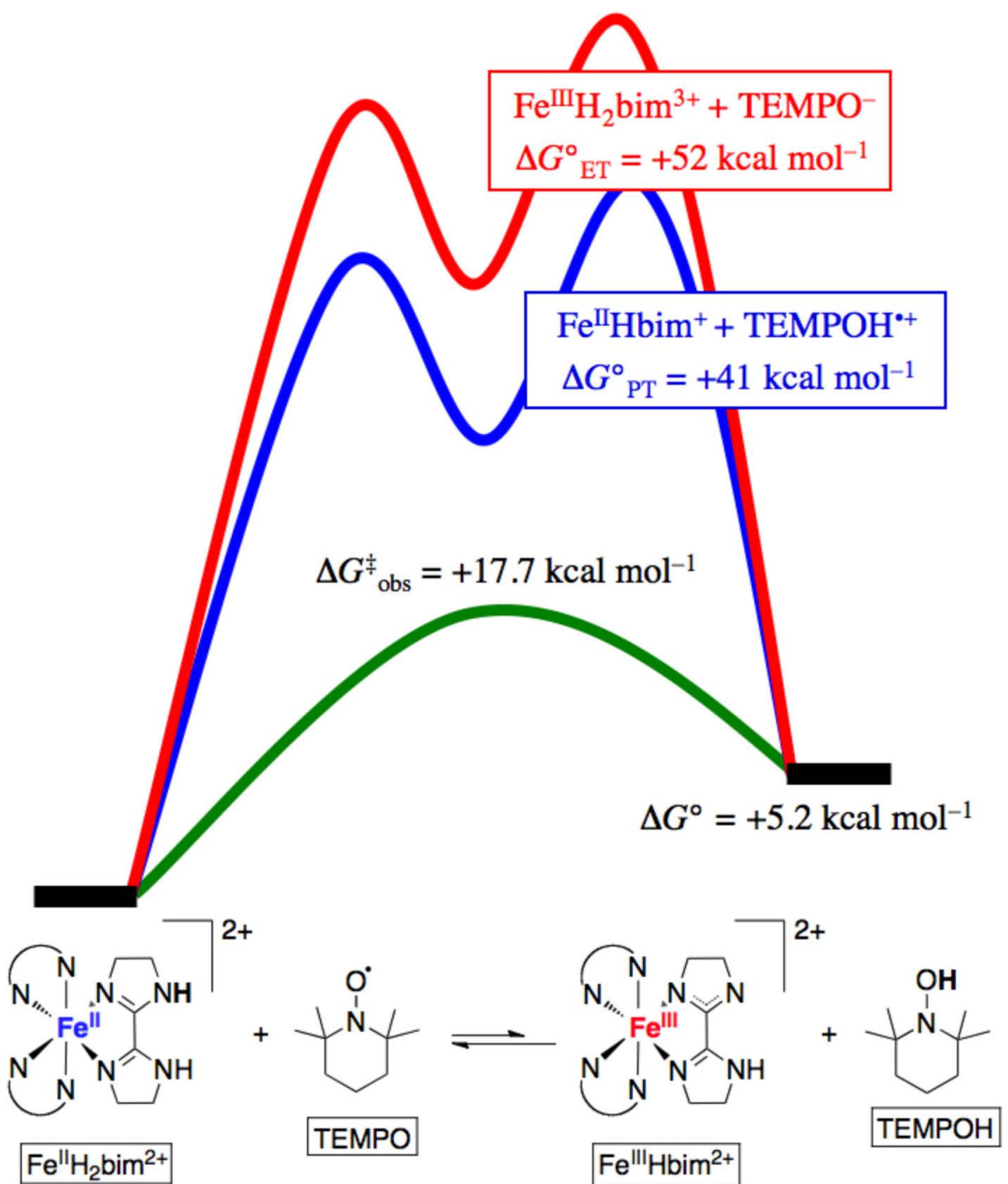

Figure 13.

Potential energy surface showing free energy changes for different mechanisms of Htransfer for the reaction of $\mathrm{Fe}^{\mathrm{II}} \mathrm{H}_{2}$ bim + TEMPO. Not drawn to scale. 

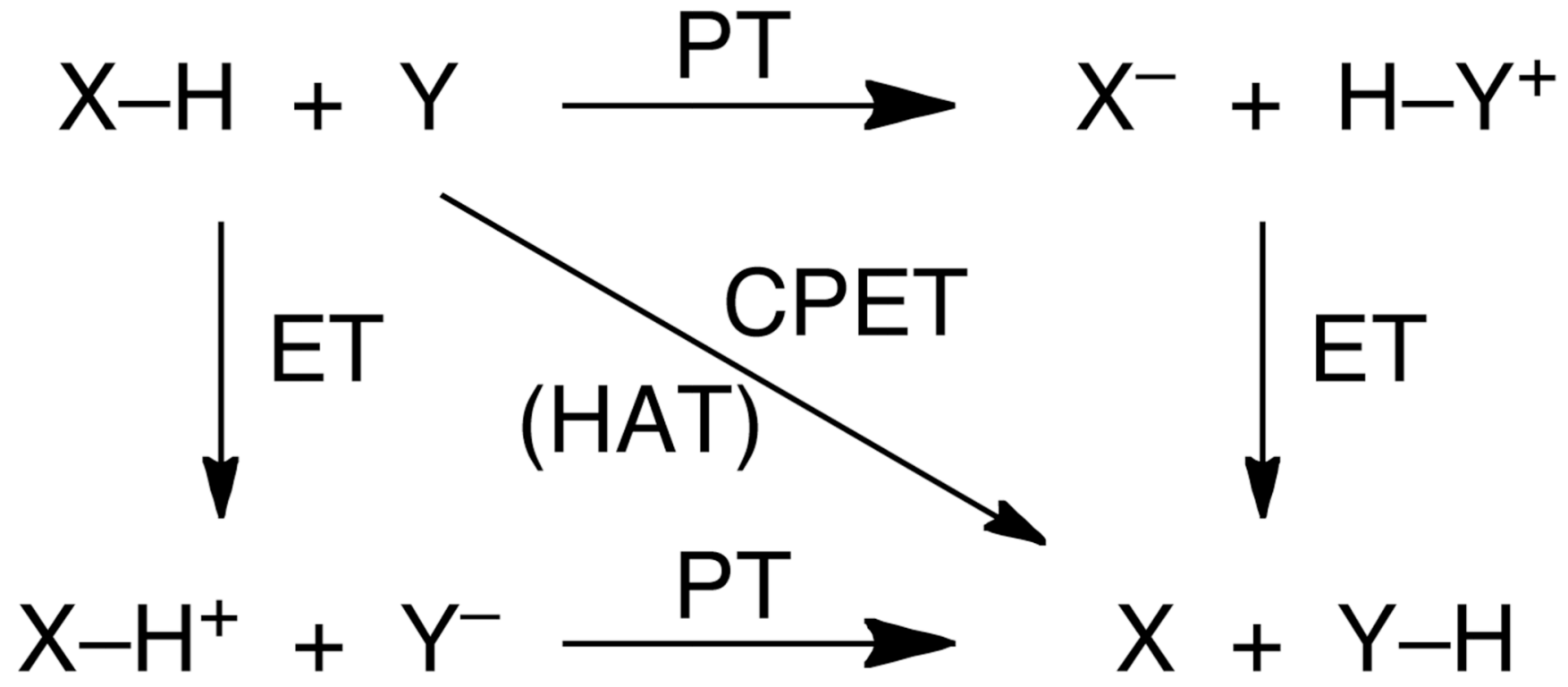

Scheme 1.

Concerted vs. stepwise transfer of $e^{-}+\mathrm{H}^{+}$. 


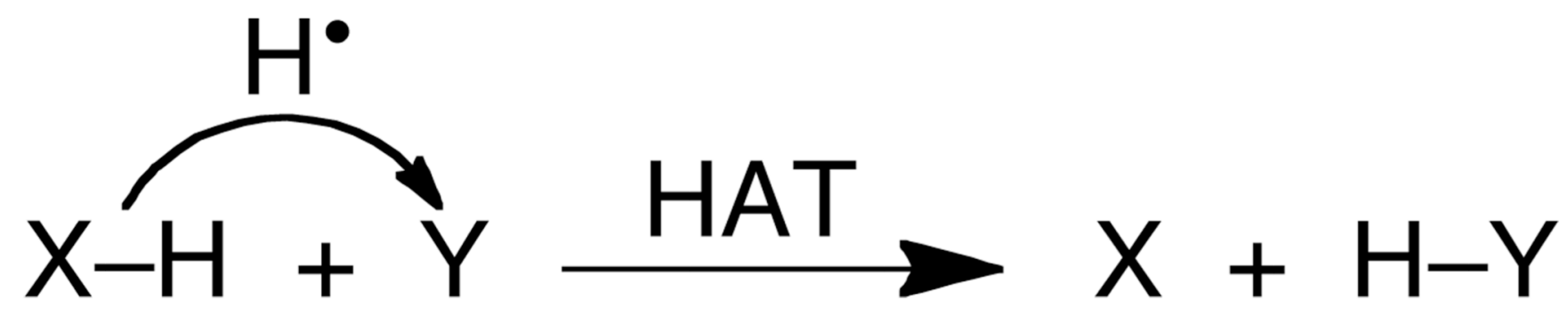

Scheme 2.

Hydrogen atom transfer. 


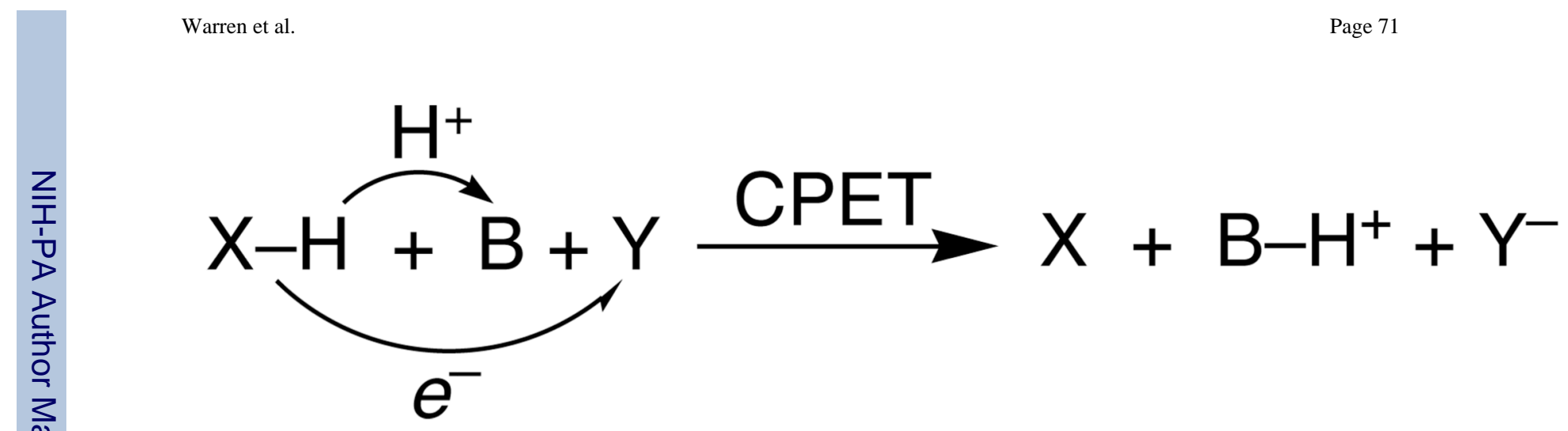

Scheme 3.

Concerted proton-electron transfer that is not HAT. 


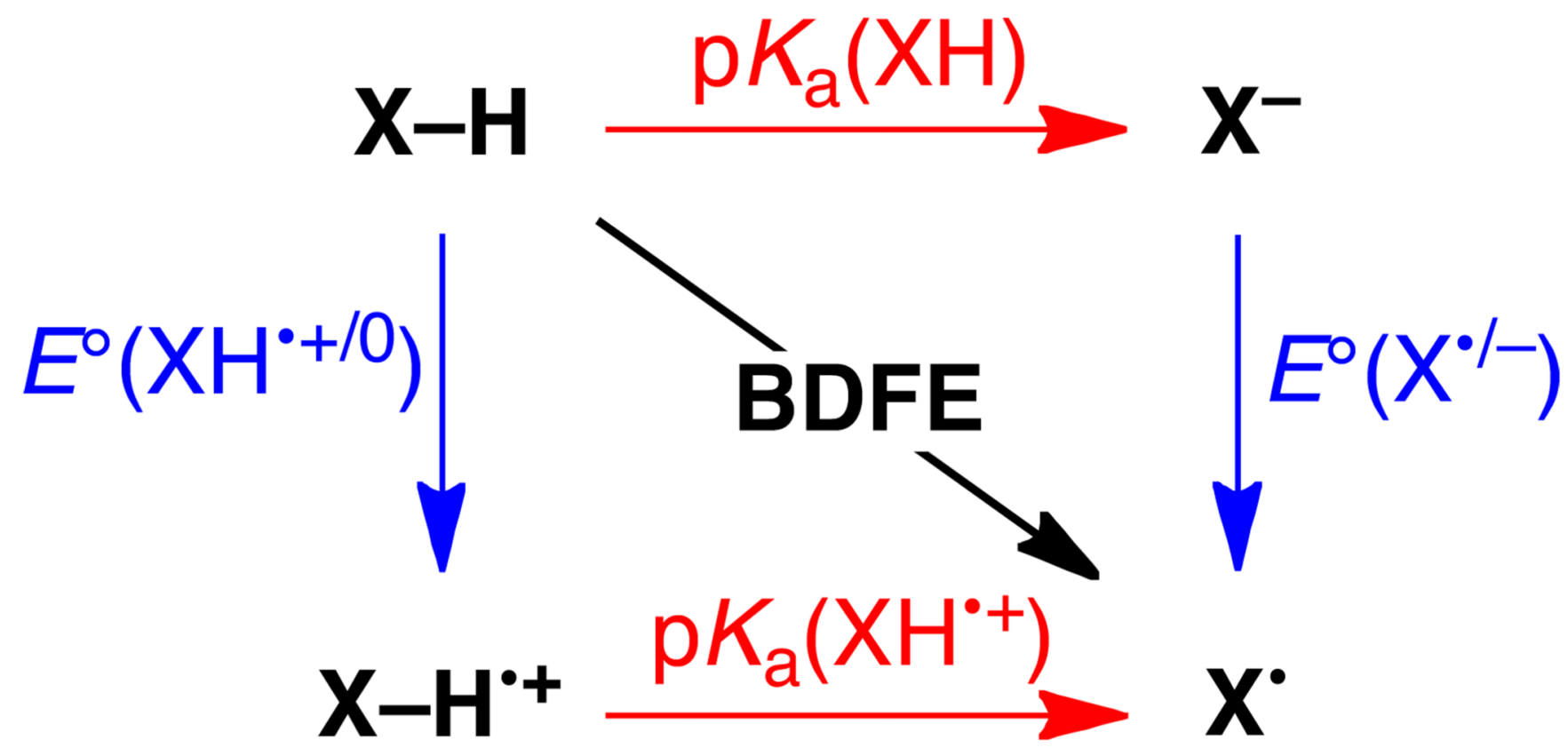

Scheme 4.

Thermochemical square scheme for a PCET reagent. 

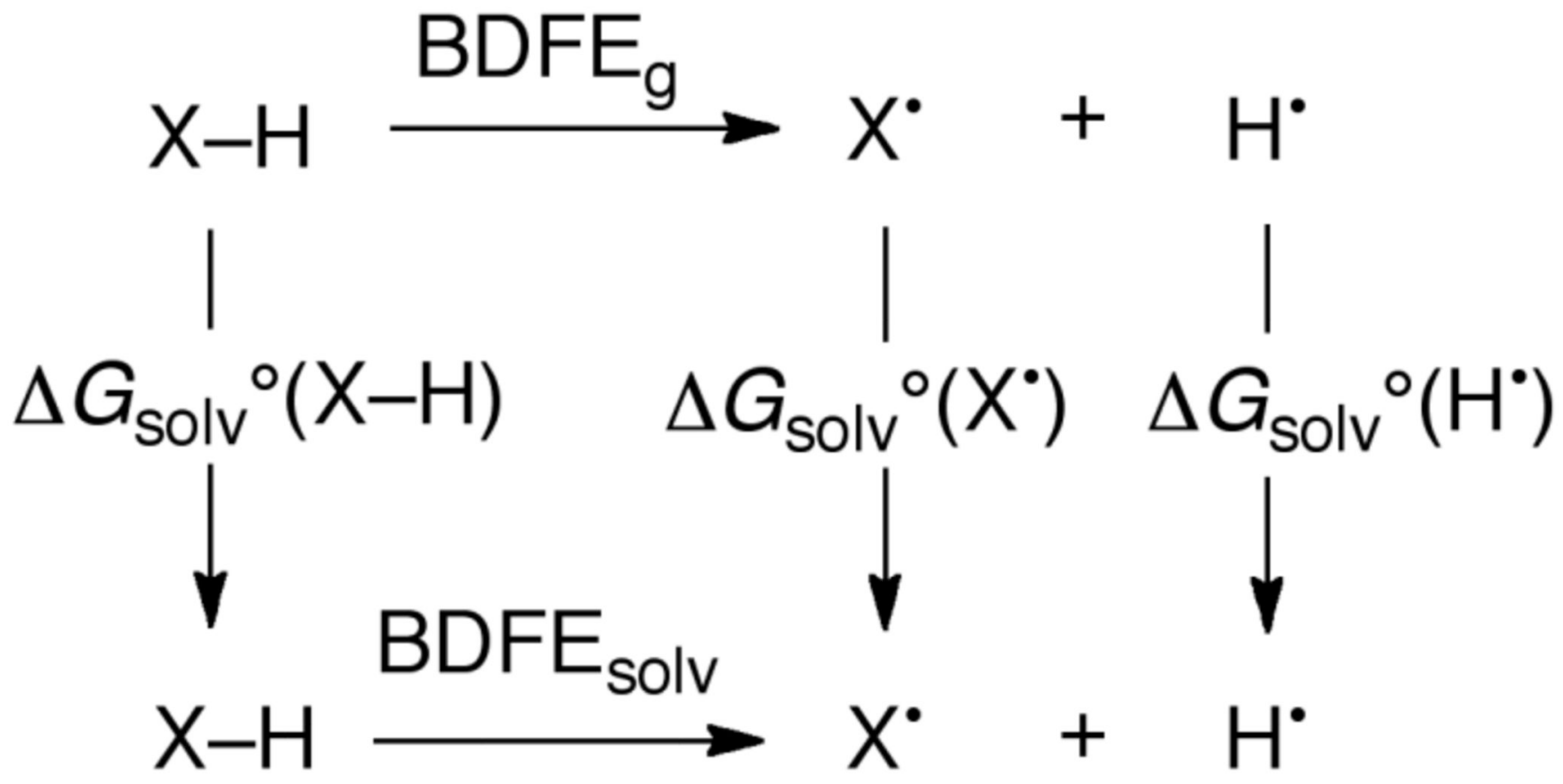

Scheme 5.

Relationship between gas-phase and solution bond dissociation free energies. 


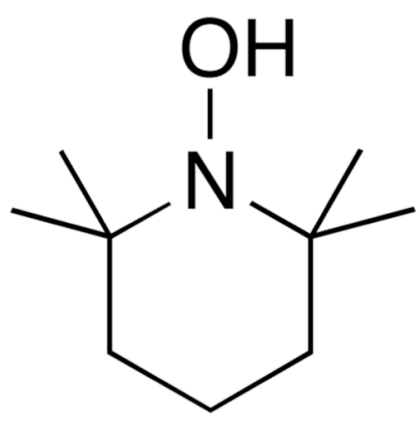

TEMPOH

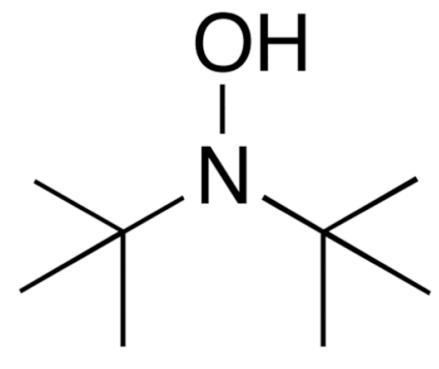

${ }^{t} \mathrm{BuNOH}$

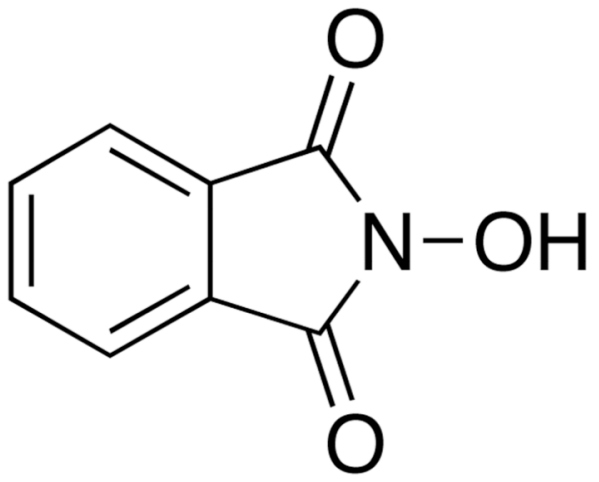

NHPI

Scheme 6.

Hydroxylamines. 


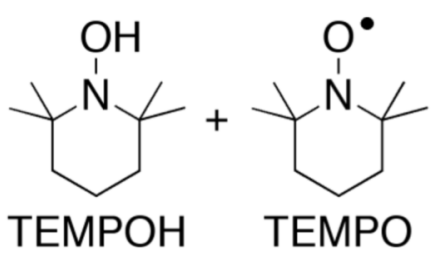

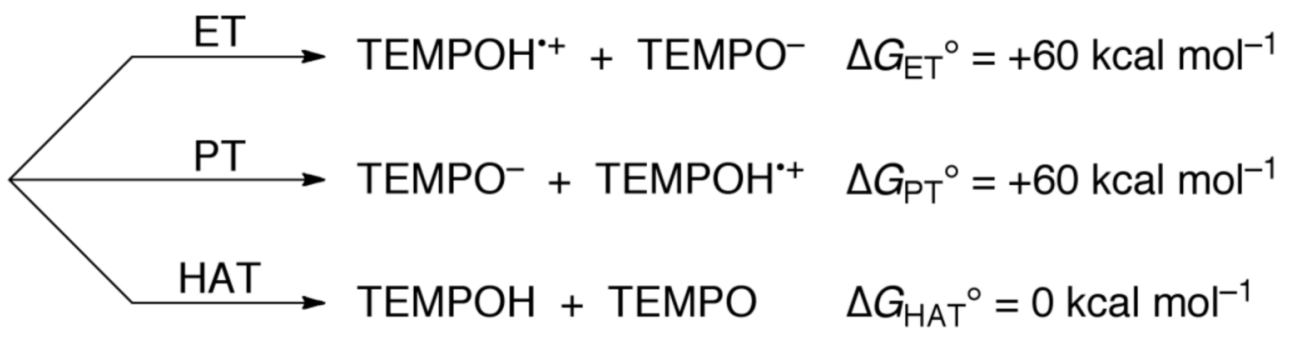

$$
\Delta G_{\mathrm{obs}^{\ddagger}}{ }^{\ddagger}=+16.5 \mathrm{kcal} \mathrm{mol}^{-1}
$$

Scheme 7.

Thermochemical analysis of stepwise $v s$. concerted pathways for the TEMPO + TEMPOH self-exchange reaction. 
<smiles>Cc1c(C)c2c(c(C)c1O)CC[C@](C)(P)O2</smiles><smiles>CCC[C@H](C)CCC[C@H](C)CCCC(C)C</smiles>

Trolox $\mathrm{C}, \mathrm{R}=\mathrm{CO}_{2} \mathrm{H}$ (mixture of isomers)

HMPC, $R=M e$

Scheme 8.

$\alpha$-Tocopherol (vitamin E) and analogs Trolox C, and HPMC. 
<smiles>O=C1C=CC=CC1=O</smiles>

Scheme 9.

$\mathrm{H}^{\bullet}$ loss and intramolecular $\mathrm{H}$-bonding in ortho-quinones. 
<smiles>[R]n1c2nc(=O)[nH]c(=O)c-2nc2cc(C)c(C)cc21</smiles>

6,7-dimethyl-isoalloxazine

$\mathrm{R}=\mathrm{H}$ (lumichrome)

Me (lumiflavin)

$\mathrm{CH}_{2}(\mathrm{CHOH})_{3} \mathrm{CH}_{2} \mathrm{OH}$ (riboflavin)

$\mathrm{CH}_{2}(\mathrm{CHOH})_{3} \mathrm{CH}_{2} \mathrm{O}\left(\mathrm{PO}_{3}{ }^{-}\right.$) (flavin mononucleotide, FMN)

$\mathrm{CH}_{2}(\mathrm{CHOH})_{3} \mathrm{CH}_{2} \mathrm{O}\left(\mathrm{PO}_{3}{ }^{-}\right)_{2}$-adenine (flavin adenine dinucleotide (FAD)

Scheme 10.

Nomenclature and structures of biologically relevant flavins. 


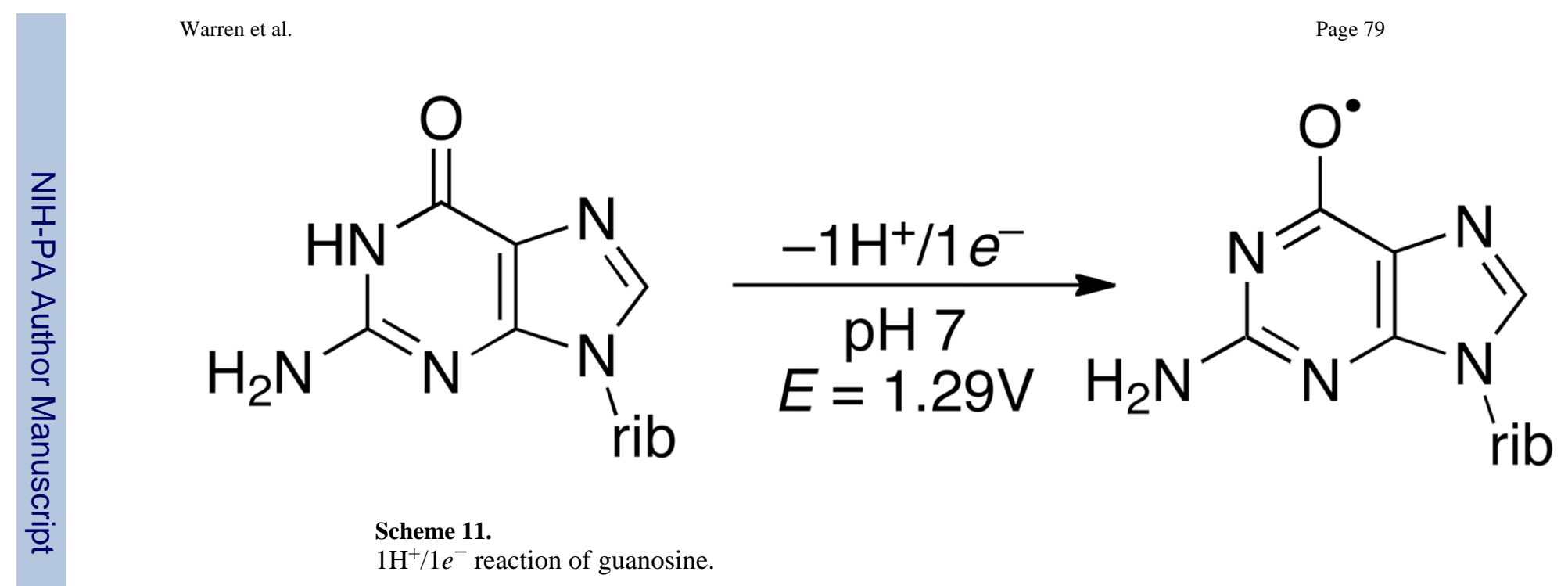




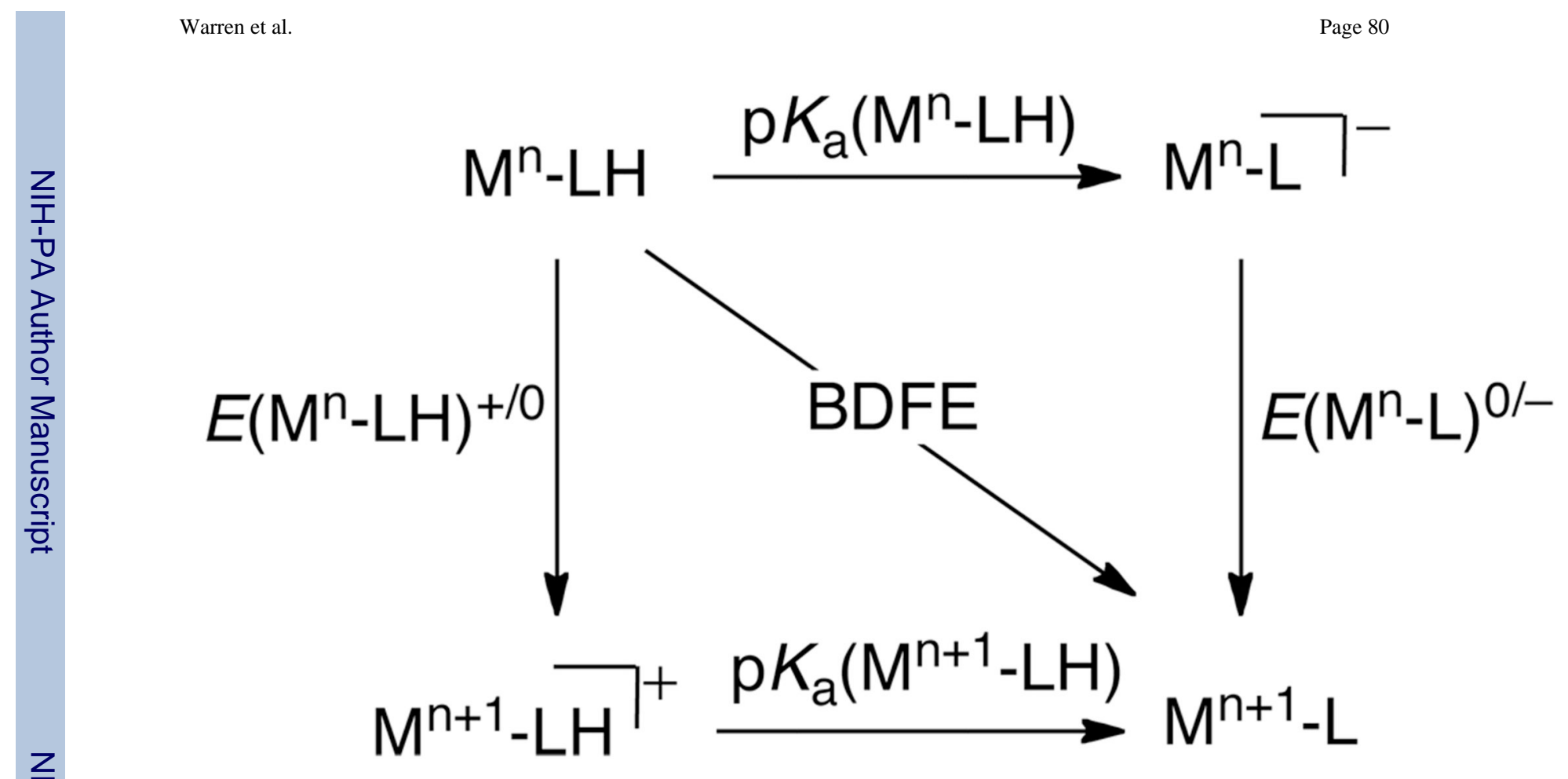

Scheme 12.

Thermochemical cycle for transition metal PCET systems. 


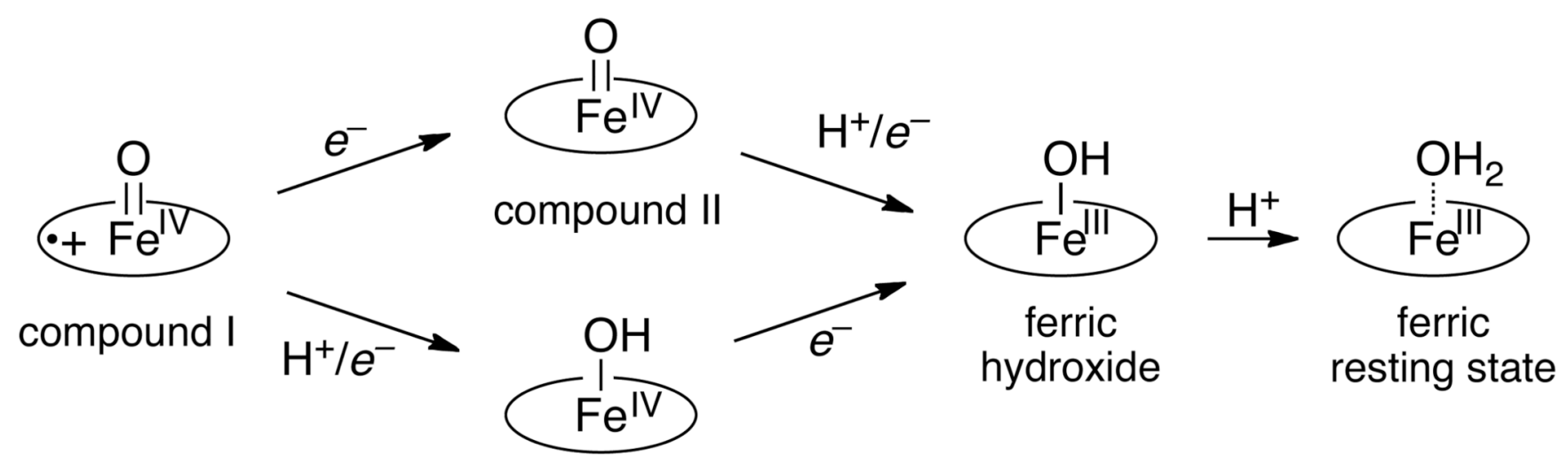

Scheme 13.

PCET Reactions of High-Valent Heme Species. 

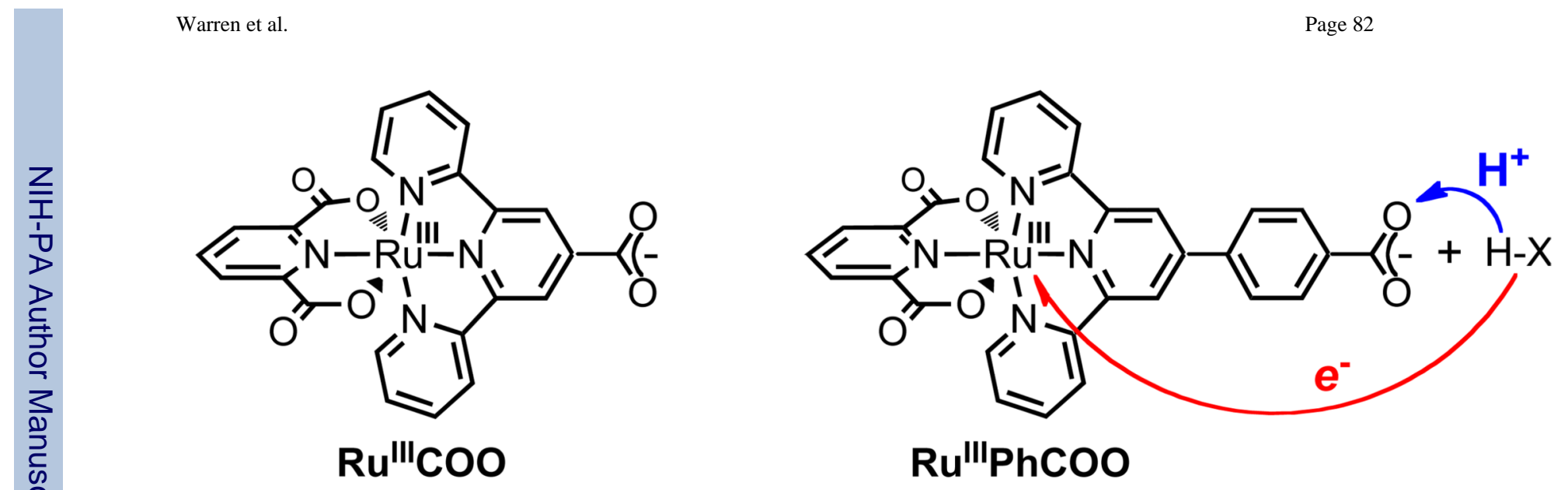

Scheme 14.

Ruthenium complexes with large separations between basic and redox sites. 
Table 1

Summary of constants $C_{\mathrm{G}}$ and $C_{\mathrm{H}}$ in common solvents. ${ }^{a}$

\begin{tabular}{|c|c|c|c|c|}
\hline solvent & $C_{\mathrm{G}}$ & $\mathbf{T}\left(\Delta S^{\circ}\right)_{\text {solv }}^{b}$ & $C_{\mathrm{H}}$ & Electrochemical Reference \\
\hline acetonitrile & 54.9 & 4.62 & 59.4 & $\mathrm{Cp}_{2} \mathrm{Fe}^{+/ 0}$ \\
\hline DMSO & 71.1 & 4.60 & 75.7 & $\mathrm{Cp}_{2} \mathrm{Fe}^{+/ 0}$ \\
\hline DMF & 69.7 & 4.56 & 74.3 & $\mathrm{Cp}_{2} \mathrm{Fe}^{+/ 0}$ \\
\hline methanol & 65.3 & 3.81 & 69.1 & $\mathrm{Cp}_{2} \mathrm{Fe}^{+/ 0}$ \\
\hline water & 57.6 & -1.80 & 55.8 & normal hydrosen \\
\hline
\end{tabular}


Table 2

Selected PCET reagents and their X-H bond dissociation free energies. ${ }^{a}$

\begin{tabular}{|c|c|c|c|}
\hline Compound (XH) & solvent & BDFE & Table below \\
\hline TEMPOH & $\mathrm{H}_{2} \mathrm{O}$ & 71.0 & Table 3 \\
\hline TEMPOH & DMSO & 67.5 & Table 3 \\
\hline TEMPOH & $\mathrm{MeCN}$ & 66.5 & Table 3 \\
\hline TEMPOH & $\mathrm{C}_{6} \mathrm{H}_{6}$ & 65.2 & Table 3 \\
\hline $\mathrm{PhOH}$ & $\mathrm{H}_{2} \mathrm{O}$ & 89.5 & Table 4 \\
\hline $2,4,6-{ }^{t} \mathrm{Bu}_{3} \mathrm{PhOH}$ & $\mathrm{MeCN}$ & 77.1 & Table 4 \\
\hline hydroquinone $\left(\mathrm{H}_{2} \mathrm{Q}\right)$ & $\mathrm{H}_{2} \mathrm{O}$ & $\begin{array}{l}\text { first } \mathrm{OH}: 81.5 \\
\text { average: } 73.6\end{array}$ & Tables 5, 6 \\
\hline ascorbate & $\mathrm{H}_{2} \mathrm{O}$ & 73.6 & Table 7 \\
\hline $\mathrm{MeO}-\mathrm{H}$ & DMSO & 102.5 & Table 8 \\
\hline OO-H & $\mathrm{H}_{2} \mathrm{O}$ & 42.7 & Table 9 \\
\hline $\mathrm{HOO}-\mathrm{H}$ & $\mathrm{H}_{2} \mathrm{O}$ & 91.0 & Table 9 \\
\hline${ }^{t} \mathrm{BuOO}-\mathrm{H}$ & $\mathrm{H}_{2} \mathrm{O}$ & 91.5 & Table 10 \\
\hline $\mathrm{H}_{2} \mathrm{NNH}-\mathrm{H}$ & $\mathrm{H}_{2} \mathrm{O}$ & 83.4 & Table 11 \\
\hline $\mathrm{PhNH}_{2}$ & $\mathrm{MeCN}$ & 94.1 & Table 13 \\
\hline tryptophan & $\mathrm{H}_{2} \mathrm{O}$ & 90.6 & Table 14 \\
\hline guanosine & $\mathrm{H}_{2} \mathrm{O}$ & 106.8 & Table 15 \\
\hline $\mathrm{PhS}-\mathrm{H}$ & DMSO & 76.9 & Table 16 \\
\hline $\mathrm{C}_{6} \mathrm{H}_{5} \mathrm{CH}_{2}-\mathrm{H}$ & $\mathrm{MeCN}$ & 87 & Table 17 \\
\hline 9,10-dihydroanthracene & DMSO & 76.0 & Table 17 \\
\hline NADH & $\mathrm{H}_{2} \mathrm{O}$ & 79.3 & Table 18 \\
\hline $\begin{array}{c}\mathrm{N}\left(2,4-\mathrm{Br}_{2}-\mathrm{C}_{6} \mathrm{H}_{4}\right)_{3}{ }^{++}+ \\
\text {2,6- }-\mathrm{Me}_{2} \text {-pyridine }\end{array}$ & $\mathrm{MeCN}$ & 100.5 & Table 20 \\
\hline $\mathrm{MnO}_{3}(\mathrm{O}-\mathrm{H})^{-}$ & $\mathrm{H}_{2} \mathrm{O}$ & 80.4 & Table 21 \\
\hline$\left[(\text { bpy })_{2} \text { pyRu }{ }^{\mathrm{III}} \mathrm{O}-\mathrm{H}\right]^{2+}$ & $\mathrm{H}_{2} \mathrm{O}$ & 84.8 & Table 21 \\
\hline
\end{tabular}

${ }^{a}$ For more examples, more data, and the origin of these values, see the individual Tables below.

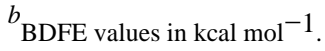




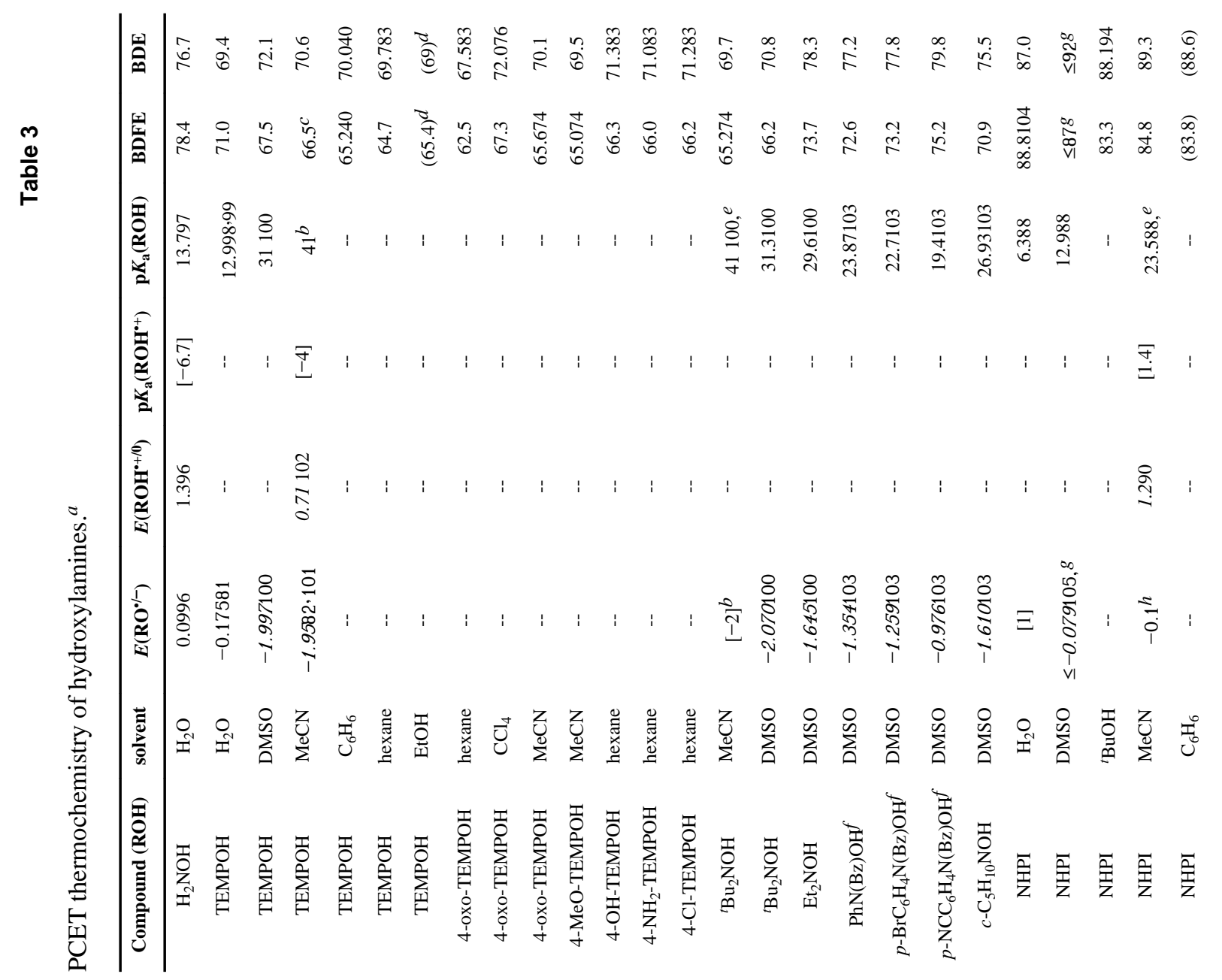




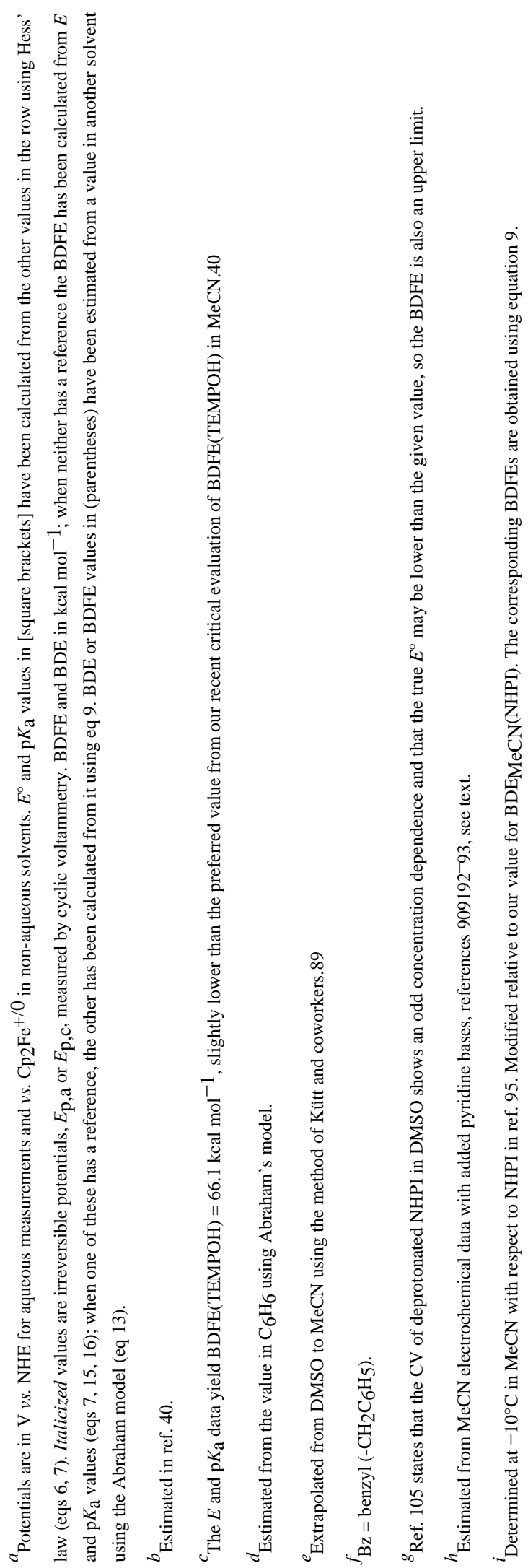




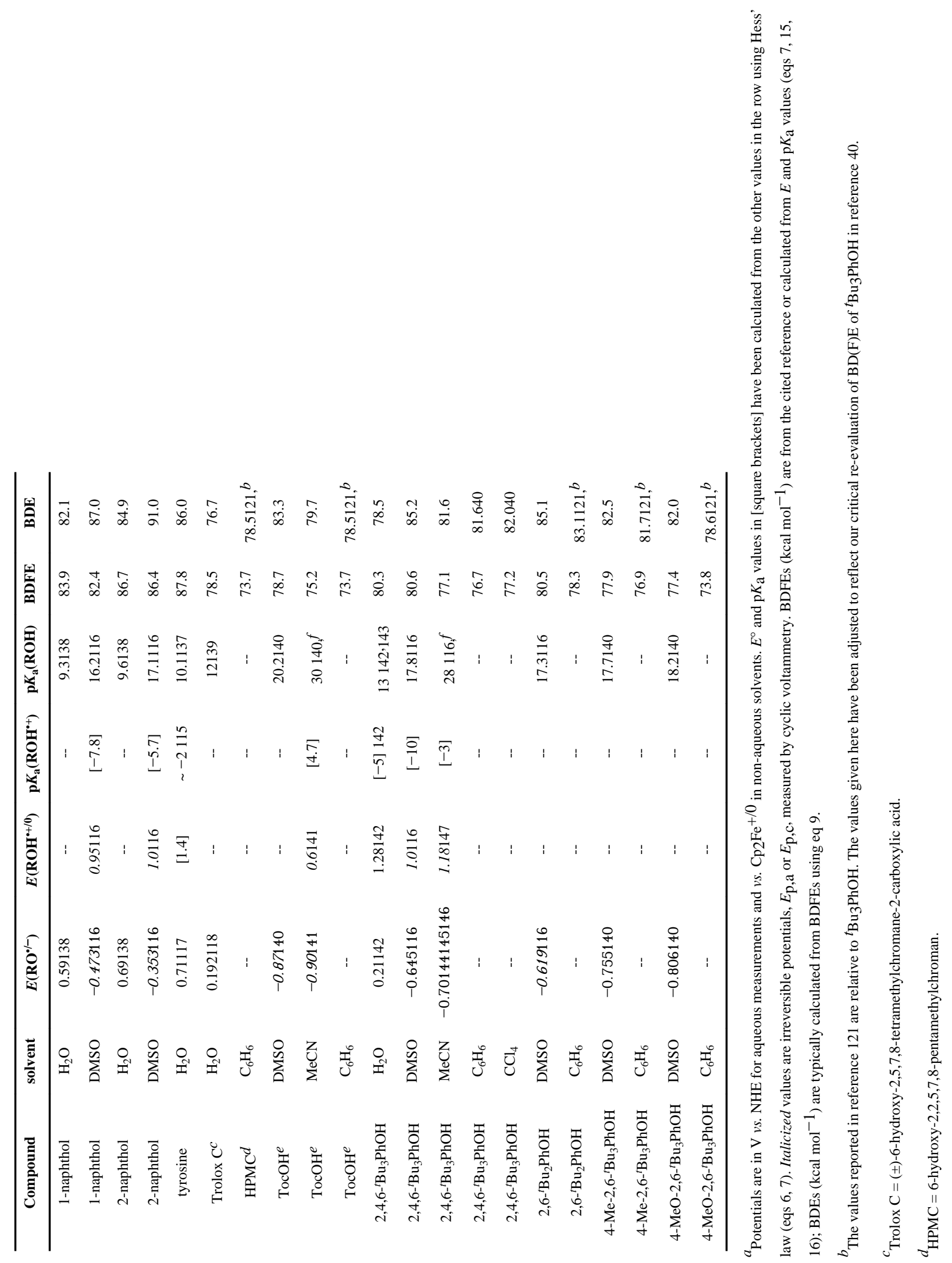




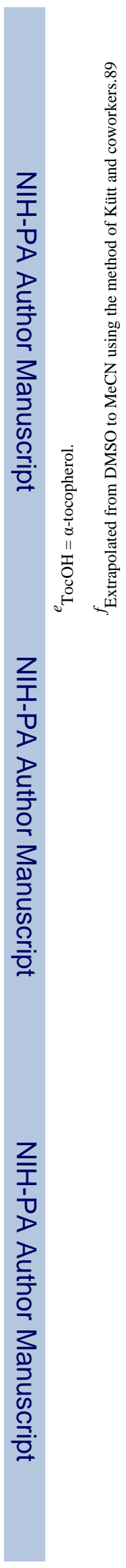

Warren et al.

Page 89$$
\text { . }
$$ 


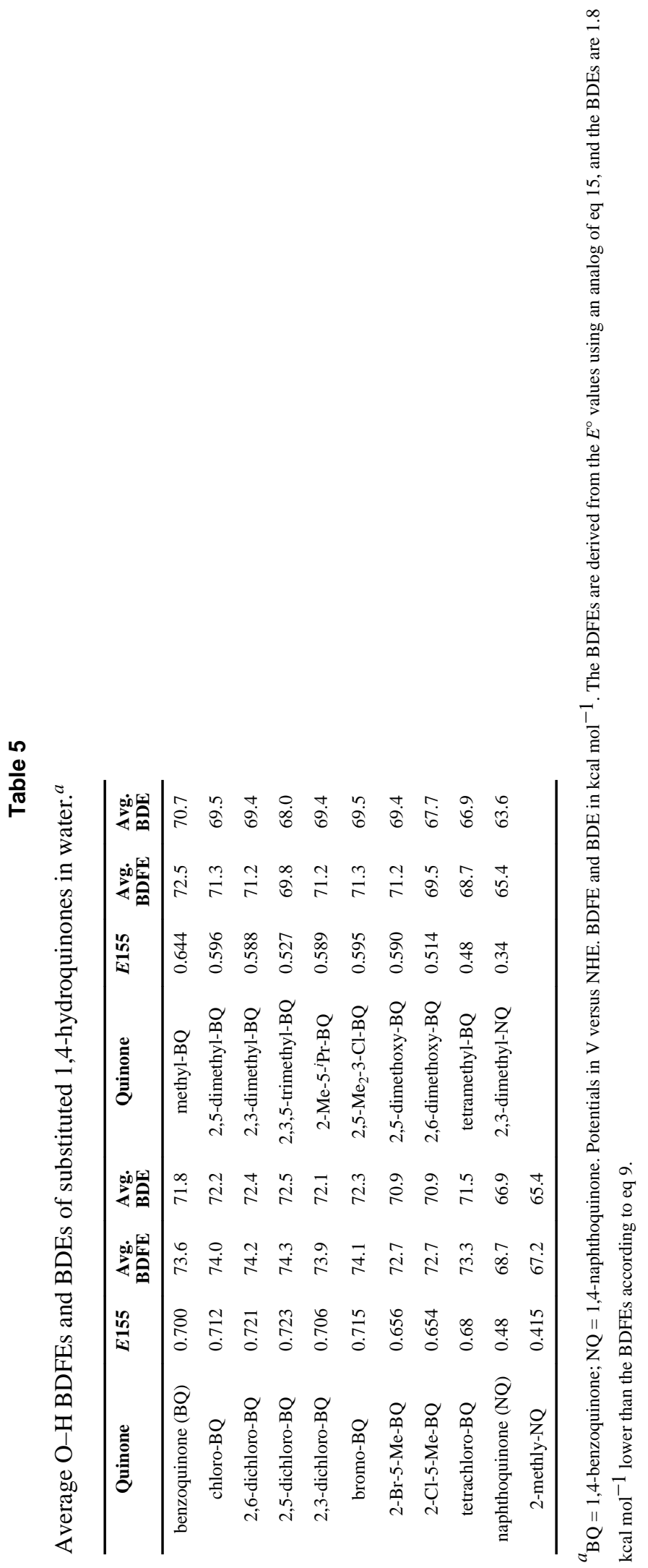




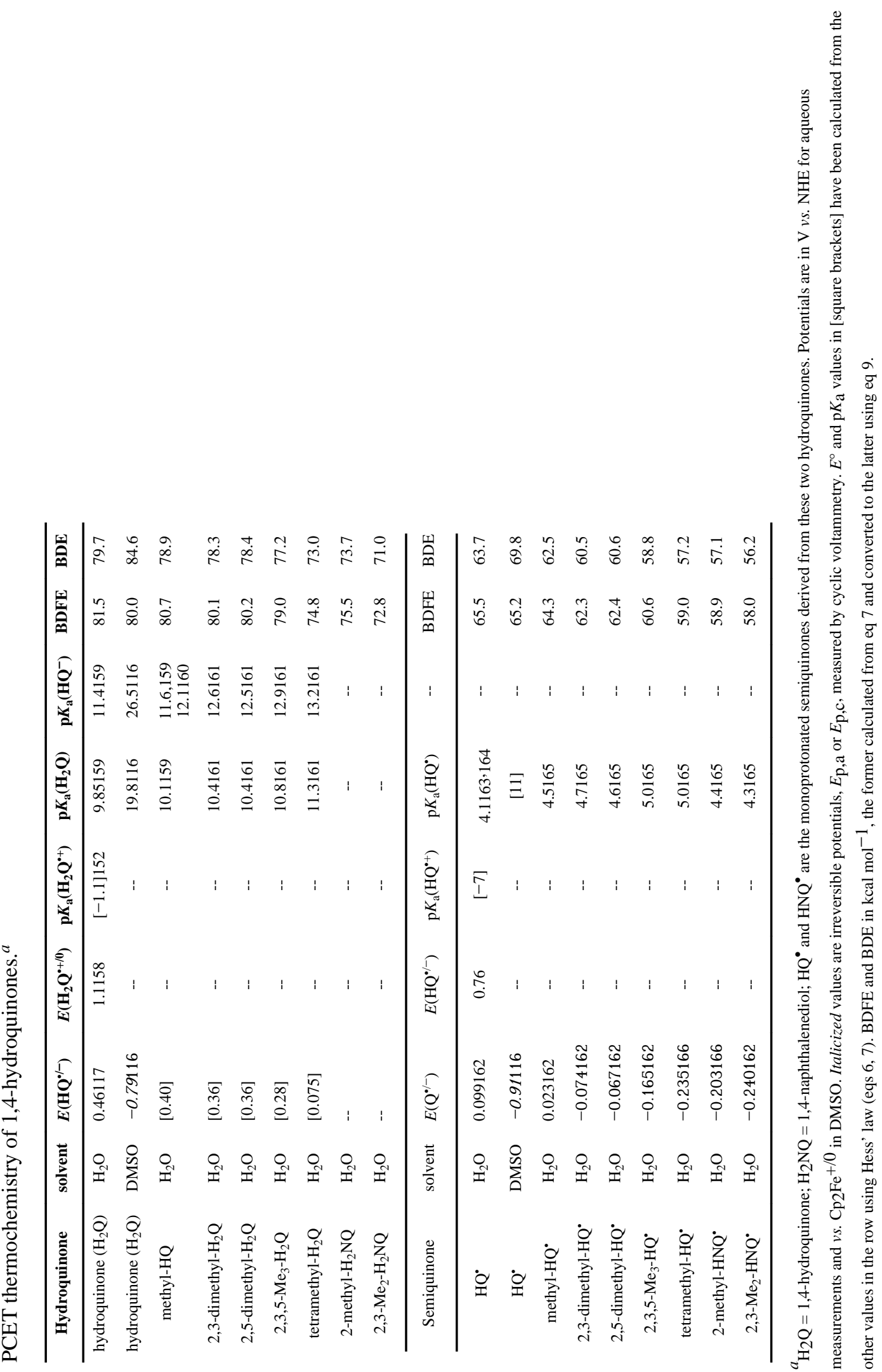




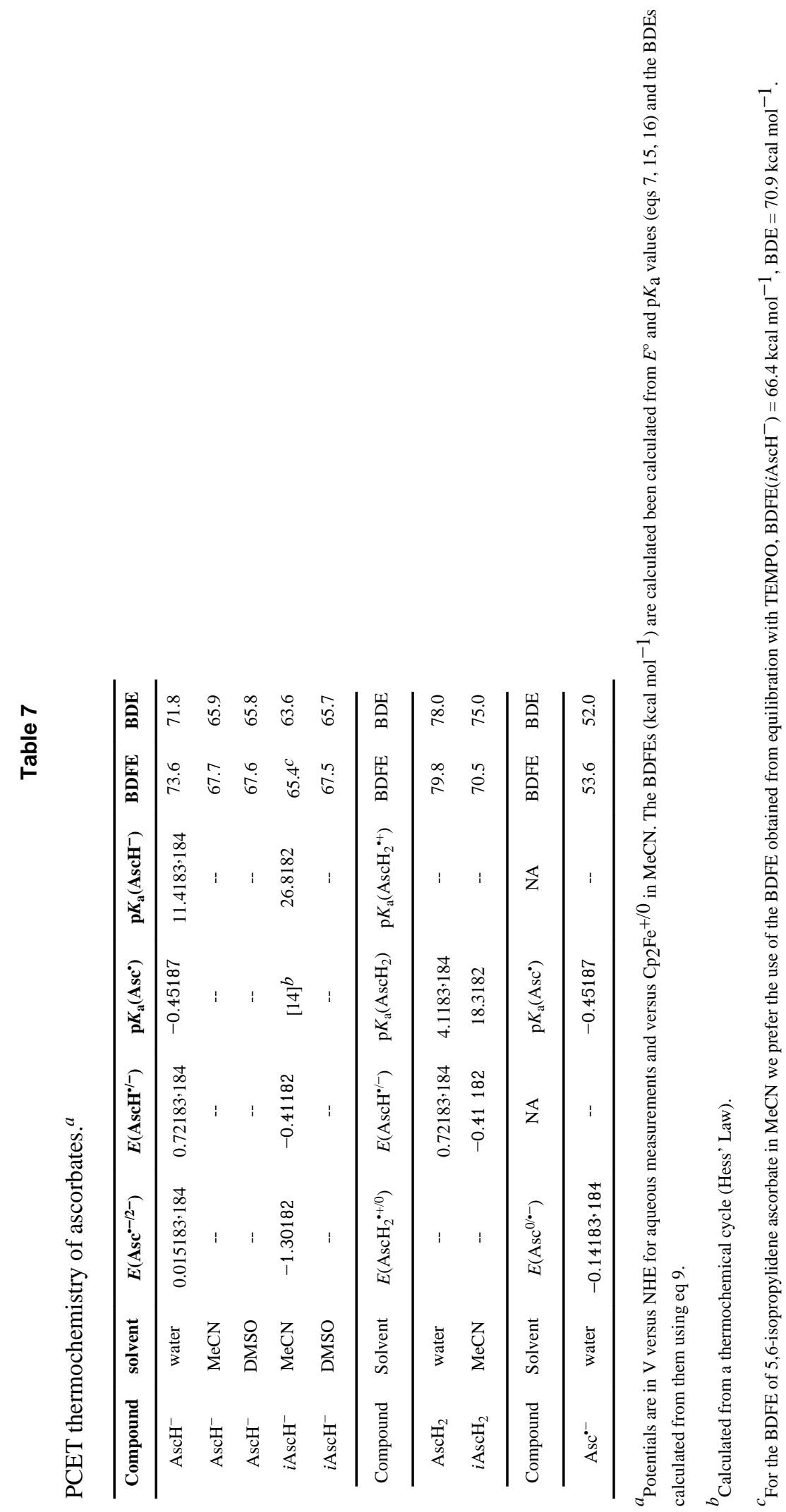




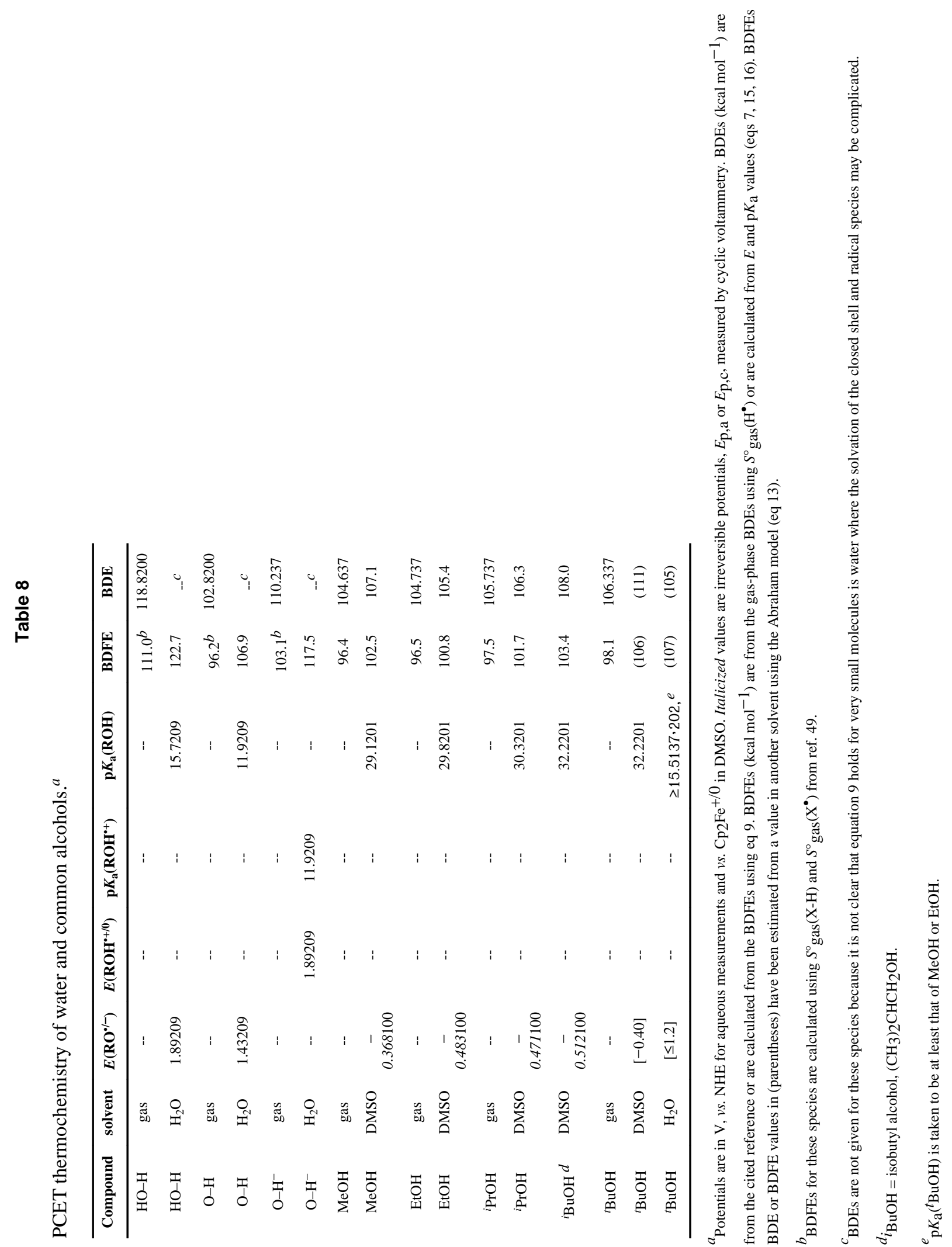




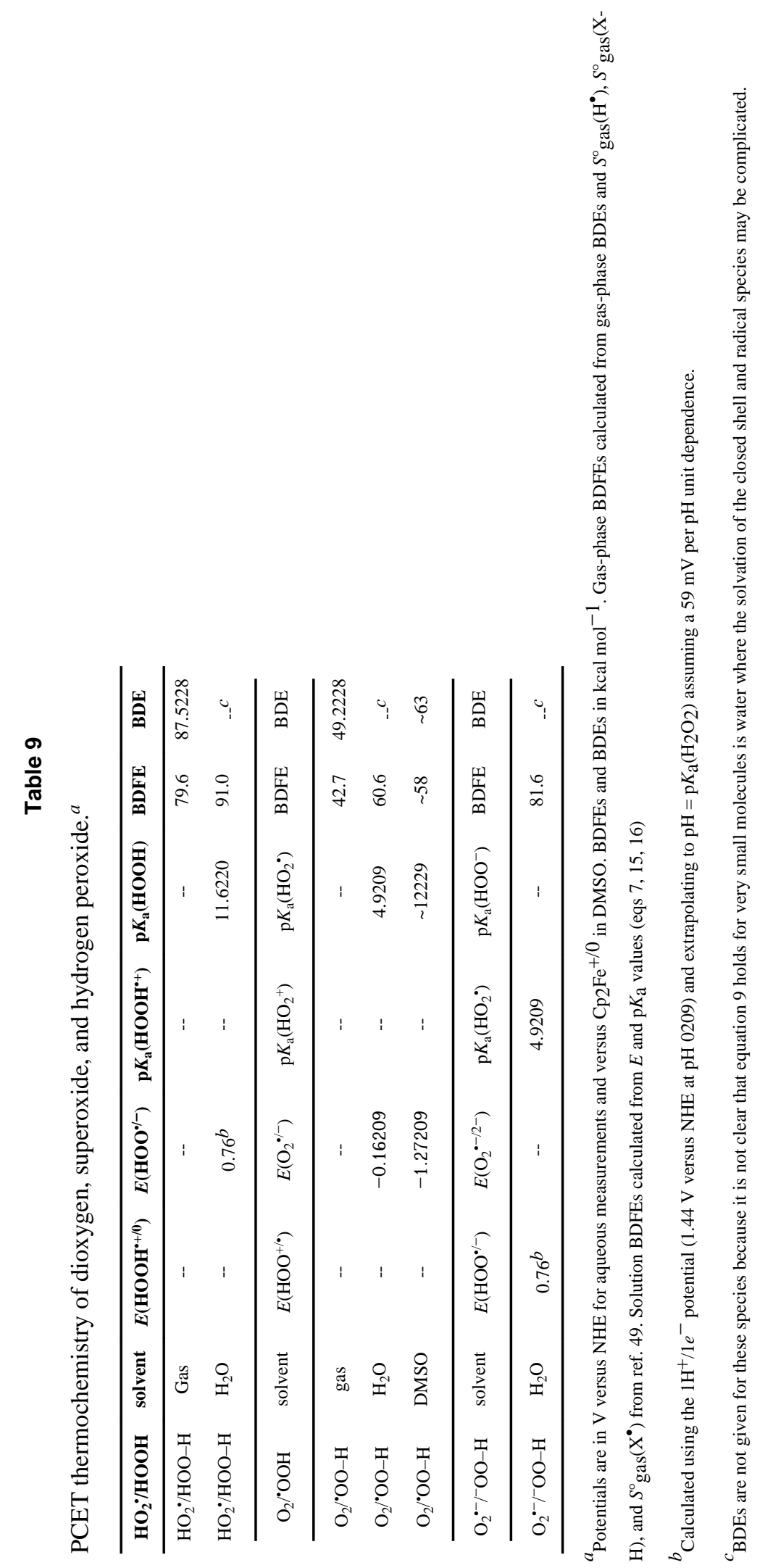




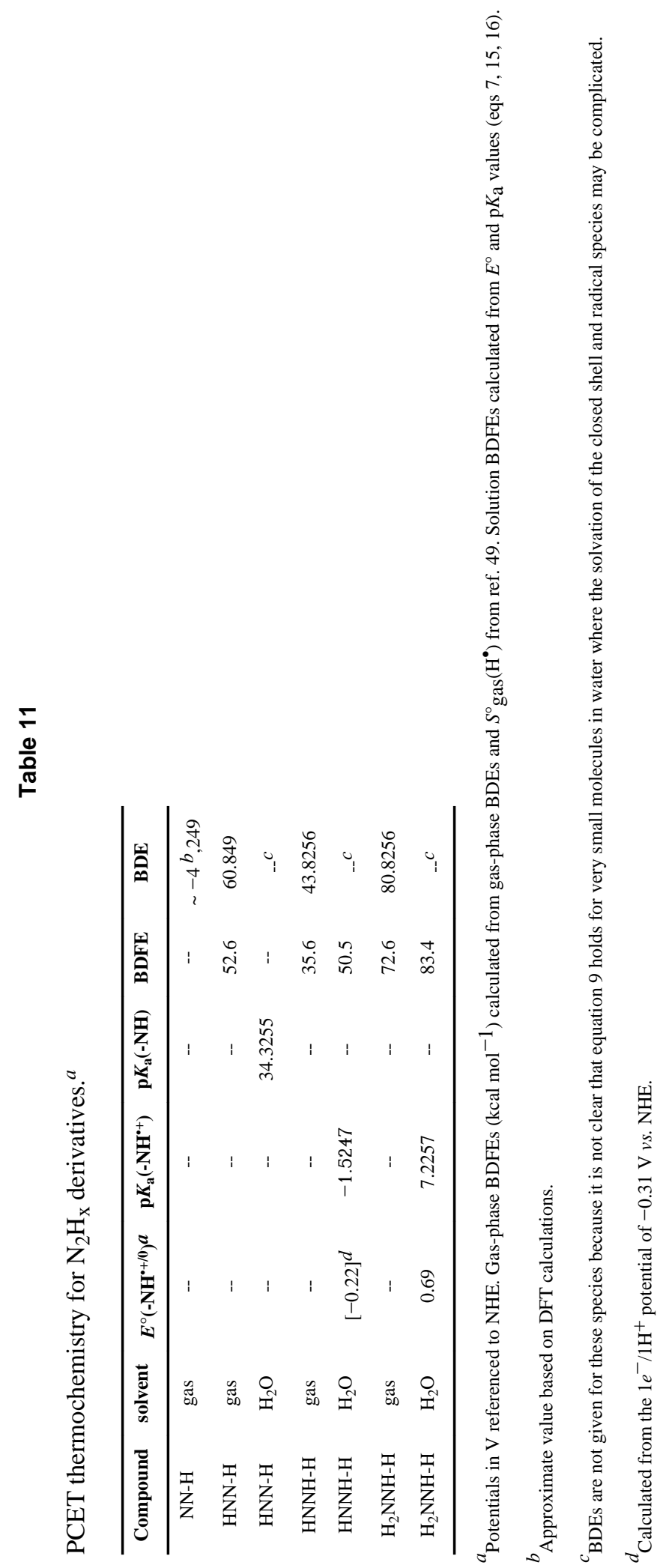

Chem Rev. Author manuscript; available in PMC 2011 December 8 


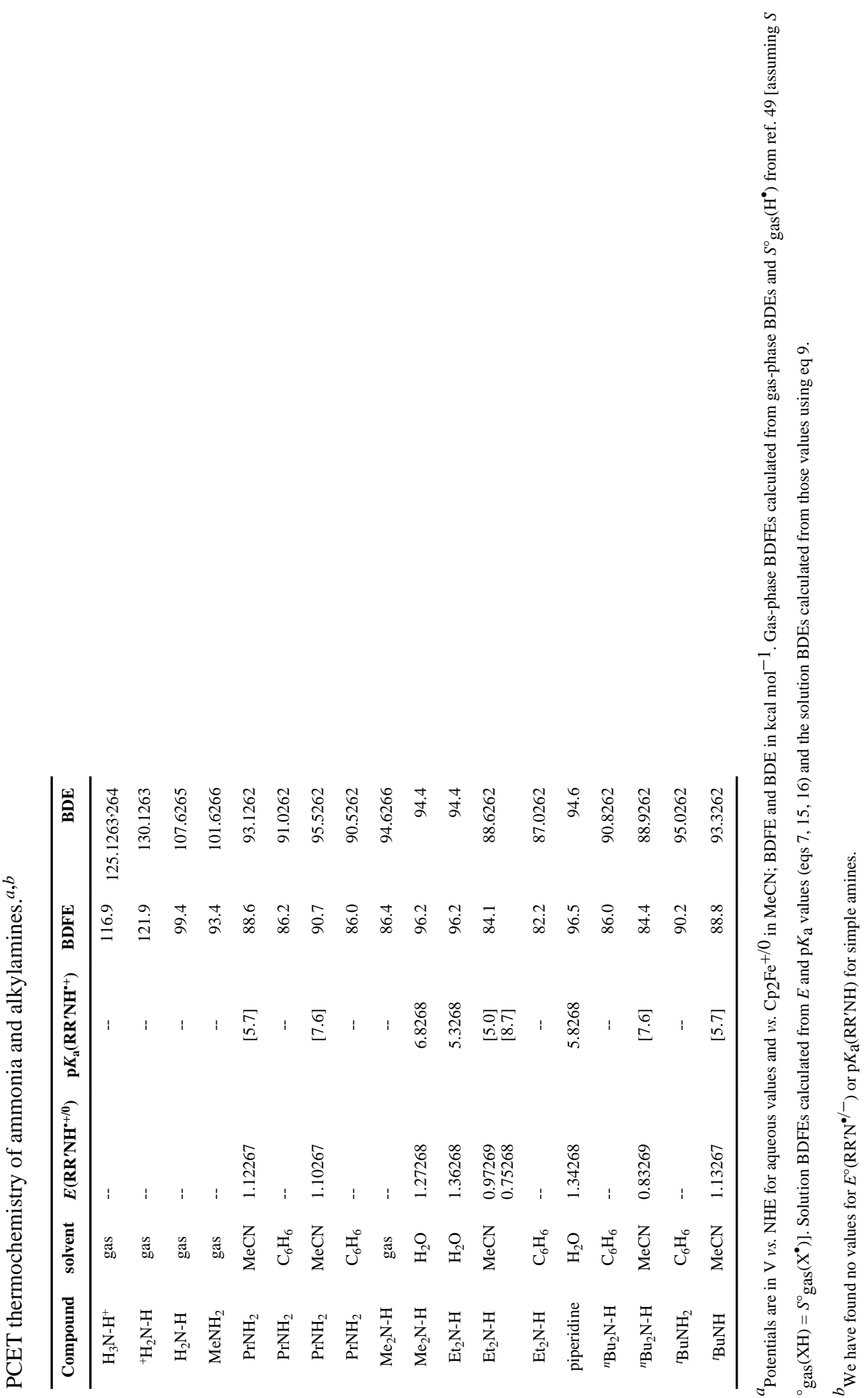




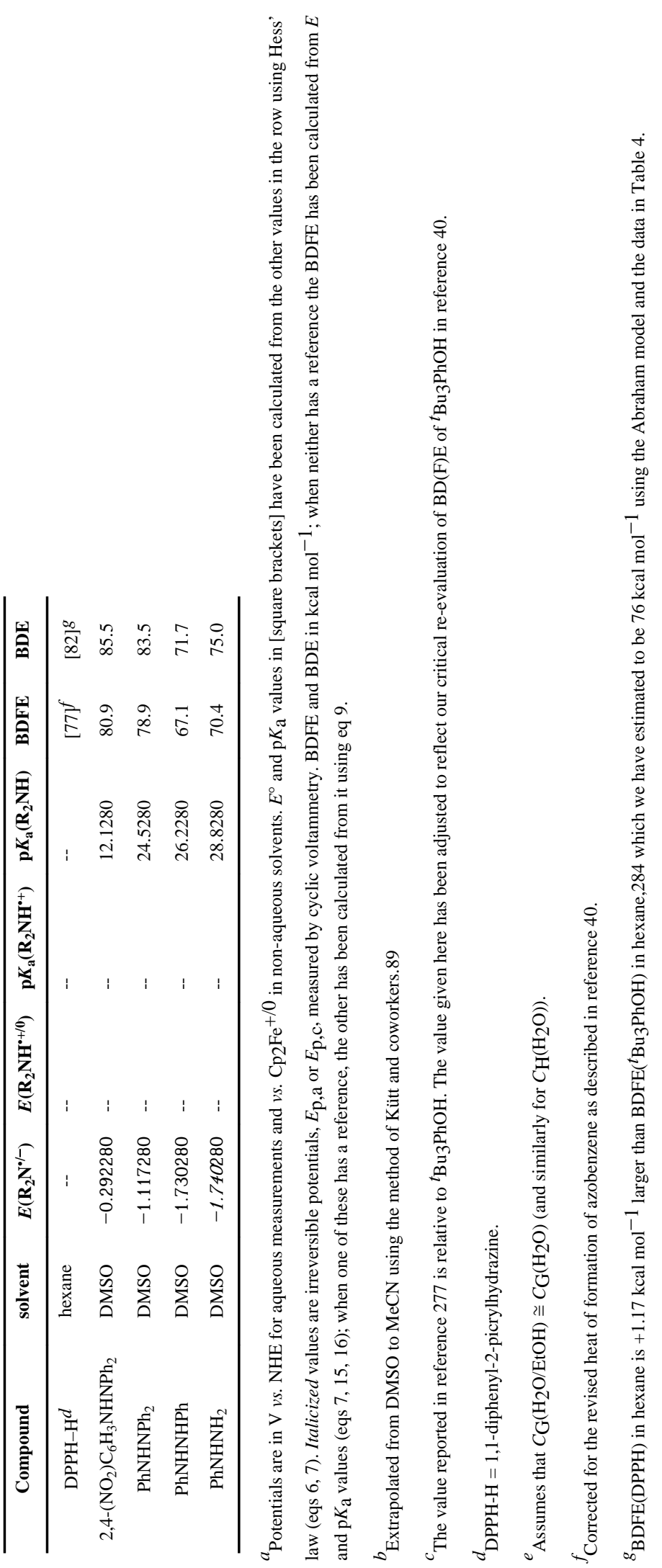

Chem Rev. Author manuscript; available in PMC 2011 December 8. 


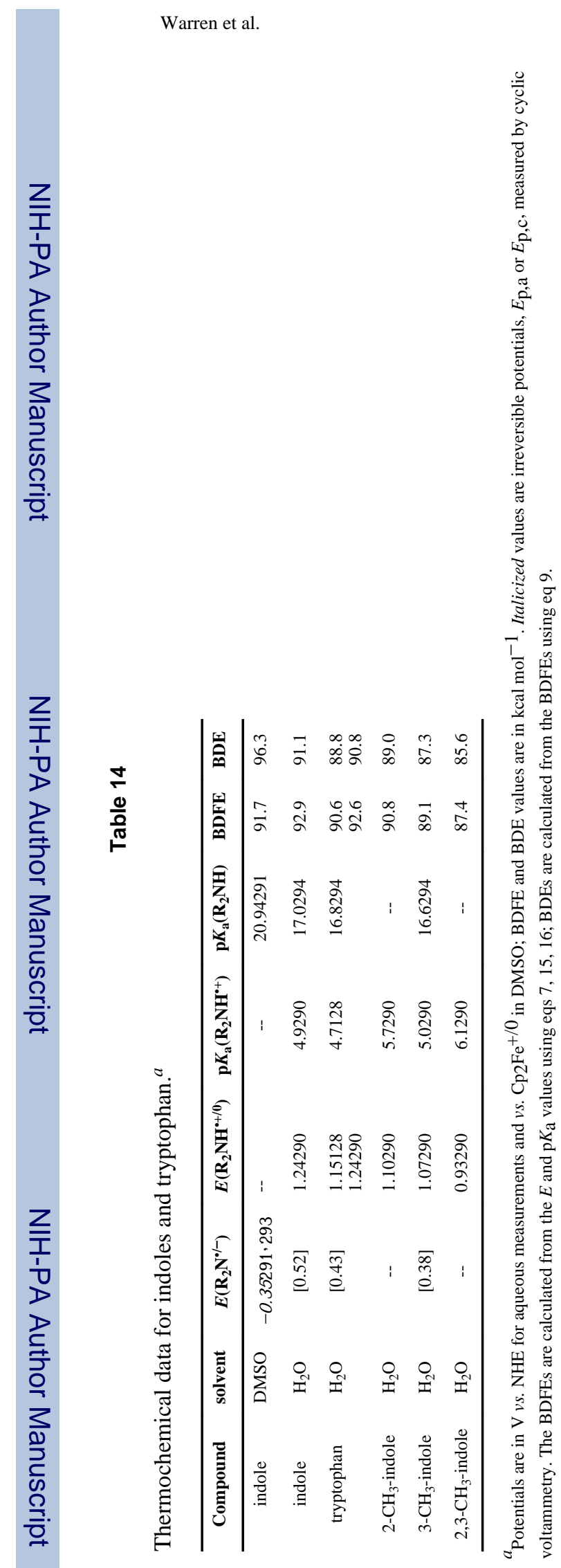

Chem Rev. Author manuscript; available in PMC 2011 December 8. 


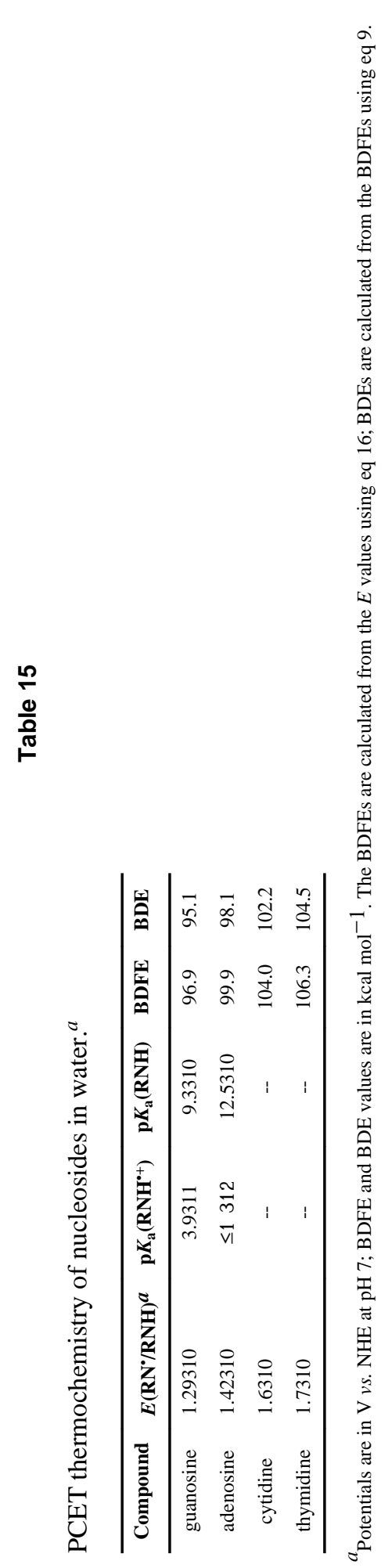

Chem Rev. Author manuscript; available in PMC 2011 December 8. 


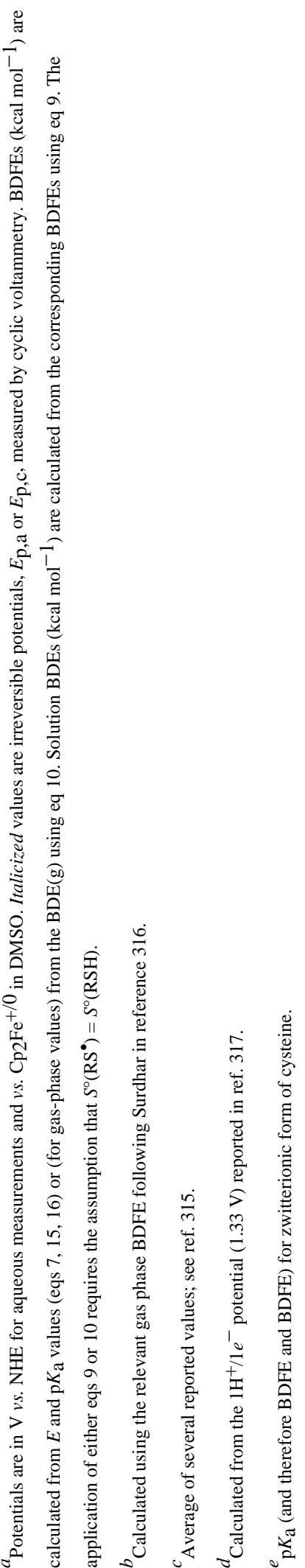




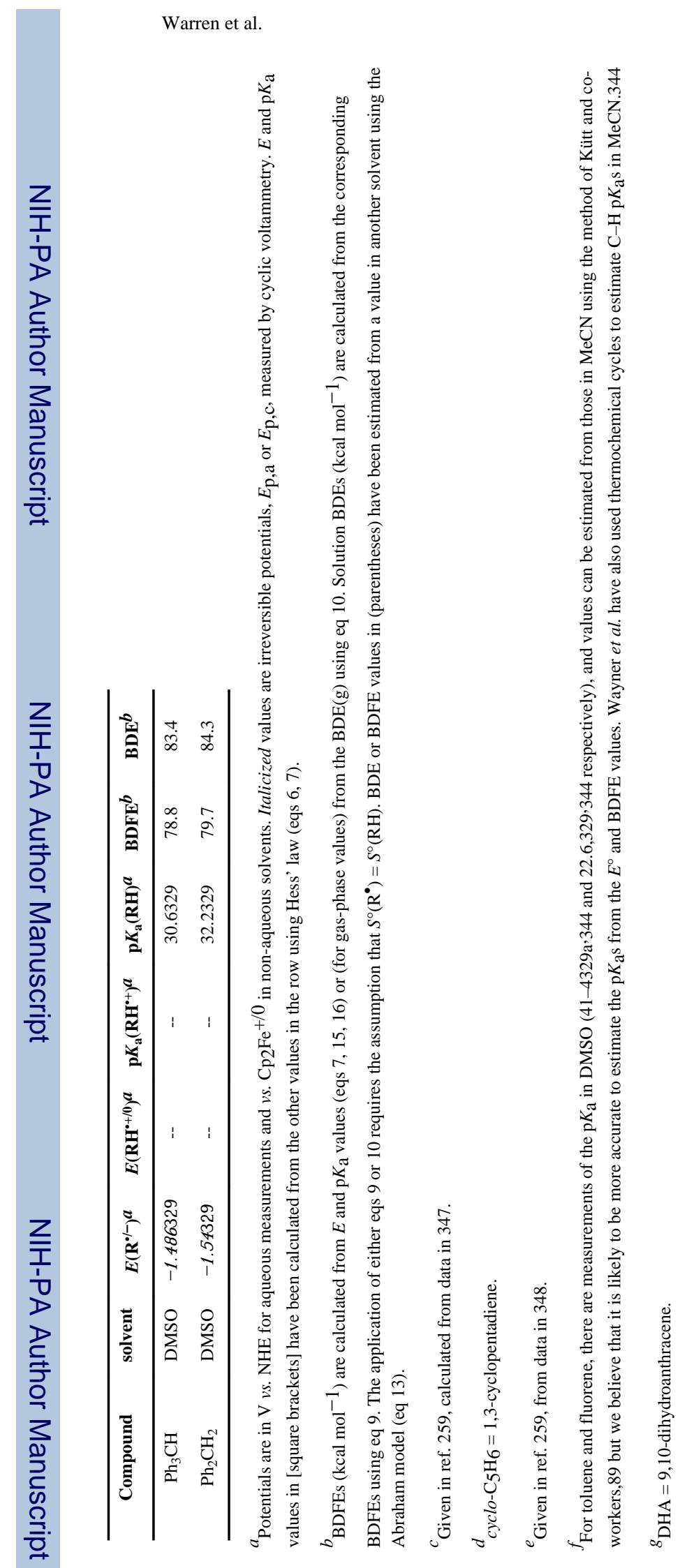

Chem Rev. Author manuscript; available in PMC 2011 December 8. 


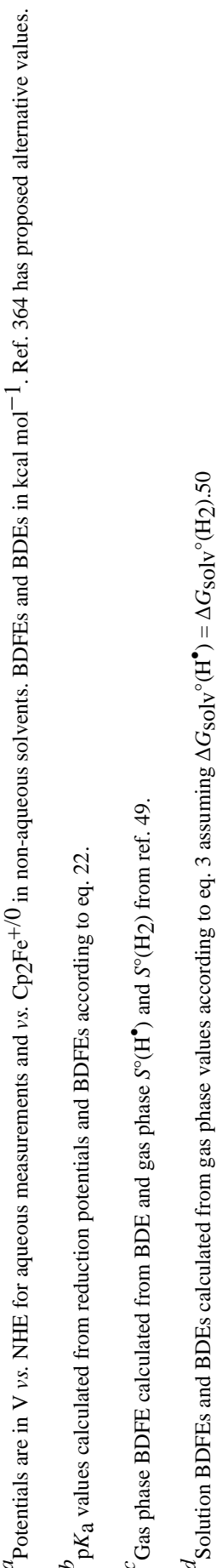

Chem Rev. Author manuscript; available in PMC 2011 December 8 
Table 20

PCET thermochemistry of a few oxidant/base or reductant/acid pairs in MeCN for separated CPET.

\begin{tabular}{|c|c|c|c|c|}
\hline Oxidant & $E_{1 / 2}^{a, b}$ & base & $\mathrm{p} K_{\mathrm{a}}^{c}$ & $\mathrm{BDFE}^{d}$ \\
\hline $\mathrm{N}\left(4-\mathrm{MeO}-\mathrm{C}_{6} \mathrm{H}_{4}\right)_{3}{ }^{\cdot+}$ & 0.16 & pyridine & 12.5 & 75.7 \\
\hline $\mathrm{N}\left(4-\mathrm{MeO}-\mathrm{C}_{6} \mathrm{H}_{4}\right)_{3}{ }^{\cdot+}$ & 0.16 & 2,6- $\mathrm{Me}_{2}$-pyridine & 14.1 & 77.9 \\
\hline $\mathrm{N}\left(4-\mathrm{Me}-\mathrm{C}_{6} \mathrm{H}_{4}\right)_{3}{ }^{\cdot+}$ & 0.40 & pyridine & 12.5 & 81.3 \\
\hline $\mathrm{N}\left(4-\mathrm{Me}-\mathrm{C}_{6} \mathrm{H}_{4}\right)_{3}{ }^{*+}$ & 0.40 & 2,6- $\mathrm{Me}_{2}$-pyridine & 14.1 & 83.5 \\
\hline $\mathrm{N}\left(4-\mathrm{Me}-\mathrm{C}_{6} \mathrm{H}_{4}\right)_{3}{ }^{*+}$ & 0.40 & 4-N(Me $)_{2}$-pyridine & 18.0 & 88.8 \\
\hline $\mathrm{N}\left(4-\mathrm{Br}-\mathrm{C}_{6} \mathrm{H}_{4}\right)_{3}{ }^{\cdot+}$ & 0.67 & pyridine & 12.5 & 87.5 \\
\hline $\mathrm{N}\left(4-\mathrm{Br}-\mathrm{C}_{6} \mathrm{H}_{4}\right)_{3}{ }^{++}$ & 0.67 & 2,6- $\mathrm{Me}_{2}$-pyridine & 14.1 & 89.7 \\
\hline $\mathrm{N}\left(2,4-\mathrm{Br}_{2}-\mathrm{C}_{6} \mathrm{H}_{4}\right)_{3} \cdot+$ & 1.14 & pyridine & 12.5 & 98.3 \\
\hline $\mathrm{N}\left(2,4-\mathrm{Br}_{2}-\mathrm{C}_{6} \mathrm{H}_{4}\right)_{3} \cdot{ }^{+}$ & 1.14 & 2,6- $\mathrm{Me}_{2}$-pyridine & 14.1 & 100.5 \\
\hline Reductant & $E_{1 / 2} a, b$ & Acid & $\mathrm{p} K_{\mathrm{a}}{ }^{c}$ & $\Delta G_{\mathrm{H}}{ }^{d}$ \\
\hline $\mathrm{Cp}_{2} \mathrm{Fe}$ & 0 & pyridinium & 12.5 & 71.5 \\
\hline$\left(\mathrm{C}_{5} \mathrm{Me}_{5}\right)_{2} \mathrm{Fe}$ & -0.48 & pyridinium & 12.5 & 61.0 \\
\hline $\mathrm{Cp}_{2} \mathrm{Fe}$ & 0 & acetic acid & 22.3 & 85.5 \\
\hline $\mathrm{Cp}_{2} \mathrm{Co} e$ & -1.34371 & acetic acid & 22.3 & $55.5^{e}$ \\
\hline
\end{tabular}

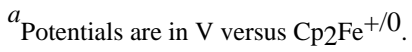

${ }^{b}$ From reference 254 unless otherwise noted.

${ }_{\mathrm{p}}^{c} K_{\mathrm{a}}$ of base $\mathrm{H}^{+}$from reference 30.

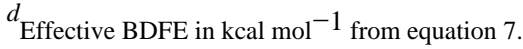

${ }^{e}$ For illustrative purposes; the stability of this combination is not known. 


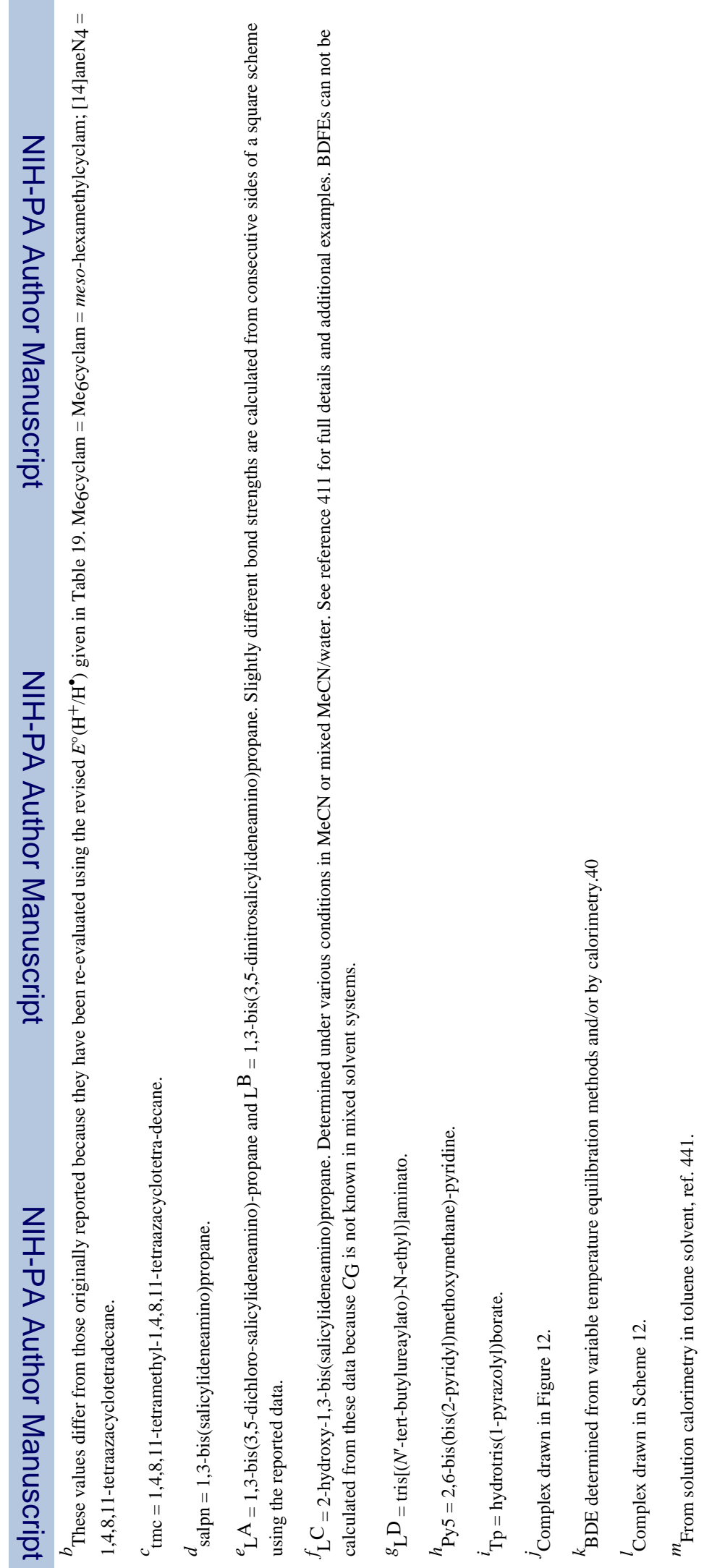

Chem Rev. Author manuscript; available in PMC 2011 December 8. 